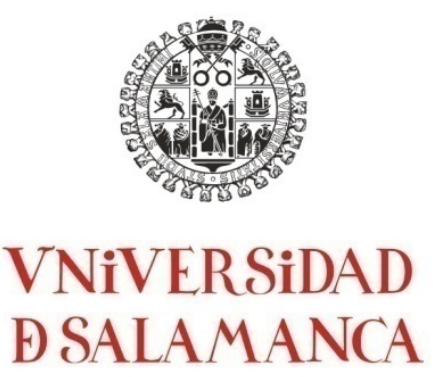

FACULTAD DE GEOGRAFÍA E HISTORIA

DEPARTAMENTO DE HISTORIA MEDIEVAL, MODERNA Y CONTEMPORÁNEA.

\title{
LA VÍA CHILENA A LA DEMOCRACIA \\ Análisis Crítico de la Transición, el Chile Reciente y su Modelo.
}

\author{
TESIS DOCTORAL \\ Presentada por David Aceituno Silva
}

Dirigida por:

Dr. Guillermo Mira Delli-Zotti

SALAMANCA, 2016. 


\section{RESUMEN}

La Transición chilena ha sido valorada internacionalmente por ser un modelo de cambio pacífico y consensuado desde la Dictadura a la Democracia. Esto ha sido reafirmado por algunos historiadores y especialmente por la bibliografía politológica. Sin embargo, el énfasis puesto en los cambios positivos vividos durante la Transición oculta una serie acontecimientos que muestran un Chile lleno de permanencias menos positivas.

En este trabajo, hacemos de documentos y fuentes de la Historia Reciente de Chile para hacer una mirada crítica a la Transición y la Democracia chilena. Los resultados revelan que el discurso que reafirma la imagen del "Chile modelo de economía y desarrollo", ha tendido a ocultar los miedos que siguieron perviviendo en la sociedad, los "amarres autoritarios" que dominaron la política de los noventa, la marginación generada por el libre mercado, que ha profundizado la desigualdad, que siguieron presentes en democracia y profundizados. Todo esto, dará cuenta de un "modelo" de Democracia paradojal, en el que la Dictadura tuvo más influencia de la que se quiere reconocer.

En una lectura de largo plazo, cuestionamos los análisis de la ciencia política bajo una mirada histórica, valorando críticamente el retorno a al democracia, poniendo énfasis en las contradicciones de la misma, que dan cuenta de una construcción particular de la democracia, los derechos y la participación ciudadana. El resultado final de la investigación da cuenta de una Democracia única, con un fuerte componente económico como pilar fundamental, con derechos ciudadanos aun en cuestionamiento y con fuerte crítica hacia las promesas incumplidas de la centro-izquierda.

Palabras claves: Historia Reciente, Transición, Dictadura, Democracia, Historia de Chile. 

Con amor para Dámaris y Fernanda que durante estos años fueron mi refugio. Agradezco su enorme paciencia. 



\section{AGRADECIMIENTOS}

Esta tesis hubiese sido imposible sin la excelente recepción que recibí por parte del Director del Departamento de Historia Medieval, Moderna y Contemporánea de la Universidad de Salamanca, el Dr. José Luis de la Heras Santos. Quién no sólo acepto a este chileno que llegaba sin conocer a nadie en la ciudad, sino que además motivó a iniciar una investigación previa para continuar luego en el doctorado. Tan importante como este primer acercamiento fue y ha sido mi profesor guía, el Dr. Guillermo Mira Delli-Zotti, quien en interesantes conversaciones me ayudó a delinear mi interés por investigar un Chile aún desconocido, a atreverme por innovar y buscar nuevas perspectivas historiográficas. Su interés constante, apoyo y motivación han sido vitales para continuar y terminar. Mil gracias.

Mis agradecimientos son también para mis colegas chilenos, el Vicerrector Académico Dr. Nelson Vásquez, el Director del Instituto de Historia de la Pontificia Universidad Católica de Valparaíso, Mauricio Molina, los profesores Ricardo Iglesias y la Dra. Gabriela Vásquez. Todos ellos fuentes de reflexiones y apoyo constante.

A mis amigos en Valladolid, el Dr. Isidoro González, la Dra. María Sánchez Agustí, la Dra. Lorena Valdivieso y Fernando Espí, todos ellos fieles compañeros de viaje y sabios consejeros.

Dicen que las segundas partes no son nunca mejores que las primeras, pero con esta segunda tesis doctoral que presento, creo que he disfrutado tanto como la primera. Me he re-encantado con la investigación y la reflexión histórica. No ha sido fácil, y de esto son conscientes mi familia, por eso a ellos les debo todo. Su amor incondicional ha sido fundamental.

A todos gracias. 


\section{INDICE}

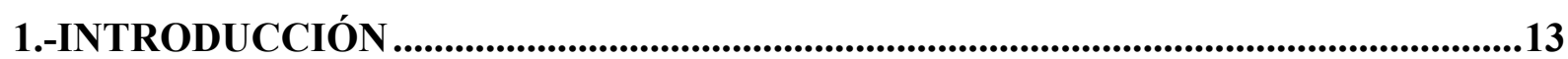

2.-PLANTEAMIENTO DEL PROBLEMA. ...................................................................19

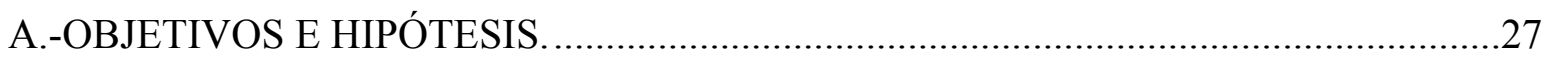

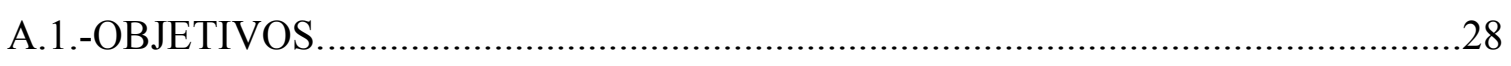

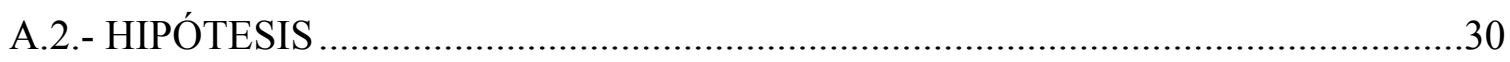

3.-MARCO METODOLÓGICO ................................................................................33

3.1.-HISTORIA DEL TIEMPO PRESENTE: CHILE POST-DICTADURA Y SUS

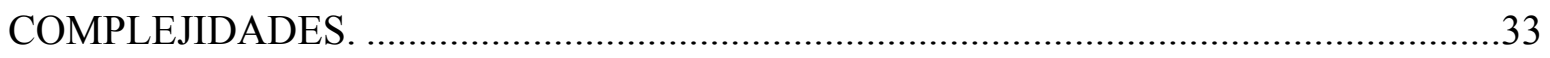

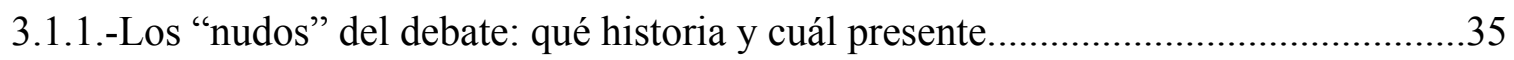

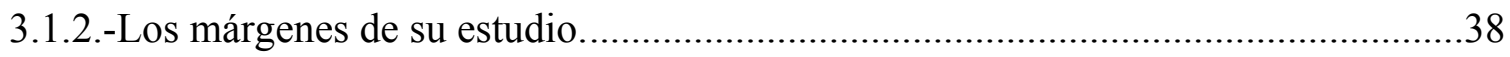

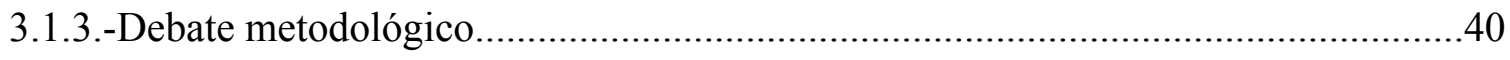

3.1.4.-Reflexión para el caso chileno: los traumas y la memoria......................................42

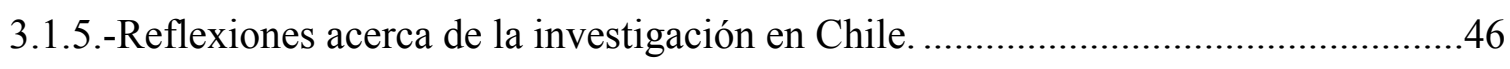

3.2.-INVESTIGAR EL CHILE DE LOS 90: DE LA MIRADA POLÍTICA A LA

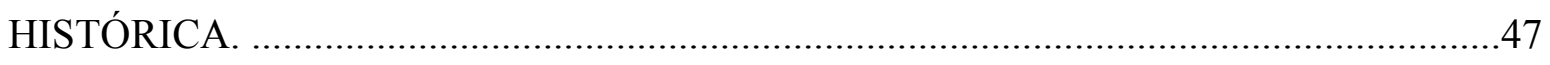

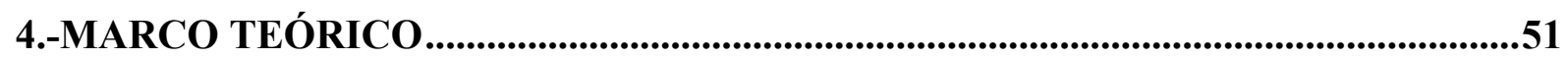

4.1.- CLAVES HISTÓRICAS DE LA TRANSICIÓN CHILENA .....................................51

4.1.1-Del quiebre democrático a la apertura del Régimen................................................52

4.1.1.1.-La Transición chilena, un proceso complejo...................................................52

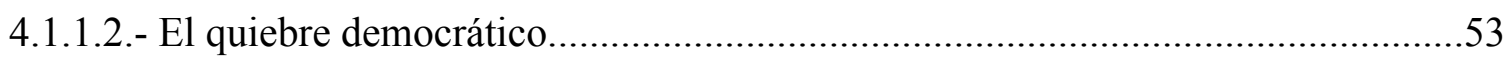

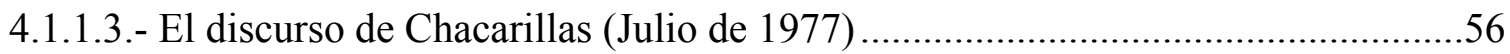

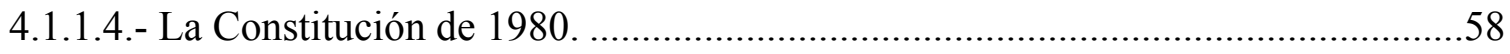

4.1.1.5.- Los primeros intentos de organización.............................................................6

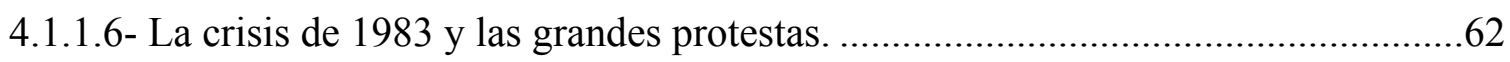

4.1.1.7.- El proceso de apertura del Régimen. El Acuerdo Nacional...............................67

4.1.2.-Del seminario del Hotel Tupahue a los primeros Gobiernos de la Democracia.........69

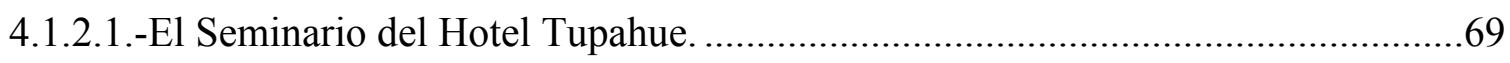

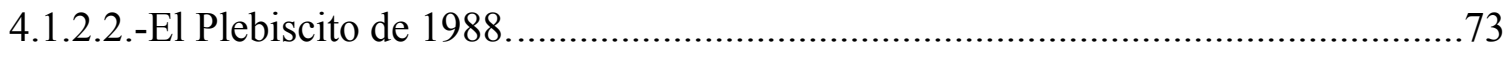


4.1.2.3.-La elección presidencial. El triunfo de la Concertación.......................................75

4.2.-VISIONES HISTORIOGRÁFICAS ACERCA DE LA TRANSICIÓN.......................77

4.2.1. Visiones y cronologías de la Transición chilena....................................................77

4.2.1.1.- La historiografía de derecha o pro-Régimen................................................. 78

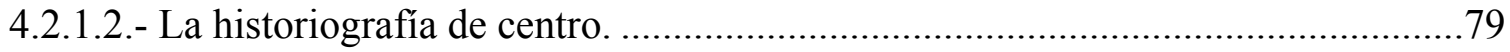

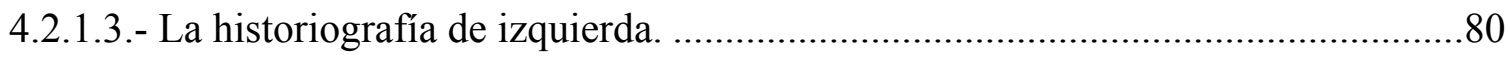

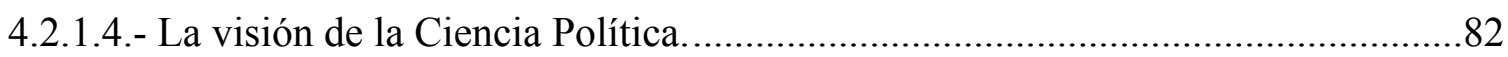

4.2.2.- Visiones críticas del "Modelo de Transición chileno". ............................................83

5.- LA TRANSICIÓN CHILENA Y LOS MODELOS DE INTERPRETACIÓN...........87

5.1- “TRANSITOLOGÍA” Y CONCEPTUALIZACIÓN DE LA DEMOCRACIA. ...........88

5.2.- TEORÍAS EXPLICATIVAS DE LA TRANSICIONES A LA DEMOCRACIA EN

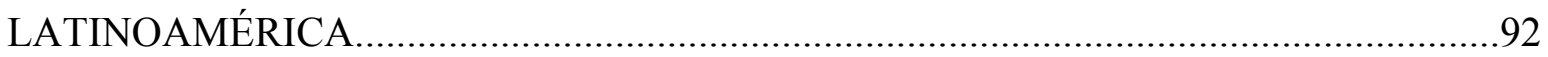

5.2.1.- Teorías de la modernización económica...........................................................93

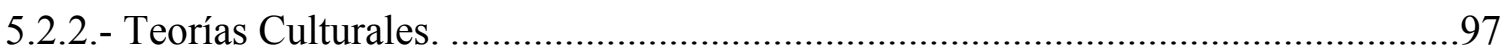

5.2.3.-Teorías del Desarrollo Capitalista y las Clases Sociales........................................98

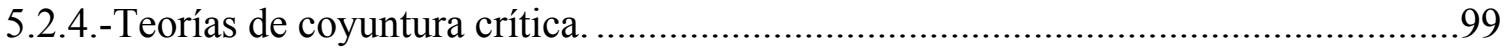

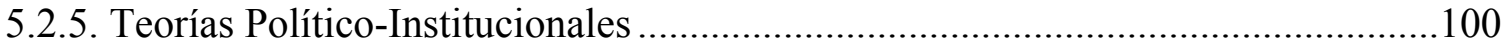

5.3.- TEORÍAS EXPLICATIVAS DE LA TRANSICIÓN CHILENA: DELINEAMIENTO

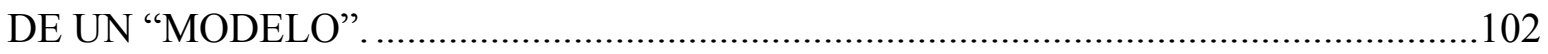

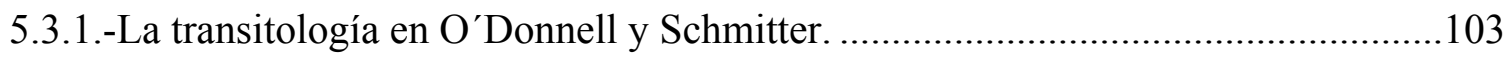

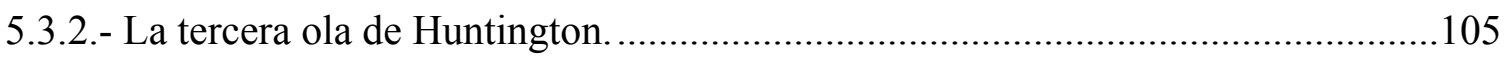

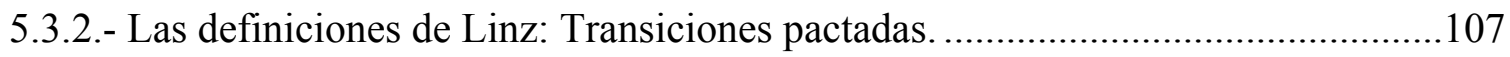

5.3.3.- "El modelo exitoso chileno": Transición pactada................................................110

6.- EL ITINERARIO DE LA DICTADURA: EL MODELO EXITOSO O UNA

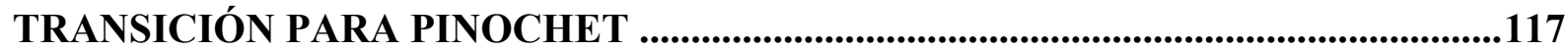

6.1.- EL "MODELO DE EXPORTACIÓN" ……................................................................ 118

6.2.-FRACTURAS DEL MODELO CHILENO: VISIONES DISIDENTES ...................123

6.2.1.- La Transición interminable y sus laberintos. ................................................... 124

6.2.2.- La verdad incómoda de la Transición (mal) pactada. ..........................................134

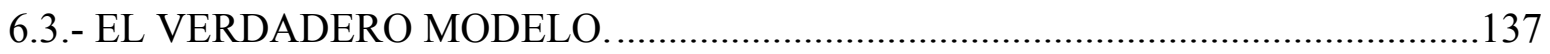

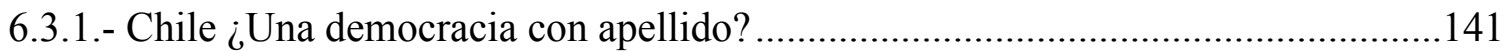


6.5.- "ELUDIR DELIBERADAMENTE": EVOLUCIÓN DEL PENSAMIENTO DE OPOSICIÓN ACERCA DE LA TRANSICIÓN

\section{7.-“EN LA MEDIDA DE LOS POSIBLE": CHILE Y LOS DERECHOS}

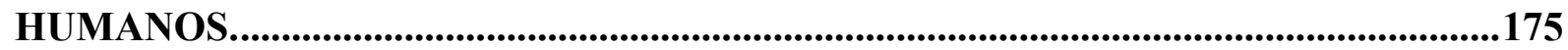

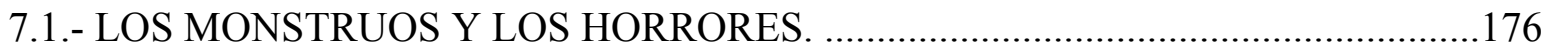

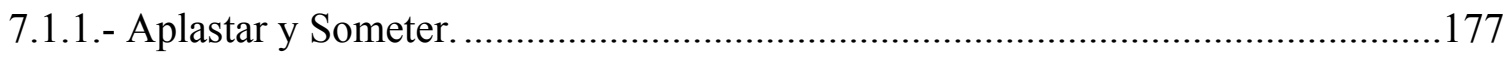

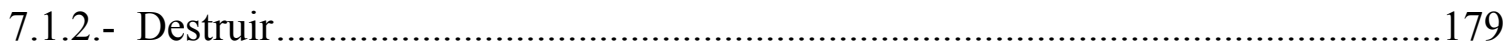

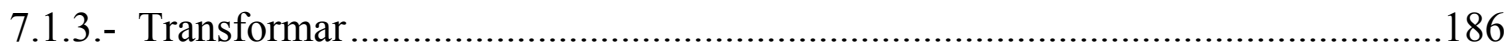

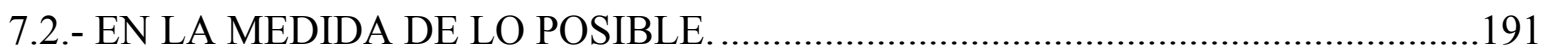

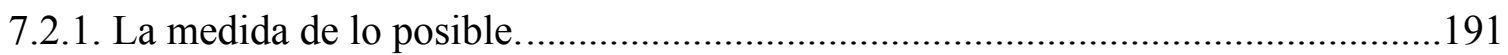

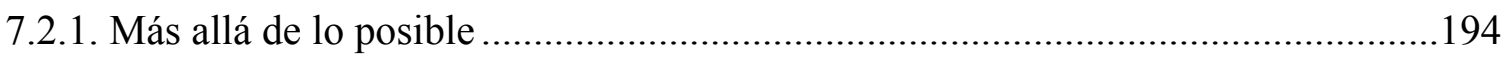

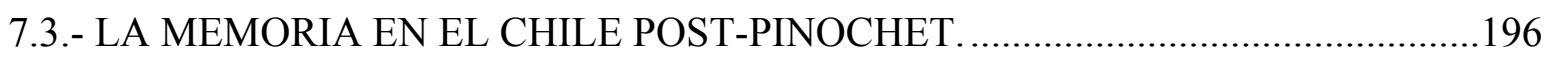

8.-LA CONSTITUCIÓN DE PINOCHET COMO MARCO PARA UNA NUEVA

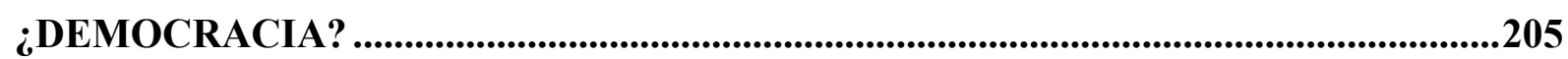

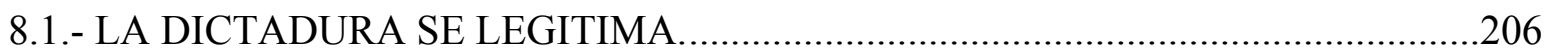

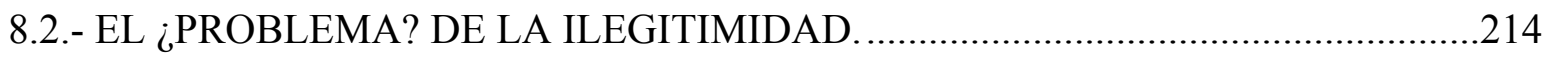

8.2.1.-La Crítica a la Constitución del "Grupo de los 24."..............................................216

8.2.2.-La Constitución de 1980. El pecado de origen........................................................218

8.3.-CONSTITUCIÓN Y TRANSICIÓN. LA ACEPTACIÓN. .........................................220

9.-LA DEMOCRACIA ADMINISTRA LA ECONOMÍA DE PINOCHET: LAS

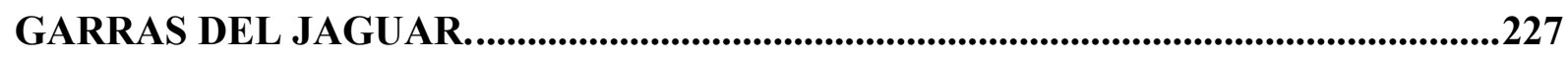

9.1.-DICTADURA Y LOS CHICAGO BOYS: FRACASO Y DEFINITIVO ÉXITO. ....228

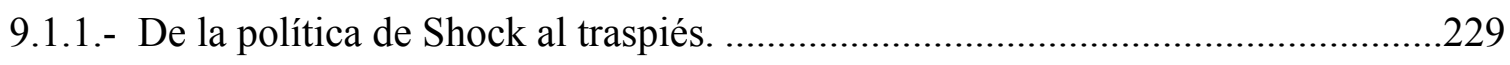

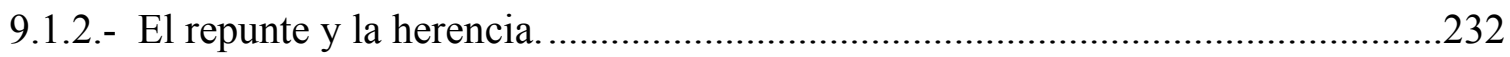

9.2.-LA GARRAS DEL JAGUAR: LA TRANSICIÓN Y LA DEMOCRACIA...............236

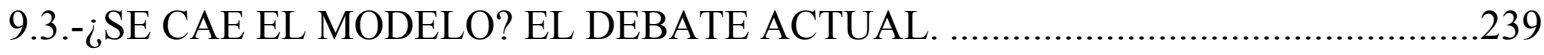

9.3.1.- El sueño chileno. La riqueza que no llegó a todos...........................................241

9.3.2.- La pesadilla chilena. El debate actual sobre el modelo.....................................248 
9.3.3.-¿De la democracia protegida a la controlada?.

10.-EDUCACIÓN PARA (CASI) TODOS: EL DESAFÍO DE LA CONCERTACIÓN DE LOS 90. .265

10.1.-LA ESCUELA COMO CAMPO DE BATALLA. 267

10.1.1.-La revolución inconclusa de Allende en Educación. 268

10.1.2.-La contra-revolución concluida e instalada de Pinochet. .271

10.2.-UNA HERENCIA MÁS: LA (MALA) EDUCACIÓN. 277

11.-CHILE Y SUS DOS SISTEMA DE SALUD: LA CRISIS DORMIDA. .285

11.1.- El ADIÓS A LA SALUD PÚBLICA. 286

11.2.-UNA CRISIS DORMIDA. 290

12.- LAS PENSIONES SE VAN A LA BOLSA O EL GRAN NEGOCIO DE LAS AFP. .297

12.1.- SISTEMA PRIVADO PARA ¿TODOS? 297

12.2.-EL DRAMA DE JUBILARSE EN CHILE 306

13.-LA ESTRATEGIA POLÍTICA DEL ORDEN: EL SISTEMA BINOMINAL........311

13.1.- HISTORIA Y CARACTERÍSTICAS DEL SISTEMA BINOMINAL. 312

13.2.- EL SISTEMA BINOMINAL ¿PARTICIPACIÓN O CONTROL?. 319

14.-LA DERECHA VUELVE AL PODER: ENCARNAR EL LEGADO O ROMPERLO. .327

14.1.- PIÑERA, EL POLÍTICO Y ECONOMISTA PRÓFUGO. 328

14.1.1.- Trayectoria empresarial. 328

14.1.2.- Trayectoria política. 331

14.1.2.- Piñera prófugo: costos y beneficios de la política y el dinero 333

14.2.- LA DERECHA EN EL PODER O EL EXITOSO EMPRESARIO DE "CLASE MEDIA.". 336

14.3.- "CHILEAN WAY" O EL "PIÑERA WAY". 341

15.-CONCLUSIONES. 349 


\section{1.-INTRODUCCIÓN}

Los años setenta para Chile fueron sin duda años intensos, tanto desde el punto de vista cultural $^{1}$, social, económico y político. Con ellos se inaugura un periodo corto en el que confluye el debate más profundo acerca de lo que se quería de este país para el futuro, en su conexión con el mundo también se hacía eco de la tensión que producía la guerra fría.

Con la llegada de Allende al poder se comienza a escribir una historia de dulce y agraz, en la que confluye el triunfo fugaz de un gobierno popular y su posterior caída. Este intenso proceso vivido durante el breve mandato de la Unidad Popular deja una estela de reflexiones acerca de lo que se denominó -y se sigue denominando- la "vía chilena al socialismo".

Este concepto, acuñado principalmente por el propio Salvador Allende -mientras otros miembros de la Unidad Popular le llamaban vía pacífica o no insurreccional, etc.- buscaba describir el proyecto iniciado con su gobierno: alcanzar el socialismo dentro de un marco democrático $^{2} \mathrm{o}$, en otras palabras, desarrollar el socialismo ejerciendo el poder legítimamente a través de elecciones competitivas en un marco de pluralismo y libertad. ${ }^{3}$ Como señalaba Luis Corvalán, senador afín al Gobierno en ese momento y miembro del Partido Comunista: "tanto la vía pacífica como la vía de la violencia son revolucionarias y exigen una tenaz lucha de

\footnotetext{
${ }^{1}$ Por ejemplo, es poco conocida la temprana reforma universitaria chilena. AGÜERO, Felipe. La Reforma en la Universidad de Chile. Eds. Sur, Chile. 1987; JADRESIC, Alfredo. La reforma de 1968 en la Universidad de Chile. Editorial Universitaria. Chile. 2002: HUNEEUS, Carlos. La Reforma universitaria. Veinte años después. CPU, Chile 1988.

${ }^{2}$ GARRETÓN, Manuel, MOULIAN, Tomás. La Unidad Popular y el conflicto politico en Chile, Ediciones Chile América CESOC y LOM Ediciones, Santiago De Chile 1993. p. 184

${ }^{3}$ Esto es lo que conceptualmente señaló desde un comienzo; sin embargo los críticos del Gobierno de la U. Popular consideran que Allende y su "vía" representaban justamente lo contrario de su discurso. De hecho, antes de comenzar su gobierno Allende debió dar garantías al Congreso - debido a que su triunfo fue estrecho- por lo que tuvo que firmar un juramento de fidelidad a las normas institucionales. Entre las justificaciones a la ruptura acontecida en Chile el año 1973 está justamente la actuación de Allende de no aceptar o seguir dichas normas constitucionales, y aún más a "romper su palabra" al declarar tempranamente que su adhesión a las exigencias constitucionales eran sólo una cuestión de táctica, como habría señalado en una entrevista a Regis Debray. Véase por ejemplo: VVAA. Antecedentes Histórico jurídicos años 1972-1973. Editorial jurídica de Chile. 1980. pp. 182-183.
} 
clases, la movilización activa de las masas, la alianza obrera y campesina, la unión y la lucha de las más amplias fuerzas populares alrededor del proletariado (...) Cuando hablamos de la revolución por la vía pacífica sólo estamos señalando la posibilidad de cambios revolucionarios sin recurrir a la insurrección armada o a la guerra civil y no estamos descartando otras posibles formas de violencia en menor escala. La huelga general, la toma de terrenos, las luchas callejeras e incluso la conquista de la tierra por los campesinos." ${ }^{4}$ De esta manera se legitima un modo de "hacer la revolución" único en el mundo en ese momento.

Esta "vía chilena al socialismo", por tanto, también revolucionaria y enmarcada en la tradición marxista-leninista, sigue los preceptos del XX Congreso del Partido Comunista de la Unión Soviética; triunfa de la mano de los cambios ideológicos que se habían consolidado en Chile durante los años 60 -especialmente el anticapitalismo- y el aumento del poder electoral de la izquierda en Chile. Pese a que los estudios acerca de este periodo son abundantes y cubren perspectivas diversas ${ }^{5}$, incluso los más recientes siguen entregando nuevas luces acerca de lo que pasó entre los años 1970 y $1973 .^{6}$

Si bien, como queda claro desde el título de esta obra, nuestro objeto de estudio no es el periodo que va desde 1970 a 1973 sino el denominado retorno de la democracia que se inició con el

\footnotetext{
${ }^{4}$ CORVALÁN, Luis. Camino de Victoria. Editorial Horizonte Chile. 1971. pp. 33-34

${ }^{5}$ Véase por ejemplo: BITAR, Sergio. Chile 1970-1973. Asumir la Historia para construir el futuro, Editorial Pehuén, Chile. 2001; CORVALÁN, Luis, El Gobierno de Salvador Allende, Editorial LOM, Chile, 2003; GARCÉS, Joan. Allende y la experiencia chilena. Santiago, BAT Ediciones. 1990; MOULIAN, Tomás. Fracturas: De Pedro Aguirre Cerda a Salvador Allende. Santiago, LOM. 2006; NOHLEN, Dieter. Chile: Das sozialistische Experiment. Hamburg, Hoffmann und Campe, 1973; SELZER, Gregorio. Los dias del Presidente Allende, Archivo Salvador Allende. México, Universidad Autónoma de México, Centro de Estudios Latinoamericanos, Tomo XIII. México. 1991; FARÍAS, Víctor. La izquierda chilena (1969-1973): documentos para el estudio de su línea estratégica. Berlín, Wissenschaftlicher Verlag. Berlín, 2000; VIAL, Gonzalo. Causas y antecedentes del 11 de Septiembre de 1973. en: VIAL, Gonzalo. Análisis crítico del régimen militar. Santiago, Universidad. Finis Terrae, 1998. p. 67-73

${ }^{6}$ FERMANDOIS, Joaquín. La Revolución inconclusa. La izquierda chilena y el gobierno de la unidad Popular. Centro de Estudios Públicos. Chile. 2013; LLANOS, Claudio. Cuando el pueblo unido fue vencido. Estudios sobre la vía chilena al socialismo. Editorial Univeristaria de Valparaíso. Chile. 2014.
} 
triunfo del "No" a Pinochet en las urnas en 1988, consideramos fundamental presentar el ciclo histórico completo (que incluye naturalmente el periodo de profundas transformaciones acelerado bajo la experiencia allendista) que nos permitirá prestar especial atención a las construcciones terminológicas, al tratamiento del lenguaje, al encadenamiento de los acontecimientos, con el fin de echar luz sobre el muy peculiar proceso de transición a la democracia que protagonizó Chile; con excesiva frecuencia considerado modélico pero que, como esta tesis pretende demostrar, muy alejado de tal carácter y de los atributos paradigmáticos que se le suelen atribuir. Por el contrario, este trabajo se propone examinar críticamente narrativas e ideas muy cristalizadas sobre el tránsito de Chile a la democracia que, como nuestras hipótesis proponen, no resisten la confrontación con los hechos ni en la gestación del proceso ni en sus consecuencias. Por lo que consideramos que la mejor forma de analizar críticamente este episodio nuclear de nuestro pasado próximo (por su proyección en el presente), es de alguna manera poniendo distancia de los conceptos y narrativas que las Ciencias Sociales construyeron en su momento para dar cuenta de lo que estaba ocurriendo en Chile o, en realidad, dialogar con ellos para integrarlos en un debate histórico enriquecido y reavivado en los últimos años como consecuencia de los ecos de ese pasado en Chile y América Latina actual.

Naturalmente, no es la primera vez (ni mucho menos) que se retoman contenidos, conceptos, etc. para dar ciertos énfasis u ofrecer interpretaciones diferentes. Ya lo hizo en los años sesenta el democratacristiano Eduardo Frei, cuando llamó a su proyecto de gobierno "Revolución en libertad"7, situándolo equidistante de los proyectos capitalistas y marxistas. En plena dictadura, sus adherentes también quisieron hacer notar que la "verdadera” revolución estaba comenzando

\footnotetext{
${ }^{7}$ GAZMURI Cristián, ARANCIBIA Patricia, GÓNGORA, Álvaro. Eduardo Frei Montalva: 1911-1982. Fondo de Cultura Económica-Fundación Eduardo Frei Montalva, 1996; PDC. Cómo avanza la revolución en libertad: un programa que se cumple y no se transa. Editorial del pacífico. Chile. 1967; JDC. La democracia cristiana y la revolución en libertad. La Nación. Chile. 1965.
} 
y no era marxista sino neoliberal, por lo que se publicó el muy ideológico libro de Joaquín Lavín -quien en democracia sería candidato a la presidencia- denominado La Revolución silenciosa." 8

Más recientemente, a propósito del rescate de los 33 mineros el año 2010 el -en ese entoncespresidente Sebastián Piñera, recogía el concepto de la "vía chilena", en este caso transformada en emblema comercial en inglés donde se habló del "chilean way" o la manera en que en Chile se hacen las cosas, para destacar la seriedad y eficiencia del quehacer chileno. En ese momento Piñera declaraba a la prensa: "lo hicimos a la chilena, y eso significa que lo hicimos bien...hoy día que Chile está preparado para grandes cosas, estamos preparados para enfrentar los desafíos que el futuro nos va a traer". ${ }^{9}$ En aquel momento se proponía la idea de algo propio, pero a su vez, el presidente de derecha quería hacer notar que bajo su gobierno las cosas se hacían con estándares altos.

Entre la "vía chilena al socialismo" de Allende y el "chilean way" de Piñera hay, como es evidente, un abismo de diferencias; sin embargo, en ambos casos la intención era que se viera a Chile de una manera distinta, que se reconozca aquello que lo hace único en términos políticos, económicos y sociales. Los resultados fueron disímiles en ambos casos, el primero terminó abruptamente y trajo consigo olas reiteradas de violencia para sus seguidores y el segundo, en el contexto del juego democrático termino su ciclo de manera natural.

El contenido de la vía chilena al socialismo, como se observa fue vaciado y llenado por un concepto más propio del nuevo contexto mundial, aquel donde ser competitivo y eficiente es lo más buscado y valorado. Esto no es un mero cambio semántico sino el resultado de un largo

\footnotetext{
${ }^{8}$ LAVIN, Joaquín. Chile: Una revolución silenciosa. Editorial Zig-Zag, Chile. 1987

${ }^{9}$ PIÑERA, Sebastián. “En menos de 24 horas Chile rescató a sus 33 mineros. Especial de prensa. BBC Londres.” [en línea] 14 de Octubre del 2010. [Fecha de consulta: 2 de mayo del 2014] Disponible en internet: http://www.bbc.co.uk/mundo/noticias/2010/10/101014 chile mineros ultimo final az.shtml
} 
proceso histórico que se inicia con la caída del gobierno de la Unidad Popular, se instala violentamente en dictadura y se conserva, profundiza y perpetúa en democracia.

Esta otra "vía" a la democracia tras la dictadura, la que nos proponemos analizar aquí, es también única porque nace de procesos bastante paradojales. Como veremos a lo largo de nuestra investigación, explicar las características de nuestra transición es relevante para entender el Chile de hoy, fruto de experimentos tempranos de neoliberalismo en los años 80 y una consciente instalación y conformación de lo que se denominó tempranamente una "democracia protegida" ${ }^{10}$. Los años noventa, por tanto, ponen en evidencia para Chile estas contradicciones que hoy están en discusión en el mundo entero: las de la posibilidad de vivir en democracia con fuertes niveles de desigualdad sin que esto desencadene episodios crónicos de marginalidad, discriminación y violencia social. Esto, que ha sido una realidad soslayada en Chile durante los últimos 20 años, ha comenzado a resquebrajarse y ahora surgen autores vaticinando el derrumbe del modelo ${ }^{11}$; el cual, sin duda, surgió de las cenizas de la experiencia de la Unidad Popular, de la dictadura que la sepultó y la inextricable conexión de ésta con el núcleo de nuestra investigación: la "vía chilena a la democracia."

En cuanto a la organización de los contenidos, en la primera parte de la tesis - capítulos 1 a 4definiremos los aspectos formales de la misma, tanto relativos a las hipótesis como a la metodología, señalando los ejes principales de la investigación en Chile respecto al tema de la transición a la democracia. También estableceremos los hitos claves del proceso y el debate historiográfico y su organización para entender y dimensionar el debate propuesto en esta investigación. En el capítulo 5 abordamos el núcleo conceptual del trabajo y proponemos un análisis detallado de los modelos de interpretación utilizados para entender el cambio político,

\footnotetext{
${ }^{10}$ ESTÉVEZ, Jorge. "La "democracia protegida" en Chile". Revista de Sociología. FACSO. № 21. Chile. 2007.

${ }^{11}$ MAYOL Alberto. El derrumbe del modelo. La crisis de la economía de mercado en el Chile contemporáneo. Editorial LOM. Chile. 2013.
} 
de acuerdo al acervo teórico que proporciona la Ciencia Política. En el capítulo 6 arranca el análisis histórico de largo plazo, para entender la democracia actual y sus vínculos con la transición diseñada por Pinochet, y ofrecemos una reconstrucción histórica del proceso hasta culminar en las primeras elecciones sin el general como candidato.

Del capítulo 7 en adelante desplegamos los argumentos que nos ayudan a entender y delimitar esta "vía chilena a la democracia" y sus características únicas y paradojales, comenzando con el tema de la memoria y los derechos humanos y su tratamiento en democracia. En el capítulo 8 abordamos uno de los pilares de la democracia actual, la Constitución y sus vínculos con el pinochetismo. Mientras que en los capítulos 9 al 14 abordamos ejemplos de cómo pervive en ámbitos estratégicos la influencia de la dictadura sobre nuestra democracia y como ésta fue profundizando el modelo heredado de la dictadura en lugar de desmontarlo. Priorizamos el análisis del modelo económico neoliberal, tempranamente instalado en dictadura y mantenido en democracia. Después abordamos la educación, la salud y las pensiones (capítulos 10, 11 y 12) como ámbitos donde se reflejan las desigualdades y la carencia de derechos asegurados por el Estado, y se pone en evidencia que el modelo de democracia existente ha evitado acercarse a los ciudadanos, en especial a los más vulnerables. El capítulo 13 se ocupa del sistema político que ha mantenido el statu quo de la "democracia protegida" impuesta por Pinochet, asegurando cuotas de poder a favor de sectores privilegiados e intereses sectoriales (que coinciden con la derecha más leal al legado pinochetista) y en detrimento de sectores mayoritarios de la ciudadanía. Finalmente, con el análisis del gobierno de Sebastián Piñera que proponemos en el capítulo 14, ponemos sobre la mesa el enigma que supone el retorno al poder en Chile de una derecha inequívocamente ligada al pinochetismo en un país que, alguna vez y de forma mayoritaria había manifestado jubilosamente su rechazo al General y su fervor por la democracia dificultosamente recuperada. 


\section{2.-PLANTEAMIENTO DEL PROBLEMA.}

"Los que, como ávidos aficionados, nos acercamos a los textos de los historiadores, agradecemos que sus perspectivas sean variadas, sus metodologías distintas y sus énfasis diferentes, porque sobre el pasado hay visiones encontradas. Esto lo sabemos bien los chilenos, en especial en lo que se refiere a nuestra historia más próxima, llena de violencia política y abierta, como toda época, al debate histórico entre posiciones contrapuestas. Por lo mismo, llama la atención que nadie cuestione que, en los hechos, se haya ido construyendo una versión única de ese período (...)

El pasado, el único lugar donde todos hemos estado de alguna forma, deja de cumplir así uno de sus roles clave, el cual es ayudar a formar la conciencia histórica nacional. Se ha convertido en bandera de lucha política de un sector que busca manejarlo de manera monopólica ante el abandono de la mayoría de los expertos y la deserción de algunos grupos intimidados. ¿Dónde quedó el país de historiadores?”

Juan Ignacio Brito. "Ideas y Debates: Historia y Verdad Oficial”,12

Mucho ha cambiado desde "los días del arcoíris", 13 aquella etapa de la historia de Chile relatada por Antonio Skármeta en su novela ${ }^{14}$ que relata los avatares de la campaña del "No" a Pinochet y que ha quedado plasmada en la memoria de los chilenos como el período cúlmine de la lucha

\footnotetext{
${ }^{12}$ BRITO, Juan Ignacio. "Ideas y Debates: Historia y Verdad Oficial”. Diario La Tercera, Chile, [en línea] 28 de abril del 2011. [Fecha de consulta: 2 de mayo del 2011] Disponible en internet: $<$ http://www.latercera.com/noticia/opinion/ideas-ydebates/2011/04/895-361586-9-historia-y-verdad-oficial.shtml>. En esta columna se replica una de las noticias más importantes del último tiempo en relación a la investigación del asesinato del presidente Allende el 11 de septiembre de 1973 y la propuesta de que el poder judicial establezca una "verdad histórica oficial".

${ }^{13}$ El arcoíris fue el símbolo de la campaña del No a Pinochet. La idea era transmitir mediante dicho símbolo esperanza y alegría en el futuro.

${ }^{14}$ SKÁRMETA, Antonio. Los días del arcoiris. Planeta-Casa-América. Chile. 2011.
} 
por el retorno a la democracia. No es sólo el hecho de que hayan pasado los años, ni que el dictador esté muerto, ni que se haya logrado la alternancia en el poder tras la llegada de la derecha al gobierno lo que marca el verdadero cambio. En estricto rigor, muchas de las políticas económicas y sociales perviven tal cual se heredaron del periodo autoritario, incluida la propia Constitución de la República ${ }^{15}$

Lo que realmente ha ido cambiando es la percepción que se tiene del proceso de transición a la democracia. Los jóvenes en primer lugar, pero también los adultos, han salido a las calles durante la última década a remover, con pancartas en mano, los mitos que habían estado enquistados por años: el milagro del desarrollo económico, la "libre" competencia, las “autolimitaciones" de la izquierda para modificar la Constitución o implementar políticas sociales, etc.

Así queda patente en uno de los últimos discursos de Gabriel Boric ${ }^{16}$ como presidente de la Confederación de Estudiantes Universitarios de Chile (CONFECH), en una de las marchas realizadas por los estudiantes:

“A nosotros, como generación, no nos tocó experimentar la dictadura. Algunos éramos muy pequeños para entender lo que pasaba y la mayoría no había siquiera nacido. Pero sí nos tocó ver la esperanza de nuestros padres, hermanos, y vecinos de que con el retorno a la democracia iba a significar un cambio profundo en sus

\footnotetext{
${ }^{15}$ GARRETÓN, Manuel A. y GARRETÓN, Roberto. "La Democracia incompleta en Chile: la realidad tras los rankings internacionales". Revista de Ciencia Política. Vol. 30, №. 1, 2010. pp. 115-148; SQUELLA, Agustín y SUNKEL, Osvaldo (comp.), Democratizar la Democracia: reformas pendientes. Santiago de Chile: Editorial LOM. 2000.

${ }^{16}$ Actualmente Boric es diputado por la izquierda autónoma, junto a otros dirigentes estudiantiles conocidos como la "bancada estudiantil”, entre ellos Karol Cariola y Camila Vallejos del PC, y Giorgio Jackson de Revolución Democrática.
} 
vidas, y nos tocó estar ahí cuando dicho anhelo fue lentamente cayéndose a pedazos."17

Los historiadores, como se lee en el extracto citado al principio de estas líneas, poco han tenido que ver con este “despertar" en tanto sus libros se mantienen en círculos académicos mas bien acotados o en referencias a aspectos específicos del periodo ${ }^{18}$ sin atreverse totalmente aún a hacer análisis más globales. De hecho, al parecer, queda esta tarea pendiente. ${ }^{19}$ El Chile con su "drama interior, presente e inacabado", ${ }^{20}$ producido por nuestra historia más reciente, permanece intacto y reclama con urgencia nuevas miradas.

El retorno a la democracia supuso nuevos desafíos, tanto para la clase política como para la ciudadanía en general, ya que implicaba retomar la "esencia del Chile democrático",21 que terminó por colapsar el año $1973 .^{22}$ Lo que vino después está lleno de lo mejor y peor de Chile, dependiendo desde el punto de vista con que se mire.

\footnotetext{
${ }^{17}$ BORIC, Gabriel. ¿Podemos los estudiantes creer en el Presidente? Discurso realizado en la marcha en Santiago de Chile el 16 de mayo del 2012. [en línea] Diario THE CLINIC [fecha de consulta 3 de mayo del 2011]. Disponible en internet: $<$ http://www.theclinic.cl/2012/05/16/discurso-de-gabriel-boric-podemos-los-estudiantes-creer-en-el-presidente/>
}

18 Son destacables, por ejemplo, las investigaciones recientes acerca de la derecha durante la dictadura realizados por Pablo Rubio Apiolaza, volcadas en su libro Los civiles de Pinochet. La derecha en el régimen militar chileno, 1983-1990. Dirección de Bibliotecas, Archivos y Museos - Centro de Investigaciones Diego Barros Arana, Santiago. 2013.

${ }^{19}$ Las críticas más fuertes al modelo por parte de intelectuales han venido de sociólogos u otros cientistas sociales, como por ejemplo Alberto Mayol y Fernando Atria. MAYOL, Alberto. El derrumbe del modelo. LOM. Chile. 2012; ATRIA, Fernando. La Constitución tramposa. LOM. Chile. 2013.

${ }^{20}$ STERN, Steve. Recordando el Chile de Pinochet: en vísperas de Londres 1998. Libro uno de la trilogía la caja de la Memoria del Chile de Pinochet. Santiago de Chile: Ediciones UDP, 2009. p. 29.

${ }^{21}$ Ponemos entre paréntesis "la esencia del Chile democrático" porque es una tesis actualmente bastante debatida. En especial, tras la publicación de los libros de Felipe Portales, que generaron un importante debate acerca de la supuesta "tradición democrática" chilena, ya que desde la perspectiva del autor, Chile sufrió constante embates dictatoriales, gobiernos autoritarios u oligárquicos a los largo de su historia, que poco reflejan la participación real de las mayorías en el ejercicio y vivencia de la democracia y que hacen pensar que en realidad la democracia chilena es más un constructo discursivo que una realidad. Véase: PORTALES, Felipe. Los mitos de la Democracia chilena. Volumen I. Desde la Conquista a 1925. Santiago de Chile: Editorial Catalonia. 2004 y PORTALES, Felipe. Los mitos de la Democracia chilena. Volumen II. Desde 1925 a 1938. Santiago de Chile: Editorial Catalonia. 2010.

${ }^{22}$ VALENZUELA, Arturo. El quiebre de la Democracia en Chile. Chile: FLACSO, 1989. 
Por un lado, Chile se transforma en el laboratorio del neoliberalismo con el que, después de algunos traspiés iniciales, se logra una mejora considerable en la vida económica chilena en el mediano plazo. Por otro, se convierte en el escenario de una de las más represivas dictaduras de la región (se suspenden las libertades individuales y políticas, se generan persecución y tortura, etc. $)^{23}$. En el intertanto se configuraba una coalición de partidos de oposición al régimen que lideraría las presiones y negociaciones para una salida pacífica. El objetivo se logró y el año 1989 se elige a Patricio Aylwin -un viejo conocido de la Democracia Cristiana- como el presidente del retorno a la Democracia. ${ }^{24}$

Hoy, a 42 años del Golpe de Estado y a 26 del retorno de la democracia, siguen apareciendo voces que consideran insuficiente lo dicho y hecho hasta ahora. Sobre lo dicho, podemos señalar que la historia escrita parece que no ha sido capaz de satisfacer la necesidad de verdad. Esto, quizá, porque más que ayudar a comprender o entender las diferentes perspectivas ha ido tomando primacía una postura determinada, "blanqueada" u oficial de lo sucedido, que ha llevado a una especie de desencanto, o por lo menos, a una desconfianza acerca de lo sucedido. Sin embargo, no se puede desconocer su implicación en la formación de la cultura ciudadana a través de la enseñanza escolar, instalando la idea del consenso como pilar fundamental del retorno a la democracia.

Por otra parte, lo hecho, útil como punto de partida para debatir sobre los problemas de nuestra propia Historia Reciente, y en especial de nuestra transición de la dictadura a la democracia, nos plantea varios desafíos intelectuales y prácticos como país.

\footnotetext{
${ }^{23}$ VERDUGO, Patricia: Tiempo de días claros. Los desaparecidos. Ediciones Chileamérica-Cesoc. Santiago de Chile. 1990; HUNEEUS, Carlos. El Régimen de Pinochet. Santiago de Chile: Editorial Sudamericana. 2000; CAVALLO, Ascanio (et. al.) La Historia Oculta del Régimen Militar, Santiago-Chile: Editorial Antártica, 1989

${ }^{24}$ Para una información más completa acerca del proceso que llevó a la democracia en Chile se puede consultar el Anexo 3 que da las claves históricas del proceso.
} 
El Chile pos-Pinochet -usando la terminología de Manuel Antonio Garretón-, aquél que ya no es el Chile de Pinochet y ni se podría decir que es el de la Transición, ha sido un Chile contradictorio. Por un lado, para algunos se presenta como el país con un gran crecimiento económico, ${ }^{25}$ democratización social y política, y para otros, un país de una "pésima calidad...una sociedad desgarrada por la ausencia de cohesión social y de un proyecto políticocultural $^{26}$. Este Chile, atrapado, incapaz de salir del pos-pinochetismo actúa de manera reactiva o correctiva sobre las políticas heredadas de la dictadura. ${ }^{27}$ Un hecho es claro: la Constitución en vigor sigue siendo la de 1980, redactada en plena dictadura.

No hemos de negar que en algunos aspectos se haya avanzado, por ejemplo en derechos humanos, tema fundamental para la reconstrucción de un proyecto de país, aunque sea sólo en el plano del reconocimiento y la reparación como sucedió con los Informes Rettig y Valech que documentan los casos de violencia política y tortura. ${ }^{28}$

Con todo lo positivo de estos documentos (aunque no está de más decir que son poco conocidos por el común de la gente) no debemos olvidar que, más allá de los crímenes terribles explicitados en los informes, existen un par de generaciones de chilenos que también sufrieron de una u otra forma 17 años de Dictadura y sobre lo que muy poco se habla y escribe,

\footnotetext{
${ }^{25}$ BARDÓN, Álvaro (et. al). Una década de cambios económicos: la experiencia chilena: 1973-1983. Alfabeta. Santiago de Chile. 1985. FONTAINE, Arturo. La historia no contada de los economistas y el presidente Pinochet. Editorial Zig-Zag. Santiago de Chile. 1988.

${ }^{26}$ GARRETÓN, Manuel Antonio. Del Pinochetismo a la sociedad democrática. Globalización y política en el Bicentenario. Debate. Santiago de Chile. 2007. p. 242

${ }^{27}$ MAIRA, Luis. Chile, la Transición interminable. Editorial Grijalbo. México. 1999. pp. 115-116.

${ }^{28}$ COMISION Nacional de verdad y reconciliación. Informe de la Comisión Nacional de verdad y reconciliación. Tomo 1. Reedición de 1996. Andros impresores. Santiago de Chile. 1996; COMISIÓN Nacional sobre Prisión Política y Tortura. Informe de la Comisión Nacional sobre política y tortura. [en línea] Chile [fecha de consulta 3 de mayo del 2011] disponible en internet: $<\underline{\text { http://www.comisionvalech.gov.cl/InformeValech.html }>}$
} 
principalmente porque implica reconocer nuestra dolorosa historia; siendo que para un Chile en vías de desarrollo pareciera que la fórmula del olvido es la más útil.

Esa “compulsión del olvido", como la denomina Tomás Moulián, ha creado una realidad típica de sociedades que han experimentado situaciones límites. Una especie de pérdida del discurso, una carencia de palabras comunes para narrar lo vivido, lo que reafirma los antagonismos de siempre: trauma o victoria ${ }^{29}$. Junto a esto se alcanza uno de los más importantes logros de la transición: el consenso, piedra angular del paradójico proceso chileno. En él se representa la imaginaria armonía alcanzada hacia fines de los 80 , dejando atrás los debates, con lo que se “manifiesta discursivamente la decisión del olvido absoluto.” ¿Cómo se vive entonces la ciudadanía en una sociedad democrática como ésta?

Debemos señalar que en términos prácticos aquellos bienes básicos que sustentan la ciudadanía han estado asegurados por el momento y han mejorado de manera clara durante los últimos años. Así lo demuestra el que Chile haya descendido su tasa de pobreza total al $18 \%$ y su índice de desarrollo humano sea el segundo más alto de América Latina, ubicándose entre los países de desarrollo humano alto. A su vez, se ha realizado -con todas las limitaciones antes señaladasun proceso de transición a la democracia y de reforma de las instituciones dejadas por la Dictadura Militar en un contexto de gobernabilidad y legitimidad popular. Todo lo cual favorece la percepción positiva que se tiene de la democracia, lo que se constata en el Informe de Latinobarómetro donde Chile es destacado por alcanzar en el año 2010 el índice más alto de apoyo a la democracia con un $65 \%$ de aprobación ${ }^{31}$.

\footnotetext{
${ }^{29}$ MOULIÁN, Tomás. Chile actual: Anatomía de un mito. LOM-ARCIS. Chile. 2002. p. 31

${ }^{30}$ MOULIAN, Tomas. Op. Cit. 2002. pp. 37-38.

${ }^{31}$ CORPORACIÓN Latinobarómetro. Informe Anual 2010. [en línea] [fecha de consulta 3 de mayo del 2011] Santiago de Chile. Diciembre 2010. p. 44. Disponible en internet: $<$ http://www.latinobarometro.org/latino/LATContenidos.jsp $>$
} 
Esta visión bastante positiva de la ciudadanía -basada en estudios de opinión pública- oculta, sin embargo, realidades más complejas propias del cambio cultural vivido en los últimos años. Conviven en su seno dos mundos que parecen en ocasiones bastante distantes: por un lado una élite inmóvil y por otro, una ciudadanía cada vez más desvinculada de los problemas de antaño, los "hijos de la democracia" que no han vivido en carne propia ni la violencia política ni la ausencia de libertad y que ven con desprecio los éxitos económicos al contrastarlos con los altos índices de desigualdad acumulada. ${ }^{32}$ Esta dualidad está causando, como era de prever, una serie de fricciones que retan al sistema, como los movimientos ciudadanos que año a año se manifiestan pidiendo cambios en el modelo político, educativo, constitucional, ambiental, etc.

El sociólogo Pedro Güell recoge muy bien estos problemas al señalar que la sustentabilidad y el rendimiento de la democracia en Chile, asegurada ya en sus bienes básicos, están siendo desafiados por la “oligarquización de sus élites dirigentes y su débil renovación generacional, por sus débiles vínculos con la producción de conocimientos autónomos, por la debilidad en la formulación de proyectos de largo plazo, y por la transformación de los partidos en máquinas puramente electorales”. A su vez señala que, "su desafío mayor está en la dificultad creciente para mediar entre la organización de un orden social cada vez más complejo, opaco y distante, y las transformaciones que afectan a la dimensión subjetiva de la vida ciudadana. ${ }^{, 33}$

Por su parte los sociólogos Eugenio Tironi y Felipe Agüero, también reconocen este problema denominándolo "enfriamiento" de la ciudadanía, que incluye, entre otras cosas, una mayor desafección y apatía hacia la política por parte de la juventud. En su análisis realizado en 1999 señalaban como posibles causas de esta situación al consenso como característica de la

\footnotetext{
${ }^{32}$ En Chile, la distribución de ingresos se ha mantenido relativamente estable desde fines de los ochenta. Se presenta un coeficiente de Gini mayor a 0,50 durante el periodo 2000-2011, lo que refleja una sociedad con altos niveles de desigualdad. Estos y más datos se pueden consultar en línea en: http://datos.bancomundial.org/indicador/SI.POV.GINI

${ }^{33}$ GÜELL, Pedro. "Desarrollo Humano y ciudadanía en Chile: los nuevos desafíos” [en línea]. Revista Polis No 12, 2005. p. 2 [fecha de consulta: 3 de mayo del 2011]. Disponible en internet: $<$ http://www.revistapolis.cl/12/guell.htm $>$
} 
transición chilena, la percepción de escasas diferencias programáticas entre las coaliciones, el papel de los medios de comunicación y la extensión de las relaciones de mercado. ${ }^{34}$ En resumen, similar problema y similar diagnóstico. En palabras sencillas, lo que estos autores proponen es que el gran problema del desarrollo de la ciudadanía chilena en democracia ha estado en la dificultad para transformar a las personas en ciudadanos y al orden social en un asunto que importe a la vida individual.

Ahora bien, este problema, muy bien definido por las investigaciones politológicas, ha sido muy poco estudiado desde otras perspectivas. La Historia, sin ir muy lejos, es uno de estos ámbitos.

Consideramos, de todas maneras, que ha sido natural que esto suceda así, en especial cuando las fuentes a las que se ha tenido acceso para reconstruir los años noventa chilenos son principalmente de tipo político. Además, en muchos casos las investigaciones han sido realizadas por historiadores relacionados con el oficialismo o por lo menos con cierto respeto al mismo. En otras ocasiones, la "falta de perspectiva" con que justifican algunos historiadores el no hacer historia del tiempo presente les ha llevado a no indagar en temas importantísimos para comprender el Chile actual.

Con todo lo señalado, ¿es posible dar nuevas miradas a la transición desde nuevas fuentes? Creemos que sí y además defendemos la necesidad de indagar, criticar y reflexionar sobre un periodo tan contradictorio desde una perspectiva de más largo plazo, en lo que podríamos denominar un "presente extendido"35. Un país que supuestamente "brillaba de alegría" en los

\footnotetext{
${ }^{34}$ TIRONI, Eugenio y AGÜERO, Felipe. “¿Sobrevivirá el nuevo paisaje político chileno?” Estudios Públicos (74). 1999. pp. $151-168$

${ }^{35}$ Se entiende que esta concepción del tiempo, es una de las mayores aportaciones de la Historia del Tiempo Presente a la investigación histórica de problemas contemporáneos. Véase por ejemplo: SÁNCHEZ GONZÁLEZ; Sebastián. "El concepto de presente extendido: un aporte de la Historia del Tiempo Presente a las Ciencias Sociales" Coetánea: III Congreso Internacional de Historia de Nuestro Tiempo. coord. por Carlos Navajas Zubeldía, Diego Iturriaga Barco, 2012. pp. 131-140
} 
noventa comienza a tornarse apático y crítico casi de la noche a la mañana. Algo no estaban viendo en aquella época o algo no queremos ver aún, como señala uno de los protagonistas de la novela de Skármeta parafraseando a Platón:

“Según Platón, los hombres vivimos como zombis mirando contra la pared de una caverna las cosas que pasan, que no son nada más que las sombras de cosas reales proyectadas por un fuego contra el fondo. Esos hombres, que nunca han visto las cosas de verdad, creen que las sombras son cosas reales. Pero si salieran de la caverna y vieran las cosas bajo la luz del mismo sol se darían cuenta de que han vivido en un mundo de apariencias y lo que tenían por cierto es un pálido reflejo de la realidad. ${ }^{, 36}$

Dar una mirada desde la Historia del Tiempo Presente quizás nos pueda dar luces diferentes sobre las sombras ocultas tras los colores del arcoiris. Mal que mal, como señala Chomsky, o se adoctrina en favor de los más poderosos o se educa de manera crítica a vivir la democracia ${ }^{37}$ y para esto es fundamental revisar nuestra historia más reciente.

\section{A.-OBJETIVOS E HIPÓTESIS.}

Como ya hemos señalado reconocemos que existe la necesidad de hacer relecturas de la Historia Reciente de Chile, en especial del proceso de Transición a la Democracia. Si bien existen varios estudios que analizan las causas que explicarían el retorno a la democracia en diversos países de Latinoamérica, incluyendo a Chile, la mayoría de ellas han sido hechas por politólogos o sociólogos, que en vez de buscar explicaciones profundas y complejas, han intentado

\footnotetext{
${ }^{36}$ SKÁRMETA, Antonio. Op. Cit. p. 8.

${ }^{37}$ CHOMSKY, Noam. La (des) educación. Editorial Crítica. Barcelona. 2001.
} 
simplificar y "encajar" los procesos en determinadas terminologías, como señala Guillermo Mira cuando se refiere a las obras de O'Donnell, Schmitter y Whitehead y el libro de Huntington: ${ }^{38}$ “A la distancia se comprueba que ambas piezas, antes que por un afán minucioso de descripción de los hechos que tuvieron lugar, parecían mucho más motivadas por encontrar un modelo interpretativo capaz de dar cuenta de un fenómeno inesperado."39 Por otra parte, los trabajos históricos más recientes han redundado en hacer lecturas específicas, sin abordar el tema de manera global, como pretendemos hacerlo en este estudio.

En este sentido, nos hemos planteado como tarea principal abordar el estudio desde una perspectiva histórica, reconociendo que en una obra como la que presentamos de ninguna manera podría cubrir todas las expectativas explicativas. Sin embargo, sí puede aportar algunas reflexiones e interpretaciones desde nuevas perspectivas, como es la Historia del Tiempo Presente que sirva de punto de partida para un camino que se está aún por recorrer.

\section{A.1.-OBJETIVOS.}

\section{1.-Objetivo general.}

Conocer, analizar y reflexionar desde la historia del tiempo presente la complejidad del proceso de transición de la dictadura a la democracia en Chile, con el fin de desentrañar un periodo que ha sido idealizado y mitificado como un momento triunfal para la sociedad chilena, pero ha

\footnotetext{
${ }^{38}$ O’DONNELL, Guillermo; SCHMITTER, Philipe y WHITEHEAD, Laurence, Transiciones desde un gobierno autoritario. 2 América Latina. Paidós, Barcelona. 1986; HUNTINGTON, Samuel P. La Tercera Ola. La democratización a finales del siglo XX, Paidós, Buenos Aires. 1994.

${ }^{39}$ MIRA DELLI-ZOTTI, Guillermo. "Transiciones a la Democracia y democratización en América Latina: un análisis desde la Historia del presente". Actas del Congreso Internacional XIV Encuentro de Latinoamericanistas Españoles: 1810-2010: 200 años de Iberoamérica. Santiago de Compostela 15-18 de septiembre de 2010. p. 1458
} 
inaugurado un periodo de democracia con baja inclusión política y donde la economía resulta ser el pilar fundamental de medición de calidad de la misma.

En la actualidad están surgiendo voces disidentes acerca del significado y resultados reales en la sociedad chilena de la transición en Chile; sin embargo, los análisis son parcelados y distan de ser históricos. En este sentido, queremos indagar en las raíces del discurso triunfal difundido por los políticos e intelectuales de los años noventa y profundizar en el "verdadero" Chile. Uno menos conocido pero, desde nuestro punto de vista, el que realmente forjó la sociedad chilena actual. Un aspecto central del estudio es conocer cómo los enclaves y amarres se consolidan en las primeras décadas de los 90, para convertirse en los verdaderos pilares de la democracia chilena y su modelo: la Constitución, la política electoral, la educación, la economía y la salud.

\section{2..-Objetivos específicos.}

1.- Analizar la bibliografía que explica el proceso de transición de manera general y específica para el caso chileno, con el fin de conocer y reflexionar acerca de las diversas posturas; con especial atención en las propuestas que contienen visiones más disidentes del discurso oficial acerca del periodo.

2.-Analizar el rol que tuvo la Constitución en la consolidación de una transición y democracia que se ancla firmemente en los principios establecidos por la dictadura.

3.-Analizar a la luz de los documentos de la historia reciente de Chile, tanto oficiales como no oficiales, cómo se consolidó el modelo y sus principales "pilares".

4.- Reflexionar acerca de lo que denominamos el "mito político-social" de la transición: lo relacionado con el rol de Pinochet en la transición, la idea de la "transición pactada", la constitución como eje central, el consenso, entre otros aspectos. 
5.-Analizar y reflexionar acerca del "mito económico" y lo que guarda relación con el modelo de desarrollo económico chileno y su impacto real en la sociedad.

6.-Conocer los límites de la democracia chilena, sus características específicas y las razones por las que podría ser distinta a otras democracias pos-dictatoriales.

\section{A.2.- HIPÓTESIS}

\section{1.- Hipótesis general.}

Desde nuestro punto de vista existe una imagen "estilizada" y "mitificada" de lo que fue el proceso de transición en Chile. La imagen del triunfo, del "arcoíris", de la "alegría ya viene" fue instalada, en gran medida, por la oposición, el mismo grupo que gobernó las casi dos décadas siguientes. El proceso de Transición, desde nuestro punto de vista, no fue un acontecimiento preciso y acotado, tampoco el momento "alegre y colorido" de lo que tanto se ha señalado, sino que está plagado de pactos intra-elitarios sometidos a una serie de trabas y negociaciones guiadas por el itinerario y condiciones impuestas por la dictadura por medio de la Constitución; muchas de las cuales permanecen hasta el día de hoy como pilares de la dictadura que dan incluso sustento a nuestro "modelo" de democracia.

Sostenemos que la transición chilena es una transición a una "nueva forma de democracia", no la que convencionalmente han establecido los modelos propuestos por cientistas sociales, sino uno novedoso que seguimos llamando igual a falta de una conceptualización diferente. Una democracia con baja inclusión y participación, donde lo relevante es la economía y sus indicadores y todo se diluye en ella. En este modelo nuevo, iniciado en dictadura y consolidado en democracia, donde la economía es la medida del éxito y no la inclusión política, consideramos que Chile ha sido pionero, sin mucha crítica ni presión. 


\section{2.- Hipótesis específicas.}

1.-En torno a la existencia o no de un modelo chileno es pertinente analizar la transición para reflexionar acerca de los principios fundantes del mismo. Desde nuestro punto de vista, la transición y el Chile post-Pinochet fijó los pilares de un modelo novedoso en Latinoamérica que profundizó una política económica-social y una convivencia política desarrollada en dictadura y consolidada (con matices) en democracia. Una mirada a través de la Historia del tiempo presente y los años transcurridos desde entonces nos puede dar pistas acerca de esa complejidad, lejos de los modelos tradicionales de análisis.

2.- Consideramos que existe un verdadero "mito político-social" ligado a la idea del "triunfo del pueblo", así como al consenso y el pacto en torno a la transición chilena. Esta idealización del triunfo que desconoce o aminora los amarres dejados por Pinochet, ha sido poco a poco puesta en entredicho en la medida que la ciudadanía ha ido manifestando su malestar y desencanto hacia la clase política. Sin embargo, el anquilosamiento del Chile post-dictadura es fruto tanto de la dictadura como de la democracia posterior que aceptó con pocos reparos las "reglas del juego" interpuestas.

3.- El Desarrollo económico y el "milagro chileno", en vez de promover el desarrollo social han ido generando mayores desigualdades, concentración de la riqueza y segregación. Esta es una herencia de la dictadura, pero que también ha sido reafirmada a partir de la transición por los sucesivos gobiernos democráticos, siendo el marco por el cual se ha medido el éxito del "pacto" transicional.

4.-Aspectos como la educación, la política electoral, la salud y la seguridad social siguen estando fuertemente vinculadas a la dictadura, con derechos no asegurados que "jibarizan" la ciudadanía, su rol y sus posibilidades propias de una democracia, al mismo que se garantiza su potencial de endeudamiento. 


\section{3.-MARCO METODOLÓGICO}

\section{1.-HISTORIA DEL TIEMPO PRESENTE: CHILE POST-DICTADURA Y SUS COMPLEJIDADES. ${ }^{40}$}

Ha habido mucho debate sobre los condicionamientos del estudio del tiempo presente, por ejemplo: ¿es posible tener la suficiente perspectiva para estudiarlo?, ¿qué puede hacer el historiador? Julián Casanova, en una columna del periódico El País reflexiona acerca de esto en el contexto del caso Wikileaks:

"Los historiadores necesitamos años, décadas, para averiguar los hechos más relevantes del pasado, reconstruir el curso de los acontecimientos, sacar a la luz las intenciones de sus protagonistas. Una mirada rigurosa a la Historia exige para nosotros, necesariamente, la aplicación de métodos críticos para evaluar las fuentes, la adopción de técnicas reconocidas para presentar y editar el material y un notable ingenio para detectar los errores en la transmisión de la información y determinar la fiabilidad de los testimonios individuales. Y, de repente, en apenas unos días, la filtración de una masa ingente de material diplomático, obtenida por Wikileaks y divulgada por algunos de los más prestigiosos medios de comunicación internacionales, proporciona una minuciosa crónica de la relación de Estados Unidos de América, el país más poderoso de la Tierra, con el resto del planeta...La historia se acelera y ya no podemos aspirar a comprender las cosas pasado el tiempo, con el

\footnotetext{
${ }^{40}$ Este capítulo fue presentado en el I Jornada de Historia de Chile Contemporáneo del año 2013. Una versión se encuentra en el libro de actas. ACEITUNO, David y ESTRADA, Baldomero. (Coord.) Reflexiones y Miradas a nuestro Pasado Reciente. Actas de la I Jornada de Historia de Chile Contemporáneo. Edición Digital. Instituto de Historia. PUCV. 2013. disponible on line en: http://www.ihistoriapucv.cl/?attachment id=1883
} 
obligado reposo de las fuentes en los archivos, con el uso de métodos críticos para interpretar los textos y la información."

Ante tal disyuntiva los investigadores han tenido que replantearse los métodos, generar nuevas miradas y abrirse a nuevas reflexiones historiográficas. Es así como han surgido nuevas orientaciones históricas -con mucha discusión al respecto ${ }^{42}$-que han comenzado a diferenciar la Historia del Tiempo Presente, del Mundo Actual, Inmediata o Próxima, que establecen distinciones entre las investigaciones de lo "muy contemporáneo" respecto de la historia anterior a la segunda Guerra Mundial. ${ }^{43}$

Por nuestra parte, nos sumamos a la definición fijada por Ángel Soto que siguiendo la historiografía nacida en los años 70 en Francia e Inglaterra, define la Historia del Tiempo presente como “(...) la posibilidad de análisis histórico de la realidad social vigente, que implica una relación de coetaneidad entre historia vivida y la historia narrada, entre los protagonistas, los testigos (fuentes) de la historia y los propios historiadores"44

\footnotetext{
${ }^{41}$ CASANOVA, Julián. "Secretos de Estado" [en línea] Periódico El País, 03 de diciembre del 2010. [fecha de consulta 3 de octubre del 2011] disponible en internet <http://www.elpais.com/articulo/opinion/Secretos/Estado/elpepuopi/20101203elpepiopi 5/Tes>

${ }^{42}$ ABDÓN, Mateos. "Historia, Memoria, Tiempo Presente". Hispania Nova No 1. 1998.

${ }^{43}$ ARÓSTEGUI, Julio. "Historia y Tiempo Presente. Un nuevo horizonte de la historiografía contemporaneísta", Cuadernos de Historia Contemporánea, № 20, 1998, pp. 15-105; NAVAJAS, Carlos. “¿Qué es la historia actual?”. En: DELGADO IDARRETA, José Miguel (coord.), Franquismo y Democracia. introducción a la historia actual de La Rioja, Logroño. Gobierno de La Rioja/IER, La Rioja. 2000. pp. 13-41; CUESTA Josefina. Historia del presente. EUDEMA, Madrid.1993; DÍAZ BARRADO, Mario P. (coord.) Historia del tiempo presente. Teoría y metodología. Universidad de Extremadura, Cáceres. 1998.

${ }^{44}$ SOTO, Ángel. El presente es historia. Reflexiones sobre teoría y método. Centro de estudios bicentenario. Chile. 2006.p. 54.
} 


\subsection{1.-Los "nudos” del debate: qué historia y cuál presente.}

Uno de los primeros escollos que debe sortear todo aquel que quiera hacer Historia del Tiempo Presente es entender a qué historia hacemos referencia. La comprensión tradicional de que la historia es el estudio del pasado, y mayormente del pasado lejano, donde el historiador puede encontrar los vestigios "objetivos” para la reconstrucción histórica, y aún más, donde tiene preeminencia la Historia por sobre cualquier otra disciplina (que actuarían más bien como “ciencias auxiliares" de ésta) es una visión que la Historia del tiempo presente supera. Hoy resulta más evidente que antes que la Historia no es sólo la historia del pasado, al estilo del anticuario, sino que va mucho más allá de las creencias de historicistas y positivistas, es capaz de acercarse al presente.

Todo esto en la medida que se desmitificó sostenidamente la idea de la "verdad objetiva"45 en la Historia -y en otras disciplinas-, por lo que en la medida en que se ha aceptado que tanto las fuentes, como fragmentos de una realidad, como el historiador, en tanto intérprete de esos fragmentos, sólo acceden a una parte de la "realidad" pasada, y por lo tanto abierta a revisiones y discusiones. ${ }^{46}$ En este sentido, abrir el análisis a temáticas históricas recientes se convierte en una construcción histórica tan debatible como la discusión acerca del vasallaje o la guerra del Peloponeso, ni más ni menos.

A su vez, se reconoce que la Historia, y ya lo señalaba Bloch, si se toma aislada es como cualquier ciencia que representa más que nada un fragmento del movimiento universal hacia el

\footnotetext{
${ }^{45}$ CASANOVA, Julián. "Los límites de la objetividad y el desafío posmodernista” En: "Razones de historiador. Magisterio y presencia de Juan José Carreras”, Institución Fernando el Católico, Zaragoza. 2009.

${ }^{46}$ Acerca de esto se ha escrito bastante en relación con el giro lingüístico y la historiografía posmoderna. véase por ejemplo: TOEWS, John E. "Intellectual History after the Linguistic Turn: The Autonomy of Meaning and the Irreducibility of Experience". American Historical Review 92.1987. pp. 879-907; STONE, Lawrence. "History and post-modernism". Past and Present: A journal of Historical Studies 131. 1991. pp. 217-218.
} 
conocimiento. ${ }^{47}$ De esta manera el aislamiento autoimpuesto en el que se encontraba tradicionalmente se ha ido superando al entender que la Historia es capaz de estudiar una dimensión de hombre y no todas, esto es, la dimensión histórica, aquella que hace que un hombre del siglo III sea distinto al del siglo XII y al contemporáneo. Es así como la Historia del Tiempo Presente se abre a la multidisciplinariedad en la investigación, ya que ésta se podría enfocar en una temática u "objeto de estudio" compartiendo miradas con la antropología, sociología, etc. Como señala Pacheco, la HTP (Historia del Tiempo Presente) sería "una historia competitiva y "concurrencial" con las otras disciplinas del presente; una historia para compartir con otros sujetos provenientes de la academia, de la política y de la sociedad, sin pretender la exclusividad interpretativa, sino lograr alcanzar una visión de conjunto, plural y comprometida." 48

Otro de los debates más importantes en torno a la HTP es la redefinición del tiempo. El análisis tradicional acerca de qué es el tiempo desde un punto de vista histórico pone de relieve que los ejes cardinales para entenderlo están contenidos en la relación pasado-presente-futuro; sabiendo que es el presente el único momento donde el hombre puede actuar y que este presente es siempre instantáneo y fugaz. Esta delimitación minimalista de la concepción del tiempo, en especial del presente, se va complejizando en la medida que se le agregan estudios acerca de la dimensión, tipología, ritmos y densidades del tiempo, apareciendo nociones como el estudio del tiempo en espiral marxista, la visión del progreso de la humanidad en su tránsito lineal no providencial o los tres tiempos braudelianos. ${ }^{49}$

\footnotetext{
${ }^{47}$ BLOCH, Marc. Apología para la Historia o el oficio de historiador. FCE, México. 2001. p. 52.

${ }^{48}$ PACHECO, Teresa. "La historia del presente inmediato en el contexto del debate epistemológico de las ciencias sociales". LUDUS VITALIS. vol. XX. No. 3. 2012, p. 88

${ }^{49}$ BRAUDEL, Fernand, La Historia y las Ciencias Sociales, Alianza Editorial, Madrid, 1968
} 
Sin embargo, la gran pregunta surge de inmediato, ¿Si la historia estudia el pasado, entonces qué pasa con una historia que se atreve con el presente? ¿Es posible estudiar ese espacio minúsculo que desaparece en el instante, de manera fugaz? La inquietud es bastante relevante, ya que no se podría hacer historia del presente porque se requeriría que la acción esté en el pasado, que deje vestigios o -como se ha propuesto- que ese instante se extienda o se alargue lo suficiente como para hacerlo asible al estudio. La solución ha sido justamente esto último en su vinculación pasado-presente- futuro: el presente extendido. ${ }^{\mathbf{5 0}}$

Un primer antecedente acerca de lo que podía hacer la historia acerca del presente se realiza con la tantas veces reproducida sentencia de que "toda historia es historia contemporánea", dando a entender el dialogo que se puede obtener cuando se comprende el pasado y el presente en constante "conversación", lo que lleva a la posibilidad de estudiar problemas "candentes" o con testigos vivos o del que incluso el mismo historiador forma parte.

Este dialéctica del tiempo lleva a concebir de manera novedosa el tiempo histórico, ya que sería posible entender que existe claramente un tiempo objetivo -el del reloj y su manecilla que no se detiene- y uno subjetivo donde actúa claramente la percepción humana del devenir y el de la acción de los historiadores. Como señala Koselleck : "No existe ninguna historia que no haya sido constituida mediante las experiencias y esperanzas de las personas que actúan o sufren. [...] No hay expectativa sin experiencia, no hay experiencia sin expectativa [...] Por lo tanto, nuestras dos categorías indican la condición humana universal; si así se quiere, remiten a un dato antropológico previo, sin el cual la historia no es ni posible, ni siquiera concebible",51

\footnotetext{
${ }^{50}$ BÉDARIDA, François. "Definición, método y práctica de la Historia del Tiempo Presente." Cuadernos de Historia Contemporánea. № 20. 1998. p. 21.

${ }^{51}$ KOSELLECK, Reinhart. Futuro pasado. Para una semántica de los tiempos histórico, Barcelona: Paidos, 1993. pp 335336.
} 
El tiempo y el presente particularmente es entonces para el historiador del tiempo presente el lugar de una temporalidad extendida que contiene la memoria de las cosas pasadas experiencia-y la expectativa de las cosas por venir. Un lugar de transición entre lo que fue futuro

y lo que deviene del pasado, una especie de continuum. ${ }^{52}$ Todo lo cual hace posible que el historiador pueda estudiarlo, y al hacerlo no deja el pasado y sus vestigios ni tampoco el presente, e incluso puede incluir al futuro, no como un profeta, sino como prospectiva, ya que ellos tres confluyen en este presente dilatado.

\subsection{2.-Los márgenes de su estudio.}

Uno de los debates generado entre los historiadores es justamente acerca de qué estudia efectivamente la Historia del tiempo presente, cuál sería el marco temporal o cronológico en que se insertaría este tipo de estudio. Qué la hace diferente a la Historia Contemporánea.

Para algunos la Historia del tiempo presente abocaría su estudio a temas ya resueltos o cerrados, cuestión muy diferente a lo que haría la Historia inmediata que analizaría los temas muy cercanos al historiador. Esta distinción, no aceptada por todos los investigadores, es parte más bien de intentos infructuosos por hacer separaciones nominativas, ya que suponer esto haría que la primera fuese "verdadera" historia, en el sentido de que ella hace lo que la historia ha hecho siempre: analizar procesos cerrados y con una distancia respecto al objeto a estudiar. En cambio la segunda, en un estilo más experimental, abordaría temáticas cercanas y desde “dentro", con el historiador como espectador de los acontecimientos.

\footnotetext{
52 BEDÁRIDA, François. "Definición, método y práctica de la Historia del Tiempo Presente", Cuadernos de Historia Contemporánea, 20. 1998. p. 21-22
} 
Este "temor" a la distancia del objeto de estudio lo han manifestado varios autores; por ejemplo, Mateos Abdón señala: “(...) además esta opción por lo más inmediato nos podría conducir hacia productos postmodernos como la ficción literaria y la prospectiva. El pasado más inmediato no suele cristalizar como memoria autobiográfica sino después del transcurso de cierto tiempo, constituyendo en todo caso la experiencia vivida un material para la ficción literaria. Como ha señalado el poeta y editor Carlos Barral, 'la experiencia se va adelgazando y haciendo borrosa y desfigurada según se acerca al presente, que naturalmente es sordo y ciego desde el punto de vista de la Memoria'" ${ }^{53}$

Este estado de "presidio" en el que vive el historiador envuelto aún en una historia positivista será algo que llevará tiempo superar. Como señala Julio Aróstegui respecto a los temas de la Historia del tiempo presente: “(...) así, el presente aparece con frecuencia como objeto de crónica, de análisis cultural, de relato de la política, de reportaje o de recuento de problemas, pero en muchas menos ocasiones como objetivo de "una historia". ${ }^{4}$

La suposición "moderna" de que la historia con perspectiva temporal puede efectivamente ser historia, se sustenta implícitamente en la idea de la objetividad del investigador y la "consolidación" de las fuentes. Ambas ideas actualmente han sido rebatidas en tanto se ha podido comprobar que el observador no es más objetivo en la medida que su objeto de estudio esté más alejado temporalmente de él; su vinculación con ideologías o preconcepciones están siempre presentes y en el "presente", por lo cual las miradas pueden estar igualmente contaminadas, tanto si fuese un acontecimiento del siglo XVI como uno del 2011.

La consolidación de las fuentes se basa más bien en el principio de acumulación, lo cual supone que en la medida que haya más fuentes que avalen o no dicho documento éste puede ser

\footnotetext{
${ }^{53}$ ABDÓN, Mateos. Op.Cit.

${ }^{54}$ ARÓSTEGUI, Julio. La Historia del presente. ¿Una cuestión de método? Actas del IV Simposio de Historia Actual: Logroño, 17-19 de octubre de 2002 / coord. por Carlos Navajas Zubeldía, Vol. 1, 2004, p. 46.
} 
utilizado más verazmente. Pero ¿Cuánto tiempo debe pasar para que una fuente sea fiable? ¿Cuántos documentos deben acumularse para que un acontecimiento pueda ser investigado?

En realidad, pensar de esta manera limita la posibilidad que tiene cualquier disciplina científica: la de que todo conocimiento -independientemente del momento en que haya sido producido- es limitado y rebatible. En este sentido, el que se haga historia del tiempo presente tiene las mismas implicancias que tiene cualquier investigación: el conocimiento generado es limitado y abierto a que sea superado por otra tesis posterior.

La categoría de una fuente -el que sea más o menos antigua- no asegura la calidad de una investigación (ya se conoce el ejemplo de la donación de Constantino), sino más bien la calidad metodológica con que se aborde la interpretación.

\subsection{3.-Debate metodológico.}

Más allá del debate historiográfico, que sigue presente en algunos círculos intelectuales, la necesidad de "hacerse cargo" de realidades históricas que se suscitan con mayor rapidez y en contextos sociales en constante cambio, con más acceso a la información y con nuevos temas (género, migración, memoria, democracia, etc.) ha llevado a que muchos historiadores comiencen a delinear con mayor precisión la metodología, los focos de análisis, el uso de las fuentes, etc. de la investigación del tiempo presente.

Actualmente las principales críticas que había recibido la Historia del tiempo presente y que se realizaban en base a explicaciones propias de la historiografía decimonónica fueron poco a poco superadas. ${ }^{55}$ Juan Andrés Bresciano, ${ }^{56}$ recoge los tres principales argumentos:

\footnotetext{
${ }^{55}$ ARÓSTEGUI, Julio. La Historia vivida. Sobre la Historia del presente. Alianza Editorial, Madrid. 2004.

${ }^{56}$ BRESCIANO, Juan Andrés (Comp.). El tiempo presente como campo historiográfico. Ensayos teóricos y estudios de casos. Ediciones Cruz del Sur. Uruguay. 2010. pp.9-12
} 
a.- Argumento cognitivo. Hablaba de cómo la neutralidad del investigador se podía ver comprometida en este tipo de investigaciones.

b.- Argumento heurístico. Que pone énfasis en la carencia de fuentes confiables para construir una estudio del presente, mientras que las otras fuentes disponibles pueden ser fragmentarias, asistemáticas o poco fidedignas.

c.- Argumento hermenéutico. Los procesos del presente están inacabados; por lo tanto, quien los estudia puede carecer de una adecuada perspectiva de ellos.

Un cambio relevante se dio gracias a los aportes de la Escuela de los Annales, entre otras corrientes, con cuyos trabajos se comenzó a entender la Historia como la disciplina que estudia a las sociedades en dimensión diacrónica y no exclusivamente como el estudio del pasado. El presente, por tanto, comienza a aparecer como un ámbito de estudio. A partir de esto, los argumentos en contra de los estudios del tiempo presente fueron refutados uno a uno.

Por ejemplo, con respecto al argumento cognitivo, se asume actualmente que la distancia temporal no es garantía de neutralidad, ni que la proximidad inhiba al historiador si procede con rigurosidad en su investigación. En relación al argumento heurístico, se reconoce que no existen fuentes y documentos más confiables que otros, sino que todos deben ser sometidos a una crítica rigurosa. Y por último, en lo que atañe al argumento hermenéutico, se debe reconocer que es muy difícil tener certeza plena acerca de cuándo un proceso histórico ha finalizado totalmente; en este sentido, la falta de perspectiva puede equilibrarse con la contextualización de los hechos en tendencias y estructuras de larga duración.

En cuanto a las metodologías utilizadas en este tipo de estudios, se puede decir que se corresponde con la diversidad de temáticas y espacios temporales y espaciales que aborda. En general, se trata de nuevos tipos de documentos que, de vez en cuando, complementan a las fuentes más clásicas (historia oral, archivos digitales, entrevistas, fuentes audiovisuales, etc.). 


\subsection{4.-Reflexión para el caso chileno: los traumas y la memoria.}

Estudiar el Tiempo Presente en Chile sigue siendo una disciplina historiográfica emergente, si bien hay algunos historiadores que se han declarado historiadores del tiempo presente o a han incorporado su pensamiento en algunas de sus investigaciones, como es el caso de Ángel Soto, Isabel Torres, o Pablo Rubio Apiolaza, ${ }^{57}$ siguen siendo un número menor comparativamente con el resto de historiadores sociales, económicos o políticos. Sin embargo, va en aumento de manera importante, por ejemplo existen grupos de investigación que han hecho pública su vinculación a estudios de este tipo como por ejemplo la Escuela de Ciencia Política y Relaciones Internacionales de la Universidad Academia de Humanismo Cristiano, en especial en los estudios democráticos, o los vínculos académicos que se han hecho con la RIEHR (Red interdisciplinaria de estudios de la historia reciente $)^{58}$ donde participan investigadores chilenos, argentinos, españoles y de otras partes del mundo, la Asociación de historia actual, la revista HAOL (Historia actual on line) e Historia a debate que reúnen en su web investigaciones de todo el mundo y que han servido como plataforma de debate de historiadores chilenos que se han ido acercando a esta línea historiográfica. ${ }^{59}$

Aquello de que sólo los países con periodos recientes traumáticos pueden hacer verdadera Historia del Tiempo Presente tiene asidero fundamentalmente en la estrecha vinculación que tiene este tipo de investigación y la memoria, como señala Mateos: “(...) los criterios de periodización de la Historia del presente han partido habitualmente de acontecimientos nodales,

\footnotetext{
${ }^{57}$ TORRES, Isabel. La crisis del sistema democrático. Ed. Universitaria. Chile. 2014; RUBIO, Pablo. Los civiles de Pinochet. La derecha en el régimen militar chileno, 1983-1990. Dibam-Centro de Investigaciones Diego Barros Arana, Santiago, 2013; SOTO, Ángel, "Historia del presente: estado de la cuestión y conceptualización”, Historia Actual Online, HAOL 3. 2004. pp.101-116.

58 http://www.riehr.com.ar

${ }^{59}$ http://www.historia-actual.org / http://www.h-debate.com
} 
de hechos fundadores ligados a una gran convulsión política (una guerra, una revolución) que afecta de manera decisiva a una determinada historia nacional. No deja de resultar significativo que la noción de tiempo presente se esté desarrollando en países de Europa continental o de Iberoamérica afectados por acontecimientos que aparentemente significaron fuertes rupturas históricas". 60

Esta idea, aunque debatible, no deja de ser cierta en relación a las temáticas sobre las cuales muchos historiadores abordan el tiempo presente. Para el caso chileno, los nodos historiográficos resultan bastante evidentes: el Golpe de Estado, la Dictadura y la Transición. En los tres casos, el trauma y la violencia podrían ser ejes sobre los cuales articular la investigación, aunque como veremos el campo es mucho más amplio.

Discutir la relación entre memoria, memoria histórica, memoria colectiva e historia es una debate que supera este artículo, y demás está decir que viene estando en el tapete ya desde principios del siglo XX con los escritos de Maurice Halbwach ${ }^{61}$, que inauguraron desde la sociología la posibilidad de escribir acerca de esta "zona sombría" que hay entre la Historia y la memoria. Sin embargo, con el tiempo -y muchos cambios en la historiografía ${ }^{62}$-, la apertura a investigar problemas que incluyan la memoria en la Historia han aumentado exponencialmente. Sin embargo, como señala Josefina Cuesta con ciertas prevenciones, porque “(...) Infinidad de estudios atestiguan el carácter limitado selectivo de la memoria tanto individual como colectiva, su textura frágil, parcial, manipulada y discontinua, por la erosión

\footnotetext{
${ }^{60}$ MATEOS, Abdón. "Historia, Memoria, Tiempo Presente". Hispania Nova, № 1. 1998.

${ }^{61}$ HALBWACHS, Maurice, On Collective Memory, Chicago University Press, 1992

${ }^{62}$ NORA, Pierre. Les Lieux de Memoire. 7 vols., Paris, 1983-1994; CUESTA. Josefina. "De la memora a la historia", ALTED, A. Entre el pasado y el presente. Historia y memoria. Madrid. UNED, 1996, pp. 55-89
} 
del tiempo, por la acumulación de experiencias, por la imposibilidad real de retenerla totalidad de los hechos y, en todo caso, por la acción del presente sobre el pasado"63.

Con todo, el género sobre el cual se han realizado trabajos en relación a la historia y la memoria ${ }^{64}$ son amplísimos: memoria familiar (memorias intimistas, afectivas, ritualistas, socioeconómicas, etc.), memoria histórica (en relación con una clase, pueblos, nación y con sus acepciones de memoria obrera, popular, etc.), memoria/olvido y los lugares de la memoria. Justamente es en este último tópico donde se ha avanzado bastante en su relación con la historia del tiempo presente, ya que en este caso la cronología y la "difuminación” de la relación pasado/presente generan un buen espacio de investigación para aquellos problemas donde no es menos importante el análisis de los hechos y su memorización, y adquiere relevancia las huellas que dejan.

Durante los últimos años, también en Chile se han publicado importantes trabajos en torno a la Memoria y la Historia Reciente ${ }^{65}$ de la mano de fuentes de documentación oficial (Informe Rettig $^{66}$ y Valech) o los archivos que han ido consolidándose durante los últimos tiempos (Museo de la Memoria, Museo de Villa Grimaldi, Archivo de la Vicaría de la Solidaridad, etc.), que han puesto en manos de investigadores información relevante como testimonios o documentos vinculados a lo acontecido en dictadura y la violación de Derechos Humanos. Junto

\footnotetext{
${ }^{63}$ CUESTA. Josefina. "Memoria e historia. Un estado de la cuestión”. Ayer, No. 32, Memoria e historia. 1998., pp. 203-246

${ }^{64}$ CONNERTON, Paul. How Societes Remember, Cambridge University Press, 1989.

${ }^{65}$ Véase por ejemplo: STERN, Steve. Recordando el chile de Pinochet: en vísperas de Londres 1998. Libro uno de la trilogía la caja de la memoria del Chile de Pinochet, 2009, STERN, Steve. Luchando por mentes y corazones, las batallas de la memoria en el Chile de Pinochet. libro dos de la trilogía la caja de la memoria del Chile de Pinochet. UDP. Chile. 2013.

${ }^{66}$ Comisión Nacional de Verdad y Reconciliación, Informe Rettig. Dos volúmenes. Santiago: La Nación, 1991; Comisión Nacional de Reparación y Reconciliación. Informe sobre calificación de víctimas de violaciones de los derechos humanos y de la violencia política. Santiago: Comisión Nacional de Reparación y Reconciliación, 1996.
} 
con esto se han difundido escritos testimoniales de lo acontecido, como son los trabajos de Sergio Bitar, Jorge Montealegre y Hernán Valdés en otros. ${ }^{67}$

En definitiva, existen otras líneas de investigación en torno a la Historia Reciente de Chile ${ }^{68}$ aunque no siempre relacionada con la metodología de la Historia del Tiempo Presente, como es, por ejemplo, la vinculada con la Historia Política y los problemas de la democracia reciente y que en algunos casos estrecha lazos con la Ciencia Política. Es remarcable esta relación que durante los últimos años han venido tejiendo sociólogos e historiadores en torno a los problemas vinculados al trauma de la dictadura y las políticas de la memoria ${ }^{69}$ en el post-pinochetismo. ${ }^{70}$ Obviamente queda aún mucho por hacer, sobre todo considerando que el tema de la memoria en Chile se ha transformado también en un espacio de disputa, con intentos de uno u otro bando político por "revelar" u "esconder" lo que no conviene.

En este sentido, la Historia del tiempo presente tiene un espacio fértil para abrirse al debate interdisciplinario, para generar reflexiones a partir de fuentes antiguas o nuevas, persiguiendo lo que mejor saber hacer el historiador: recrear el pasado sin tapujos, pero también sin condiciones. Si bien la desmitificación de periodos históricos antes intocables (como el golpe

\footnotetext{
${ }^{67}$ BITAR, Sergio. Isla 10. Santiago: Pehuén, 1987; VALDÉS, Hernán Tejas Verdes: diario de un campo de concentración. LOM/CESOC, Santiago.1996; MONTEALEGRE. Jorge. Frazadas del Estadio Nacional. LOM, Santiago. 2003

${ }^{68}$ Puede verse por ejemplo el prolífico trabajo realizado en el Centro de Estudios Públicos respecto a los acontecimientos pre y post golpe. Véase: http://www.cepchile.cl/dms/lang 1/historia-politica-reciente-de-Chile.htm

${ }^{69}$ Un buen resumen de las distintas líneas de investigación al respecto lo encontramos en: WINN, Peter. "El pasado está presente. Historia y memoria en el Chile contemporáneo", en PÉROTIN-DUMON, Anne (dir.). Historizar el pasado vivo en América Latina. Chile, 2007. http://etica.uahurtado.cl/historizarelpasadovivo/es_contenido.php

${ }^{70}$ Entre muchos otros véase por ejemplo: LOVEMAN, Brian y LIRA, Elizabeth. Las ardientes cenizas del olvido: vía chilena de reconciliación politica, 1932-1994. LOM/DIBAM, Chile. 2000; LOVEMAN, Brian y LIRA, Elizabeth. et al., Historia, política y ética de la verdad en Chile, 1891-2001: reflexiones sobre la paz social y la impunidad. LOM, Chile. 2001; HITE, Katherine. "Breaking the Pacto de Silencio: Memories of defeat, contemporary politics, and the Chilean political class in the 1990s" Journal of Latin American Studies . October. 2003; WILDE Y A.. "Irruptions of memory: Expressive politics in Chile's transition to democracy”. Journal of Latin American Studies. 31(2), mayo de 1999; CAVALLO, Ascanio et al., La historia oculta del régimen militar. Santiago: Antártica, Chile. 1989; AHUMADA, Eugenio et al., Chile: la memoria prohibida. Tres volúmenes. Pehuén, Santiago. 1989.
} 
de Estado y su interpretación salvífica) se ha ido desarrollando de una manera más crítica, aún quedan periodos y acontecimientos poco estudiados o que han sido analizados desde otras disciplinas -como la sociología, la antropología o la comunicación- y donde la historia casi no se ha aventurado. Como ejemplo de estos avances se puede citar el conjunto de investigaciones que vieron la luz tras la detención de Pinochet en Londres, realizadas por historiadores jóvenes junto a otros de más reconocida trayectoria. ${ }^{71}$ Con todo, la tarea apenas si ha comenzado.

\subsection{5.-Reflexiones acerca de la investigación en Chile.}

Como hemos intentado en párrafos anteriores, la conformación de una campo de investigación no es fácil, en especial cuando éste continua marcado por una constante evolución y debate; sin embargo, hemos identificado a varios investigadores nacionales que legitiman y reconocen de manera cada vez más explícita la utilización de las metodologías y miradas de la Historia del tiempo presente, actual o inmediata en sus investigaciones históricas.

No es menos cierto también que ésta es una línea historiográfica que apenas está despuntando en Chile, por lo que aún resulta difícil diferenciarla de otras investigaciones en Historia Contemporánea, Ciencia Política o incluso crónica periodística. Pero se observa un interés creciente en separar "aguas" entre las investigaciones históricas desde la Historia del tiempo Presente y el resto de trabajos acerca de nuestra historia más reciente, lo cual no significa

\footnotetext{
${ }^{71}$ GARCÉS, Mario. (comp.), Memoria para un nuevo siglo: Chile, miradas a la segunda mitad del siglo XX. LOM/ECO, Chile. 2000; OLEA, Raquel y GRAU, Olga (comps.), Volver a la memoria. LOM, Chile. 2001. GROPPO, Bruno y FLIER, Patricia (comps.), La imposibilidad del olvido: recorridos de la memoria en Argentina, Chile y Uruguay. Ediciones A1 Margen, La plata. 2001. JELIN, Elizabeth (comp.), Las conmemoraciones: las disputas en las fechas "in-felices”. Siglo XXI, Madrid. 2002; JELIN, Elizabeth y LANGLAND, Victoria (comps.), Monumentos, memoriales y marcas territoriales. Siglo XXI, Madrid. 2003, DA SILVA CATELA, Ludmila y JELIN, Elizabeth (comps.), Los archivos de la represión: documentos, memoria y verdad. Siglo XXI, Madrid. 2002.
} 
desvincularla de las otras disciplinas -lo que sería hacerla perder parte de su esencia- sino más bien generar una diferenciación más clara. Como ha pasado en el resto del mundo, habrá que profundizar el debate acerca de sus límites y temáticas, cuestión que desde nuestro punto de vista aún está pendiente.

Por último, reconocemos que existe un gran avance en temas relacionados con "historizar la memoria" pero que en su mayoría no corresponden a investigaciones relacionadas con la Historia del tiempo presente, ni siquiera con la misma investigación histórica en general (ni social, ni cultural, etc.), sino que son fundamentalmente análisis sociológicos, psicológicos, audiovisuales, documentos oficiales o testimonios. El desafío, por lo tanto, es revisitar las fuentes con una mirada histórica, ofreciendo relecturas novedosas acerca del pasado próximo. Así como la memoria corre el riesgo de ser olvidada, también hay que evitar que sea desfigurada o acomodada. He aquí un desafío para la Historia del tiempo presente en Chile.

\section{2.-INVESTIGAR EL CHILE DE LOS 90: DE LA MIRADA POLÍTICA A LA HISTÓRICA.}

Sin redundar en algo ya bastante conocido, hay que reconocer que durante la década de 1990 -e incluso desde antes- la investigación política tuvo bastante preeminencia. No sólo para el caso chileno, sino mundial. No por nada se anunciaba con entusiasmo el "fin de la Historia" frente a los fenómenos políticos internacionales ${ }^{72}$ y se delineaban las “oleadas" democráticas. ${ }^{73}$

\footnotetext{
${ }^{72}$ FUKUYAMA, Francis. The end of History and the last Man. Free press. 1992.

${ }^{73}$ HUNTINGTON, Samuel. La tercera ola. La democratización a finales del siglo XX, Paidós, Barcelona, 1994
} 
En este sentido, la literatura que emergía a partir del "modelo español" de transición servía como precedente a lo que podría suceder en otras latitudes, por lo que alcanzó bastante difusión. $^{74}$

Resulta razonable, por tanto -y teniendo en consideración las características de la investigación histórica-, que fuesen pocos los historiadores que se animarán a escribir de procesos que estaban aconteciendo. El caso chileno no fue excepcional: la historia ocupó un plano absolutamente secundario y los primeros escritos que hacían mención al clima político pos-dictadura estaría dominado por sociólogos, analistas políticos y políticos.

Entre los políticos encontramos a Edgardo Boeninger, quien participó directamente de las negociaciones de la transición y a Alejandro Foxley, que fue parte del primer gobierno democrático, quienes escribieron Democracia en Chile: lecciones para la gobernabilidad en 1998 y La economía política de la Transición en 1993 respectivamente.

Por su parte Cristian Toloza, psicólogo social y posteriormente asesor de la presidencia en 1990, escribe junto a Eugenio Lahera en 1998 el libro "Chile en los noventa". Al año siguiente comienzan a aparecer de manera incipiente las primeras críticas a la Democracia en ejercicio. Entre ellas se destacan los trabajos del Álvaro Briones, economista y luego embajador, denominado "La pata coja y la transición infinita" y el escrito del sociólogo Felipe Portales quien hace una dura crítica en su libro titulado Chile. Una Democracia tutelada.

Ese mismo año se publican escritos de varios autores que desde distintas miradas, en especial la política, reflexionan acerca de la complejidad de la transición, como el libro de Amparo Menéndez-Carrión y Alfredo Joignant, La caja de Pandora: el retorno de la Transición

\footnotetext{
${ }^{74}$ Véase por ejemplo: BALOYRA, Enrique (ed.). Comparing new democracies. Transition and consolidation in Mediterranean Europe and the Southern cone. Boulder. Colorado. 1987; HUNEEUS, Carlos (ed.) Para vivir en Democracia, dilemas para su consolidación. CERC. Santiago. 1984; LINZ, Juan y STEPAN, Alfred. (Ed). The breackdown of democratic regimens. John Hopkins University Press. Baltimore. 1978.
} 
chilena, e el de Paul Drake e Iván Jaksic, El Modelo Chileno. Democracia y Desarrollo en los noventa, que ya ponía en evidencia los beneficios que había traído consigo, en algún sentido, la economía de mercado. ${ }^{75}$

Con todo, son pocas las lecturas globales del periodo. Posiblemente una de las más relevantes lleva la firma del sociólogo Tomás Moulian, quien en su ensayo Chile actual: Anatomía de un mito (2002), pone en evidencia en el largo plazo las limitaciones y herencias que dejó el golpe de Estado, la dictadura y los primeros años de la democracia sobre la sociedad. Durante estos primeros años uno de los pocos historiadores que escribió con bastante popularidad acerca del largo proceso que va desde los años 70 a los novena fue Alfredo Jocelyn-Holt, quien vuelca con una notable pluma e inusual desparpajo para la época -y para la narrativa histórica- su balance particular acerca del periodo reciente: "Mi impresión es que esta negociación, la de 1988-89, resultó, como casi siempre sucede en Chile, en un empate״,76

Como queda en claro, en este breve recapitulación -en los próximos capítulos profundizaremos en alguno de estos textos- el análisis político y sociológico ha tenido gran relevancia durante los primeros años de la transición y, si bien se realizaron varios ensayos críticos del periodo, los trabajos históricos fueron más bien escasos. Se podría pensar que con los años la situación ha cambiado, pero la memoria del periodo ha perdurado más bien por la fuerza de los hechos discursos y conmemoraciones oficiales- que por la reflexión intelectual. De hecho durante los últimos años los libros que se han publicado del periodo se refieren más bien a memorias (Ricardo Lagos, Sergio Diez, Eugenio Tironi, entre otros) ${ }^{77}$ o análisis sociológicos, jurídicos o

\footnotetext{
${ }^{75}$ Anteriormente habían publicado el libro DRAKE, Paul y JAKSIC, Iván. El dificil camino hacia la Democracia en Chile 1982-1990. Santiago de Chile: FLACSO-Chile. 1993.

76 JOCELYN-HOLT, Alfredo. El Chile perplejo. Del avanzar sin transar al transar sin parar. Planeta/Ariel, Chile.1998. p. 270.

${ }^{77}$ LAGOS, Ricardo. Asi lo vivimos. Taurus. Chile. 2013; DIEZ, Sergio. Reflexiones sobre la constitución de 1980. Aguilar. Chile. 2013; TIRONI, Eugenio. Sin miedo, sin odio, sin violencia. Una historia personal del No. Ariel. Chile. 2013.
} 
económicos acerca de la supuesta "crisis del modelo" a partir, particularmente, de las manifestaciones estudiantiles del 2009 al 2011; como por ejemplo, los escritos de Alberto Mayol y Fernando Atria ${ }^{78}$, pero sigue habiendo escasez de análisis históricos globales, críticos o que adopten estrategias innovadoras de reflexión.

En nuestro trabajo queremos retomar para la historia política nacional lo que Rene Rémond, escribió acerca de ella: "La historia política también puede incluir el estudio de estructuras. Puede ser una historia de larga duración y siempre he participado de la idea de que quizás es uno de los fenómenos más perennes, debido al peso del pasado en la memoria, consciente o inconscientemente: los fenómenos de la cultura política sólo se comprenden en una perspectiva de larga duración". ${ }^{79}$ Es menester por tanto - y así nos lo permite la historia del tiempo presentere-visitar los acontecimientos de largo alcance, en un presente extendido y en una panorámica política, que no deja de lado otras dimensiones (como la cultural) ni desestima la complejidad de la empresa; haciendo uso de fuentes diversas, compartiendo análisis con otras disciplinas, pero con rigurosidad histórica, con el fin de cuestionar un proceso en el que nos encontramos todavía en la superficie de su discusión.

\footnotetext{
${ }^{78}$ MAYOL, Alberto. El derrumbe del modelo. LOM. Chile. 2012; ATRIA, Fernando. La Constitución tramposa. LOM. Chile. 2013.

${ }^{79}$ RÉMOND, René, "Le retour du politique" en: CHAUVEAU A. y TÉTART, Ph. Questionsá l'histoire des temps présents, Bruselas, Éditions Complexe, 1992. p. 58
} 


\section{4.-MARCO TEÓRICO}

\section{1.- CLAVES HISTÓRICAS DE LA TRANSICIÓN CHILENA}

Cada 11 de septiembre la sociedad chilena vuelve a traer a la memoria el recuerdo de un suceso que marcaría la Historia Reciente de Chile: el Golpe de Estado ${ }^{80}$. La manera en que se vivencia dicho día varía radicalmente dependiendo de la posición ideológica, experiencias personales, etc. Para algunos es el día de la liberación del marxismo y para otros el día en que se estuvo cara a cara con la muerte ${ }^{81}$.

Este acontecimiento marcaría la vida de las personas durante 17 años, hasta que el triunfo de la oposición al Régimen Militar en las urnas el año 1988 propiciaría el retorno de la democracia a Chile. Sin embargo, a más de veinte años del triunfo sobre la dictadura, la sociedad se ha vuelto mucho más crítica del proceso de democratización vivido. ${ }^{82}$

Para conocer a cabalidad este proceso es necesario conocer cuáles son sus características principales. No pretendemos hacer una descripción pormenorizada del proceso, ya que existe bibliografía suficiente al respecto, sino más bien señalaremos -a partir de una sintética reconstrucción de los hechos- aquellas claves históricas que nos sirvan de guía para las

\footnotetext{
${ }^{80}$ Desde el año 1998 (Ley 19.588) quedo establecido como el Día de la Unidad Nacional, la idea era eliminar el día de la "Liberación nacional” establecido por la Dictadura. Fue feriado entre los años 1999 y 2001 en Chile, su propósito era promover la reconciliación entre los chilenos tras el régimen militar. Se eliminó así el. Sin embargo, cada vez que se celebraba, se producían enfrentamientos por lo que se suprimió el año 2002. Actualmente se siguen haciendo reuniones espontaneas para celebrar el Golpe o rememorar a los muertos.

${ }^{81}$ WALDMAN, Gilda "Chile: la persistencia de las Memorias antagónicas”. Politica y cultura No 31 México, 2009. pp. 211234.

${ }^{82}$ El año 2008 se conmemoraron los veinte años de la Transición, la asistencia al evento organizado por la Concertación (coalición de partidos de centro izquierda que dirigieron la oposición al régimen militar a fines de los 80) fue de escaso apoyo público. Esto debido al creciente malestar social que había y que sigue existiendo hacia estos gobiernos, por el poco avance visto respecto a la igualdad, segregación y equidad. Un balance de los veinte años de la Concertación se puede leer en: ESCALONA, Camilo. Chile, 20 años después 1988-2008. Editorial Diagrama. Santiago de Chile. 2008.
} 
posteriores reflexiones a partir de los discursos que circulan en el espacio público sobre una coyuntura tan señalada. En este capítulo sólo describimos los hitos que consideramos más relevantes para los diversos autores, pero no debatimos acerca de su nivel de aceptación o relevancia de las argumentaciones. Dichas reflexiones las dejamos para el capítulo siguiente donde revisaremos las diversas posturas historiográficas acerca del proceso.

\subsection{1-Del quiebre democrático a la apertura del Régimen.}

\subsubsection{1.-La Transición chilena, un proceso complejo.}

Las permanencias y los cambios son propias de los procesos históricos complejos. La transición de la dictadura a la democracia en Chile es uno de ellos, ya que si queremos entender su real dimensión y efectos sociales, políticos, económicos y culturales, no podemos limitarnos a analizar solamente lo acontecido en el plebiscito de 1989 o al primer periodo democrático (un par de años hacia atrás y un par de años hacia adelante).

Concordamos con la descripción que hace Luis Maira de la transición para el caso chileno: "la construcción de una situación intermedia, de tránsito a la Democracia, supone un equilibrio en la correlación de fuerzas entre los sostenedores del viejo Régimen que se retiran y los partidarios de la recuperación de la Democracia que logran acceder a la dirección del Estado, luego de acreditar su respaldo en la sociedad y de una negociación explícita o implícita." ${ }^{83}$

Esta situación de tránsito a la democracia de una régimen a otro es lo que la politología ha definido como transición, que implica además una cierta incertidumbre en su desarrollo y donde

\footnotetext{
${ }^{83}$ MAIRA, Luis. “Chile, la Transición Interminable”. Ciudad de México: Editorial Grijalbo, 1999. p. 116.
} 
la democracia se presenta como una de las alternativas de desenlace. ${ }^{84}$ Este fue el proceso que vivió Chile a finales de los 80 y que tiene como particularidad añadida que mientras se desarrollan las negociaciones y pactos ${ }^{85}$ para alcanzar mayores grados de democratización, por un lado el dictador continuaba en cargos de poder y, por otro, seguía en vigor el marco legal establecido por el Régimen (encarnado en la Constitución de 1980). A continuación analizamos los que consideramos como acontecimientos centrales de la dictadura y la transición, que marcarán el derrotero para alcanzar la democracia en Chile.

\subsubsection{2.- El quiebre democrático.}

En general la Historiografía enmarca la transición chilena en el periodo de la Historia Reciente que se inaugura con el Golpe de Estado (con algunas variaciones, como veremos más adelante). El "quiebre democrático", como lo denomina la historiografía, es producido por una serie de “crisis" acumuladas durante el Gobierno de la Unidad Popular, que representaba la "vía chilena al socialismo" liderada por Salvador Allende. ${ }^{86}$

Estas crisis se produjeron por diversos factores: la creciente polarización producto del aislamiento del centro político (Democracia Cristiana), la radicalización del Partido Socialista (PS )y su postura frente a la vía armada que genera roces al interior de la Unidad Popular (surgen movimientos extremistas), la falta de representación de las políticas implementadas y la exclusión de la oposición (por ejemplo, con el plan Educativo Nacional, la reforma agraria, expropiación de empresas etc.), la conformación de una oposición más radicalizada (Patria y

\footnotetext{
${ }^{84}$ ARAYA LEÜPIN, Eduardo “Transición y transiciones a la Democracia”. Iber: Didáctica de las Ciencias sociales, Geografía e Historia, $\mathrm{N}^{\mathrm{o}} 67,2011$, pp. 10-24

${ }^{85}$ BRUNNER, José J. “Chile: claves de una Transición pactada” Nueva sociedad Nº.106. Marzo-abril. 1990, pp. 6-12

${ }^{86}$ GARRETÓN, Manuel, MOULIÁN, Tomás. La Unidad Popular y el conflicto político en Chile, Ediciones Chile América CESOC y LOM Ediciones, Santiago de Chile. 1993; GARCÉS, Joan. El estado y los problemas tácticos en el gobierno de Allende. Editorial Siglo XXI S.A. Madrid 1974; BITAR, Sergio, Chile 1970-1973, Asumir la Historia para construir el futuro. Santiago de Editorial Pehuén. Chile. 2001.
} 
Libertad), o una creciente movilización de masas en pro del gobierno acentuando el temor de una Guerra $\mathrm{Civil}^{87}$. Cuestiones que para Valenzuela representan "el fracaso de las negociaciones, el consecuente deterioro de las instituciones y procedimientos mediadores tradicionales, la política de movilización social y el deterioro de la autoridad del liderazgo político sobre sus militantes." ${ }^{, 8}$

Por su parte, Edgardo Boeninger ${ }^{89}$ resume la situación vivida por Chile en 1973 de la siguiente manera:

1.- La ruptura total de los consensos básicos, políticos, sociales y económicos y la consecuente pérdida de legitimidad de las autoridades y los poderes del Estado. La confrontación capitalismo-socialismo en economía se trasladó al ámbito político y social.

2.-Se va generando poco a poco una presión sobre las Fuerzas Armadas (de carácter público, personal y familiar) para que iniciaran una intervención. A lo que se debe agregar un anticomunismo ideológico instalado en ellas (en el contexto de la "Doctrina de la Seguridad Nacional" y la ola de guerrillas en Latinoamérica) y una intensa politización (empujada por la integración de algunos generales al Gobierno de Allende y la vinculación de la institución con la derecha política).

3.-La situación generalizada de desorden, quiebre del orden público e inseguridad ciudadana, llevaron a que muchos ciudadanos y reconocidos líderes del centro político vieran la intervención militar como una opción necesaria y válida.

\footnotetext{
${ }^{87}$ COLLIER, Simon y SATER, William. Historia de Chile, 1808-1994. Cambridge University Press, Sucursal España, Madrid. 1998.

${ }^{88}$ VALENZUELA, Arturo. El quiebre de la Democracia en Chile. FLACSO, Chile. 1989. pp. 219 - 289

${ }^{89}$ BOENINGER, Edgardo. Democracia en Chile: lecciones para la gobernabilidad.. Andrés Bello, Santiago.1998. pp. 215216
} 
4.-La actuación de Estados Unidos y la CIA quienes, frente a la posibilidad de un "contagio" socialista en la región fungieron como garantes y catalizadores del Golpe de Estado. ${ }^{90}$

En este contexto el 11 de Septiembre de 1973 las Fuerzas Armadas lideran un Golpe de Estado durante el cual bombardean el Palacio de gobierno, provocan la muerte del presidente, instalan una Junta Militar e inician la persecución de los opositores al Régimen; miles escapan al exilio en tanto otros son asesinados. La ciudadanía a su vez se somete mansamente a las nueva circunstancias y se impone el Estado de sitio.

La represión que se inició una vez instalada la Dictadura Militar fue durísima. Según las cifras oficiales establecidas en los informes de la Comisión de Verdad y Reconciliación (Informe Rettig) y la Comisión Nacional sobre Prisión Política y Tortura (Informe Valech), las víctimas directas de violaciones de los Derechos Humanos en Chile, ascendería, al menos, a unas 35.000 personas. De estos unos 28. 000 fueron torturados, 2.279 de ellos ejecutados y unos 1.248 continúan bajo la figura de "detenidos desaparecidos". ${ }^{91}$ Otros tantos sufrieron el exilio.

\footnotetext{
${ }^{90}$ KORNBLUH, Peter. Pinochet: Los Archivos Secretos. Critica. Barcelona. 2004.

${ }^{91}$ Para ver los informes completos: Informe de la Comisión Nacional de Verdad y Reconciliación (Informe Rettig) en:

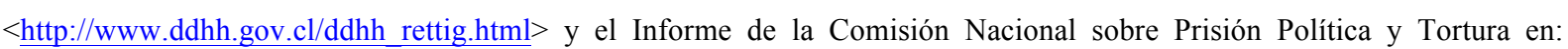
$<\underline{\text { http://www.comisionvalech.gov.cl/InformeComision.html }>}$
} 
El dolor y el sufrimiento de este periodo han sido retratados por historiadores, ${ }^{92}$ memorias personales, ${ }^{93}$ cineastas $^{94}$ y novelistas ${ }^{95}$, que muestran con crudeza la realidad que hasta el día de hoy viven las familias que no pueden recuperar a sus seres queridos.

\subsubsection{3.- El discurso de Chacarillas (Julio de 1977)}

El año 1977 se convirtió en un año clave para la dictadura y en algún sentido también para la transición. A esas alturas el Régimen, liderado por una Junta Militar, había logrado mitigar a la oposición (el año 1975 se creó la oficina de inteligencia) y comenzaba a ver los primeros frutos de su política de shock (de la mano de los "Chicago Boys"96). En este positivo contexto se realiza la reunión en el cerro Chacarillas ubicado en el Parque Metropolitano de Santiago de Chile.

Aquel 9 de julio de 1977 se reúne una multitud de personeros del gobierno, militares y civiles adeptos del Régimen Militar, muchos de ellos jóvenes, que suben esa noche al cerro con antorchas en la mano para escuchar lo que Augusto Pinochet les comunicaría:

\footnotetext{
${ }^{92}$ Véase por ejemplo: LIRA, Elizabeth; WEINSTEIN, Eugenia; ROJAS, María Eugenia. Trauma, Duelo y Reparación. Santiago de FASIC/Ed. Inter-Americana. Chile.1987; AMOROS, Mario. La Memoria Rebelde, testimonios sobre el exterminio del MIR: de Pisagua a Malloco, 1973-1975. Ediciones Escaparate, Concepción. 2008; ILLANES, María Angélica. La batalla de la memoria, Ed. Planeta. Santiago de Chile. 2002.

${ }^{93}$ AYLWIN, Andrés. Simplemente lo que vi, 1973-1990: $y$ los imperativos que surgen del dolor, Santiago de Chile. Editorial LOM, 2003; COZZI, Adolfo. Estadio Nacional.. Editorial Sudamericana, Santiago de Chile. 2000; CASTILLO, Carmen. Un dia de octubre en Santiago. Editorial Sin Fronteras, Santiago de Chile. 1987.

${ }^{94}$ Los documentales del periodo son abundantes. Además durante los últimos años varias series de televisión han abordado el tema de manera directa, por ejemplo con las miniseries "Los archivos del Cardenal" y "Los 80". Si se quiere conocer en detalle la producción cinematográfica del periodo se puede ver on line la cronología y la historia del cine chileno en $<$ Www.cinechile.cl>

${ }^{95}$ SEPUlVEDA, Luis. La sombra de lo que fuimos. ESPASA-CALPE, España. 2009; URBINA, José Leandro. Cobro revertido. Santiago de Chile: Planeta, 1992. DONOSO, José. La desesperanza. Seix Barral, Barcelona.1986.

${ }^{96}$ ANGELL, Alan. Chile de Alessandri a Pinochet.. Editorial Andrés Bello. Santiago de Chile.1993. pp. 93-107
} 
"El proceso concebido en forma gradual contempla tres etapas: la de recuperación, la de transición y la de normalidad o consolidación. Dichas etapas se diferencian por el diverso papel que en ellas corresponde a las Fuerzas Armadas y de Orden, por un lado, y a la civilidad, por el otro. Asimismo, se distinguen por los instrumentos jurídico -institucionales que en cada una de ellas deben crearse o emplearse.

En la etapa de recuperación, el poder político ha debido ser integralmente asumida por las Fuerzas Armadas y de Orden, con colaboración de la civilidad, pero en cambio, más adelante, sus aspectos más contingentes serán compartidos con la civilidad, la cual habrá de pasar así de colaboración a la participación.

Finalmente, entraremos en la etapa de normalidad o consolidación. El Poder será ejercido directa y básicamente por la civilidad, reservándose constitucionalmente a las Fuerzas Armadas y de Orden el papel de contribuir a cautelar las bases esenciales de la institucionalidad y la Seguridad Nacional en sus amplias y decisivas proyecciones modernas".

Extracto del discurso de A. Pinochet en el Cerro “Chacarillas" 9 de Julio de $1977^{97}$

Queda patente que la dictadura establecía con claridad el derrotero que seguiría mediante tres etapas: la de recuperación, la transición y la consolidación. A su vez, no se instituyen en este momento fechas sino que sólo se enumeran las metas.

\footnotetext{
${ }^{97}$ PINOCHET, Augusto. Pinochet: Patria y Democracia, Editorial Andrés Bello, Chile, 1983. pp. 87 -88.
} 
La Dictadura asumía que la ciudadanía necesitaba ser acompañada por los militares para alcanzar una madurez política e institucional suficiente para avanzar por sí sola, aunque los militares serían siempre los garantes de la estabilidad (de esta democracia protegida). El siguiente paso de este proceso sería darle validez legal a esta hoja de ruta.

\subsubsection{4.- La Constitución de 1980.}

Aunque en su autopercepción la Junta Militar había alcanzado varios logros hacia principios de los 80, aún quedaba una tarea pendiente: su propia legitimación. La idea de la elaborar una nueva Constitución que reemplazara a la de 1925 no era nueva y se venía desarrollando desde casi los primeros días tras el Golpe de Estado ${ }^{98}$, tarea en la que los civiles serían fundamentales.

Se crea entonces la Comisión de Estudios de una Nueva Constitución, presidida por Enrique Ortúza y acompañado por Jaime Guzmán ${ }^{99}$, Jorge Ovalle, Enrique Evans, Alejandro Silva y Gustavo Lorca. Sus integrantes fueron cambiando a lo largo del tiempo. En 1978 y tras cinco años de trabajo fue entregado un anteproyecto que fue revisado por el Consejo de Estado (presidido por el ex presidente Jorge Alessandri, representante de la derecha política).

Luego de realizadas las oportunas modificaciones a manos del Consejo de Estado, la Junta Militar decide hacer sus propios cambios: por ejemplo, alargar de cinco a ocho años el periodo que llamaron de transición y someter en muchos aspectos el papel del Presidente de la

\footnotetext{
${ }^{98}$ ARRIAGADA, Genaro. “Por la Razón o la Fuerza. Chile Bajo Pinochet”. Editorial Sudamericana, Santiago de Chile.1998.

99 Jaime Guzmán, abogado constitucionalista y asesor jurídico de Augusto Pinochet, fue un actor muy relevante para la dictadura y la transición. Fue fundador y líder del partido político más fiel a la dictadura, la Unión Demócrata Independiente (UDI). Además participó en la redacción de la Constitución de 1980. Fue defensor del Golpe de Estado y de la implementación de una democracia protegida. Fue asesinado en 1991 por grupos extremistas. Véase: GUZMÁN, Jaime. Escritos Personales, Editorial Zig-Zag. Chile. 1993; CRISTI, Renato. El pensamiento político de Jaime Guzmán. Autoridad y libertad, Editorial LOM, Chile. 2000; MONCADA, Belén. Jaime Guzmán El Político. Una Democracia contrarrevolucionaria 1964-1980, Editorial Ril Editores. Santiago de Chile. 2006.
} 
República a las Fuerzas Armadas. Esto no fue del agrado de Jorge Alessandri, quien sería uno de los principales críticos de la versión final de la Constitución; a pesar de lo cual llamó igualmente a votar por el sí en el plebiscito de 1980.

El 10 de Agosto de 1980, Pinochet convocó (por radio y televisión) al acto plebiscitario, en que se debía aprobar o no el texto constitucional propuesto por la Junta de Gobierno ${ }^{100}$. Como era lógico, la opción por el "Si” a la Constitución tenía toda la cobertura publicitaria, mientras a los que apoyaban la opción por el "No" se les prohibía su difusión.

La oposición no tardó en remarcar que dicho plebiscito no tenía las garantías suficientes para asegurar su legalidad. Genaro Arriagada señalaba al día siguiente de la votación:

"Un plebiscito es un proceso que tiene varias etapas y éste estuvo viciado en todas sus etapas: en la forma como se presentó la alternativa (yo o el caos); en la más extrema disparidad en el acceso a los medios de información; en nuestra absoluta exclusión de los espacios en televisión; en la no existencia de registros electorales; en el hecho de una oposición luchando contra un Gobierno que manejaba el estado de emergencia, y tantos otros ejemplos que sería largo de enumerar".

El Mercurio, Viernes 12 de Septiembre de $1980^{101}$

Esta será la crítica que marcará el discurso de la oposición (el "Grupo de los 24”, como se les conoció en ese momento) a Pinochet durante los primeros años de la década de los 80 . Sin embargo, pese a todo el manto de dudas que rodeó el plebiscito de 1980 (ausencia de registros

\footnotetext{
${ }^{100}$ ORTEGA FREI, Eugenio. de una alianza politica: el partido Socialista de Chile y el partido Demócrata Cristiano: $1973-$ 1988. CED-CESOC. Santiago de Chile.1992.

${ }^{101}$ ARRIAGADA, Genaro. 10 Años: Visión Crítica. Editorial Aconcagua. Chile.1983. pp. 125 - 126.
} 
electorales, represión, etc.) la opción del sí gana con 67\% de aprobación. De esta manera el Régimen Militar, a pesar de todas las irregularidades del proceso, quedó legitimado y con una "amplia mayoría" de apoyo.

De esta manera, desde la perspectiva de la derecha y el Régimen quedaba inaugurado el inicio de la transición. Como señala Canessa y Balart: "Con la ratificación ciudadana del texto constitucional propuesto por la H. Junta de Gobierno mediante el plebiscito realizado el día 11 de septiembre de 1980, culminó la fase arquitectónica del orden político surgido el 11 de septiembre de 1973 y se inició la Transición hacia su fase agonal, esto es, aquella en la que de acuerdo a las normas en vigor resulta legítima la competencia por el poder político."102

\subsubsection{5.- Los primeros intentos de organización.}

Con el fin de establecer una oposición a la constitución que se estaba gestando, nació en 1978 el denominado "Grupo de los 24", el cual en su etapa inicial estaba formado precisamente por 24 integrantes, entre los que destacan Patricio Aylwin, Edgardo Boeninger, Fernando Castillo, Raúl Rettig, Sergio Villalobos y Jaime Castillo entre otros. Este grupo, siempre señaló que actuaba a título personal y al margen de todo exclusivismo ideológico o partidista (debido a que existía prescripción de la política partidista) y que su interés primordial era estudiar, en conjunto, las causas del proceso que había culminado con la ruptura de la tradición democrática chilena.

El grupo se reunía de manera permanente con el fin de redactar una alternativa a la Constitución de 1980 y sus elementos más autoritarios. Como ellos mismos señalaban:

\footnotetext{
${ }^{102}$ CANESSA, Julio. BALART, Francisco.Pinochet y la restauración del consenso nacional. Geniart. Chile. 1998. p. 311.
} 
"No hemos trabajado encerrados entre cuatro paredes, al margen de la realidad ni del sentir de nuestros compatriotas. Conscientes de la profunda crisis que ha afligido a Chile en los últimos años, de la que el quiebre institucional y la decadencia que vivimos son manifestaciones dramáticas, hemos partidos del análisis de los caracteres y causas de esa crisis hecho por hombres y mujeres venidos de todos los sectores de la vida nacional.

Tampoco nos hemos dejado llevar por ningún ideologismo unilateral, sino que procuramos recoger en nuestro estudio, junto a los más modernos aportes de las ciencias sociales, las visiones provenientes de múltiples concepciones ideológicas. Convencidos de que un régimen político, para que sea legítimo y perdurable, deber ser expresión del "sentido común del pueblo", es decir, de las ideas esenciales generalmente compartidas por la comunidad nacional, nos hemos esforzado por buscar soluciones que el más alto grado de acuerdo entre los chilenos.

Como no pretendemos arrogarnos una representación popular que a nadie ha sido conferida, hacemos públicos nuestros acuerdos en el carácter de simples proposiciones al pueblo de Chile, único titular del poder soberano de resolver sobre la materia".

Informe del Grupo de los “24”. $1979^{103}$

El Régimen Militar les negó en variadas ocasiones la posibilidad de manifestar públicamente sus estudios y conclusiones acerca de la Constitución de 1980.

\footnotetext{
${ }^{103}$ VARIOS. "Informe del Grupo de los 24” [en línea]. Revista HOY. octubre de 1979. [fecha de consulta 12 de septiembre del 2011] disponible en Internet en: $<$ http://www.archivochile.com/Partidos burguesia/doc gen/PBdocgen0013.pdf $>$
} 
Una vez instalado y "legitimado" el Régimen parecía ser que todo marcharía según se había establecido. Sin embargo, la década de los 80 se convertiría en un punto de inflexión en el proceso, debido a la crisis económica que golpeó al país y que puso en entredicho el proyecto neoliberal de la dictadura ${ }^{104}$ que hasta ese momento mostraba signos bastante positivos de recuperación ${ }^{105}$.

Como señala Tironi: "El proyecto político autoritario descansaba también en la suerte del modelo económico. Se preveían dos fases, ambas consagradas en la Constitución Política de 1980. La primera, de corte dictatorial, debía crear las bases de una próspera economía de mercado; la segunda y definitiva sería de una Democracia estable apoyada en una ciudadanía satisfecha, pragmática, ocupada de su enriquecimiento personal y alejada de cualquier extremismo ideológico. El derrumbe del modelo, sin embargo, restó viabilidad a la estrategia de tránsito lento y gradual hacia esa "Democracia protegida". 106

Justamente dicha crisis gatilló, entre los años 1982 y 1984, una serie de protestas masivas que fueron cada vez más intensas debido a la represión y el asesinato de algunos de los líderes sindicales de mayor renombre (como fue el caso de Tucapel Jiménez, que fue encontrado degollado en 1982).

Con respecto a las causas del desplome del sistema neoliberal en Chile durante estos años, Cristián Gazmuri señala que se debió a "una serie de errores macroeconómicos del equipo de

\footnotetext{
${ }^{104}$ SHOEMAKER, Luke, "La Crisis Financiera de 1982-1983 en Chile: Orígenes, Intervención, Efectos e Implicancias para el Modelo Neoliberal" ISP Collection. Paper 711. 2009.

${ }^{105}$ FONTAINE, Juan Andrés. “Transición económica y política en Chile: 1970-1990” Estudios Públicos, №50, 1993. pp.229280

${ }^{106}$ TIRONI, Eugenio. El Régimen Autoritario. Para una Sociología de Pinochet. Ediciones Dolmen, Santiago de Chile. 1997. p. 82 .
} 
gobierno, al perpetuar la mantención artificial de un precio bajo del dólar, sumados a la recesión mundial que se produjo ese año, llevó a una cadena de quiebras que comenzaron por algunas de las industrias más grandes del país y culminaron con las de algunos de los mayores bancos particulares. El pasivo de todo el sistema bancario, descontando capital y reservas, superaba los seis mil millones de dólares de la época. La cesantía se disparó hasta más de un 20 por ciento nominal y un porcentaje real bastante más alto (quizás hasta un 30 por ciento). El PIB que había venido subiendo desde 1976 cayó en un 14,1 por ciento en 1982 y otro 0,7 por ciento en 1983 . El Estado tuvo que socorrer con miles de millones de dólares al aparato financiero en quiebra. Era el fin del boom y naturalmente esto tendría sus consecuencias políticas."

Efectivamente, las consecuencias políticas no tardaron en llegar; considerando el debilitamiento del Régimen se comenzaron a realizar por primera vez acercamientos entre el Gobierno militar y la oposición con el fin de encontrar una salida exitosa del autoritarismo. Las tres instancias de organización civil y política más importantes del periodo fueron el "Proyecto de Desarrollo para un Consenso Nacional" (PRODEN), el "Manifiesto Democrático" y la "Alianza Democrática”. En paralelo, se organizaron grupos mucho más radicalizados como fueron el Frente Patriótico Manuel Rodríguez (FPMR) y el Movimiento Democrático Popular, como una alternativa de la izquierda, que incluía al PC-MIR-IC-PS Almeyda (ambos surgieron en 1983, por no sentirse insatisfechos con la propuesta de la Alianza Democrática).

El "Proyecto de desarrollo para un Consenso Nacional" (PRODEN) emerge amparado en el debilitamiento del Régimen, debido a la crisis económica y las fuerte protestas ocurridas entre los años 1982 y 1983. Nace en el año 1982, bajo la figura de una sociedad anónima (para eludir la prescripción) conformada por militantes de diversos partidos políticos de la oposición

\footnotetext{
${ }^{107}$ GAZMURI, Cristian. "El Lugar de Pinochet en la Historia: Una Interpretación Política de la Experiencia Autoritaria 19731990" [en línea]. Diario La Tercera, 1999 [fecha de consulta 12 de octubre del 2011] disponible en internet en $<\underline{\text { http://www.uc.cl/historia/cinfo/Articulos/gazmuri7.htm> }}$
} 
al Régimen Militar que buscaban una alternativa independiente para la salida de la dictadura. Entre los miembros del PRODEN se encontraban dirigentes "conservadores y de la convergencia socialista; radicales y social demócratas; del PADENA (Partido Democrático Nacional) y la Izquierda Cristiana; demócratas cristianos y nacionales". ${ }^{108}$

El objetivo del grupo era proyectar, realizar y evaluar una serie de estudios alternativos a los que realizan los partidos políticos u otras organizaciones de características similares para conseguir el retorno a la democracia. Las principales actividades de esta organización consistieron en envíos de cartas a las diferentes autoridades de gobierno y un proyecto de reforma constitucional con el fin de derogar las disposiciones transitorias de la Constitución de 1980 consideradas como antidemocráticas. A su vez, se realizó una acusación constitucional contra el Ministro de Hacienda y de Economía Rolf Lüders ${ }^{109}$ y se impulsaron las movilizaciones civiles en 1983 y 1984.

Los logros de dicha organización fueron importantes, llegando a sostener conversaciones con el Ministro de Interior Sergio Onofre Jarpa; sin embargo, también produjeron una serie de conflictos con el otro grupo de oposición, la Alianza Democrática, debido a las fuertes presiones políticas que se generaron. Finalmente el PRODEN prefirió seguir de manera independiente, teniendo acercamientos a grupos izquierda como el Movimiento Democrático Popular.

Sin embargo, la desaparición definitiva del PRODEN se da cuando se les pide a los militantes de la Democracia Cristiana que apoyen con exclusividad a la Alianza Democrática. Finalmente, en 1984 Jorge Lavanderos deja la presidencia de la organización, lo que a su vez significó dejar el camino libre a la Alianza Democrática.

\footnotetext{
${ }^{108}$ FONTAINE, Juan Andrés, Op. Cit. p. 268.

${ }^{109}$ AYLWIN, Patricio. El Reencuentro de los Demócratas: Del Golpe al Triunfo del No. Ediciones Grupo Zeta, Santiago de Chile. 1998.
} 
La Alianza Democrática surge también al amparo de la coyuntura de ese gran movimiento social. Se formó con la intención de que los partidos políticos de oposición lograran llevar adelante una sola estrategia y un programa único frente a la dictadura. Fue así que el 6 de agosto de 1983 nace la Alianza Democrática conformada por la Democracia Cristiana (DC), sectores de la derecha democrática y el socialismo renovado. Sus objetivos seguían los principios del “Manifiesto Democrático” de 1983 (que veremos a continuación) el cuál contenía tres puntos: la necesidad de un acuerdo nacional para impulsar una Asamblea Constituyente y una nueva Constitución; la renuncia del Presidente Augusto Pinochet, y el establecimiento de un Gobierno Provisional para una breve Transición. ${ }^{110}$

La Alianza Democrática surge en un acto realizado el 6 de Agosto de 1983 en el "Círculo Español", donde expusieron Eduardo Arriagada, el presidente del Colegio de Ingenieros Fernando Castillo y el presidente de la Democracia Cristiana, Gabriel Valdés. Posteriormente se unieron como firmantes al documento "Bases del Diálogo Para un Gran Acuerdo Nacional”, Patricio Aylwin, Luis Bosay, Duberildo Jaque, Fernando Luengo, Enrique Silva Cimma, Ramón Silva, Julio Stuardo, Julio Subercaseaux, Gabriel Valdés, Hernán Vodanovic y Hugo Zepada.

La Alianza Democrática inicia conversaciones con el Ministro del Interior, pero el contexto social no era muy favorable, lo que tensiona las relaciones y marcará todo el diálogo entre las partes (la cuarta protesta fue muy sangrienta, deja un saldo de 27 personas muertas). En agosto de 1985 se firma Acuerdo Nacional, patrocinado por la Iglesia Católica, que avanzará aún más en el compromiso por una transición a la democracia. Sin embargo, la dictadura no mantiene su compromiso, lo que debilita a la Alianza y sus ideales. Finalmente en 1986, con el retiro del

\footnotetext{
${ }^{110}$ BOENINGER, Edgardo. Op. Cit. p. 301.
} 
Bloque Socialista, la Alianza Democrática se ve muy disminuida, lo que la lleva a desaparecer en 1987.

El Manifiesto democrático, ${ }^{111}$ fue un documento fundamental para el proceso de transición, ya que fue el primer documento en que las fuerzas de la oposición al Régimen (incluidos algunos líderes de derecha) llegaban a un acuerdo en los puntos que debían exigir a éste, como también en la estrategia que se debía seguir para su consecución (anteriormente hubo dos escritos, uno de la Conferencia Episcopal $(1982)^{112}$ y otro de un grupo de sindicatos enviados a Pinochet (1983), los cuales podrían considerarse como prolegómenos del Manifiesto).

El Manifiesto se presenta como el escrito de un grupo pluralista de oposición: hace una descripción del contexto en que se vivía (critica a la Constitución de 1980 y la mala imagen que el país cosechaba en el exterior) y plantea los caminos de solución al mismo (aspiración al retorno a la vida democrática y republicana).

De esta manera resume el Manifiesto uno de sus firmantes y, posteriormente, uno de sus líderes más destacados, Patricio Aylwin: "Luego de denunciar la grave profunda y prolongada crisis que afectaba al país y describir sus principales síntomas, de atribuirla a un sistema que limitaba, la justicia y la participación, de proclamar su fe en la Democracia como en la forma de vida y de gobierno que hizo posible el progreso nacional y la única capaz de concitar el esfuerzo de toda la comunidad para la justa solución de los más urgentes problemas nacionales, el Manifiesto llamaba a todos los chilenos a un gran esfuerzo nacional para el restablecimiento de

\footnotetext{
${ }^{111}$ VARIOS. Manifiesto Democrático. [en línea] Santiago de Chile. 14 de marzo de 1983. [fecha de consulta 12 de octubre de 2011] disponible en internet $<$ http://es.wikisource.org/wiki/Manifiesto democr\%C3\%A1tico (14 de marzo de 1983)>

${ }^{112}$ GARRETÓN, Manuel A. y RAMMSY, Claudio. Iglesia y Transición en Chile. Ediciones Rehue. Santiago de Chile.1990; FERNÁNDEZ, David. La "Iglesia" que resistió a Pinochet: historia, desde la fuente oral, del Chile que no puede olvidarse. IEPALA. Madrid. 1996.
} 
la Democracia, sobre la base del diálogo entre los chilenos en un clima de respeto recíproco y con un espíritu de solidaridad nacional, sin odios ni revanchismos."

\subsubsection{7.- El proceso de apertura del Régimen. El Acuerdo Nacional.}

Con la llegada al Ministerio del Interior de Sergio Onofre Jarpa (1983), en medio de una situación crítica (protestas, crisis económica, organización de la oposición) para el Régimen, se inicia un proceso de apertura.

Según Ascanio Cavallo, el entonces Ministro del Interior estableció las siguientes tareas para 1984 y 1985: terminar las leyes de elecciones y partidos y convocar a un plebiscito para aprobarlas, levantar el receso político y fijar un período para la organización de los partidos, crear un movimiento político independiente, pero defensor del Régimen, fijar fechas de elecciones parlamentarias, organizar el movimiento político para ganar tales elecciones. ${ }^{114}$ Sin embargo, dicho plan se vería enturbiado por la represión en las protestas, que pese a la oposición del Ministro, llevaba a cabo Pinochet.

Esto produjo un verdadero "circulo vicioso" en las negociaciones: el gobierno molesto por las protestas civiles, respondía duramente, tanto a quienes asistían, como a quienes las convocaban, por lo cual, la oposición respondía duramente al gobierno, y este volvía a reprimir. Con gran esfuerzo el Ministro del Interior logró cambiar en algo esta situación incluyendo en sus discursos la necesidad de "consensos", de "reconciliación”, incluso anunció la posibilidad de un plebiscito para modificar la Constitución y elegir un parlamento antes de 1989.

\footnotetext{
113 AYLWIN, Patricio. Op. Cit. p. 224.

${ }^{114}$ CAVAllo, Ascanio (et. al.) La Historia Oculta del Régimen Militar, Editorial Antártica, Chile. 1989. p. 406.
} 
A partir de aquí se inician una serie de sesiones entre el Régimen y la oposición. Mientras tanto, la derecha más fiel al Régimen decidió tomar su propio camino, creando el grupo denominado Avanzada Nacional ${ }^{115}$ (que existió hasta 1990) y un nuevo partido político, nacido del gremialismo universitario, la Unión Demócrata Independiente (UDI) liderada por Jaime Guzmán y Sergio Fernández. ${ }^{116}$

La "otra derecha" más democrática también conformó un nuevo movimiento denominado Unión Nacional liderado por Andrés Allamand; su ideario se sustentaba en el apoyo y adhesión al programa de Transición propuesto por Onofre Jarpa.

Tras la tercera reunión entre la oposición y el Ministro del Interior en la que no se logró avanzar mucho más, la situación se tensionó nuevamente, ya que el Régimen no quería fijar los plazos para establecer la salida de los militares del poder. Hubo intentos de la Conferencia episcopal del acercar a las partes pero fue infructuoso.

Finalmente el Régimen vuelve a su habitual represión en contra de las fuerzas de la oposición, con lo que se cierra el ciclo de apertura del Ministro Onofre Jarpa, quién terminó por renunciar en febrero de $1985^{117}$. Con ello se abrió un nuevo período de incertidumbre política y de distanciamiento entre el Régimen y la oposición. Sin embargo, desde aquí en adelante se generó una pérdida de la unidad política gobiernista a la par que la oposición y el movimiento social recuperaba su organicidad.

\footnotetext{
${ }^{115}$ FRIEDMANN, Reinhard. La Política Chilena de la A a la Z. Santiago de Chile: Melquíades Servicio Editorial, 1988.

${ }^{116}$ VALDIVIA, Verónica. Nacionales y gremialistas: el "parto" de la nueva derecha política chilena 1964-1973. LOM. Santiago de Chile. 2008; VALDIVIA, Verónica (et. al). Su revolución contra nuestra revolución: La pugna marxistagremalista en los ochenta. Vol II. LOM. Chile. 2008

${ }^{117}$ CAÑAS KIRBY, Enrique. Proceso politico en Chile: 1973-1990.. Editorial Andrés Bello. Santiago de Chile. 1997. pp. 175185.
} 


\subsection{2.-Del seminario del Hotel Tupahue a los primeros Gobiernos de la Democracia.}

\subsubsection{1.-El Seminario del Hotel Tupahue.}

Durante 1984, la oposición intentó la estrategia de crear "Cabildos Abiertos" para presionar a la dictadura, pero fracasarían por no tener continuidad en el tiempo. Sin embargo, una instancia muy relevante se dará ese mismo año que, según la tesis de Rafael Otano ${ }^{118}$, podría ser el origen del proceso de transición a la democracia: el seminario del Hotel Tupahue en Santiago los días 27 y 28 de Julio de 1984, que se tituló “Un Sistema Jurídico -Político Constitucional para Chile".

Los principales líderes de la oposición asistieron al encuentro, incluidos dos ex ministros de Allende, un Contralor General de la República y gente cercana al Régimen. Las mesas conformadas eran muy pluralistas y fueron convocadas por el Instituto Chileno de Estudios Humanísticos (ICHEH). Entre los temas a tratar figuraban: "Las bases fundamentales de un Régimen jurídico-político Constitucional en Chile adecuado a la realidad de la Próxima Década”, “Análisis crítico de las constituciones de 1925 y 1980” y “Una salida jurídico-política para Chile".

Este último tema fue expuesto por Francisco Bulnes -cercano al Régimen- y dos representantes de la oposición como Patricio Aylwin y Enrique Silva, y fue muy relevante para la estrategia que se siguió en los años siguientes: soslayar el cuestionamiento a la legitimidad de la Constitución de 1980, lo cual generó más de una crítica. Sin embargo, esta opción era la única posible según Aylwin, porque "vamos camino -decía - de convertirnos en una Torre de Babel, en la que cada cual habla su lenguaje, sin importarle ni entender lo que otros dicen"119. Por

\footnotetext{
118 OTANO, Rafael. Nueva crónica de la Transición. LOM. Chile. 2006.

${ }^{119}$ OTANO, Rafael. Op. Cit. 2006. p. 20.
} 
tanto, sólo había dos salidas de acuerdo al líder de la democracia Cristiana: o la guerra civil o la solución pacífica por la vía jurídico -política.

Finalmente, tres acontecimientos marcarán esta última etapa del proceso de transición a mediados de los 80: la "Asamblea de la civilidad", el atentado contra Pinochet y la visita del Papa Juan Pablo II a Chile.

La Asamblea de la Civilidad se conformó en 1986 a partir de la reunión realizada en el Teatro Cariola en Santiago, donde participaban varios dirigentes y políticos. Durante el desarrollo de este acto se convocó a constituir una "Asamblea Nacional de la Civilidad, que reuniera a todas las organizaciones representativas de las distintas actividades y sectores de la comunidad nacional, con el fin de presentar al gobierno sus necesidades y aspiraciones sectoriales y globales, formalizadas en lo que se llamaría "La demanda de Chile", para cuya satisfacción lucharían por medios pacíficos". ${ }^{120}$

Lo más destacado de este llamado -además del amplio espectro de grupos adherentes (Consejo de Federaciones de estudiantes de Chile (CONFECH), el Partido Demócrata Cristiano, Alianza Democrática, Confederación Nacional de Trabajadores, etc.)- fue que se logrará incorporar al Partido Comunista, excluido de todos los acuerdos políticos, debido a que se daba por sentado que los comunistas no aceptaban acuerdos por la vía del consenso para derrotar al Régimen Militar, sino que planteaban la lucha armada. Por tanto, la Asamblea de la Civilidad sirvió de "vehículo de incorporación del Partido Comunista a la lucha social sin mediar compromiso político y en un plano de acción no violenta."121

Cerca de 400 organizaciones suscribieron un documento denominado la "Demanda de Chile". Dicho escrito presentaba una serie de peticiones acerca de diversos ítems, que iban desde

\footnotetext{
${ }^{120}$ AYLWIN, Patricio. Op. Cit. p. 307.

${ }^{121}$ BOENINGER, Edgardo Op. Cit. p. 313.
} 
cuestiones relacionadas con la política hasta aspectos relacionados con el ámbito social y educativo (asignación familiar, deudores hipotecarios, fin de la privatización, municipalización, autonomía universitaria, etc.).

El petitorio no fue considerado por la dictadura, como era de esperarse, como consecuencia de los cual se hizo un llamado a una serie de protestas en el marco de una "desobediencia civil" para los días 2 y 3 de julio de 1986. La represión fue durísima, apresando a los principales dirigentes y descabezando el movimiento. En este contexto se dio uno de los casos más emblemáticos de violación de los Derechos Humanos conocido como el de los “jóvenes quemados” (el joven Rodrigo Rojas, resultó muerto y Carmen Gloria Quintana, sobrevivió pero con terribles quemaduras). Esto llevó a que la Asamblea terminara poniendo sus esfuerzos en el reclamo de justicia ante los Tribunales. Se intentaría reunir una vez más a las diversas organizaciones de oposición, pero un atentado contra el general Pinochet provocaría un nuevo giro de los acontecimientos.

En paralelo a lo desarrollado por la Asamblea, los grupos más extremos -como el denominado Frente Patriótico Manuel Rodríguez (FPMR) ${ }^{122}$ - señalaban 1986 como el “año decisivo", cuestión que era reforzada por declaraciones del propio Pinochet, quien amenazaba con “quedarse con la banda presidencial hasta el 98". ${ }^{123}$ El aumento de la violencia desatada por la dictadura en contra de la ciudadanía llevó a que estos grupos violentos comenzaran a concretar aún más la idea de atentar físicamente contra el dictador (en la práctica, se empezó a acopiar armamento, como lo prueba el arsenal interceptado en Carrizal Bajo en 1986).

\footnotetext{
122 ÁlVAREZ VALLEJOS, Rolando "Los "hermanos Rodriguistas”. La división del Frente Patriótico Manuel Rodríguez y el nacimiento de una nueva cultura política en la izquierda chilena. 1975-1987” Revista IZQUIERDAS Año 2, № 3, 2009.

${ }^{123}$ OTANO, Rafael. Op. Cit. p. 29
} 
Resultado de este clima "enrarecido", el día domingo 7 de septiembre Augusto Pinochet sufre un atentado terrorista en el sector de Achupallas, ubicado en Cajón del Maipo. El dictador sale con vida pero fallecen cinco de sus escoltas de seguridad. El atentado fue realizado por un comando del Frente Patriótico Manuel Rodríguez, grupo que se consideraba el brazo armado del Partido Comunista, en el contexto de la denominada "Operación Siglo XXI".

Como resultado del atentado la represión se agudizó de manera notable, incluso ese mismo día se declaró el Estado de sitio y se realizó una operación de venganza que culminó con la muerte de tres opositores de la dictadura. A su vez, toda tentativa de diálogo fue abortada inmediatamente. La única posibilidad de avanzar hacia la democracia estaría puesta en la intermediación del Papa, quien visitaría el país justo al año siguiente.

El Papa Juan Pablo II viajó a Chile en 1987 y recorrió el país de norte a sur, reuniéndose con la oposición al Régimen militar, los mapuches, los trabajadores, los presidiarios y los miembros de la Junta Militar de Gobierno, teniendo incluso una reunión privada con Augusto Pinochet.

De esta manera la visita del Papa "logró por medio de milimétricos equilibrios y reequilibrios dejar aceptablemente contentos a los distintos grupos: a conservadores y progresistas dentro de la Iglesia Católica, a amigos y enemigos de Pinochet, dentro del cuadro político general; a duros y blandos, dentro de las filas mismas del Régimen. Fue un ejercicio celestial de álgebra vaticana. Prácticamente todos creyeron que habían sacado una tajada un poco más grande de la prevista, de las palabras, gestos, saludos y silencios pontificios" ${ }^{\prime 24}$. Sin embargo, en la práctica la situación no cambió en nada el cronograma trazado por Pinochet en la Constitución de 1980, por lo que la oposición al Régimen debió comenzar a prepararse para afrontar el plebiscito de 1988.

\footnotetext{
${ }^{124}$ OTANO, Rafael. Op. Cit. p. 41.
} 


\subsubsection{2.-El Plebiscito de 1988.}

Pese a que la oposición quería terminar con la dictadura, dudaba de la efectividad del Plebiscito porque pensaba que no tendría ninguna garantía sobre su legalidad, tal como había sucedido antes con la Constitución de 1980. Por lo tanto, se elaboraron estrategias para afrontar la consulta popular. Como señala Godoy: “el proceso político central y global chileno a partir del plebiscito de octubre de 1988, como señalé oportunamente en el CEP, es el retorno a la Democracia. Esa es la característica principal de ese proceso. Y su correlato: la extinción del Régimen autoritario. Y lo digo en presente porque esa dirección está y estará vigente por un largo período, mientras dure la consolidación del sistema político, que aún deberá pasar por muchas correcciones". ${ }^{125}$ A partir del plebiscito de 1988, por tanto, se inauguraría un periodo de redemocratización en Chile.

De esta manera y siguiendo el itinerario constitucional de la dictadura, se realizaron los preparativos para el plebiscito por parte del gobierno. En octubre de 1986 se publicó en el Diario oficial la Ley Orgánica Constitucional sobre inscripciones electorales y servicio electoral, y también la ley de partidos políticos. ${ }^{126}$ Para asegurar que el proceso fuese lo más transparente posible, la oposición creó un Comité de Elecciones Libres (CEL).

Por su parte Alianza Democrática, junto a miembros del partido Socialista y algunos exiliados retornados, se pusieron a la tarea de realizar una enérgica campaña por la inscripción masiva de ciudadanos en los registros electorales. El año 1987 la izquierda se unió al trabajo por el plebiscito creando "Izquierda Unida". Un hito muy relevante fue la decisión autónoma del

\footnotetext{
${ }^{125}$ GODOY, Oscar. "Algunas Claves de la Transición Política en Chile”. Estudios Públicos. No 38, 1990. p. 143.

${ }^{126}$ FARIÑA, Carmen. "Génesis y Significación de las Ley de Partidos Políticos”. Estudios Públicos. N ${ }^{\circ} 27.1987$.
} 
Tribunal Constitucional que determinó que el plebiscito presidencial de 1988 debería someterse a la ley general de elecciones.

En 1988, en un acto en el hotel Tupahue de Santiago, cristalizó la constitución de la “Concertación de Partidos por el NO"127 (que cubrían un amplio espectro de partidos de centro izquierda). De esta manera se formalizaba la concertación opositora más amplia contra el Régimen del General Augusto Pinochet. Por otra parte, un grupo de Socialistas, Radicales y Demócrata Cristianos plantean la propuesta de constituir un partido único de oposición denominado "Partido por la Democracia" (PPD), que se concreta finalmente en $1987 .{ }^{128}$ En este contexto todos los partidos estaban llamando a inscribirse y a votar NO.

Por su pare el Régimen, con el pleno apoyo del gremialismo y de los sectores nacionalistas (agrupados desde 1984 en Avanzada Nacional), había explicitado su irrevocable decisión de que Pinochet sería el candidato del SI, hubo algunos obstáculos en el seno del oficialismo, pero que no llevaron a desechar esta idea. Se crea en 1987, con apoyo del empresariado, conjuntamente con un gran número de personas de tendencia ideológica de derecha, el partido de Renovación Nacional. Este grupo proponía la idea de un candidato civil, a diferencia de la Unión demócrata independiente (UDI) que apoyó férreamente a Pinochet.

El día 5 de octubre de 1988 se llevó a cabo el plebiscito, con la más alta inscripción de la historia electoral de Chile (90\%) y la más baja abstención (2,39\%). Los resultados del escrutinio fueron $54,7 \%$ por el NO y $43 \%$ por el SÍ. ${ }^{129}$ Pese a que en un principio se temió que el Régimen no reconociera el triunfo de la oposición, éste terminó por aceptarlo con total claridad. ${ }^{130}$

\footnotetext{
${ }^{127}$ QUIROGA, Yesko y ENSIGNI,Jaime (ed.) Chile en la Concertación (1990 - 2010): Una mirada critica, balance y perspectiva. Friedrich Ebert Stiftung, Santiago de Chile. 2010

${ }^{128}$ ARRIAGADA, Genaro. ¿Hacia un "big bang" del sistema de partidos? Editorial Los Andes, Santiago de Chile. 1997

${ }^{129}$ CAVAllo, Ascanio (et. al). Op. Cit. p. 484.

${ }^{130}$ GARRETÓN, Manuel. El plebiscito de 1988 y la Transición a la Democracia. Editorial FLACSO. Santiago de Chile. 1988.
} 


\subsubsection{3.-La elección presidencial. El triunfo de la Concertación.}

Tras el plebiscito, como señala Escalona, “el Régimen no tenía otro proyecto o alternativa estratégica que no fuera aceptar, por duro que fuera para sí mismo, la entrega del liderazgo del país a la Concertación; ni nacional ni internacionalmente era posible otra cosa." ${ }^{, 131}$ Sin embargo, la oposición debía sortear aún otra prueba, ganar las primeras elecciones del retorno a la Democracia en 1989.

Pese a que no existía un consenso en la oposición para designar a un candidato único, el triunfo reciente en las urnas ayudó aunar los ánimos. La Democracia Cristiana decía estar en mejores condiciones para que el candidato a presidente fuese de sus filas. Los posibles candidatos eran Patricio Aylwin o Gabriel Valdés, líderes de la etapa de la movilización social, Andrés Zaldívar, el héroe de la resistencia y el exilio y Eduardo Frei Ruiz-Tagle, quien poseía un capital político con muchas proyecciones. Tras algunas disputas internas, finalmente fue elegido Patricio Aylwin.

A pesar de los distintos problemas para elegir a candidatos a la presidencia y el Congreso, se siguió con el itinerario trazado por la Dictadura, en Diciembre de 1989 se enfrentaron en las primeras elecciones democráticas después de 17 años: Patricio Aylwin candidato de la Concertación; Hernán Büchi (ex - Ministro de Pinochet) representando a la derecha y continuador del Régimen Militar y Francisco Javier Errázuriz vinculado a la elite tradicional de Chile quien abrió una opción de centro -centro, pero que no tenía mayor relevancia en la política nacional.

\footnotetext{
${ }^{131}$ ESCALONA, Camilo. Op. Cit. p. 30.
} 
Se impuso el candidato de la Concertación, obteniendo un 55,2\% de los votos contra un 29,4\% de Hernán Büchi y un 15,4\% de Francisco Javier Errázuriz. A su vez, se realizaron elecciones simultáneas para Diputados y Senadores. La Concertación gano la mayoría absoluta en la Cámara de Diputados, pero no en la de Senadores, debido al sistema binominal ${ }^{132}$ y a la presencia de Senadores Designados (9 en total que eran elegidos por el Presidente de la República, el Consejo de Seguridad Nacional y la Corte Suprema de Justicia, y que el Régimen Militar dejó designados antes de su entrega del poder). De esta manera la Concertación obtuvo el $56 \%$ de las preferencias eligiendo a 72 diputados y 22 senadores y la alianza de derecha, denominada Democracia y Progreso eligió a 48 diputados y 16 senadores con tan sólo el 33\% de las preferencias electorales.

Con este gran apoyo ciudadano en las urnas, como señala Paul Drake e Iván Jaksic, “los líderes de la coalición prometieron reinstalar una Democracia plena dentro de las reglas del orden constitucional impuesto por Pinochet; prometieron mantener el modelo económico liberal con un énfasis mayor en la justicia social, y, además enfrentar el quemante tema de los Derechos Humanos sin revivir las luchas del pasado. Todas estas promesas contenían los gérmenes de sus propias contradicciones y limitaciones". ${ }^{133}$

\footnotetext{
${ }^{132}$ VON BAER, Ena. 2009. “Sistema Binominal. consensos y disensos”. En FONTAINE, Arturo (et al.). Reforma al Sistema Electoral Chileno. Cep-Cieplan-Pnud-Lyd-Proyectamérica, Santiago de Chile. 2009. pp. 177-206.

${ }^{133}$ DRAKE, Paul y JAKSIC, Ivan (comp.) El Modelo Chileno. Democracia y Desarrollo en los Noventa”, LOM, Santiago de Chile. 1999. p. 16.
} 


\section{2.-VISIONES HISTORIOGRÁFICAS ACERCA DE LA TRANSICIÓN.}

La historiografía acerca del proceso de transición de la dictadura a la democracia en Chile es abundante y diversa. La clasificación más general, como veremos, está desarrollada a partir de la posición ideológica a la que cada corriente adhiere. Por ejemplo, encontramos visiones de la transición que, siendo pro-Régimen militar, valoran determinados acontecimientos por sobre otros para explicar la transición (y los periodos anteriores como el Golpe de Estado ${ }^{134}$ ). También existe una bibliografía cercana a la oposición y otra, mucho más crítica, que puede calificarse de izquierda. Esto sucede particularmente en la historiografía del siglo XX, donde los historiadores fueron poco a poco identificándose con determinadas posiciones ideológicas o doctrinarias (en especial en el periodo que va desde el año 1960 a la transición, donde el país vivió una clara división al nivel ideológico).

También existen análisis del periodo que se pueden identificar con otras Ciencias Sociales como la Sociología y las Politología. A continuación damos un panorama general sobre cada una de ellas.

\subsubsection{Visiones y cronologías de la Transición chilena.}

Las diversas interpretaciones acerca de la transición contienen además de su propia versión del proceso una cronología particular, debido a que ponen un énfasis particular en uno u otro acontecimiento, dependiendo de la visión que se tiene del proceso.

\footnotetext{
${ }^{134}$ GAZMURI, Cristián. La Historiografia Chilena 1842.-1970. Tomo 2. Editorial Aguilar. Santiago de Chile. 2009.
} 


\subsubsection{1.- La historiografía de derecha o pro-Régimen.}

Este grupo de historiadores consideran que el Golpe de Estado o "Pronunciamiento militar" como le han denominado, fue la reacción lógica de las Fuerzas Armas y Carabineros ante el descalabro social, político y económico que vivía el país durante el Gobierno de Salvador Allende, responsabilizado por la decadencia de la vida nacional. De esta manera, el golpe militar venía a poner orden ante el caos que se vivía en el país en todo orden de cosas.

En esta interpretación el Régimen Militar había sido un proceso de 17 años que llevó a la restauración democrática ${ }^{135}$ y que habría evitado la instalación de un régimen totalitario marxista en Chile. Asimismo considera que la intervención militar recuperó la institucionalidad en el país, democratizándolo y modernizándolo hasta finalmente entregar el poder por decisión popular, momento en el cual la transición chilena a la democracia habría culminado. ${ }^{136}$

Este proceso comenzaría con la promulgación de la Constitución de 1980 y su término, con el Plebiscito de 1988, señalado, claro está por la misma Constitución (se dan algunos matices en su desarrollo pero el itinerario sería éste). ${ }^{137}$

Uno de los historiadores de derecha más importantes de Chile como es Gonzalo Vial, propone esta tesis en sus escritos. ${ }^{138}$ Según él, los últimos cuarenta años de la historia del país se pueden dividir en dos períodos: el primero entre 1964 y 1973 -cuando la violencia pone al país al borde de una guerra civil- y el segundo -que iría desde el Golpe de Estado en 1973 hasta el plebiscito de 1988-, cuando el país adquiere nuevas orientaciones en varios ámbitos como el económico (implantación del sistema neoliberal), social y político. Esta última idea también es reafirmada

\footnotetext{
${ }^{135}$ FERNÁNDEZ, Sergio. Mi lucha por la Democracia. $2^{\mathrm{a}}$ ed., Los Andes, Santiago de Chile. 1997.

${ }^{136}$ GUZMÁN, Jaime. "El sentido de la Transición”. Revista Realidad, № 38, julio de 1982.

${ }^{137}$ VELÁSQUEZ, Edgar de Jesús. "La Transición a la Democracia en Chile según la derecha” Estudios Políticos Nº 29, juliodiciembre 2006. pp.189-215.

${ }^{138}$ VIAL CORREA, Gonzalo. “Historia de Chile en el Siglo XX”,. Editorial Santiago, Santiago de Chile. 2003.
} 
por otro de los historiadores más importantes identificado con la derecha chilena, Ricardo Krebs $^{139}$ (galardonado con el Premio Nacional de Historia). El hito más importante sería, para estos autores, la Constitución de 1980

En los últimos años han ido apareciendo algunas miradas de derecha más moderada o liberal que desarrollan una visión más crítica del actuar de la derecha antes y durante el Régimen Militar. ${ }^{140}$

\subsubsection{2.- La historiografia de centro.}

Los historiadores que siguen esta línea de investigación son muy heterogéneos. Van desde aquellos que están relacionados con la Democracia Cristiana (que es parte del centro político) y, por tanto, serían parte del discurso "oficial” de la transición, hasta aquellos que realizan miradas de la historia considerando el papel de las clases medias (unos más conservadores y otros más liberales).

Entre estos historiadores destacan Sergio Villalobos ${ }^{141}$, Cristián Gazmuri ${ }^{142}$, Carlos Bascuñan y Sol Serrano. ${ }^{143}$ Estos autores comienzan su análisis con el Golpe de Estado. Según ellos, Allende se vio sobrepasado por los grupos extremistas de izquierda y por su propio partido. Se produce así una situación caótica, mientras que la movilización social se tornaba cada día más

\footnotetext{
${ }^{139}$ KREBS, RICARDO. (et. al.) Nueva Historia de Chile: Desde los Origenes Hasta Nuestros Días, Editorial Zig-Zag, Instituto de Historia de la Pontificia Universidad Católica de Chile, Santiago de Chile. 1996. pp. 510-535

${ }^{140}$ JOCELYN - HOLT LETELIER, Alfredo. El Chile Perplejo. Del Avanzar Sin Transar al Transar Sin Parar. Santiago de Chile: Editorial Planeta / Ariel, 1998.

${ }^{141}$ VILLALOBOS, Sergio. Chile y Su Historia. Editorial Universitaria, Chile. 1992.

${ }^{142}$ GAZMURI, Cristián. “Nueva Historia de Chile: Desde los Orígenes Hasta Nuestros Días”, Editorial Zig-Zag, Chile. 1996; GAZMURI, Cristián. La Persistencia de la Memoria. Reflexiones de un civil sobre la Dictadura. Ril Editores, Santiago de Chile. 2000.

${ }^{143}$ AYLWIN, Mariana; BASCUÑÁN, Carlos; SERRANO, Sol (et. al). Chile en el siglo XX. Planeta. Santiago de Chile. 1990.
} 
amenazante y decidida. Según estos autores, en especial Gazmuri, la democracia heredada de la dictadura sería fundamentalmente protegida. $^{144}$ Además, se reconoce y valora la implementación de un sistema neoliberal que habría favorecido el desarrollo económico.

La duración de la transición para estos autores se iniciaría en 1990 con el primer Gobierno democrático y terminaría con el fin del Gobierno de Aylwin en 1994. Esta versión coincide con el cierre "oficial" dado por el propio Aylwin.

\subsubsection{3.- La historiografia de izquierda.}

La historiografía de izquierda que estudia este periodo es también muy diversa. Existen miradas desde el marxismo, que podríamos denominar clásico, representado en los trabajos de Luis Vitale. ${ }^{145}$ También encontramos estudios que se pueden considerar de "sensibilidad" marxista como son las investigaciones de Gabriel Salazar ${ }^{146}$ y Tomás Moulián ${ }^{147}$, y otros relacionados con el socialismo como los de Luis Maira ${ }^{148}$ o Camilo Escalona. ${ }^{149}$

En términos generales, estos autores condenan la dictadura, poniendo especial énfasis en el tema de los Derechos Humanos, donde critican los limitados avances de la justicia. También, en algunos escritos posteriores se puede encontrar evaluaciones críticas de los gobiernos de la Concertación, en especial acerca de sus políticas sociales y económicas, que serían la continuación de las políticas implantadas por el Régimen.

\footnotetext{
${ }^{144}$ GAZMURI, Cristian. Op. Cit. 1996.

${ }^{145}$ VITALE, Luis. Interpretación marxista de la Historia de Chile, Tomo I, $7^{\mathrm{a}}$ edición. CELA-LOM, Santiago de Chile. 1991. ${ }^{146}$ SALAZAR, Gabriel y PINTO, Julio. Historia Contemporánea de Chile, Volúmenes I al V, Editorial LOM. Santiago de Chile. 1999-2002.

${ }^{147}$ MOULIAN, Tomás. Chile actual anatomía de un mito. Santiago: LOM.2002; MOULIÁN, Tomás. Conversación Interrumpida con Allende. Editorial LOM, Santiago de Chile.1998.

${ }^{148}$ MAIRA, Luis. Los tres Chile de la Segunda Mitad del Siglo XX. Editorial LOM, Santiago de Chile. 1998.

${ }^{149}$ ESCALONA, Camilo. Una Transición de dos caras. Crónica crítica y autocrítica, Editorial LOM, Santiago de Chile. 1999
} 
Para estos historiadores, sociólogos y politólogos, la transición es un proceso inconcluso. Las deudas pendientes están relacionadas principalmente con las reformas constitucionales o, definitivamente, con un cambio total de la Constitución de 1980 que se considera uno de los principales "enclaves" de la transición.

La bibliografía marxista considera que la transición estuvo sometida por los "amarres constitucionales" dejados por Pinochet y que la Concertación (el grupo gobernante durante los 20 primeros años de la democracia) no habría sido capaz de generar cambios en el modelo. En el caso de las investigaciones con "sensibilidad marxista", se repiten las críticas a la Concertación, quienes habrían gobernado bajo un conformismo político y una complacencia intelectual. $^{150}$

Existe también entre algunos escritores socialistas una visión autocrítica de la transición, muy bien resumida por Camilo Escalona, quien señala que desde el inicio del proceso, que sitúa desde el cambio de mando el 11 de Marzo de 1990, “comenzaba a instalarse el pernicioso hábito del doble discurso, de una escéptica ambigüedad, de un falso pudor ante las limitaciones del proceso, ocultando o intentando ocultar el sol con un dedo, desconociendo una porfiada realidad cuyas debilidades eran tan evidentes que ignorarlas vendría a ser lo peor. Se dibujó desde entonces una Transición de dos caras." ${ }^{151}$ Estos escritos, algunos más y otros menos, no se pueden calificar como una historiografía totalmente crítica del proceso, aunque sí de algunos de los aspectos de ella. Sin embargo, varios de ellos -en especial los que se publicaron desde mediados de los años 90-, enlazan con los estudios que hacen una crítica estructural del proceso de transición, mucho de los cuales recogen algunos de sus postulados, como veremos más adelante.

\footnotetext{
${ }^{150}$ MOULIÁN, Tomás. El consumo me consume. Santiago de Chile: LOM Ediciones. 1998.

${ }^{151}$ ESCALONA, Camilo. Op. Cit. p.15.
} 


\subsubsection{4.- La visión de la Ciencia Política.}

Mucho más que los análisis históricos (que apenas si están despuntando en los últimos años) ocupan un lugar estelar en este balance bibliográfico los autores que han echado luz sobre el proceso de transición ${ }^{152}$ desde la Ciencia Política. Repasamos sus visiones porque ellos, en general, han sido responsables de construir un relato fundante que ha sido asumido como explicación de un cambio político tan complejo como decisivo para el Chile contemporáneo. ${ }^{153}$

Los estudios encuadrados en la perspectiva politológica han dejado una herencia muy prolífica, abordando temas como la ruptura de las instituciones democráticas en 1973, el rol de los partidos, los factores institucionales, los actores sociales partícipes en el proceso, la resistencia al Régimen, etc. De la misma manera y en base a los modelos teóricos propuestos por la Ciencia Política para entender los procesos de transición, analizan y explican de forma detallada la política de la negociación. Para realizar esto hacen estudios en perspectivas comparadas -por ejemplo teniendo en consideración el "modelo español”-, analizan los elementos y factores que facilitaron el inicio del proceso de transición en Chile, las características de los actores involucrados, etc.

\footnotetext{
${ }^{152}$ Para conocer los procesos históricos de otras transiciones se puede ver: PEREZ SANCHEZ Guillermo. "Crisis, Revolución y Transición en la Europa del Este.” Madrid: Editorial ARIEL, 1999; TAIBO, Carlos. Las transiciones en la Europa central y oriental: ¿copias de papel carbón? Madrid: Los libros de cataratas. 1998.

${ }^{153}$ CAÑAS KIRBY, Enrique. Proceso Político en Chile: 1973 -1990. Editorial Andrés Bello, Santiago de Chile. 1997; BOENINGER, Edgardo. Democracia en Chile. Lecciones Para la Gobernabilidad. Editorial Andrés Bello, Santiago de Chile. 1998; ARRIAGADA, Genaro. Por la Razón o la Fuerza. Chile Bajo Pinochet. Editorial Sudamericana, Santiago de Chile. 1998; HUNEEUS, Carlos. El régimen de Pinochet. Editorial Sudamericana, Santiago de Chile. 2000 HUNEEUS, Carlos Los chilenos y la política. Cambio y continuidad en el Autoritarismo, Editorial Fundación Konrad, Adenauer RFA, Santiago de Chile. 1987; HUNEEUS, Carlos; GODOY, Oscar; GARRETÓN, Manuel A. “¿Terminó ya el proceso de Transición?” Revista de Ciencia Política. No. 1-2, 1994. pp. 9-40.
} 
En este sentido, estos autores consideran que el caso chileno puede encuadrarse bajo el modelo de la vía de la transacción, donde tanto el Régimen Militar como las fuerzas de la oposición llegaron a una serie de pactos y acuerdos, ${ }^{154}$ por lo menos en sus primeros años, para así alcanzar la Democracia. ${ }^{155}$

Alguna de estas perspectivas sostienen que la transición habría comenzado en 1980 y se habría desarrollado por medio de una serie de pactos y negociaciones. Finalizaría, por tanto, con el primer Gobierno de la Concertación, aunque naturalmente consideran que la democracia debe continuar avanzando hacia un proceso de consolidación.

\subsection{2.- Visiones críticas del "Modelo de Transición chileno".}

Durante los primeros años de la transición se llegó a ver a Chile como un verdadero modelo de democracia, alcanzada mediante una transición pactada, grandes consensos entre gobierno y oposición, con un "partido transversal” al frente de la nueva etapa y un enfoque de "democracia de los acuerdos”. En este sentido, las investigaciones replicaron esta visión realizando análisis bastante positivos respecto del proceso de la transición. ${ }^{156}$

\footnotetext{
${ }^{154}$ GODOY, Oscar. "La Transición chilena a la Democracia: Pactada”. Estudios Públicos, N No 74, otoño 1999; GODOY, Oscar. “Algunas claves de la Transición Política en Chile”. Estudios Públicos, No 38, Chile. 1990.

${ }^{155}$ Un análisis muy completo acerca de la visión de la politología, sus conceptos y los problemas acerca de la Transición, fue realizado por Eduardo Araya. Véase: ARAYA LEÜPIN, Eduardo "Transición y transiciones a la Democracia". Iber: Didáctica de las Ciencias sociales, Geografia e Historia, № 67, 2011, pp. 10-24; ARAYA LEÜPIN, Eduardo. "Las transiciones chilenas: Una retrospectiva sobre el estado del arte y construcciones discursivas. Comunicación presentada en el XII Seminario didáctica de la Historia, "La enseñanza de las transiciones de la Dictadura a la Democracia en el mundo escolar " P. Universidad Católica de Valparaíso. 1 y 2 de diciembre del 2010. También se pueden ver los libros clásicos acerca de las Transición. LINZ, Juan. Transiciones a la Democracia. REIS. № 51. 1990; LINZ, Juan. "Del autoritarismo a la democracia" Estudios Públicos, Chile. $\mathrm{N}^{\mathrm{o}} 23.1986$.

${ }^{156}$ TOLOZA, Cristián y LAHERA, Eugenio (comp.) Chile en los noventa. Santiago de Chile: Dolmen, 1998; BOENINGER, Edgardo. Democracia en Chile: lecciones para la gobernabilidad. Andrés Bello, Santiago de Chile. 1998; FOXLEY, Alejandro. La economía política de la Transición. Dolmen, Santiago de Chile. 1993.
} 
Sin embargo, esta especie de exitismo presente en los escritos de la primera mitad de la década de los 90, que se sustentaba en el desarrollo económico, comienza a diluirse a la par que se dan acontecimientos muy relevantes para el país. Aparece una especie de "segunda "oleada" de investigadores coincidiendo con un episodio clave para el futuro de la política chilena: la detención de Pinochet en Londres y la llegada de la "crisis asiática" que llevaría a la caída del PIB por primera vez en 17 años, a un 1,1\% en 1999. A su vez, se registran al interior de la Concertación los primeros "roces" entre los miembros de la coalición de partidos. Por otra parte, la sociedad comienza a dar los primeros atisbos de malestar hacia el modelo. En este marco es que las críticas a la transición y sus líderes comienzan a surgir con más fuerza.

Álvaro Briones, en su libro La pata coja y la Transición infinita ${ }^{157}$ hace un crudo análisis de Chile, tanto del modelo económico (añora un capitalismo más amable) como de la dirigencia política de la Concertación. Por primera vez se comienza a hablar del "desencanto" y del surgimiento de una marcada desigualdad. Por su parte, el sociólogo Felipe Portales en su libro Chile: Una Democracia tutelada ${ }^{158}$ centra su crítica en lo que él denomina las políticas concesivas de la Concertación las cuales, señala, serían culpables de la imposibilidad de avanzar. Según el autor, habría sido la propia Concertación la que se puso voluntariamente una enorme camisa de fuerza. Por lo tanto, descubrimos que en una parte importante de la dirigencia concertacionista no había voluntad por cambiar el modelo de desarrollo generado bajo la dictadura. Para justificar su tesis, el autor menciona (con mucho detalle y rigurosidad) las concesiones hechas por la Concertación en el Congreso o como cedió a las presiones de las Fuerzas Armadas cada vez que se quería avanzar en el esclarecimiento de las violaciones contra los Derechos Humanos.

\footnotetext{
${ }^{157}$ BRIONES, Álvaro. La pata coja y la Transición infinita. Ediciones B, Santiago de Chile. 1999

${ }^{158}$ PORTALES, Felipe. Chile: Una Democracia tutelada. Editorial Sudamericana Chilena, Santiago de Chile. 1999.
} 
En esta misma línea los politólogos Amparo Menéndez- Carrión y Alfredo Joignant se suman a las críticas: subrayan el carácter todavía abierto del caso chileno y la necesidad de perfeccionamiento de la democracia realmente existente. En su trabajo La caja de Pandora: el retorno de la Transición chilena ${ }^{159}$ reúnen a importantes investigadores internacionales como son Laurence Whitehead y Norbert Lechner quienes introducen miradas mucho más matizadas respecto al tan idealizado proceso de transición.

Por su parte, Paul Drake e Iván Jaksic, con sus libros El difícil camino hacia la Democracia en Chile y El modelo chileno: Democracia y desarrollo en los noventa, ${ }^{160}$ reúnen a destacados investigadores de las Ciencias Sociales chilenos y norteamericanos como Patricio Meller, Dagmar Raczynski y Brian Loveman; y ofrecen interesantes balances de los logros y fracasos de lo que se considera como la peculiar combinación de liberalismo económico y “democracia restringida" propia del Chile de los noventa. A su vez, se analizan temas emergentes de la política chilena de los noventa, como son la cuestión indígena, el feminismo y el medio ambiente.

\footnotetext{
${ }^{159}$ MENÉNDEZ-CARRIÓN, Amparo; JOIGNANT, Alfredo. (ed.) La caja de Pandora: el retorno de la Transición chilena, Editorial Planeta. Santiago de Chile. 1999.

${ }^{160}$ DRAKE, Paul y JAKSIC, Ivan (ed.). El dificil camino hacia la Democracia en Chile 1982-1990. FLACSO-Chile. Santiago de Chile. 1993; DRAKE, Paul y JAKSIC, Ivan (comp.) El Modelo Chileno. Democracia y Desarrollo en los Noventa”, Editorial LOM, Santiago de Chile. 1999
} 


\section{5.- LA TRANSICIÓN CHILENA Y LOS}

\section{MODELOS DE INTERPRETACIÓN}

Entender los procesos de cambio y permanencia en la Historia no es una tarea fácil, esto lo sabe muy bien el historiador que se enfrenta a la tarea compleja de comprender la sociedad en su dimensión histórica. Braudel en una de las obras más importante de la historiografía contemporánea como es El mediterráneo y el mundo mediterráneo en la época de Felipe II ${ }^{161}$ pone de manifiesto de manera magistral cómo es posible entender entornos y problemas humanos en diversas dimensiones y temporalidades y aún así no fue una obra final, a partir de ahí se ha seguido pensando y repensando el mediterráneo. ${ }^{162}$

La historia latinoamericana, como la de muchos espacios, aún sigue siendo una verdadera "caja negra”, pese a que los escritos acerca de ella, tanto desde miradas locales como extranjeras son abundantes, las incógnitas siguen en pie. Durante años se han aplicado consecutivamente modelos explicativos (la mayor parte traídos desde Estados Unidos o Europa) para entender nuestra realidad, lo que no termina de darnos explicaciones suficientemente satisfactorias.

El caso chileno contemporáneo es particularmente interesante al respecto. Muchas veces se buscan explicaciones excesivamente tributarias de modelos, categorías o circunstancias externas a nuestra región a falta de conceptualizaciones locales; así ,por ejemplo, se habla de la

\footnotetext{
${ }^{161}$ BRAUDEL, Fernand. El Mediterráneo y el mundo mediterráneo en la época de Felipe II. Fondo de Cultura Económica de España. España. 2001.

${ }^{162}$ BRAUDEL, Fernand y DUBY, Georges (comp.). El Mediterráneo. Los hombres y su herencia, FCE. Ciudad de México. 1990
} 
existencia de una burguesía a principios del siglo $\mathrm{XX}^{163}$ o de la Cuestión Social ${ }^{164}$ para referirse a grupos o episodios históricos de contornos singulares y específicos, como puede ser la instalación de empresas salitreras en el norte o el desarrollo de las ciudades, por mencionar algunos. Con la transición chilena ocurriría algo similar. En la imbricación "política/relato" el discurso acerca de la "transición modélica" "165 quedó instalado en el espacio público a través de la educación y los medios, refinándolo cada vez más con el fin de difuminar el rol preponderante del dictador Pinochet en la misma y exaltando la de los partidos y sus élites. ${ }^{166}$ A continuación haremos un recorrido por las diversas propuestas o modelos interpretativos existentes, destacando especialmente aquellos que han consolidado un discurso oficial del periodo, muchas veces distorsionando la complejidad del mismo proceso, o en su defecto reduciéndola para que "encaje" en las propuestas de la "transitología".

\section{1- “TRANSITOLOGÍA” Y CONCEPTUALIZACIÓN DE LA DEMOCRACIA.}

Una de las primeras definiciones que se deben hacer para entender cómo se consolidaron los modelos "transitológicos" para entender las nuevas democracias en Latinoamérica son las que guardan relación con la democracia. Efectivamente como señala Alan Knight, la democracia tal como la concibe Robert Dahl ${ }^{167}$ ha pasado a ser la norma en América Latina, pese a sus

\footnotetext{
${ }^{163}$ VILLALOBOS, Sergio. Origen y ascenso de la burguesía chilena, Editorial Universitaria, Santiago, 1987.

${ }^{164}$ MORRIS, James. Las elites, los intelectuales y el consenso: estudio de la cuestión social y del sistema de relaciones industriales de Chile. Ed. del Pacífico, Chile. 1967; GREZ, Sergio. La cuestión social en Chile: ideas y debates precursores : (1804-1902).DIBAM, Chile. 1997

${ }^{165}$ Esta idea y sus repercusiones la explicaremos unas páginas más adelante.

${ }^{166}$ En este intento, hace algunos años se buscaba quitar valor en el currículum oficial de Historia la palabra Dictadura por una más moderada como Régimen Militar, lo que generó un amplio debate nacional. véase por ejemplo: "Mineduc propondrá uso conjunto de términos “dictadura” y "régimen militar” en textos escolares” en Prensa on line Radio Bío-Bío. [fecha de consulta 15 de octubre del 2014] disponible en internet en http://radio.uchile.cl/2013/10/03/mineduc-propondra-uso-conjunto-determinos-dictadura-y-regimen-militar-en-textos-escolares

${ }^{167}$ DAHL, Robert. La poliarquía. Participación y oposición. Tecnos. Madrid, 1989.
} 
propias limitaciones históricas y la constante tensión con otras propuestas ${ }^{168}$, que de tanto en tanto se instalan en la palestra pública, como la posibilidad -real o no- de establecer democracias no burguesas, populares o similares. Estas dificultades en la democracia y sus limitaciones nacen de su propia característica, ya que al ser un concepto polisémico, por una parte un ideal de sistema político y, por otro, un conjunto de sistemas políticos reales, la tensión existente entre estos dos “ámbitos” es constante.

La búsqueda de Dahl fue, en definitiva, dar una explicación a estos dos ámbitos en una compleja y única teoría. Desde su punto de vista el fundir un ideal sirve, en primer lugar, para generar crítica proporcionando estándares de evaluación y juicio de las instituciones y prácticas democráticas y, en segundo lugar, tiene una función de índole empírica, ya que contribuye a la descripción de las características estructurales y el funcionamiento de un sistema democrático bajo un conjunto de condiciones ideales. ${ }^{169}$ Este intento globalizador va a ser uno de los puntos más criticados de su planteamiento. ${ }^{170}$

De manera sintética, la idea y práctica de la democracia propuesta por el autor, que como ya señalamos busca profundizar una teoría normativa, formula las exigencias de un ideal estableciendo principios y procesos- la democracia- y proponiendo una teoría de orientación empírica que se conocerá como "poliarquía”.

En este sentido, las premisas que justifican la democracia estarían unidas por el ideal de la igualdad, como son el principio de igualdad intrínseca, el principio de la consideración equitativa de los intereses, la presunción de la autonomía personal y el principio categórico de

\footnotetext{
${ }^{168}$ KNIGHT, Alan. Revolución Democracia y populismo en América Latina. Centro de estudios bicentenario. Chile. 2005. p. 107-110.

${ }^{169}$ DAHL, Robert. Democracy and its Critics Yale U. Press, New Haven. 1989.

${ }^{170}$ LEE, Donald. Poliarchy. The Political Theory of Robert Dahl. Gatland. New York, 1991.
} 
la igualdad. Por otra parte, Dahl sintetiza los criterios que debe necesariamente reunir todo proceso democrático, como son: 1. Participación efectiva; 2. Igualdad de los votos en la etapa decisoria; 3. Autonomía; 4. Control final de la Agenda; 5. Inclusión.

Por su parte, el autor define la "poliarquía" como un sistema político en el que las instituciones necesarias para el funcionamiento de un proceso democrático con los que cumplan ciertos requisitos, existen por encima de un umbral determinado. En otras palabras, las poliarquías constituyen actualizaciones del proceso democrático más o menos próximas al ideal $\mathrm{y}$, en cualquier caso, son su realización histórica más adecuada en el marco de la escala ampliada de los Estados.

Dichas características serían por tanto: 1. Derecho a voto; 2. Igualdad de voto; 3 . Subordinación de los funcionarios no elegidos a los elegidos; 4. Posibilidad de alternativa en el Gobierno; 5. Pluralidad de fuentes de información; 6. Oportunidad de políticas y candidatos alternativos.

De manera sintética y siguiendo a Knight, entre los cientístas políticos es común que se considere la democracia liberal representativa definida en los términos de Dahl como la norma, ya que esta definición abarcaría los dos principios de libre asociación y expresión (derechos cívicos) y participación electoral (derechos políticos). ${ }^{171}$

Este "encuadre” que elaboró Robert Dahl sirvió como marco conceptual para entender las democracias que comenzaban a emerger en Latinoamérica. No con pocas dificultades, ya que según esos modelos -basados principalmente en el desarrollo de la democracia liberal en Estados Unidos- no se podían cumplir muchas ni siquiera en el propio país que sirvió como ejemplo o modelo. De hecho las condiciones en que se debían fundamentar las poliarquías para mantener sus instituciones son bastante específicas:

\footnotetext{
${ }^{171}$ KNIGHT, Alan. Op. Cit. 2005. pp. 107-108
} 
a.- Los medios de coacción, especialmente las policías y los ejércitos no se utilizan para obtener el poder o mantenerse en él.

b.- Se trata de una sociedad moderna, dinámica y pluralista. La caracterización de pluralista indica la existencia de una gran variedad de grupos y de organizaciones relativamente autónomos en la esfera de la economía.

c.-La sociedad es culturalmente homogénea. En caso de sociedades heterogéneas se mantiene un nivel tolerable de conflicto.

d.-En la comunidad hay un consenso razonable en cuanto a las creencias y prácticas democráticas y, especialmente, entre los individuos dedicados a la política como activistas, militantes y dirigentes.

e.-No existe intervención, influencia o control de una potencia extranjera que sea hostil a la poliarquía.

En una rápida mirada a estas condiciones para mantener las instituciones en contextos democráticos, tal como lo plantea Dahl, en muchos casos latinoamericanos son bastante exiguas. Esto ha llevado a que los mismos cientistas políticos comiencen a buscar explicaciones o matices a al modelo, como señala Knight:

“De ahí se desprende que los estudiosos de la política latinoamericana hayan tenido que recurrir a sus propios calificativos académicos (la contrapartida a la democracia "de los trabajadores", "social" y "orgánica" en la jerga de los políticos): "regímenes 
híbridos", "democracia delegativa", "democracia de baja intensidad"; todos ellos términos que buscan transmitir el importante "déficit democrático" del que adolece América Latina"

En este contexto, la conceptualización de democracia más utilizada por los analistas de la transitología, no deja de ser deficiente para las explicaciones históricas. Es por esto que los incumplimientos de las promesas establecidas, como por ejemplo, que no se hayan logrado conquistar más que una parte muy reducida de la sociedad en su conjunto, como serían los de la sociedad civil aún en muchos caso gobernados de manera autocrática (escuelas, cárceles, etc. ${ }^{173}$ ha llevado a que actualmente se separen ámbitos o esferas para analizar la política: así aparece la "esfera política, la esfera pública y la esfera privada."

Para comprender mejor las implicaciones de las teorías acerca de la democracia y la democratización en Chile y Latinoamérica es necesario conocer los diversos enfoques con que han sido abordadas, como analizaremos a continuación.

\section{2.- TEORÍAS EXPLICATIVAS DE LA TRANSICIONES A LA DEMOCRACIA EN}

\section{LATINOAMÉRICA.}

Entendido que ya se plantea un desafío el comprender de qué se habla cuando se analiza la democracia desde el punto de vista de la transitología y las variaciones de su comprensión que

\footnotetext{
${ }^{172}$ KNIGHT, Alan. Op. Cit. 2005. pp. 111

${ }^{173}$ YTURBE, Corina. Pensar la democracia: Norberto Bobbio. UNAM. México. 2002. p. 93.
} 
esta misma disciplina ha tenido que agregar cuando el concepto no es apropiado, lo que ha sucedido de manera particular en el caso de Latinoamérica. En general esta dificultad surge de la, muchas veces, incomprensión de los fenómenos democráticos latinoamericanos, en especial cuando estos se intentaban comprender desde las teorías de la modernización que consistía en aplicaciones del marco estructural-funcional sin conocimiento previo de América Latina $^{174}$

Para comprender de mejor manera estas dificultades es necesario comprender las diversas teorías y métodos que han surgido para interpretar las transiciones latinoamericanas observando tanto sus orígenes como analizando las razones de su durabilidad, ${ }^{175}$ las cuales nos darán señales acerca de cómo se mirará la transición chilena desde estas perspectivas.

\subsection{1.- Teorías de la modernización económica.}

Como ya señalamos en unas líneas atrás uno de los primeros debates que se generó para comprender la democracia en América Latina está basada en el pensamiento de la escuela de la modernización, liderada por Seymor Martin Lipset y su tesis que planeta básicamente que el desarrollo económico - entendido como aumento del nivel de ingresos- aumentaba el nivel la

\footnotetext{
${ }^{174}$ ALMOND, Gabriel y COLEMAN James (eds.). The Politics of the Developing Areas. Princeton, N.J. Princeton University Press. 1960

${ }^{175}$ MUNCK, Gerardo (ed.), Regimes and Democracy in Latin America. Theories and Methods Oxford University Press. Oxford. 2007
} 
probabilidad de una transición a la democracia y aseguraba mayormente que esta permaneciese en el tiempo. ${ }^{176}$

En su tesis establecía que ha mayor riqueza, que a su vez incluía, industrialización, urbanización y educación quedaba patente, por lo menos a través de los "datos", que los países más democráticos eran los que más altos índices relacionados con estas variables tenían. Así aparecían liderando la tabla- hacía fines de los años 50- países como Australia, Bélgica, Canadá, entre otros. La mayoría eran países angloparlantes, algunos ubicados en Europa, en esta misma lista Latinoamérica se clasificaba en dictaduras estables o democracias inestables y dictaduras, Chile estaba en esta última lista, el grueso de países estaban en la primera lista (Bolivia, Cuba, R. Dominicana, etc.).

Es razonable esta división entre países con democracias estables y lo que sucedía en Latinoamérica, sobre todo considerando que en la época en que se escribe adscribe aun periodo complejo, lleno de quiebres democráticos en América Latina -años 60 y 70- su tesis fue contra argumentada por O’Donnell quien señaló Latinoamérica había seguido otro camino, distinto al de las economías más desarrolladas y que el resultado de esto había sido más conflictos sociales lo cual a su vez atentó contra la Democracia. ${ }^{177}$ En el fondo puso en entredicho la relación entre desarrollo económico y político, sin criticar necesariamente la primera, a diferencia de lo que haría Linz que parte criticando la teoría de la desde la base planteada en relación con los datos del desarrollo económico. ${ }^{178}$

\footnotetext{
${ }^{176}$ LIPSET, Seymour. "Democracy and Working-Class Authoritarianism”, American Sociological Review 24 (4): $482-501$. 1959; LIPSET, Seymour. "Some Social Requisites of Democracy: Economic Development and Political Legitimacy", American Political Science Review 53 (1): 69-105. 1959.

${ }^{177}$ O'DONNELL, Guillermo. Modernization and Bureaucratic-Authoritarianism: Studies in South American Politics. Institute of International Studies/University of California. Berkeley. 1973.

${ }^{178}$ LINZ, Juan J. “Totalitarianism and Authoritarian Regimes”, 175-411, en GREENSTEIN, Fred y POLSBY, Nelson (eds.), Handbook of Political Science 3, Macropolitical Theory. Addison-Wesley Press. USA. 1975.
} 
De esta manera se inauguró el debate acerca de las transiciones a la Democracia durante los años 80 , en algunos casos se sugirió que aunque la durabilidad de la democracia podría estar fuertemente influenciada por factores económicos estructurales, las transiciones a la democracia son procesos más abiertos, ya que en muchas ocasiones las decisiones estratégicas de los actores políticos y sociales pueden anteponerse a los prerrequisitos estructurales. ${ }^{179}$

Esto se condice con la realidad chilena, que en plena dictadura y con un moderado éxito económico de la política de shock implementado durante fines de los setenta, la tendencia durante los ochenta fue a consolidar a Pinochet en el poder mediante la promulgación de una nueva constitución política. Finalmente el año 1983 se desata una nueva crisis económica que agrego tensión al régimen militar y se comenzaron las primeras negociaciones con la oposición, sin embargo faltarían varios años para alcanzar algún acuerdo por un retorno a la Democracia. En definitiva, ni con buenos indicadores económicos se pensó en un retorno a la Democracia, sino que por el contrario, fueron más relevantes los intereses y agenda estratégica de los actores que el propio desarrollo económico, es aún más debatible lo que sucedió en los años noventa cuando Chile mostraba importantes indicadores económicos (con un crecimiento del 7\%), pero que ha quedado manifiesto que en la misma época la democracia seguía intervenida por el dictador.

Pese a este interesante debate, se han seguido realizando estudios cuantitativos acerca de la teoría de Lipset, los resultados siguen yendo en la dirección contraria a lo que proponía el autor en los años 60, pero establecido algunas interesantes conclusiones como que si bien el desarrollo económico no genera mayor propensión a la transición, si es probable que en ellas

\footnotetext{
${ }^{179}$ PRZEWORSKI, Adam. Democracy and the Market. Political and Economic Reforms in Eastern Europe and Latin America. Cambridge University Press. Nueva York. 1991.
} 
tengan menor riesgo de un quiebre democrático, ${ }^{180}$ aunque señalan que podría haber una especie de "expecionalismo" en Latinoamérica porque pese a la existencia de un mayor desarrollo económico, igualmente se podrían dar quiebres democráticos. ${ }^{181}$ Este estudio y otros como los de Diamond, han complejizado la premisa de Lipset, aportando otras aristas a su análisis y, aunque en este último caso, esté de acuerdo con la vinculación desarrollo/democracia hace evidente que en algunos ejemplos como el de los regímenes autoritarios un mayor desarrollo económico no tiene los mismos efectos legitimadores en el tiempo que sí tiene en las democracias. ${ }^{182}$

Otras de sus conclusiones igual de interesantes son que aquellas que señala que no es el desarrollo económico per se, y ciertamente no el mero crecimiento económico, el factor más conducente al establecimiento de la democracia, sino un conglomerado de cambios y mejoras sociales, ampliamente dispersos en la población, resumidos en forma lata en el término desarrollo socioeconómico, y de los cuales los que tienen mayor gravitación son aquellos que inciden en las condiciones físicas y en una vida digna, que el desarrollo económico conduce o facilita el tránsito a la democracia sólo en la medida que consigue modificar en una dirección adecuada las siguientes cuatro variables mediadoras: cultura política, estructura de clases, relaciones Estado-sociedad y sociedad civil. Y por último, si estas últimas variables se presentan en términos adecuados, puede haber democracia incluso en situaciones de bajo desarrollo económico. Con todo, e incluso en sus reinterpretaciones, la teoría de la modernización no es suficiente para comprender el caso chileno.

\footnotetext{
${ }^{180}$ PRZEWORSKI, Adam. "The Mechanics of Regime instability in Latin America", Journal of Politics in Latin America. 2009. pp. 5-36

${ }^{181}$ LANDMAN, Todd. "Economic Development and Democracy: The View from Latin America”, Political Studies 47 (1). 1999. pp. 607-626.

${ }^{182}$ DIAMOND, Larry. "Reconsideración del nexo entre desarrollo económico y democracia". Estudios Públicos 49. 1993. pp$37-98$
} 


\subsection{2.- Teorías Culturales.}

Estas teorías asumen que se puede llegar a la democracia y esta puede prevalecer siempre y cuando sus ciudadanos tengan actitudes democráticas y que apoyen el conjunto de valores que se consideran consistentes con el funcionamiento de la democracia. Estas ideas están vinculadas a lo propuesto por los teóricos de la modernización, ya que consideran el cambio cultural como una variable que interviene en la modernización económica y una mejor democracia.

Al igual que las tesis de la modernización los investigadores son bastante escépticos acerca del rol que juega la cultura cívica, señalando por ejemplo que siguen restándole importancia al claro papel que desempeñado las interacciones entre élites y las instituciones políticas, de hecho señalan que incluso sería posible tener democracia sin demócratas, de esta manera la cultura cívica sería más bien un producto de la democracia. ${ }^{183}$ Entendido así, es posible comprender por que para algunos ideólogos del Régimen de Pinochet, por lo menos después 1980, se podía denominar "Democracia protegida" a la Dictadura. ${ }^{184}$

Algunos autores han mantenido, pese a todo, la tesis de que la democratización y la estabilidad de la democracia pueden ser explicadas en términos de factores culturales Sin embargo, la crítica es similar a algunas teorías que nacen fuera del ámbito Latinoamérica, esta fueron hechas en base a encuestas con base principal en Europa -sin considerar el sesgo que se pude generar cuando se hace una encuesta en contextos no democráticos- Con todo hay estudios, como el de Muller y Seligson que incluyendo a América Central, terminaron por rechazar la tesis culturalista sosteniendo en cambio que las actitudes fundamentales de una cultura cívica, como la confianza interpersonal, son un producto de la democracia en lugar de una causa de la

\footnotetext{
${ }^{183}$ BARRY, Brian. Sociologists, Economists and Democracy. University of Chicago Press. 1978; SCHMITTER, Philippe. 2009; "Twenty-five Years, Fifteen Findings", Journal of Democracy 21 (1). 2009. pp. 17-28

${ }^{184}$ VERGARA, Jorge. "La democracia protegida en Chile". Revista de Sociología. U. de Chile. № 27. 2007.
} 
misma. $^{185}$

De esta manera y aunque se sigan realizando investigaciones al respecto se pude seguir señalando que as creencias de los habitantes en general acerca de la legitimidad de la democracia no son, en sí mismas, un factor clave, ni en las transiciones a la democracia ni en la durabilidad de la democracia.

\subsection{3.-Teorías del Desarrollo Capitalista y las Clases Sociales.}

Desde el punto de vista de estas teorías, el capitalismo sería una condición necesaria para la Democracia. Entendiendo que su modelo de desarrollo ofrecería oportunidades a la democracia para su fortalecimiento, ya que mediante esto los grupos sociales se situarían como un contrapeso al Estado o podrían actuar para una mayor representatividad de su grupo.

Los teóricos de la modernización sin embargo, vinculan el fortalecimiento de la Democracia, ${ }^{186}$ no con los grupos vinculados al trabajo o sectores populares, ya que estos tendrían un comportamiento más bien autoritario $^{187}$, sino que sería la clase media la llamada a actuar como un mejor catalizador de la Democracia en contextos capitalistas.

Pese a que muchos estudios no han incorporados análisis latinoamericanos, se señala que la burguesía urbana y su robustecimiento sería un causal de un mayor grado de democracia. Sin embrago en estudios realizados Alain Touraine en el periodo que va desde 1930 a los años 80

\footnotetext{
${ }^{185}$ MULLER, Edward y SELIGSON, Mitchell. "Civic Culture and Democracy: The Question of the Causal Relationships", American Political Science Review 88 (3). 1994. pp. 635-652

${ }^{186}$ LIPSET, Seymour Martin. "Some Social Requisites of Democracy: Economic Development and Political Legitimacy". American Political Science Review 53. 1959. pp. 69-105.

${ }^{187}$ LIPSET, Seymour. "Democracy and Working-Class Authoritarianism”, American Sociological Review 24. 1959. pp. 482501.
} 
evidenció que si bien el desarrollo económico en América Latina fue de carácter capitalista, este no fue dirigido necesariamente por una burguesía nacional, como consecuencia las clases sociales fueron poseían menos independencia y las democracias son más democracias de masas que de representación. ${ }^{188}$

Con todo, no hay estudios que comprueben suficientemente la tesis, ni siquiera para el caso chileno que en la década del 30 hasta los 70 del siglo XX estuvo dominada intermitentemente por la clase media (Arturo Alessandri), grupos obreros (Frente Popular) y militares (Grove, Ibañez y Pinochet), sin considerar que en el siglo XIX va a ser la propia elite conservadora la que delimitará los procesos de democratización. ${ }^{189}$ En este sentido, quien propone que la élite ha sido la que ha por lo que hay suficiente evidencia empírica de que no hay un solo grupo el que portador fundamental de la democracia o el principal obstáculo para la misma. ${ }^{190}$

\subsection{4.-Teorías de coyuntura crítica.}

Las investigaciones realizadas bajo esta perspectiva buscan determinar cuál sería el elemento clave para determinar la dinámica de los regímenes en América Latina durante la segunda mitad del siglo XX, a su vez que conocer su desarrollo histórico en el pasado. Los investigadores principales son Collier y Collier, quienes analizan la dinámica de los partidos políticos -en especial el vínculo oligarquía, clase media y sectores obreros- en la década de los años 20 y 30

\footnotetext{
188 TOURAINE, Alain. América Latina: Política y sociedad. Madrid, Espasa-Calpe. 1989.

${ }^{189}$ VALENZUELA, Arturo y VALENZUELA, Samuel. "Los orígenes de la democracia: Reflexiones teóricas sobre el caso de Chile", Estudios Públicos 12. pp. 3-39. 1983

${ }^{190}$ SMITH, Peter. Democracy in Latin America: Political Change in Comparative Perspective. Oxford University Press. USA. 2005.
} 
para poder entender los quiebres de los años 60 y 70 del siglo XX en Latinoamérica. ${ }^{191}$

Aunque algunos investigadores profundicen su análisis en el desarrollo de los movimientos obreros en plena cuestión social, a otros retrotraen su análisis al desarrollo de las reformas liberales del siglo anterior (s. XIX) o a la formación del Estado en el mismo periodo, determinado en gran manera por la experiencia colonial (España y Portugal).

Con todo, el gran problema de esta literatura son los pocos estudios empíricos al respecto, ya que la mayoría de las conclusiones son más bien inductivas. Resulta interesante de todas maneras para nuestro trabajo saber que existen estudios actuales que están analizando la década de los 80 y 90 y su relación con la instalación de políticas neoliberales como una nueva coyuntura crítica. ${ }^{192}$

\subsubsection{Teorías Político-Institucionales}

Esta última línea que presentamos centra su atención en la autonomía que tendría la políticacaracterísticas de las élites políticas y la dinámica de la esfera política- yendo más allá que las teóricas de la modernización que dan más valor a los factores societales (desarrollo económico, cultura cívica y clases sociales).

Esta es la línea de investigación desarrollada por Linz, quien llegó a establecer una tipología para los regímenes políticos y señaló como hipótesis central que la dinámica política de cada régimen afecta a las perspectivas de una transición a la democracia; de esta forma establece la

\footnotetext{
${ }^{191}$ COLLIER, Ruth Berins y COLLIER, David Shaping the Political Arena: Critical Junctures, the Labor Movement, and the Regime Dynamics in Latin America. Princeton University Press. Princeton. 1991.

192 TANAKA, Martin (ed.). La nueva coyuntura crítica en los paises andinos. IEP e IDEA. Lima. 2009; WIARDA, Howard J. 2001. The Soul of Latin America: The Cultural and Political Tradition. Yale University Press. USA. 2001.
} 
vinculación entre gobernantes y el desarrollo de las democracias. ${ }^{193}$ Por su parte, O’Donnell y Schmitter contemplan el análisis de las decisiones estratégicas de los actores políticos a la hora de entender cómo un tipo de régimen no democrático accede a la democracia. Entre las acciones estaría la de aceptar un pacto sobre algunas cuestiones políticas fundamentales. Estas dos teorías son las que más fuertemente han impactado la interpretación chilena de la transición, como veremos más adelante. ${ }^{194}$ De esta propuesta surgieron trabajos teorizando acerca de regímenes del siglo XX caracterizados como burocráticos autoritarios, "sultanísticos", de partido dominante y autoritarios "movilizacionales", todos ellos con una importante representación bibliográfica.

Otros estudios han analizado la duración de las democracias una vez que en Latinoamérica se regresaba a ellas en los años 80 y 90, para establecer cómo afectan los regímenes no democrático a las perspectivas de la consolidación de la democracia y determinar el por qué las transiciones negociadas o pactadas son la mejor forma de acceder a ella. ${ }^{195}$ En general, los estudios empíricos en Europa y América Latina avalan la idea que las transiciones pactadas tienen un impacto mayor en la consolidación de la democracia. ${ }^{196}$

En definitiva, estas teorías han tenido amplía difusión y son hoy en día, para el caso de Chile, las teorías más consideradas a la hora de interpretar la transición. Sin embargo, como queda en claro, el factor político y sus acciones van a estar en el centro de este estudio, aplicando análisis de la ciencia política que no siempre revelan la complejidad de la toma de decisiones o la mixtura que en ella pueden tener o no diversos grupos sociales, lo cual constituye un verdadero

\footnotetext{
${ }^{193}$ LINZ, Juan J. y STEPAN, Alfred. Problems of Democratic Transition and Consolidation: Southern Europe, South America and Post-Communist Europe. The Johns Hopkins University Press. Baltimore.1996.

${ }^{194}$ O'DONNELL, Guillermo y SCHMITTER, Philippe Transiciones desde un gobierno autoritario 4. Conclusiones tentativas sobre las democracias inciertas. Paidós, Buenos Aires. 1994.

${ }^{195}$ KARL, Terry Lynn. "Dilemas de la democratización en América Latina”, Foro Internacional 31. pp. 388-417. 1991.

${ }^{196}$ SCHNEIDER, Carsten. The Consolidation of Democracy: Comparing Europe and Latin Americ. Routledge. Londres. 2009
} 
desafío para las interpretaciones históricas del periodo, como la que propone este estudio.

\section{3.- TEORÍAS EXPLICATIVAS DE LA TRANSICIÓN CHILENA: DELINEAMIENTO DE UN “MODELO”.}

En una conferencia dictada el año 2013 en la que presentaba su libro Allende y la vía chilena. Las armas de política, el profesor y antes asesor de Allende, Joan Garcés, relata con vívido detalle los acontecimientos acaecidos el 11 de septiembre de 1973 y se detiene particularmente en las semejanzas que el encuentra entre los casos español y chileno, señalando "las similitudes entre lo que sucedió en el Chile del 73 y el levantamiento militar de Franco contra la II República, salvando las diferencias"; pero va incluso más allá al explicar cómo también la transición de la dictadura a la democracia chilena “(...) siguió el modelo español. Franco nombró sucesor al frente del Ejército a otro cargo vitalicio [el rey] y ajeno al control de la soberanía popular. La adaptación de Chile en los 90 dejó la Fuerzas Armadas en manos de los propios militares y no de órganos representativos." 197

Esto que para algunos puede resultar un ejercicio interpretativo bastante amplio, considerando los detalles particulares de cada acontecimiento histórico, refleja que existe una tendencia por intentar entender problemas históricos específicos por medio de la detección de ciertos rasgos generales posibles de aplicar. Se debe reconocer que dichos esfuerzos a veces representan avances importantes, pero también que el establecimiento de ciertos modelos o caracterizaciones generales no son ciento por ciento idóneas para comprender fenómenos específicos.

\footnotetext{
197 DIARÍO PÚBLICO. "La transición de Chile tras Pinochet siguió el modelo español" 10 de abril del 2013. [en línea] Santiago de Chile. 14 de marzo de 1983. [fecha de consulta 12 de diciembre de 2014] disponible en internet $<$ http://www.publico.es/culturas/transicion-chile-pinochet-siguio-modelo.html>
} 
En este apartado analizaremos cada una de estas propuestas y los modelos que han intentado explicar la transición chilena, ubicándola en una de las tantas teorías -como las antes señaladasllegando incluso a hacer pensar a algunos que la propia transición chilena es un modelo para otras transiciones. Esto que para el caso de la transitología es una virtud, ya que es posible generalizar explicaciones y buscar respuestas comparativas, para la historia puede resultar más bien una atadura para profundizar en las realidades específicas y únicas de cada proceso. En adelante, intentaremos desenredar la madeja para adentrarnos en el proceso chileno con más detalle.

\subsection{1.-La transitología en O'Donnell y Schmitter. ${ }^{198}$}

La amplia definición que establece que las transiciones corresponderían a ese periodo o intervalo que va entre un régimen y otro deja amplio margen interpretativo, pero además establece con claridad que su el periodo posterior requiere un estudio diferente, ya que correspondería a un periodo de consolidación.

Según los autores lo propio de este periodo de transición es, por una parte, que las reglas del juego político no están definidas o son emergentes; por otra parte, que los dictadores o gobernantes autoritarios tienen el control y conservan su poder discrecional en mayor o menor medida. Los autores establecen la relación entre liberalización (entendida como redefinición y ampliación de derechos) y democratización, reconociendo que no siempre se dan necesariamente de manera simultánea, pero ambas son requeridas aunque las podemos encontrar en distintas gradaciones. Incluso puede darse el caso en que los gobernantes autoritarios entreguen ciertas cuotas de libertad para "despresurizar" su gobierno, frente a lo

\footnotetext{
${ }^{198}$ O’DONNELL, Guillermo y SCHMITTER, Philippe. Op. Cit. 1994.
} 
cual es posible encontrar "dictablandas" o "democracias tuteladas". Para el caso chileno ambos conceptos fueron utilizados por la propia Dictadura e incluso se estableció que la Democracia posterior a la Dictadura (en especial después que se permitió cierto tipo de organización política tras el establecimiento de la Constitución de 1980) sería una de tipo protegida. ${ }^{199}$

Según O`Donnell, la transición se iniciaría con la liberación, en la medida que el dictador o gobernante autoritario anuncia su propósito de ampliar en algún grado los derechos individuales o colectivos que gozarán de protección y sus declaraciones son creíbles por la población. ${ }^{200} \mathrm{El}$ final de dicha transición es mucho más impreciso, ya que el mismo O’Donnell propondrá luego la necesidad en ocasiones de una segunda transición. ${ }^{201}$

Siguiendo el pensamiento del mismo autor, la Dictadura chilena podría analizarse desde la perspectiva del autoritarismo burocrático que se caracterizaba por ser el garante y organizador de la dominación por parte de la alta burguesía oligopólica y transnacional; retener el poder en manos de militares que a través del dominio coercitivo buscaban reinstalar el orden se unió a la acción de un grupo de tecnócratas enfocados en aplicar políticas económicas de shock, excluyendo al sector popular. Por esta misma razón se dejó fuera de juego político a los partidos y se buscó conscientemente despolitizar la sociedad.

Para el caso de las democracias en Latinoamérica, O’Donnell utiliza el término de Democracias delegativas al señalar que casi todas no cumplen con todos los aspectos de la poliarquía (concepto bastante debatible, como vimos anteriormente). Señala como excepciones a Chile y

\footnotetext{
${ }^{199}$ El propio Pinochet en una conferencia de prensa señala “...esto nunca ha sido una dictadura, esto es una "dictablanda”, pero si es necesario vamos a tener que apretar la mano..." Véase: PINOCHET, Augusto. "Esto no es una dictadura señores esto es dicta blanda Augusto Pinochet" Conferencia de prensa. [en línea] Santiago de Chile. Septiembre de 1985. [fecha de consulta 13 de diciembre de 2014] disponible en internet $<$ https://www.youtube.com/watch?v=OVveqVRPyb4 >

${ }^{200}$ O’DONNELL, Guillermo y SCHMITTER, Philippe. Op. Cit. 1994. pp. 25-27

${ }^{201}$ O’DONNELL, Guillermo. 1992. “Transitions, Continuities, and Paradoxes.” en: Mainwaring, Scott, Guillermo O’Donnell, and J. Samuel Valenzuela., Issues in Democratic Consolidation, Notre Dame, Indiana: University of Notre Dame Press. 1992 pp. $17-56$.
} 
Uruguay que serían más bien democracias representativas, o algo cercano a ello (cuestión que también ha sido discutida para el caso chileno). Con todo y siguiendo la caracterización de los estados antes de la transición, varios de los autores que han considerado el caso chileno parten de la concepción del citado autor acerca del autoritarismo burocrático para explicar el derrotero de la transición a la democracia en Chile. ${ }^{202}$

\subsection{2.- La tercera ola de Huntington.}

"La tercera ola de democratizaciones en el mundo moderno comenzó de manera poco convincente e involuntaria veinticinco minutos después de medianoche, el martes 25 de abril de 1974 en Lisboa, Portugal (...)". ${ }^{203}$ Con esta frase inicia el primer capítulo del libro de Huntington que buscará a explicar a lo largo de sus páginas la aparición de nuevos regímenes democráticos que desde los años 70 comenzaban a reiniciarse o a iniciarse en Europa del sur y centro, América del Sur y África. El término utilizado por el autor, se instaló en el discurso de todos los especialistas y se difundió rápidamente.

Estos cambios de régimen no pasaron desapercibidos para los cientístas sociales, sobre todo, por la magnitud y la celeridad que adoptaron. Los cambios que coincidieron en Europa con la caída del muro de Berlín y el fin de la guerra fría modificó la forma en que se comenzó a conceptualizar los procesos de democratización. De manera distinta a lo sucedido en Latinoamérica en Europa fue proceso mucho más expuesto a los medios de comunicación y donde tanto las ONGs como otras instituciones fueron actores relevantes. ${ }^{204}$

\footnotetext{
${ }^{202}$ GODOY, Oscar. "La Transición chilena a la democracia: pactada". Estudios Públicos, 74. otoño 1999.

${ }^{203}$ HUNTINGTON, Samuel. Op. Cit. 1994. p. 17.

${ }^{204}$ PRIDHAM G. Y VANHANEN T. (eds.). Democratization in Eastern Europe: domestic and international perspectives. Routledge. USA. 1994.
} 
Estas experiencias Europeas dejaron ciertas evidencias que mostraron que la distribución de la democracia en el sistema internacional estaba fuertemente influenciada por procesos de difusión entre los Estados, lo que abría nuevas líneas de investigaciones, útiles para entender las transiciones latinoamericanas, ya que al parecer no sólo los regímenes tienden a ser similares dentro de las regiones, sino que también puede haber una fuerte tendencia a que se produzcan las transiciones de regímenes de una manera más parecida a la media regional. ${ }^{205}$ Esto fue estudiado en especial en aquellas transiciones tardías, o sea las que se dieron tras el fin de la Guerra Fría. En este sentido, Huntington, si bien reconoce que los aspectos internacionales jugaron un papel trascendente en las transiciones, también reconoce que existe una mayor importancia de los actores nacionales. Según el autor debería distinguirse entre "actores" y "factores" como espacios separados, lo que diluye un poco la influencia internacional en los estudios transitológicos. Como señala el mismo Huntington, “(...) Un régimen democrático se instaura no por medio de tendencias sino por medio de la gente. Las democracias fueron creadas no por las causas sino por los causantes" 206

Con todo, los estudios comparativos han acercado la investigación siguiendo el pensamiento de Huntington, en especial con aquellas primeras transiciones propias de la tercera ola, como por ejemplo es la española. En este caso, se une comparativamente tanto porque puede caber dentro de este campo de análisis como otras ciertas similitudes con los casos latinoamericanos, como señala Waisman, "España como casi toda América Latina y gran parte de Europa Central /Oriental era una nación carente de tradiciones democráticas fuertes y (...) como América Latina fue parte de un proceso más amplio que abarcan una conversión económica bastante radical”207.

\footnotetext{
${ }^{205}$ PEDROSA, Fernando. "La influencia externa en las transiciones de la "tercera ola" en América Latina. Debates, definiciones y propuestas teóricas”. Polis. Año 6 No 12. 2013. p. 211.

${ }^{206}$ HUNTINGTON, Samuel. Op. Cit. 1994. p. 105.

${ }^{207}$ WAISMAN, Carlos. "Las transiciones latinoamericanas en el espejo español”. En: WAISMAN, Carlos.et. al. Transiciones de la dictadura a la democracia: los casos de España y América Latina. UPV. EHU. Bilbao. 2005. pp. 15-21.
} 
En estudios comparativos, Chile se muestra como el de mejor desempeño en su curso “democratizante" (por lo menos en indicadores generales, puntaje Freedem House).

Si bien en muchos aspectos las teorías de Huntington han delineado los estudios sobre la transición en Latinoamérica y Chile en particular, las criticas urgidas son bastante evidentes, principalmente frente a la ausencia de aspectos cualitativos involucrados en su estudio, como señala José Luis Egío “(...) no son tenidos en cuenta en el análisis de Huntington aspectos cualitativos (como la transparencia en el funcionamiento de las instituciones o el grado de información de los ciudadanos respecto a cuestiones políticas, entre otros muchos), pese a que éstos son de crucial importancia para verificar si, a lo largo de los siglos XX y XXI, en los distintos regímenes democráticos se ha producido un cambio positivo en las prácticas de gobierno a la par que nuevos miembros se incorporaban al otrora llamado Mundo Libre."208 Estos aspectos, en los últimos años en particular, son justamente los que más en entredicho se han puesto a la hora de valorar la calidad de la democracia que emergió de la Transición, especialmente para el caso chileno.

\subsection{2.- Las definiciones de Linz: Transiciones pactadas.}

Durante los años setenta, como ya vimos, se generaron una serie de estudios acerca de la democracia, entre ellos se encontraron los importantes volúmenes escritos por Juan J. Linz y Alfred Stepan titulados The Breakdown of Democratic Regimes y publicados el año $1978 .^{209}$ Posteriormente ha ido reflexionando acerca de los importantes cambios que trajo consigo esta “tercera oleada". Como el mismo señala, su interés es más bien estudiar aquellos regímenes que

\footnotetext{
${ }^{208}$ EGÍO, José Luis. "Políticas del rompeolas". $\Delta \alpha \iota \mu \omega v$ Revista de Filosofia, no 39, 2006. p. 88.

${ }^{209}$ LINZ, Juan J. y STEPAN, Alfred (eds.), The Breakdown of Democratic Regimes, vols. 1, 2 y 3. Baltimore: John Hopkins, 1978 .
} 
conducen hacia la democracia política, aunque existan muchos otros que posean distintos niveles de desarrollo social y económico. En sus consecutivos trabajos se centra por tanto en describir los diversos tipos de regímenes, como por ejemplo el de tipo "sultanato". A su vez define con detalle lo propuesto junto a Stepan para definir las transiciones pactadas (reformapactada/ruptura - pactada). ${ }^{210}$

Estos "caminos alternativos" son los siguientes:

1.- Aquellos que involucran un conflicto armado y una intervención externa.

2.- Los titulares del poder autoritario que promueven un proceso de democratización.

3.- Aquellos en que las fuerzas de oposición juegan el papel principal.

4.- Una transformación dirigida desde dentro del régimen autoritario.

5.- Una transición iniciada por los militares en cuanto gobierno.

6.-Una liberación encabezada por los militares en cuanto institución.

Junto con estos seis tipos de transición destacan cuatro más: “(...) dos en que las fuerzas de oposición jugaron el papel preponderante, ya sea porque la sociedad encauzó la transición del régimen, ya sea a través de un pacto de partidos políticos opositores con o sin elementos de asociación, la revuelta paramilitar o la guerra revolucionaria." ${ }^{211}$ En este sentido el caso de la transición española coincide con el modelo de reforma pactada realizada en términos de ingeniería política con ayuda de la perspectiva de la revolución (en noviembre de 1975 y la convocatoria del Parlamento, en 1977). El mismo autor define una Reforma Pactada para el

\footnotetext{
${ }^{210}$ LINZ, Juan. J. "Del autoritarismo a la democracia”. Estudios públicos. N 23. 1986. pp. 5-58.

${ }^{211}$ LINZ, Juan J. Op. Cit. p. 27.
} 
caso español, en términos de quienes estaban en el poder, y una Ruptura Pactada, en términos de la oposición democrática.

El autor también establece cierta características para regímenes donde los militares participan de la transición; en este sentido la actitud que toman los militares frente a la democratización va afectar de manera concreta el tipo de democracia resultante, ya que tiene la posibilidad cierta de una vez entregado el poder derrocar un gobierno, pero también, por el mismo poder que ejercen podrían servir de catalizadores. Los vínculos entre el ejército y el mundo civil son puestos en evidencia en la transición española para generar ciertos pactos que le lleven de vuelta a la democracia, aspecto que ha sido recogido también para la realidad chilena por investigadores que ven en el modelo español el mejor referente.

Sin embargo, el mismo Linz, deja abierta una posibilidad diferenciadora entre ambas transiciones al señalar que “ (...) vale la pena señalar que el proceso conducente hacia la reforma-ruptura-pactada en España no fue llevado a cabo por los tecnócratas del régimen de Franco, ni por aquellos con un trasfondo puramente burocrático, sino que principalmente por una nueva generación de políticos del régimen con experiencia como gobernadores provinciales en regiones que contaban con una oposición considerablemente fuerte, y en organizaciones funcionales, tales como los movimientos juveniles y estudiantiles y los sindicatos oficiales del régimen" $^{\text {212 }}$. El caso de Chile difiere en su origen (en el artículo del citado autor no se menciona este caso. ya que fue publicado el año 1986), puesto que los procesos de negociación fueron llevados a cabo en su mayoría por los políticos de oposición, en especial aquellos que habían formado parte del sistema con anterioridad a 1973. Pese a esto, como veremos en líneas

\footnotetext{
${ }^{212}$ LINZ, Juan J. Op. Cit. p. 44.
} 
siguientes, el modelo adoptado por Chile seguirá más bien los lineamientos definidos por el modelo que establece un pacto como el marco definitorio del fin del régimen autoritario.

\subsection{3.- "El modelo exitoso chileno”: Transición pactada.}

Entre las tesis más difundidas por los politólogos y que definen el modelo chileno encontramos la sustentada por Oscar Godoy ${ }^{213}$, quien sigue la larga tradición de investigadores que intentan dilucidar los problemas transitológicos, en este caso, el de Chile. El autor inicia su argumento desmontando el análisis que hace Garretón acerca de la Transición ${ }^{214}$, señalando fundamentalmente que “(...) es indudable que quienes sostienen que no hay transición a la democracia porque estamos plenamente instalados en ella, a partir de la entrada en vigor de la Constitución de 1980, afirman la validez de la concepción de democracia contenida en ese texto constitucional. Por lo mismo, participan y adhieren a la ideología de la democracia protegida por un guardián o tutor constitucional: las Fuerzas Armadas. Y, a la vez, marcan una preferencia por dispositivos extraordinarios y excesivos de protección de los derechos de la minoría política contra la voluntad popular, hasta el punto de no permitir que ésta se exprese adecuadamente."215 Pese a esto reconoce, junto al mismo Garretón, que la misma democracia en Chile es incompleta, entendiendo que aquella es un proceso a través del cual se realizan las condiciones procedimentales mínimas para que la democracia entre en la fase de consolidación y profundización.

\footnotetext{
${ }^{213}$ GODOY, Oscar. "La transición chilena a la democracia: pactada. Estudios Públicos. N ${ }^{\circ} 74.1999$

${ }^{214}$ GARRETÓN, Manuel A. "Las revanchas de la democratización incompleta”. Mensaje. Santiago. 1999 y GARRETÓN, Manuel A. "La transición chilena. Una evaluación provisoria”. Documento de Trabajo FLACSO. Serie Estudios Políticos, 8. Enero de 1991.

${ }^{215}$ GODOY, Oscar. Op. Cit. p. 81.
} 
Sin embargo, donde Godoy focaliza mayormente su análisis es en la naturaleza de la transición chilena que sería según el autor, de carácter pactado. El autor parte del mismo análisis transitológico que hemos señalado líneas atrás al señalar que para entender de qué índole es la transición se debe reconocer la dependencia que se tiene del periodo inmediatamente anterior, en este caso al autoritarismo, y de manera particular, respecto al modelo de régimen burocrático autoritario. En este caso, siguiendo a O'Donnell, este tipo de autoritarismo que tuvo mayor difusión en América Latina descansaría en la relación que tenían los militares con una elite tecnocrática. Por un parte, los militares eran quienes tomaban decisiones y aplicaban la coerción y, por otra, la tecnocracia organizaba y hacía eficiente el sistema económico. Así mismo las clases altas son el soporte del régimen y los sectores populares están desmovilizados o reprimidos.

En este contexto, señala Godoy, los plazos contemplados por los militares se cumplieron y no había atisbos de que el poder autoritario hubiese menguado; por el contrario se puede decir que conservaba casi intacto su poder y decisión original de instaurar una democracia protegida. De hecho, no se dio ninguna situación extraordinaria que quebrara este itinerario como sí se dio en otros contextos, como por ejemplo, la muerte del líder o su caída o la derrota en algún enfrentamiento armado. Más bien, existía una especie de consenso a nivel de las elites militar, tecnocrática y adherentes en torno a la liberalización del régimen. A todo lo anterior habría que sumar los cambios sociales que se vinieron dando desde mediados de los años ochenta con una mayor pluralización por una parte y más protestas por otra, en ambos casos producto de las mismas contradicciones de la economía de mercado.

Algunos de los hitos mencionados por el autor, están centrados principalmente en la capacidad -y voluntad- de negociación que tendría el mismo régimen, bajo ciertas limitaciones obvias. El punto de disputa fue naturalmente la legitimidad del régimen. Superado este desencuentro y aceptando las "reglas del juego" establecidas por el Dictador, como señala Boeninger se adoptó 
un nuevo derrotero ya entrando en la segunda mitad de los años ochenta “ (...) la nueva estrategia que culmina con la Concertación por el No y la extraordinaria campaña que condujo al triunfo del 5 de octubre de 1988, fue la suma de la decisión primera de la Democracia Cristiana, la nítida definición del PS-Núñez distanciado tempranamente del PC y la espectacular evolución del PS-Almeyda, que dejó definitivamente aislado al extremismo PC-MIR y permitió a la Concertación por el No convertirse en un referente claramente mayoritario, sustentado a su vez en una amplia mayoría social”. ${ }^{216}$

Hay un matiz en esta aceptación del itinerario del Régimen: por una parte, al aceptar esto el año 1984 -tanto a nivel discursivo como práctico- se acepta tácitamente el orden político establecido por Pinochet y se acatan sus reglas; pero por otra parte, se está en desacuerdo con que democracia resultante de este proceso termine siendo protegida (por lo menos así lo considera Godoy). Esto último se habría cumplido tras las negociaciones establecidas después del el triunfo del "no", que establecían claramente en el Acuerdo Nacional por la Democracia la necesidad de una "transición consensual" y los requisitos para que esto fuera posible. Dichas exigencias eran las siguientes:

A.- Elección íntegra del Congreso Nacional por sufragio popular con un sistema proporcional.

B.-Flexibilización de las normas que regulan las reformas constitucionales y término de las proscripciones políticas.

C.-Derogación del artículo octavo de la Constitución y Fortalecimiento del pluralismo; D.modificación de la composición y funciones del Consejo de Seguridad Nacional.

D.- Derogación de la inamovilidad de los Comandantes en Jefe de las Fuerzas Armadas y de Orden.

\footnotetext{
${ }^{216}$ BOENINGER, Edgardo. Op. Cit. p. 308.
} 
No era la primera vez que la oposición proponía un acuerdo de estas características; el año 1985 algo parecido ya había sido desestimado por Pinochet por considerarlo ambiguo y carecer de “definiciones y coherencia". ${ }^{217}$ Sin embargo, esta vez en medio de la derrota electoral, aquel fue recogido por el Dictador, pero no sin una larga negociación que dio como resultado una propuesta mucho más limitada que fue anunciada el 11 de marzo de 1989:

A.- Derogación de la facultad presidencial para disolver la Cámara de Diputados.

B.- Eliminación de algunas facultades presidenciales durante el estado de sitio (expulsión y prohibición de ingreso al territorio nacional)

C.- Revisión de la composición del Consejo de Seguridad Nacional.

D.- Probable reducción de la duración del mandato presidencial.

Se acordó una comisión técnica que finalmente dio frutos en abril de 1989, estableciendo:

a) Substituir el artículo octavo de la Constitución, que limitaba severamente el pluralismo.

b) Limitar algunas restricciones a las libertades públicas durante los estados de excepción.

c) En relación al Congreso Nacional, aumentar el número de los diputados a 150 y de los senadores a 50 .

d) Suprimir los senadores designados (Renovación Nacional propuso mantener el estatuto de senador vitalicio para los ex Presidentes de la República);

\footnotetext{
${ }^{217}$ EL PAÍS. "Pinochet rechaza el acuerdo nacional propuesto por la oposición". 22 de Diciembre de 1985. [fecha de consulta: 3 de mayo del 2012]. Disponible en internet: http://elpais.com/diario/1985/12/22/internacional/504054014 850215.html
} 
e) Respecto del Consejo de Seguridad Nacional, cambiar su composición, integrando a la misma al Presidente de la Cámara de Diputados y al Contralor General de la República, y además conferirle al mismo un carácter asesor y consultivo del Presidente de la República.

f) Adopción de un sistema electoral proporcional.

g) Respecto de las normas para reformar a la Constitución, suprimir el requisito de la aprobación por dos legislaturas sucesivas para hacer las modificaciones que correspondieren a los capítulos I (Bases de la Institucionalidad), III (Derechos y Deberes de las Personas) y XIV (Reforma de la Constitución), mantener la norma general de los 3/5 para las reformas constitucionales, pero elevar ese quórum a 2/3 para los capítulos específicos ya mencionados. También se proponía substituir el quórum de 4/7 para aprobar las leyes orgánicas constitucionales por la mayoría absoluta.

El resultado de esta comisión técnica tampoco fue aceptado inmediatamente por el Régimen, más bien había sido impulsado por la Concertación (oposición) y Renovación Nacional (partido de derecha), la contrapropuesta no era tan satisfactoria pero, como señala Boeninger "La Concertación, consciente de lo que estaba ocurriendo, tuvo que adoptar una decisión política de enorme trascendencia: o rechazaba la propuesta gubernativa por insuficiente, manteniendo su negativa a reconocer la legitimidad del orden institucional (con las consecuencias antes señaladas) o se conformaba con una reforma sustancialmente más modesta, para evitar la prolongación del conflicto constitucional al período de gobierno que se iniciaría en marzo de 1990, aceptando las consiguientes limitaciones a la soberanía popular y al poder de la

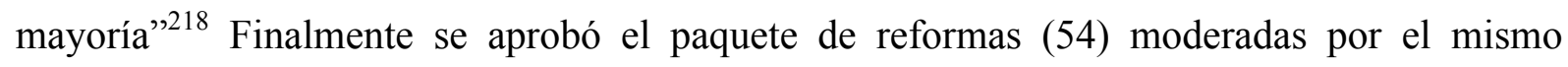

\footnotetext{
${ }^{218}$ BOENINGER, Edgardo. Op. Cit. p. 364.
} 
Régimen y la Junta de Gobierno aprobó, sujeto a la ratificación plebiscitaria $(85,7 \%$ de aprobación y un 8,2\% las rechazó).

De esta manera Godoy señalar que se dan dos pactos simultáneos para entender la transición, el pacto tácito de aceptación del itinerario y el pacto expreso de las reformas constitucionales que permitirían destrabar el primer gobierno de la concertación. Este modelo de transición ha sido ampliamente difundido como un éxito, porque bajo otras condiciones quizás la crisis se hubiese extendido asta el primer gobierno democrático, o aun peor, este habría hecho retroceder los avances. Sin embrago, como veremos en adelante, ¿por qué este pacto incomodo pervivió y se profundizó en años siguientes? ¿Fue realmente un éxito? ¿No se terminó igualmente en una democracia protegida? 


\section{6.- EL ITINERARIO DE LA DICTADURA: EL MODELO EXITOSO O UNA TRANSICIÓN PARA}

\section{PINOCHET}

Como vimos en el capítulo anterior la mayoría de las interpretaciones de las transiciones y los modelos que les analizan nacen de la investigación politológica, contienen un fuerte énfasis liberal y en algunos casos utilizan abiertamente el paradigma estadounidense. Tal como señala Mira, casi 30 años después de los acontecimientos, es oportuno revisar y matizar la secuencia lógica y lineal establecida -con los hechos en caliente y los procesos incompletos- por los politólogos que intentaron describir el fenómeno del cambio político (liberalización de la dictadura/negociación civiles-militares/celebración de elecciones limpias/transición/ consolidación y persistencia de la democracia). La misma consideración podría recibir la teoría holística de Huntington que pretende sintetizar en un puñado de factores y requisitos la ola de transiciones a la democracia en el caso de los países latinoamericanos. ${ }^{219}$

En las siguientes páginas analizaremos las principales fracturas del modelo propuesto para el caso chileno, poniendo en evidencia sus limitaciones. Consideramos relevante esa operación de cara a evaluar los efectos de esta transición en la calidad o características de la democracia resultante.

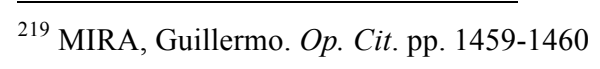




\section{1.- EL "MODELO DE EXPORTACIÓN"}

Los modelos de interpretación no son tales si no se transforman en fuente o molde para analizar otros contextos. Tal como fue la transición española para latinoamérica, y en especial para el caso chileno, nuestro país se transformó en el corto plazo en un contexto digno de estudiar e imitar, por lo menos en algunos aspectos. Mencionaré aquí brevemente dos de los más conocidos: los derechos humanos y la economía.

El reconocido investigador Laurence Whitehead, analizaba en un destacable artículo publicado el año $1999,{ }^{220}$ la perspectiva internacional de la transición chilena, comparándola con diversos procesos de transición que se desarrollaban de manera más o menos paralela y en condiciones relativamente similares. Una de ellas es la comparación binaria entre Chile y Sudáfrica que parte de un debate intelectual iniciado el año 1995 entre ambos países y varios académicos de la Universidad de Cape Town y la Universidad de Chile.

En el tapete se pusieron temas como el papel de Pinochet al encauzar el proceso de transición contra sí mismo en 1988, uniendo a la oposición en su caída. Así se habló acerca de si el NP actúo con suficiente visión de futuro o Klerk se habría equivocado en sus cálculos. En este sentido la experiencia chilena -más que como un modelo exacto- se convirtió en un experimento del cual sacar lecciones con el fin de impulsar las reflexiones para salir del apartheid. $^{221}$

\footnotetext{
${ }^{220}$ WHITEHEAD, Laurence. "El lugar de Chile en los estudios comparados". En: MENÉNDEZ, Amparo y JOIGNANT, Alfredo (edit). La caja de Pandora. El retorno de la Transición chilena. Editorial Planeta-Ariel. Chile. 1999.

${ }^{221}$ Aunque sea un aspecto más que nada simbólico es notable que tanto el símbolo de la opción del "No" a Pinochet fuera un Arcoíris y el utilizado por el Congreso Nacional Africano y Mandela sea lo mismo (la nación del arcoíris). La idea conceptualmente es similar, el arcoíris como imagen presenta una diversidad de colores dispuestos en unidad y armonía, juntos sin mezclarse, representados igualitaria y no equitativamente.
} 
Más allá del intercambio bilateral, hubo contactos prácticos entre ambos países que se transformó en un intercambio de ideas para llevar adelante políticas similares a la chilena, como sucedió con el caso de los derechos humanos y su Comisión de verdad y reconciliación sudafricana.

Como es sabido, en 1990, el presidente Frederic de Klerk anunció la liberación de los principales presos políticos- con Nelson Mandela entre ellos- y declaró la abolición de varias de las leyes fundantes del apartheid. Se creó la Convención para una Sudáfrica Democrática, compuesta por todas las fuerzas políticas, con el objetivo de fundar las bases para la transición. La Convención aprobó la Constitución Interina de 1993, que derogó 69 leyes racistas y fue el marco legal de las primeras elecciones democráticas y multirraciales (1994). Sin embargo, dicha constitución no menciona el apartheid ni el racismo en su escrito. Será solo en el apartado "Unidad nacional y reconciliación” donde se sentarán las bases de la Ley 34 que creará la Comisión.

En 1995 se aprobó la Ley 34 para la Promoción de la Unidad Nacional y la Reconciliación, específicamente para crear la Comisión. Este órgano revisaría las violaciones a los derechos humanos cometidas entre 1960-1994 y su principal objetivo era "promover la unidad nacional y la reconciliación en un espíritu de entendimiento que trascienda los conflictos del pasado" El Comité de Graves Violaciones a los Derechos Humanos se formó y recibió 21.198 testimonios de víctimas sobre más de 40.000 violaciones a los derechos humanos, de estos cerca de 2.000 testimonios fueron llevados a la audiencia pública, difundidos por radio y televisión en vivo y simultáneamente en todo el país. ${ }^{222}$

${ }^{222}$ CABANILLAS, Natalia. "Incorporando la nación: mujeres africanas ante la comisión de verdad y reconciliación sudafricana." Nómadas № 38, Colombia. abril de 2013. 
Como queda patente, salvo las audiencia públicas y su tele-difusión la orientación es bastante similar a lo realizado en Chile por el Informe Rettig y la Comisión de derechos humanos que le dio origen. En concreto es sabido que hubo intercambios directos entre embajadores para replicar, lo que en Sudáfrica se consideró como modélico, en este caso, la forma en que enfrentó Chile la violación de los derechos humanos, en especial lo referido ha privilegiar la estabilidad del sistema democrático más que el ejercicio del castigo por violaciones pasadas. De hecho, así lo declaró en 1997 un político sudafricano que habló acerca del tema:

“(...)Sin embargo, como sucedió con ustedes en Chile, no hubo ningún triunfo revolucionario. Tampoco hubo derrota militar con respecto a aquellos responsables del terror. En cambio, cuando el ANC (Congreso Nacional Africano) y otras entidades dejaron de estar prohibidas en 1990, nosotros mismos nos encontramos en una situación inmensamente frágil, en que a pesar de no tener poder; al mismo tiempo éramos responsables del futuro desarrollo de nuestro país.

Para enjuiciar a aquellos que estaban bajo sospecha de ser finalmente responsables de violaciones a los derechos humanos, según nuestra opinión, se habría comprometido la transición en sí misma. No podíamos darnos el lujo de atacar a aquellos con quienes estábamos negociando. Las expectativas de instituir un Gobierno de Unidad Nacional tal como a la larga se acordó, habrían disminuido mucho. Las nuevas libertades políticas que precisamente habíamos conseguido, la esperanza de establecer una sociedad nueva y abierta, en donde se respetaran verdaderamente los derechos humanos, todo eso habría estado bajo amenaza. Pero enjuiciar a aquellos quienes efectivamente cometieron actos de tortura y asesinatos y no a aquellos que los fomentaron $\mathrm{u}$ ordenaron llevarlos a cabo, habría sido totalmente injusto. Las tropas constituyeron el modelo de sus superiores.

Y de esta forma, dolorosamente y tras mucho debate, se forjó la idea de una Comisión de Verdad. Fuimos afortunados de que pudiéramos beneficiarnos de lo que había sucedido antes en otros países, tales como en Chile y Argentina. 
Vuestro Presidente Aylwin, al decidir acerca de su propia línea de acción, advirtió que era necesario equilibrar la virtud de la justicia con la virtud de la prudencia. La experiencia de otros países, él dijo, demostró que la estabilidad del sistema democrático es la mejor garantía contra futuras violaciones a los derechos humanos, más que el ejercicio del castigo por violaciones pasadas. Su compatriota, José Zalaquett, que visitó Sudáfrica, también fue una voz influyente. Y aquí yo debo rendir homenaje a su idóneo y respetado Embajador ante mi país, Excmo. Sr. Jorge Heine, quien desempeñó un papel de incalculable valor a través de su amistad con muchos de los principales involucrados en la formación de nuestra Comisión y su orientación y estímulo a ellos. $" 223$

Acerca de si es pertinente considerar un buen modelo el de nuestra transición en temas de derechos humanos o es más bien una de las trabas más fuertes de nuestra democracia aún pendiente y lo veremos en un capítulo posterior. Sin embargo, no es menor el considerar, como los políticos de los noventa que formaban parte del gobierno fueron capaces de aprovechar su experiencia en temas de derechos humanos y difundirla como un éxito, sabiendo que internamente no había mucho consenso de sus reales alcances.

Otra de las experiencias, aunque un poco más reciente pero que también es el resultado de la importante difusión de los éxitos del modelo chileno, es el tema económico. Particularmente el modelo "social de mercado" que ha tenido una amplia recepción en el "vecindario". Nos referimos en este caso a Perú. En este sentido, y paradojalmente, los grandes promotores del modelo en los países latinoamericanos han sido justamente los economistas de Pinochet como José Piñera y Hernán Büchi entre otros, quienes quedaron -al parecer- bastante contentos de cómo se mantuvo el modelo en plena democracia, y en especial en los temas vinculados a la

\footnotetext{
${ }^{223}$ ASMAL, Kader. "Verdad y Reconciliación en la Transición a la Democracia en Sudáfrica" Revista de Relaciones Internacionales Nro. 13. UNLP. 1997.
} 
seguridad social como son las AFP (pensiones privadas), la Isapre (salud privada) e incluso la Educación.

Con Alan García, especialmente, el modelo chileno se fue "adaptando" al Perú a tal punto que el mismo ex mandatario en un comentario realizado el 2011 señala fehacientemente que "el modelo económico chileno-peruano es el más eficaz."224 Esta incorporación del modelo económico de mercado, que ha tenido como asesores a importantes economistas de la Dictadura, ha llevado a que actualmente se hable del "milagro peruano" con un crecimiento cercano al 6\% desde antes del 2011 y con un promedio el 2013 de 5,8\% que se estima se mantendrá ligeramente por debajo del 6\% hasta el 2017. Obviamente no se habla de los costos del crecimiento, ni mucho menos del intenso debate llevado en Chile acerca de la dura inequidad y desigualdad que ha producido este "modelo exitoso". Hemos dejado también un capítulo más adelante para analizar críticamente este punto.

Con todo, se pude observar que teóricamente existe un "modelo chileno de transición y democratización", que incluso ha sido "exportado" en algunos de sus componentes, sin embargo no ha sido poco el debate que ha provocado, ya que la discusión acerca de las limitaciones del éxito chileno es importante, incluso en aquellos que algunos economistas y político interesadamente han logrado difundir en el exterior como ejemplo. A continuación veremos algunas opiniones disidentes acerca de la "verdadera" transición que nos ayudarán a comprender el verdadero modelo de transición y democracia que tiene Chile y que pocos conocen o quieren reconocer.

\footnotetext{
${ }^{224}$ DIARIO EL COMERCIO. "Alan García: El modelo económico chileno-peruano es el más eficaz" [en línea] 20 de enero del 2011. [fecha de consulta 12 de octubre de 2013] disponible en internet $<\underline{\text { http://elcomercio.pe/politica/gobierno/alan-garcia- }}$ modelo-economico-chileno-peruano-mas-eficaz-noticia-701285>
} 


\section{2.-FRACTURAS DEL MODELO CHILENO: VISIONES DISIDENTES.}

El tema de sí el modelo chileno esta resquebrajado ha comenzado a analizarse durante los últimos años aún someramente y en algunos casos de manera mucho más radical que otras. Sin embargo, estos análisis críticos no han surgido de la política oficial o de algún estudio histórico.

En estricto rigor ha sido la propia ciudadanía, o parte de ella, la que ha resultado ser mucho más crítica del desenvolvimiento de la Democracia en las últimas décadas. Son finalmente los protagonistas quienes han terminado percibiendo que su participación en la toma de decisiones ha sido baja o que han sido afectados en sus derechos toda vez que se señala que es una democracia de todos, exitosa, pero de la cual no se sienten parte o el éxito sólo ha alcanzado para algunos pocos. ${ }^{225}$ La crítica más dura ha sido hecha por los estudiantes, tanto universitarios como secundarios; es en ellos en quienes ha repercutido de manera directa la toma de decisiones de la política de los años 90, permisiva con los empresarios en pos del emprendimiento y poco audaz en aumentar los derechos ciudadanos.

Este movimiento que ve su origen el año 2006, en lo que se conoció como la "Revolución de los pingüinos", que fue la que puso por primera vez en serios problemas al popular gobierno de Michelle Bachelet. Se habló de traición contra los estudiantes al conformar una mesa de trabajo que no tuvo mayores efectos, se pudo calmar las aguas por un pequeño lapso de tiempo, pero terminó por "reventar" el año 2011 nuevamente y en consecutivos paros el 2013-2014 y 2015, no con las dimensiones del 2011, pero en el mismo tenor. Con todo, las protestas estudiantiles se transformaron en el punto neurálgico y catalizador de la apertura de un nuevo escenario para la política chilena $\mathrm{y}$ en particular, que ha permitido ir revitalizando un proceso de

\footnotetext{
${ }^{225}$ RAMÍREZ, Álvaro. "Las grietas del modelo chileno frente a los desafíos del siglo XXI". Revista Más poder local, , Nº 8 , 2011. pp. 16-18
} 
democratización desde la ciudadanía que no sólo ha superado la contingencia de la política pública específica (como el caso de la defensa de la educación pública) sino que da cuenta además de un malestar sumergido hasta ahora mucho más profundo, que hace mención de un modelo que ha sido ineficiente, poco inclusivo y nefasto para grandes sectores de la población. $^{226}$

Ahora bien, ¿este "modelo" no fue criticado antes? ¿No se podían prever sus resultados? En realidad, sí ha habido autores que desde mediados de los años noventa han planteado duras críticas a limitaciones de su instalación. En este caso y puesto que ya hicimos mención en el marco teórico a varios de ellos, elegiremos sólo dos para dar cuenta de las críticas tempranas a un modelo que aparecía fracturado. Por una parte el aporte de Luis Maira, socialista, exiliado, abogado y político e investigador de larga trayectoria. También formó parte del segundo gobierno de la transición chilena como Ministro de Planificación. Por otra parte, analizaremos los escritos de Carlos Ominami, economista exiliado y miembro del primer gobierno de la transición. Hemos elegido a dos escritores e intelectuales que además han tenido participación directa en los años noventa para evidenciar que no sólo había intelectuales criticando el modelo, como fue el caso de Tomás Moulian, sino también actores y referentes clave de la política de los años setenta y ochenta.

\subsection{1.- La Transición interminable y sus laberintos.}

Luis Maira en su libro titulado “Chile, la transición interminable” publicado el año 1999, realiza una fuerte crítica al modelo de chileno, en este caso centrándose en lo que denominará el

\footnotetext{
${ }^{226}$ MAYOL, Alberto. Op. Cit. 2013.
} 
"proceso de amarre" que definirá la entrelazada relación existente entre la Dictadura y la transición.

Su análisis parte también de su memoria como político y como los cambios vividos en Chile y Latinoamérica contradecían todo lo presupuestado en los años cincuenta en la región. El despegue productivo y la posibilidad de convertirse en países modernos quedaba enterrado por los golpes de Estado, y las posteriores crisis de fines de los años setenta y comienzo de los ochenta, lo que gatilló el pesimismo en la región. Hay razones para esto, señala el autor, desde 1980 a 1995 se ha duplicado la pobreza (se pasó de 130 millones a 205 millones de pobres), sumado a crecientes problemas de seguridad pública y gobernabilidad en algunas zonas de Latinoamérica, todo pese al aumento del número de democracias. La reinserción internacional no ha sido fácil tampoco, la posguerra y los procesos de globalización y libre mercado han encontrado a varios países a trasmano, debido a la tardía verificación de su desarrollo. Algunos avances -no tan exitosos como se esperaba al inicio- se han gestado, por ejemplo, con el inicio del Mercosur en 1991 entre Brasil y Argentina y unos años después con Uruguay y Paraguay y algunos países asociados como Chile y Bolivia.

Con todo, los años noventa fueron años de reticencias en torno al si seguir replicando modelos foráneos y se prefiere el estudio comparado más que el de casos exitosos, de allí es más fácil vislumbrar errores y corregirlos. Por esto mismo, las grandes ideologías de la izquierda de los años setenta cedieron su paso a pequeñas utopías programáticas, mucho más centrada en los resultados de corto y mediano plazo.

En este contexto, Chile es uno de los países que sufrió transformaciones más radicales, obviamente sin existir oposición alguna se consolidó en dictadura, según Maira, Chile ha vivido 
tres momentos: el Chile republicano, el Chile autoritario y el Chile de la transición. ${ }^{227}$ En este sentido nuestro país no tendría una historia común, sino que presentaría una suma de visiones e interpretaciones que no se encuentran necesariamente, por lo mismo la reconciliación de visiones contrapuestas es inviable mientras existan historias paralelas. ${ }^{228}$

Su tesis se inicia señalando que Chile representó hasta 1973 una larga tradición republicana, renovando sus gobernantes mediante elecciones periódicas, con plazos alterados rara vez y por cuestiones circunstanciales más bien, como el fallecimiento en el ejercicio de algún presidente (como sucedió en 1941 y 1946). En la "Suiza de América" como le denomina en la época algunos historiadores y que recoge Maira, los militares tuvieron tuvo poca influencia y peso político, a tal punto que, aunque si bien se dieron un par de golpes de Estados, estos fueron fuertemente rechazados por la ciudadanía en la década del 30 (como sucedió con Ibañez del Campo y las breves juntas de gobierno que le sucedieron por corto lapso de tiempo).

La economía en este periodo estuvo marcada por la crisis de 1929 y la pérdida del salitre como fuente de financiamiento del erario público y se reorienta a la industrialización por sustitución de importaciones, ${ }^{229}$ a su vez que en la década del 40 -imitando lo que sucedía en Europa- se crea el Frente Popular (Radicales, Comunistas y Socialistas) ${ }^{230}$ que gobernará en tres periodos consecutivos. Los estudios acerca del desarrollo de la región quedan en manos de la CEPAL, que analiza críticamente las condiciones de desarrollo de los países latinoamericano en su condición de espacios periféricos. Con todo, el Chile de los años sesenta proyectaba una imagen distinta, se forjó el mito de la excepcionalidad democrática, anclado en su consistente

\footnotetext{
${ }^{227}$ MAIRA, Luis. Los tres Chile de la segunda mitad del siglo XX. LOM. Chile. 1998.

${ }^{228}$ MAIRA, Luis. Op. Cit.. 1999. p.19

${ }^{229}$ SILVA, Eduardo. "The import substitution model. Chile in comparative perspective", Latin American Perspectives, issue 154, Vol. 34, No 3, 2007. pp. 67-90.

${ }^{230}$ MILOS, Pedro. Frente Popular en Chile. Su configuración: 1935-1938. LOM, Chile, 2008.
} 
estabilidad y el poseer una Fuerzas Armadas guiadas férreamente por la Constitución. A la par se consolidaba de la mano del Estado una mesocracia contundente y un movimiento obrero cada vez más involucrado en la contingencia política.

Los años sesenta en Chile son reconocidos como de mayor tensión. Con el ascenso de la Democracia Cristiana al poder se desarrolla una política de tres tercios, donde la izquierda, la derecha y el centro se quedarán en sus tres espacios con poco margen para negociar entre uno y otro, generando lo que Maira denominará "primacía de lo ideológico. Los acuerdos fueron vistos cada vez más por los militantes de base como concesiones inaceptables por lo que el camino a la crisis del sistema de consolido rápidamente. Esta política, que hacía que llegará al poder aquel que sobrepasase momentáneamente el $30 \%$ de apoyo electoral, pero una vez en el poder, si las otras dos partes lograban cierto grado de acuerdo, podían fácilmente dejar en minoría al ostentador del poder en ese momento. Lo que sucedió a fines de los 60 y comienzos de los setenta es el reflejo de este accionar político como de otros factores más propios del Gobierno de la UP, el rol de la derecha, el apoyo de USA en el contexto de la Guerra Fría y la apabullante y dramática entrada en la arena política de los militares. Hacía 1973, se inicia lo que Maira denominará la "refundación conservadora de Chile."

Lo original del periodo dictatorial, destaca el autor, hay que buscarlo en la idea temprana de buscar un nuevo ordenamiento jurídico que fuese concordante con los intereses y valores que deseaba proyectar en la sociedad con el fin de justificar en el contexto inmediato el Estado Autoritario y luego que perdurasen en el tiempo. A su vez, se fue afianzando la idea de un reordenamiento profundo de la economía de la mano de la naciente ideología de neo-liberal con Milton Friedman y Arnold Harberger quienes visitaron Chile hacia 1975 y conversaron privadamente con el General Pinochet. ${ }^{231}$ En esto Chile será pionero, mucho antes incluso que

\footnotetext{
${ }^{231}$ VALDÉS, Juan Gabriel. La escuela de Chicago: Operación Chile. Ediciones Grupo Zeta. Buenos Aires. 1989.
} 
la Gran Bretaña de Thatcher y los Estados Unidos de Reagan (sobre esto y sus efectos profundizaremos en un capítulo posterior).

Si nos centramos propiamente en la hipótesis del autor respecto a la transición chilena, él establece que el eslabón decisivo para comprenderla es lo que denomina "proceso de amarre." Será por tanto en el campo institucional donde más férreamente habría actuado la Dictadura en relación con su "herencia" para la Democracia a a la chilena. Pinochet habría sido más astuto que otros dictadores latinoamericanos al utilizar el ordenamiento jurídico para hacer valer su hegemonía más allá de su mandato, de hecho será en el breve tiempo que va entre 1989 y 1990 donde logra generar una mayor cantidad de "amarres" o conjunto de reglas y normas legales debidamente coordinadas entre sí, cuyo propósito fue prorrogar los criterios prevalecientes en la Dictadura militar, condicionando a los futuros gobiernos Democráticos. ${ }^{232}$ Un verdadero modelo a la medida de Pinochet, sin fecha de caducidad.

Para Maira, Pinochet tendría similitudes con Franco, al apostar por una resistencia activa contra toda presión internacional, además en ambos casos se consideraban el último bastión de defensa de la cultura de occidente, incluido Estados Unidos, donde se le hacía fácil infiltrar a grupos liberales e incluso del comunismo internacional y sus intereses. Sin embargo, frente a la transición ambos tuvieron distinto actuar -por razones prácticas también, ya que Pinochet se mantuvo con vida- siendo el dictador chileno mucho más hábil para hacer prevalecer sus criterios y visiones en la democracia. De hecho, como lo señala el autor, los asesores estudiaron detenidamente el caso español y su transición con el fin de adoptar un diseño más sistemático con el fin de resguardar los pilares básicos de la sociedad chilena o por lo menos lo que ellos consideraban así.

\footnotetext{
${ }^{232}$ MAIRA, Luis. Op. Cit.. 1999. p.80
} 
Los tres amarres fundamentales señalados por el autor son:

\section{1.- El sistema binominal.}

El sistema binominal es el sistema electoral establecido con el fin de asegurar una fuerte representación a la primera minoría opositora (aliada con la Dictadura). El modelo seguido fue el Polaco de Wojtiel Jaruselski. La idea era dividir al país en distritos de diputados y circunscripciones de senadores que eligen a dos representantes; en este tipo de sistema las mayorías se relativizan, puesto que solo pueden ser elegidos si logran doblar a la primera minoría, caso en el cual la mayoría alcanza los dos cupos parlamentarios; cuestión muy difícil de alcanzar y cada vez más complejo en la medida que hayan más competidores. Por su parte, a las fuerzas políticas que se encuentran por debajo de las dos mayores quedan sin representación por más que sus porcentajes sean representativos (a veces por encima del 20\%). Debido a esto, hasta la actualidad, el sistema fue criticado por la sobre-representación que tenían los partidos de derecha (RN y UDI que con un poco más del 30\% conseguían un diputado o senador), a su vez que existe un claro perjuicio hacia los partidos más pequeños y el propio partido Comunista. $^{233}$

El año 2015, el sistema binominal fue cancelado, no sin fuertes críticas ya que se incrementó de todas maneras el número de representantes al Congreso, justificando que con esto habría mayor representatividad. ${ }^{234}$

\footnotetext{
${ }^{233}$ De todas maneras existen análisis positivos del sistema, véase por ejemplo: CAREY, John. "Las virtudes del sistema binominal." Revista de Ciencia política. (Santiago) [en línea]. vol. 26, No 1. 2006. pp. 226-235 . [fecha de consulta 12 de mayo de 2015] disponible en internet: http://www.scielo.cl/scielo.php?script=sci arttext\&pid=S0718090X2006000100016\&lng=es\&nrm=iso

${ }^{234}$ BCN (Biblioteca del Congreso Nacional). "Nuevo sistema electoral para elecciones parlamentarias (Fin del sistema binominal)" [en línea] 5 de mayo del 2015. [fecha de consulta 12 de mayo de 2015] disponible en internet http://www.bcn.cl/leyfacil/recurso/nuevo-sistema-electoral-para-elecciones-parlamentarias-(fin-del-sistema-binominal)
} 


\section{2.- Los Senadores designados.}

Los senadores designados son un bloque de nueve senadores que eran designados y no elegidos. Entre ellos estuvo desde 1998 el propio Pinochet como senador vitalicio. Dos eran designados por el presidente de la república: un ex ministro de Estado y Un ex rector de Universidad. Otros tres, eran dos ex ministros de la Corte Suprema y un ex contralor general, estos eran designados por la Corte Suprema y finalmente cuatro representantes de los estamentos militares nombrados por el consejo de seguridad nacional. El propósito de este amarre era clave, generar un equilibrio de fuerzas a favor de la Derecha leal a Pinochet. Lo senadores designados fueron terminados en un proceso concluido el 10 de marzo de 2006.

3.- Las normas rígidas para la reforma de la constitución de 1980.

Las normas que señala Maira son variadas pero todas están sustentadas en la rigidez para su modificación, con quórums que van del 60 al 66\% de los senadores en ejercicio (también existen otras leyes denominadas Orgánicas constitucionales que para su modificación requieren los cuatro séptimos de los miembros del Congreso). Obviamente en la actualidad varias de ellas ya no existen, pero es interesante mencionarlas porque marcaron el quehacer de la política durante los primeros años, e incluso pervivieron por varios años más.

Esta "red" constitucional o "malla de contención" como le denomina el autor, ha sido uno de las más importantes cortapisas para el pleno desarrollo democrático de Chile. Entre estas normas se encuentra la denominada Ley Rosende y su efecto sobre la reorganización de la corte suprema, en este caso la misma constitución de 1980 establecía que los miembros de la Corte debían cesar funciones a los 75 años, sin embargo se estableció una clausula a través de una disposición transitoria que permitió que los Jueces se mantuvieran por más tiempo en el cargo. Debido a esto, hacia 1989 algunos miembros de la Corte Suprema bordeaban los 81 años. 
Esto era una oportunidad para que en democracia se renovase la Corte; sin embargo el Ministro de Justicia de Pinochet, Hugo Rosende, presente una propuesta- "triquiñuela" más bien- para que se retirarán varios jueces antes de que se traspasará el poder a Aylwin, por lo que renovó tempranamente la Corte, con jueces favorables a Pinochet. En total se ocuparon 17 nuevas plazas en el máximo tribunal con jueces más jóvenes pero escogidos minuciosamente por el Dictador.

Otras de las normas corresponde al afianzamiento de las ley de amnistía (de 1978) y las competencias del tribunal militar. Esto resultó ser bastante favorable a la Dictadura, por razones obvias, ya que es un tema relevante el de la responsabilidad penal, especialmente cuando los militares siguen en ejercicio. Lo militares hicieron todo lo posible para que los tribunales no investigasen, para lo cual se echó mano a la ley de amnistía, pasando por encima incluso de la comisión de derechos humanos. Con este mismo fin se buscó ampliar la jurisdicción de los tribunales militares.

Por otra parte, también se consolidó el Tribunal Constitucional, que existía previamente pero que se amplió en Dictadura en su composición (paso de 5 a 7 miembros). Uno de los temas que debió revisar el Dictador antes de entregar el poder fue el del artículo $8^{\circ}$ que privaba de derechos políticos a la izquierda, donde debió ceder a partir de un incidente en 1987 con un ex - militante de izquierda que retorna al país (Clodomiro Almeyda). Para que esto no se repitiera - el ver perder al Tribunal constitucional en temas delicados para el régimen- en 1989 Pinochet designó a tres juristas afines y les puso en el Tribunal y afianzó otras tareas que le convenían, como por ejemplo el rol del tribunal en los plebiscitos o el de "tercera cámara negativa" en el Congreso con poder para derogar normas válidamente derogadas. 
En temas políticos Pinochet también pudo mantenerse en el cargo de Comandante del Ejército hasta 1998, lo que lo mantuvo en primera línea durante todos esos años. También decretó la inamovilidad de los funcionarios designados por la dictadura, entre ellos los alcaldes.

Otro capítulo dramático vino dado por la prohibición de investigar al nuevo parlamento establecido en 1990, ya cuando estaba por asumir el nuevo gobierno y la disolución anticipada de los cuerpos de seguridad, lo que en definitiva siguió obstruyendo el "supuestamente" exitoso avance en temas de derechos humanos.

Como hemos visto, salvo el amarre de los senadores designados que tuvo duración hasta el año 2006 a partir de una reforma a la Constitución, recién el año 2015 se inició el proceso de cambio del sistema binominal poniéndose punto final al mismo definitivamente. La Constituían de 1980 sigue vigente, aunque ha sufrido reformas desde el mismo año 1989 hasta el año 2014. Sin embargo, la más relevante, por su profundidad es la del año 2005, con todo sigue estando en la palestra su legitimidad, también hablaremos de ella en un apartado posterior.

Si bien Maira da en el clavo acerca de estos "amarres" y sus impacto en la democracia chilena, existen otros factores tan o más relevantes para el modelo de democracia que tiene Chile, y que son mencionados también por el autor, como son la propia economía y la educación, dos aspectos que hoy en día causan desagrado y malestar en la ciudadanía.

Más allá de los amarres, Maira señala que la Democracia chilena es un verdadero "laberinto." Según el autor, este periodo estaría "entrelazado" con la Dictadura, es más el Chile republicano habría desaparecido para siempre en 1973, por lo que resurgió en 1990 sería más que nada el resurgimiento de un sistema híbrido de democracia/autoritarismo. Esta combinación es la habría hecho que la Transición chilena fuese la más larga de toda Latinoamérica, en contraste a la prudencia mostrada por Patricio Aylwin estaba el apoyo irrestricto de las Fuerzas Armadas 
al aún General Pinochet que también había obtenido un 43\% de adhesión en las elecciones de octubre de 1988, mucho más que cualquier otro militar en el cono sur. En definitiva según el autor, este entramado laberíntico de amarres que conviven con una naciente democracia en los años 90 sostenida por el apoyo de las fuerzas armadas a Pinochet y los logros de la, hasta ese momento, eficiente economía neoliberal (creciendo hasta el 8,1\% anual entre 1990 y 1997). Lo que se ocultaba de este desarrollo y que hacía aún más complejo este entramado eran los elevados niveles de pobreza aún existentes ${ }^{235}$ y los leves avances en derechos humanos y condenas para los involucrados en los excesos y asesinatos, más allá de los informes presentados en el mandato de Aylwin.

Para terminar Luis Maira, analiza los datos de desarrollo de las políticas económicas y sociales y deja en evidencia las dramáticas carencias que tenía el Chile de los años 90, por ejemplo como el $45,1 \%$ de la población se encontraba en situación de pobreza hacia 1987 , de los cuales 17,4\% eran indigentes, cuestión que según Maira -que escribe como representante de la Concertación- habría sido modificado sustancialmente hacia finales de 1996 reduciéndola a la mitad. En este punto, el autor retoma su visión de político y favorece positivamente el actuar de la Concertación durante la Democracia, señalando que habría cambiado sustancialmente lo propuesto en la economía por Pinochet, adoptando una fuerte política de disminución de la pobreza y de una amplia gama de programas sociales. Sin embargo, hoy día y pese a los avances señalados por Maira, Chile sigue siendo uno de los países más desiguales, además de haber profundizado en la privatización, incluida la Educación y la seguridad social, que sigue tal cuál la delinearon los Chicago Boys con Pinochet.

\footnotetext{
${ }^{235}$ MIDEPLAN. Integración al desarrollo, balance de la política social 1990-1993. Mideplan, Santiago. 1994.
} 


\subsection{2.- La verdad incómoda de la Transición (mal) pactada.}

Carlos Ominami es un político reconocido en Chile, casi siempre vinculado a la política contingente y en la actualidad un poco opacado por la fama de su hijo adoptivo Marco Enríquez Ominami, dos veces candidato a la presidencia e hijo biológico a su vez del reconocido militante de la izquierda revolucionaria asesinado en dictadura, Miguel Enríquez.

El ex senador es un político que inicio su vida en la acera de la izquierda más radical en los años setenta, en el MIR, más precisamente. Posteriormente estuvo exiliado en Bélgica y a su regreso a Chile se unió al Partido Socialista de Chile. Además de político fue reconocido economista de izquierda al hacer análisis más reformados acerca de lo que debía suceder tras la salida de Pinochet, siendo parte incluso del consejo coordinador de economía en 1989, llegando a ser Ministro de Economía del Presidente Aylwin entre 1990-1992.

Luego va a ser senador de la república y el año 2009 se retira de la Concertación para apoyar la candidatura de su hijo, Marcos Enríquez Ominami. Con todo ha seguido vinculado a la exconcertación, actual nueva mayoría, de hecho el año 2014 fue convocado en el comité asesor en la demanda de Bolivia en la Haya.

Al igual que Maira, Carlos Ominami, ha realizado escritos bastante críticos acerca de la propia Transición donde participó, escribiendo importantes documentos de análisis acerca de dicho problema. Uno de ellos titulado "Chile: una transición paradojal. Notas para un examen crítico"236 que forma parte de un libro acerca de un análisis de los 20 años de la Concertación.

\footnotetext{
${ }^{236}$ OMINAMI, Carlos. “Chile: una transición paradojal. Notas para un examen crítico.” En: QUIROGA, Yesko y ENSIGNIA, Jaime. (Ed). Chile en la Concertación (1990 - 2010). Una mirada crítica, balance y perspectivas. Tomo II. Friedrich Ebert Stiftung, Santiago. 2010. pp. 21-62.
} 
El otro es parte de un escrito biográfico, publicado el año 2011, titulado "Secretos de la Concertación., 237

El autor explica en sus escritos las dificultades que se habría tenido al originarse el proceso de transición, lo que él llama, paradojas y que habrían marcado el quehacer actual al grado de señalar que la crisis “actual” (refiriéndose al 2011, año de muchas movilizaciones sociales) se debe a una crisis política enraizada en las malas negociaciones realizadas en el periodo de transición a la democracia.

El punto clave, según el autor, se encuentra en la negociación constitucional realizada entre 1988 y 1989 entre las fuerzas democráticas y la dictadura, en la cuál habría quedado claro que Carlos Cáceres, el representante de Pinochet, miraba a sus oponentes como débiles negociadores, que no fueron capaz de imponer la fuerza que la ciudadanía había hecho notar en la urnas, sacando a Pinochet del poder.

Esta negociación tendría una mezcla de debilidad e ingenuidad por parte de la Concertación. De debilidad al aceptar que la Constitución de 1980 se mantuviera en vigor, sin ser capaz de llamar a cambiarla radicalmente e ingenuidad al mantener en la carta fundamental disposición que afectarían su propio quehacer en democracia, como por ejemplo la mantención de los senadores designados que hacía difícil la aprobación de leyes ordinarias aún teniendo mayoría. Un punto importante destaca Ominami al señalar que si bien no hubiese afectado a los grandes cambios Constitucionales, sí podría haber servido para derogar, por ejemplo, la ley de amnistía que protegía a los violadores de los derechos humanos.

En este mismo plano, el Gobierno entrante renunció a la posibilidad de disolver la cámara de diputados, aunque sea una vez, como sucede en otras naciones, y que es muy útil como medida

\footnotetext{
${ }^{237}$ OMINAMI, Carlos. Secretos de la Concertación. Recuerdos para el futuro. La Tercera Ediciones. Santiago. 2011.
} 
de presión para imponer puntos de vista a la oposición. Toda la negociación, terminó finalmente a mediados de 1989 con un plebiscito bastante poco informado a la ciudadanía y con las promesas de la derecha, especialmente del Andrés Allamand (Renovación Nacional) de que aportarían con sus votos para quitar todo resabio de la Dictadura en la Constitución, cuestión que obviamente no sucedió.

Se pecó de inocente también a tal punto que se pensó que el equilibrar la balanza mediante el ingreso de uno de los miembros de la Concertación al Congreso como senador designado podría ayudar a destrabar avances en la democracia. Como sucedió con uno de los principales negociadores de este pacto, como era Edgardo Boeninger que ejerció como senador designado entre 1998 y el 2006. Se justificaba este ingreso como un acto de pragmatismo y de equilibrios de fuerzas, que nunca se concretó. De esta manera se renunció durante años al ideario de la Alianza Democrática de 1983 de dotar al país con una nueva Constitución mediante una asamblea constituyente una vez retornada la Democracia.

Toda esta autocrítica del proceso negociador el mismo Ominami, como parte de la Concertación, la refiere al Chile modélico cuando señala que: "Ignorando las originalidades de su proceso, Chile fue interesadamente trasformado en un modelo susceptible incluso de ser exportado internacionalmente. La transición generó así una espectacular imagen internacional, fundamento de lo que posteriormente algunos le adjudicarían como "liderazgo conceptual.,"238 Esta imagen creada "interesadamente", como señala el mismo autor, esconde otras dimensiones más oscuras y polémicas, como veremos en capítulos posteriores y de los que se habla mucho menos, porque empañarían la imagen modélica que difundió durante los primeros años la

\footnotetext{
${ }^{238}$ OMINAMI, Carlos. Op. Cit. 2010. p. 25.
} 
Concertación y que se instaló finalmente como “imagen-país”. Sin embargo, este liderazgo iniciado en los 90 hay que entenderlo más como conceptual (imaginario) que concreto.

\section{3.- EL VERDADERO MODELO.}

Como hemos visto y han señalado a su vez actores claves de la Transición, ésta ha sido definida en general como exitosa, pero incluso han ido más allá y la han consagrado un modelo, uno de tipo conceptual o, como señala Moulian, más bien la han convertido en un mito. ${ }^{239}$ Es cierto que nuestra transición comparte similitudes con los casos sistémicos o "desde arriba" planteados por la politología, lo que la hace compartir hitos con la transición española o brasileña, por ejemplo. Pero también tiene importantes diferencias en la teoría y la práctica.

Nuestra transición no se produjo por la caída de los militares, ni por un golpe de una facción militar o por un conflicto interno violento, ni menos por efectos de una reforma negociada entre militares y civiles, como aconteció en Argentina, Grecia, Portugal, Nicaragua o Uruguay. ${ }^{240}$ Tampoco fue como el caso español, como efecto de la muerte de Franco en 1975 que generó un realineamiento político; en estricto rigor, en Chile no hubo una ruptura pactada como lo explica Linz para el caso de España. ${ }^{241}$

Nuestro país vivió una situación "sui generis" al tener que lidiar con el dictador vivo y en el poder por lo menos hasta 1998, año de su detención en Londres. Pese a que España se desenvolvió a partir de las normas heredadas del franquismo (desde un sistema político de leyes

\footnotetext{
${ }^{239}$ MOULIAN, Tomás. Contradicciones del desarrollo político chileno. 1920-1990. LOM-Arcis. Santiago. 2009. p. 117.

${ }^{240}$ GARRETÓN, Manuel Antonio. "Revisando las transiciones democráticas en América Latina". Revista Nueva sociedad. Chile, 1997.

${ }^{241}$ LINZ, Juan J., "La transición española en perspectiva comparada". En TUSELL, Javier y SOTO, Álvaro (eds.), Historia de la transición 1975-1986, Alianza Universidad, Madrid. 1996.
} 
orgánicas hasta la Constitución de 1978 que establecería la monarquía democráticoparlamentaría), no hubo un bloqueo efectivo como sí se dio en Chile (en el caso español contribuyó la presión por entrar en la Europa comunitaria). En realidad, lo reseñable del modelo chileno no está en sus "logros" sino más bien en sus "imperfecciones"; en otras palabras, su éxito radica en el triunfo de los militares por imponer una democracia limitada o "protegida", pero a su vez en consolidar una economía de mercado de carácter neoliberal.

La democracia chilena, sin embargo, fue pacífica y allí también reside uno de sus logros principales. De hecho el Partido Comunista, una vez retornada la democracia, volvió a la arena política - aunque en condiciones desmejoradas de competencia obviamente- y pudo participar desde 1990 en las elecciones parlamentarias. Según Moulian, el "modelo" es más bien fruto de los errores cometidos por la oposición a Pinochet entre los años 1980 y 1986. En este periodo se habría perdido la posibilidad de llevar adelante una transición mucho más democrática si se hubiese continuado con la idea de no aceptar la Constitución de Pinochet; sin embargo la lucha entre facciones al interior de la oposición terminó por ceder ante la presión por generar un cambio, llegando al punto que se aceptaron las reglas del juego impuestas por la dictadura, las cuales consistían en seguir el itinerario de la Constitución de $1980 .^{242}$

El modelo impuesto por Pinochet es en apariencia tranquilo y ejemplar, cuenta con una dinámica que favorecía el bloqueo de la democracia -ya mencionamos por ejemplo lo señalado por Luis Maira acerca de los amarres constitucionales-; sin embargo, también existen otros factores culturales y políticos que hacen de este modelo algo mucho más complejo que nos hace pensar que el camino jurídico, por sí solo, no sería suficiente para desmantelarlo.

\footnotetext{
${ }^{242}$ MOULIAN, Tomás. Op. Cit. 2009. p. 120.
} 
En primer lugar, hay aspectos institucionales que impedirían que la democracia se profundice; estos aspectos están mediados por la Constitución de 1980 que aunque suavizados en el inicio de la democracia - gracias a las reformas electorales- siguieron generando que en Chile existiera una democracia representativa imperfecta, gracias al sistema binominal que distorsionaba la representación de ciertos partidos políticos, pero también a la continua sombra del dictador que permanecía en el poder.

Un caso emblemático de esta presión constante sobre el andamiaje institucional será el denominado "Ejercicio de enlaces" acontecido en septiembre de 1990. Este "ejercicio" que fue más bien un movimiento de tropas o acuartelamiento de nivel uno, sirvió como amenaza al Gobierno, debido a que se habían comenzado a investigar varios casos en los que estaban envueltos familiares de Pinochet y el mismo ejército (el caso de su hija con su yerno, el del ejército y una financiera ilegal, y el de su hijo en lo que se denominó "pinocheques"). ${ }^{243}$ Esta demostración de fuerza de Pinochet y su poder sobre el ejército, paradojalmente no fue debido a los cuestionamientos por la violación de los Derechos Humanos y su judicialización. Al parecer en ese campo se sentía intocable; su reacción más bien se produjo cuando vio involucrada a su familia en el esclarecimiento de ilegales cometidas al amparo de la dictadura. Queda claro con esto que la institucionalidad vivió en amenaza cierta durante los primeros años del post-pinochetismo, pero además el terror al retroceso sería una constante utilizada por la oposición para mantener la "prudencia" en años posteriores. Peter Siavelis analizó este problema demostrando cómo en el medio plazo esta capacidad de acción política real que tuvieron los militares los convirtió en actores políticos convencionales. ${ }^{244}$

\footnotetext{
${ }^{243}$ BOENINGER, Edgardo. Op. Cit. 1998. p. 408-409.

244 SIAVELIS, Peter. The presidente and congress in postauthoritain Chile: Institutional contraints to democratic consolidation. Penn State University Press. USA. 2000.
} 
Otra de las características que sustentó las deficiencias del modelo o, más bien, le otorgaron su propia identidad, fue cómo se consolidaron los actores políticos, en especial los de oposición al gobierno democrático. De hecho, el mantenimiento de los militares como actor político en gran parte es debido a que la propia derecha o derechas existentes otorgaban espacios a las pretensiones políticas de Pinochet y le avalaban.

El que la Constitución demarcarse un camino tan difícil para hacer prosperar leyes que fuesen en sentido contrario llevó al Gobierno a que su accionar fuese fundamentalmente un compromiso constante. A esto se le denominó -y denomina hasta hoy- la "política de los acuerdos", en contraposición con la "retroexcavadora", reclamada por algunos políticos de la Concertación ya en los 90, pero nunca llevada a efecto.

Los "acuerdos" fueron entonces un "win-win" ya que evitaban que la Concertación se entrampase y la derecha aparecía como colaboradora. A esto habría que sumarle el aparente juego político y su competencia, ya que en la práctica el tercio de la derecha aparecía como "protegido" y apuntalado además por los senadores designados. Por su parte la izquierda, principalmente el Partido Socialista, fue un contrapunto a la Democracia Cristiana en el poder, promoviendo algunos cambios importantes - o avances- en legislación laboral y social. Eso sí, esta izquierda debió convertirse antes en una "nueva izquierda", lo que sucedió con el PS en 1980 que marcó un quiebre con la evolución del mismo partido en las décadas anteriores: así se pasó del marxismo renovado a una tipo de social-liberalismo. Esta izquierda encontrará su ícono en Ricardo Lagos, quien se acercó tanto a los empresarios que para algunos no termina de distinguirse de cualquier otro gobernante de derecha. ${ }^{245}$

\footnotetext{
${ }^{245}$ CLAUDE, Marcel. El retorno de Fausto. Ricardo Lagos y la concentración del poder económico. Ediciones Política y Utopía, Santiago, 2006.
} 
En este sentido, se entiende que el modelo "ataviado" por una parte por la legislación presente en la Constitución, el empoderamiento de los militares y con una derecha confabulada con ella y favorecida por el sistema electoral, haya sólo realizado avances que podríamos denominar minimalistas en su primera etapa. Sin embargo, la pervivencia y profundización de un tipo de democracia es causa más bien del reacomodo de la izquierda y su “derechización”. A esto habría que sumar un último factor, el cambio cultural. En este sentido hasta los años sesenta la sociedad había consolidado un modus vivendi que favorecía el fortalecimiento del espíritu societal, que canalizó las demandas de la sociedad y evitó en varios momentos la quiebra del sistema. Durante la dictadura, en cambio, lo anterior se habría ido desmedrando, sustituido por un ánimo mercantilizador e individualista donde el mérito es el slogan más fuerte y que traspasó hasta la democracia. Una sociedad de consumo y consumidores, de clientes más que de ciudadanos, donde el hedonismo adquisitivo fue tomando preeminencia y en el cual la buena vida se asocia con logros materiales.

En este sentido, habría triunfado la "revolución silenciosa", ${ }^{246}$ aquel libro publicado en dictadura que celebraba la ideología neoliberal "a la chilena". Así, el modelo de transición y democracia estaría más bien basado en ese modelo de sociedad, política y economía que en el de las democracias competitivas planteadas por los politólogos norteamericanos. En el siguiente apartado profundizaremos un poco más en los márgenes de actuación de este Chile heredado de la dictadura.

\subsection{1.- Chile ¿Una democracia con apellido?}

Puede parecer simplista pero la necesidad de entender la democracia chilena con un "apellido" -democracia protegida, democracia incompleta, democracia limitada, etc.- nos lleva a pensar

\footnotetext{
${ }^{246}$ LAVIN, Joaquín. La revolución silenciosa. Editorial Zig-Zag. Chile 1987.
} 
necesariamente que sus características la hacen algo distinta a otras. Puede ser entendible que se busquen explicaciones politológicas a su desarrollo previo, denominando y ubicando a su transición dentro de alguno de los modelos más conocidos, como la de transiciones pactadas, negociada, por transacción, ${ }^{247}$ etc.

Es cierto que alcanzar un democracia ideal, que cumpla con todos los requisitos propuestos por los diversos autores es casi imposible, por lo que sólo queda la opción de acercarse lo más que se pueda a ese ideal. En el caso chileno, ese ideal esta distorsionado por el interés de los ideólogos de la dictadura, en el sentido que la democracia que se quiere alcanzar es a todas luces única, una democracia liberal, sin libertades, moralista en muchos sentidos -es evidente su similitud con el modelo autoritario portaliano que consideraba a los ciudadanos como incapaces de ejercer sus derechos ${ }^{248}$ - bajo una economía neoliberal que promueve su propio modelo, aperturista y libre, una contradicción política-económica.

Este modelo de democracia surge, desde nuestro punto de vista, no sólo de la configuración hecha por Pinochet y sus asesores- especialmente Jaime Guzmán- sino de la propia convicción que se irá generando en los miembros de la oposición y que se va desarrollando en el transcurso de los años ochenta -como vemos más adelante- y que va creando un estado de opinión acerca del potencial del modelo económico y el funcionamiento de la constitución, que terminarán por aceptar.

\footnotetext{
${ }^{247}$ MAINWARING, Scott; O'DONNEL, Guillermo; VALENZUELA, J. Samuel. (Eds). Issues in democratic consolidation: The new south american democracies in comparative perspective. University of notredame press. Notre Dame. 1992.

${ }^{248}$ BRAVO LIRA, Bernardino. "La Constitución de 1833" Revista Chilena de Derecho, (2): mayo-agosto de 1983. pp. $217-$ 329; HEISSE GONZÁLEZ, Julio.. "Del autoritarismo al régimen parlamentario" Revista Chilena de Historia y Geografía, (138). 1970. pp. 140-174.
} 
En este caso funcionarán eficientemente los "pactos de élite",249, entendidos como los "amplios compromisos previamente acordados entre las facciones enfrentadas de la élite, lo que resulta en la estabilidad política y proporciona una condición necesaria para la práctica sostenida de la democracia representativa" ${ }^{250}$ que ponen en evidencia que no sólo fueron amarres constitucionales los que convirtieron la democracia chilena en un modelo único, sino que también las decisiones estratégicas de la oposición con el fin perpetuarse en el poder liderado por los "tecno-pols" legitimando y manteniendo la democracia de Pinochet en base a su desempeño y rendimiento. ${ }^{251}$

Llama la atención que los "consensos" alcanzados por los políticos en los primeros años de la democracia hayan sido también limitados y centrados o en aspectos económicos o en algunas aristas políticas, pero se pasan por alto cuestiones centrales como los derechos humanos o el acuerdo constitucional, dejando de lado el discurso de la "aplanadora" utilizado solo meses antes de asumir el nuevo presidente de la democracia chilena, para asumir un discurso de acuerdos que buscaba la "estabilidad". Por otra parte, muchos acuerdos declarados “transitorios" terminaron por convertirse en permanentes, lo que daño aún más la propia democracia, cuando las manifestaciones sociales comenzaron aponerlas en evidencia, por ejemplo el sistema binominal y el cambio constitucional definitivo. Es evidente que es necesario que existan acuerdos durante la primera etapa de democratización, pero cuando ellos se mantienen en el tiempo perjudican la calidad de la democracia, como lo propone Bartolini. ${ }^{252}$

\footnotetext{
${ }^{249}$ HIGLEY, John. "Elite Theory in Political Sociology". Paper IPSA. 2008; JOIGNANT, Alfredo y GÜELL, Pedro (ed.). Notables, tecnócratas y mandarines. Elementos de sociología de las elites en Chile (1990-2010). Ediciones Universidad Diego Portales Santiago de Chile. 2011.

${ }^{250}$ HIGLEY, John y BURTON, Michael. “Elite Settlements”.American Sociological Review, Vol. 52, No 3. Jun 1987. pp. 295-307.

${ }^{251}$ HUNEEUS, Carlos. La democracia semisoberana: Chile después de Pinochet. Editorial Taurus. Chile. 2014.

${ }^{252}$ BARTOLINI, Stefano. "Collusion, competition, and Democracy. Part I." Journal of theorical politics. Vol. 11. N ${ }^{\circ}$ 4. pp. $435-470$
} 
Alan Angell señala respecto a esto, que para entender el Chile actual se debe reconocer que existe una "democracia incompleta" en el sentido que incorporó un modelo que no se fue “ajustando" a la realidad del país, quedando tempranamente obsoleto. ${ }^{253}$ El gran problema para este análisis es que, como hemos visto, no es posible hablar de una democracia completa, todas, unas menos u otras más poseen limitaciones o poseen más o menos distorsiones. Sin embargo lo que ha hecho de Chile un caso único, es que estas "distorsiones" se convirtieron en la regla y se han mantenido por más de veinte años.

Debido a esto, se puede señalar que la democracia en Chile sería más bien el resultado de la continuidad del modelo Pinochet, que incluiría un compromiso ideológico con algunos aspectos clave de las políticas sociales y económicas que han hecho de su pervivencia un aspecto atípico para una democracia que debería haber avanzado a su mejora. Como veremos unas páginas más adelante, en el largo proceso que va desde fines de los 70 a comienzos de los 90 el modelo neoliberal y la democracia protegida se fue convirtiendo en un dogma político casi uniforme en Chile. $^{254}$

\section{4.- DE LA REVOLUCIÓN SILENCIOSA A LA DEMOCRACIA.}

No bastó con tener el poder total por parte de los militares, sino que había que cambiarlo todo, no se trataba sólo de reponer a la oligarquía sino de hacer un cambio institucional mucho más

\footnotetext{
${ }^{253}$ SEHNBRUCH, Kirsten y SIAVELIS, Peter. El balance: política y politicas de la concertación 1990-2010. Editorial Catalonia. Chile. 2014. pp. 11-17

${ }^{254}$ Véase por ejemplo: WINN, Peter. (Ed.) Victims of the chilean miracle: Workers and neoliberalism in the Pinochet era. 1973-2002. Duke University. London. 2004.
} 
profundo. ${ }^{255}$ Ésta fue la premisa que quedó patente en la temprana Declaración de Principios publicada el 11 de marzo de 1974 y que señalaba categóricamente que:

"Después de largo tiempo de mesianismos ideológicos y de la prédica de odios mezquinos, el Gobierno de las Fuerzas Armadas y de Orden, con un criterio eminentemente nacionalista, invita a sus compatriotas a vencer la mediocridad y las divisiones internas, haciendo de Chile una gran nación. Para lograrlo, ha proclamado y reitera que entiende la unidad nacional como su objetivo más preciado, y que rechaza toda concepción que suponga y fomente un antagonismo irreductible entre las clases sociales.

La integración espiritual del país será el cimiento que permitirá avanzar en progreso, justicia y paz, recuperando el lugar preponderante que los forjadores de nuestra República le dieron en su tiempo dentro del continente. Reivindicar y sembrar en el corazón de cada chileno el ejemplo de nuestra Historia Patria, con sus próceres, héroes, maestros y estadistas, debe transformarse en el acicate más poderoso para despertar el verdadero patriotismo, que es amor entrañable a Chile y deseo de verlo nuevamente grande y unido. Conspiran en contra de esa unidad las ideologías foráneas, el sectarismo partidista, el egoísmo o antagonismo deliberado entre las clases sociales, y la invasión cultural extranjerizante.

(...) En la tarea de convertir a Chile en una gran nación, el Estado deberá ir diseñando un "Proyecto Nacional", entendido como una imagen factible y deseable para la República, mirando su evolución a largo plazo y considerando la utilización eficiente de nuestras potencialidades reales."256

\footnotetext{
${ }^{255}$ GOICOVIC, Igor. "La refundación del capitalismo y la transición democrática en Chile (1973-2004)." HAOL, № 10 Primavera, 2006. pp. 7-16.

${ }^{256}$ PINOCHET, Augusto. Declaración de Principios del Gobierno de Chile. Edición Oficial. 11 de marzo de 1974
} 
Esto se reiterará en el Plan Nacional y en el discurso presidencial de 1975 de Pinochet. ${ }^{257}$ Sin embargo y pese a los grandes esfuerzos por "blanquear" la imagen de Pinochet en el exterior, el triunfo más relevante vendrá desde el plano económico y su penetración en la sociedad, lo que en el mediano plazo será lo que generará el verdadero cambio cultural de la sociedad chilena. Esto va a quedar graficado en la serie de escritos que los “Chicago Boys" publicarán durante los años ochenta mostrando incesantemente el triunfo de la política monetarista -como se le llamó inicialmente- o del neoliberalismo, como se le conoce en la actualidad. ${ }^{258}$

Un libro aparecido en 1987, con un lenguaje menos tecnicista resume bastante bien el logro de la dictadura que se perpetuará en democracia: La Revolución Silenciosa -como se titula el libro escrito por Joaquín Lavín- que habría triunfado por sobre la Revolución “con empanadas y vino tinto" de Salvador Allende.

El autor será muy relevante en la democracia, economista (realizó su maestría en Chicago), miembro del Opus Dei y un actor político de la derecha (UDI); alcalde, senador, Ministro y candidato a la Presidencia que plasmó las ideas del régimen y su herencia tempranamente. El libro fue ampliamente difundido por el Régimen militar y se dice que alcanzó una venta de más de 114 mil ejemplares. Con base en las publicaciones del periódico afín a la dictadura como era el Mercurio, La revolución silenciosa es un ensayo que permite asomarse a cuál fue la motivación de Lavín en aquellos tiempos y a qué se debió su desempeño como Ministro de Educación en el gobierno actual, sin mostrar algún tipo de evolución respecto a sus criterios y principios de antaño. El ensayo basa gran parte de la información en el Centro de Documentación de la empresa "El Mercurio" de la época y el libro éxito de ventas de John

\footnotetext{
${ }^{257}$ PINOCHET, Augusto. Mensaje Presidencial: 11 septiembre 1975-11 septiembre 1976: S.E. el Presidente de la República General de Ejército Augusto Pinochet Ugarte informa al país. BCN. Chile. 2006.

${ }^{258}$ CARRASCO, Camilo, VIAL, Álvaro, BARDÓN, Álvaro. Una década de cambios económicos: la experiencia chilena : 1973-1983. Editorial Andrés Bello. Chile. 1985.
} 
Naisbitt titulado Megatrends ${ }^{259}$, que anunciaba en diez puntos el éxito que podía alcanzar USA si se preocupaba de su desarrollo, el acceso a las tecnologías y la conectividad que traía la globalización, y los cambios en los clientes/ciudadanos que comenzaban a reclamar nuevos “derechos."

Con estas bases, más los datos que la segunda etapa de la implementación neoliberal había logrado (la primera no había sido tan exitosa) su libro se estructura en los siguientes once capítulos: 1) Las tendencias de la revolución silenciosa; 2) Integración al mundo; 3) Made in Chile; 4) Nuevos polos de desarrollo; 5) El Chile informado; 6) La empresa eficiente; 7) El gobierno se acerca; 8) "Clientización” de la economía; 9) Los nuevos negocios del sector privado; 10) Profesionalización al combate a la pobreza; 11) La sociedad de las opciones.

Los temas son bastante transversales y siguen la lógica de los "diez puntos" del autor norteamericano y van desde una especie de "modelo" de desarrollo que estaría siguiendo Chile con éxito, pasando por los temas de inserción internacional, la explotación de los recursos, la conversión del ciudadano/cliente y sus beneficios, hasta la educación vinculada al mérito y la competencia, los modelos de emprendimiento y los futuros liderazgos. Estos temas, puestos en actualidad parecen bastante contingentes -como veremos a continuación- y delinean con bastante claridad lo que es el Chile de hoy.

En su primer capítulo, el libro deja en claro que la Dictadura lo ha hecho bien ¿En qué se basaría su autor para afirmar tal cosa eso? En que la gente ahora es libre...para comprar, principalmente.

"Los chilenos comienzan paulatinamente a vivir con muchas más opciones que en el pasado. La sociedad de "esto o el otro", con dos o tres alternativas como máximo, ha sido superada por

\footnotetext{
${ }^{259}$ NAISBITT, John. Megatrends: Ten New Directions Transforming Our Lives. Warner Books / Warner Communications Company. USA. 1982.
} 
una nueva sociedad de "opciones múltiples", en que es posible elegir entre las más diversas posibilidades. Una dueña de casa que entraba a comprar a un supermercado Almac en 1974, podía elegir entre 5.500 productos diferentes. Hoy sus posibilidades de opción alcanzan a 15.500 ítems distintos." 260

La verdadera tarea estaba cumplida entonces, porque aunque la gente no pudiese elegir a sus representantes sí podía comprar mejores autos o simplemente tener la opción de comprar productos de "afuera" que antes no se podía. La sensación de bienestar económico era lo más relevante.

En el segundo capítulo deja en claro también que el Chile del mañana debía reconocer que su futuro estaba en la venta de sus materias primas en el exterior, porque la interdependencia era una "megatendencia" en la cual ni USA ni la URSS quedarían fuera. Así Chile mediante "una fuerte reducción de las tarifas aduaneras y el fomento a las exportaciones, se integró para compartir con el mundo no sólo productos que compramos y vendemos, sino también tecnología, cultura e información." ${ }^{261}$ En la práctica, lo anterior ha significado vender barato las materias primas y hacer depender el presupuesto de la Nación en gran parte de la venta del cobre y sus vaivenes, y por lo mismo subordinar el resto de las políticas sociales a sus presupuestos. El autor también destaca los increíbles beneficios de la apertura del mercado para la sociedad chilena, que ha impactado fuertemente el vestir -con el bluejeans y la zapatilla- y saluda positivamente el que algunas industrias nacionales se hayan beneficiado también con el descenso del dólar para traer maquinaria moderna. Sin embargo, omite que la mayoría de la industria ya había desaparecido debido a la escasa competitividad que tenía frente a productos de bajísimo precio importados del exterior, como sucedió por ejemplo con la industria zapatera.

\footnotetext{
${ }^{260}$ LAVIN, Joaquín. Op. Cit. pp. 24-25.

${ }^{261}$ LAVIN, Joaquín. Op. Cit. p. 28.
} 
Algo parecido señala en el capítulo titulado Made in Chile, al destacar los avances en la explotación del subsuelo, de los suelos agrícolas y de la naturaleza. Obviamente en ese momento no era un tema relevante -ni lo es aún en gran medida- el daño medioambiental. Se destaca la exportación no tradicional como el Kiwi, y lo que el autor llama el "nuevo cobre", como es la madera. Para Lavín, los logros y éxitos están vinculados a la privatización, como sucedió con el sector portuario gracias a las dos "espectaculares" medidas tomadas en 1981, como serán el término de los monopolios laborales y la incorporación del sector privado a realizar funciones hasta ese entonces privativas de la Empresa Portuaria de Chile.

Por otra parte, la gran transformación de Chile estaría en la "eficiencia" que imprime el que un grupo de ingenieros asuma tareas fundamentales de la nación. La tarea fundamental es "desempapelar" a Chile quitando la burocracia y creando sistemas informáticos de entrega de información en el sector público. En el fondo esto se tradujo, obviamente, en la disminución del aparato estatal y por lo mismo en puestos de trabajo vinculados al Estado.

\footnotetext{
"Menos papeles, menos trabas burocráticas y... también, menos funcionarios públicos: entre 1977 y 1986, el número de personas que trabajan para el Estado disminuyó en 208.963. Esto significa que de cada diez funcionarios, más de seis han debido emigrar al sector privado." 262
}

El objetivo final es, como lo señala en el mismo texto, incorporar el modelo empresarial norteamericano y la subcontratación. De esta manera, en la medida que llegan cada vez más multinacionales estas van absorbiendo el trabajo de baja cualificación, especialmente en el sector servicios. En la actualidad el "Retail" y el "Mall" es donde hay mayor cantidad de mano

\footnotetext{
${ }^{262}$ LAVIN, Joaquín. Op. Cit. p. 108.
} 
de obra "subcontratada" y con las peores condiciones laborales. ${ }^{263}$ Además, la subcontratación es la forma en que más se "contrata" en Chile; de esta manera se evita pagar directamente la seguridad social cuando existe, o dejar "amarrada" a la empresa a personas por largos periodos bajando los costos. Todo esto, junto con el plan laboral de 1979 que disminuyó -o casi hizo desaparecer- el poder de organización de los trabajadores, ha hecho que los trabajadores de Chile estén desprotegidos.

Otros de los grandes logros de la dictadura, según Lavín, han sido los mall, estos enormes centros comerciales que han creado toda una cultura del "paseo"- compra, donde se tiene acceso a todo tipo de productos en un entorno de calidad y tranquilidad, a condición que se tenga con qué comprar o alguna mínima capacidad de endeudarse. Como analizará posteriormente Tomás Moulian en su famoso ensayo "El consumo me consume", en que se refiere de manera indirecta al Chile democrático, la dictadura nos habría cambiado desde dentro:

"Este capitalismo dotado de una gigantesca capacidad productiva, necesita instalar en las subjetividades el consumo como deseo. Pero como abomina de la posible morosidad de este deseo, de la tendencia a cocerse a fuego lento, también busca instalar, en el interior de cada uno, los impulsos voraces hacia el consumo, la actitud hedonista.

(...) Efectivamente, el capitalismo actual requiere la instalación de la pauta cultural del consumo como deseo hedonista. De otro modo, ¿qué haría con su enorme capacidad productiva?"264

\footnotetext{
${ }^{263}$ Véase por ejemplo: RAJEVIC, Enrique. "La precarización del empleo público en Chile y el mito de la carrera funcionaria" V Encuentro Anual de la Sociedad Chilena de Políticas Públicas, 16 de enero de 2014 o los estudios que respecto al tema tiene la Fundación SOL en: http://www.fundacionsol.cl/estudios/

${ }^{264}$ MOULIAN, Tomás. Op. Cit. 1998. pp. 22-25.
} 
Esta cosificación que habría producido el trabajo desprotegido, la necesidad de comprar y la ilusión que provocan estos "oasis" del consumo han generado un verdadero cambio cultural en el chileno promedio de la actualidad:

"Chile, por ejemplo, tiene mala distribución de ingresos y altas tasas de crecimiento económico. Pese a esta disparidad no se han producido protestas globales de los sectores más afectados, ni se vive entre medio de manifestaciones constantes. La sociedad parece haberse habituado al orden neoliberal, originado en una dictadura sangrienta. En otros países, el ajuste neoliberal ha generado acciones de rebeldía y reventones plebeyos, explicables porque parte importante del proceso ha tenido lugar en el periodo postautoritario. Las rebeliones en las provincias argentinas o el "caracazo" venezolano son un ejemplo de lo dicho"265.

Es cierto que a partir del año 2006 se han levantado los estudiantes en protestas por la mala calidad de la educación; sin embargo, el resto de la población aún aparece aletargada, sin darse cuenta del nivel de endeudamiento con el que se vive ni la presión por consumir que existe en el país. Chile, por ejemplo, es uno de los países que lidera la compra y expansión de móviles con una penetración de la telefonía móvil de 125\%, superior a la de Latinoamérica en su conjunto $(110 \%)$.

El modelo de profesionales también es propuesto por Lavín en su escrito de 1987 como el de un emprendedor, con lo cual lo vincula a esta tendencia mercantilizadora, e incluso va más allá situando a una ONG como el modelo empresarial a replicar (el del Hogar de Cristo) al implementar la subcontratación en sus actividades, así se ha llegado a profesionalizar el combate de la pobreza, sin que lo tenga que hacer el Estado, obviamente. Para que hablar de la protección social, de ella señala Lavín que: "El Estado se bate en retirada. La empresa privada

\footnotetext{
${ }^{265}$ MOULIAN, Tomás. Op. Cit. 1998. p. 45.
} 
lo está reemplazando en áreas que hasta hace poco parecían inexpugnables: la previsión privada, la salud privada y la educación privada, son ya un hecho de la vida diaria, dando impulso a nuevas industrias que mueven miles de millones de pesos."266 Este sería el espacio para estos profesores empresarios, médicos empresarios y recolectores como empresarios, etc. Cuestión que ha pasado en parte, ya que tanto en salud como en educación lo que más prolifera son grandes sociedades anónimas o empresarios sin conocimiento específico del área que invierten, más que el capital y la rentabilidad que pueden sacar de dichos emprendimientos.

Para terminar Joaquín Lavín hace un análisis acerca de quiénes son aquellos hombres que deben liderar este modelo de país.

\begin{abstract}
"Nos acostumbramos a un país líder en la producción de cobre, pero no conocíamos a un Chile primero en el mercado mundial de la uva, o primero en cuanto a superficie plantada de pino radiata. Sabíamos que Codelco era una gran empresa que se codeaba a nivel mundial con los otros gigantes del mercado, pero no lográbamos dimensionara David del Curto como la frutera más grande del hemisferio sur, o a Sonda como la mayor multinacional de la computación en Latinoamérica."267
\end{abstract}

Chile es un país líder y se estaría transformando en un país de líderes, un discurso muy parecido al optimismo de los primeros años de la democracia, cuando se hablaba del milagro chileno, los ingleses de Latinoamérica o del jaguar de Latinoamérica. ${ }^{268}$

En resumen, la propuesta de la dictadura graficada en el libro de Joaquín Lavín recoge justamente el triunfo de un modelo que se verá perpetuado en la democracia, que va más allá de lo jurídico, electoral o político; que penetró en lo cultural y social creando una "democracia" con tintes particulares, donde el ciudadano se siente poco partícipe, o que más bien vive una

\footnotetext{
${ }^{266}$ LAVIN, Joaquín. Op. Cit. p. 133.

${ }^{267}$ LAVIN, Joaquín. Op. Cit. p. 155.

${ }^{268}$ EASTMAN. Jorge. De Allende y Pinochet al "milagro" chileno. Editorial Ariel, Chile. 1997.
} 
ciudadanía donde los empresarios tienen más poder que sus representantes. A su vez, el ciudadano/cliente se siente más cómodo en la medida que haya qué comprar, donde la educación -esa que se puede comprar- se transformó en un ícono del ascenso social o donde los servicios sociales son mejores mientras más caros resultan. Al final de cuentas, el modelo chileno mejor vendido ha sido justamente el de la revolución silenciosa de Pinochet, como señala Felipe Moreno. El caso del proyecto de la dictadura es un buen ejemplo de lo que puede ocurrir cuando la ascensión del mercado se desarrolla de forma independiente (e incluso inversa) a la expansión de la democracia y las libertades sociales. ${ }^{269}$

\section{5.- "ELUDIR DELIBERADAMENTE": EVOLUCIÓN DEL PENSAMIENTO DE OPOSICIÓN ACERCA DE LA TRANSICIÓN}

"Vamos camino de convertirnos en una Torre de Babel, en la que cada cual habla su lenguaje, sin importarle ni entender lo que otros dicen..." 270

La frase citada, que es con la que Patricio Aylwin inaugura su intervención en el Seminario denominado "Un Sistema Jurídico - Político Constitucional para Chile” realizado en el Hotel Tupahue de Santiago el día viernes 27 y 28 de Julio de 1984, es una declaración efectiva del camino que optaría por tomar la oposición en los siguientes años. Es en el fondo la concesión al régimen de que se aceptaría definitivamente el itinerario impuesto por la dictadura, no se podía seguir hablando o discutiendo acerca de la legitimidad de la Constitución, jamás habría acuerdo entre unos y otros sobre el punto, se debía aceptar y punto.

\footnotetext{
${ }^{269}$ MORENO, Felipe. "Silent Revolution: An Early Export from Pinochet's Chile." GCG Georgetown University - Universia. Vol. 2 No 2. 2008. pp. 90-98.

${ }^{270}$ OTANO, Rafael. Op. Cit. 2006. p. 20
} 
Esta tesis será el pilar sobre el que se actuará en los años subsiguientes, en especial tras la salida de Sergio Onofre Jarpa, el negociador de ese momento de Pinochet, que habría logrado lo que se denominaría la "primavera de Jarpa" con el retorno de exiliados en medio de las protestas contra el dictador. Desde mediados de 1985 se iniciaría un proceso de reconstitución de la oposición para sacar a Pinochet el año 88, tal como había quedado estipulado años atrás en la carta magna.

Sin embargo, y pese a que se ha mitificado el rol político de la oposición durante los ochentas como un grupo fiel y coherente en la lucha democrática por sacar al Dictador en la urnas, esta será una tesis tardía. Inicialmente serán muchas más las dudas y debates al interior de los grupos que querían sacar a Pinochet, y no nos referimos a los actores que apelaban a la vía insurreccional y violenta de oposición al Régimen como eran el Frente Patriótico Manuel Rodríguez (FPMR) brazo del Partido Comunista, el MIR, el PS (Almeyda) o la Izquierda Cristiana que crearon el movimiento más radical conocido como "Movimiento Democrático Popular" el año $1983,{ }^{271}$ sino a los propios grupos de oposición que hablaban de una salida política del régimen.

Los grupos de centro y derecha que desde los setenta habían apelado a una salida de la dictadura modificarán sus intereses dependiendo del contexto socio político en que se encontraban, partiendo por el interés por llamar a una Asamblea Constituyente, pasando por el momento de esplendor de los 80 de la mano de los movilizaciones sociales que hacía presagiar una caída del régimen, a la definitiva aceptación del itinerario. En las siguientes páginas seguiremos su visión y su evolución a partir de una serie de documentos que presentaron varios miembros de la

\footnotetext{
${ }^{271}$ Véase: SALINAS, Sergio. El tres letras. Historia y contexto del Movimiento de Izquierda Revolucionaria (MIR). RIL Editores, Santiago de Chile. 2013; ROJAS, Luis. De la rebelión popular a la sublevación imaginada (FPMR). Editorial LOM. Chile. 2011.
} 
oposición durante estos años, y terminaremos con un análisis global acerca de cómo estos mismos grupos habrían enfrentado la Democracia en sus inicios.

Uno de los primeros documentos postulados por la oposición fue el que emergió del trabajo del conocido “Grupo de los 24”. Esta agrupación formada el 21 de julio de 1978 por 24 juristas y políticos de oposición dedicados a los Estudios Constitucionales, realizaron un trabajo paralelo al que ejecutaba la "Comisión Ortúzar", establecida en 1973 por la Dictadura. Pese a que no lograron que se recogieran sus postulados en la Constitución de 1980, sirvieron como base para el debate de oposición durante los primeros años.

Entre los primeros documentos publicados por este grupo de estudios esta el conocido "Informe del Grupo de los 24,272 publicado en la Revista Hoy el año $1979^{273}$ donde queda patente que el interés de la oposición durante estos primeros años de la dictadura era más bien promover sus propuestas para una nueva Constitución que con seguridad se instalaría en Chile a partir de los años 80 . Se destaca que en su informe se presente que el resultado de su trabajo es parte de un trabajo colaborativo con distintos “compatriotas” con base en las más diversas ideologías, siendo enfáticos en que ellos no se abrogan la representación popular, ya que es el "pueblo de Chile" quien soberanamente debe autodeterminarse:

\footnotetext{
"Convencidos de que un régimen político, para que sea legitimo y perdurable, deber ser expresión del "sentido común del pueblo", es decir, de las ideas esenciales generalmente compartidas por la comunidad nacional, nos hemos esforzado por buscar soluciones que el más alto grado de acuerdo entre los chilenos.
}

Como no pretendemos arrogarnos una representación popular que a nadie ha sido

\footnotetext{
${ }^{272}$ Para un estudio jurídico de los postulados del grupo véase: QUINZIO, Jorge. "El grupo de los 24 y su critica a la constitución política de 1980" Revista de Derecho de la Universidad Católica de Valparaíso XXIII. 2002.

${ }^{273}$ VV.AA. "Informe del Grupo de los 24" [en línea]. Revista HOY. octubre de 1979. [fecha de consulta 12 de septiembre del 2011] disponible en Internet en: $<$ http://www.archivochile.com/Partidos burguesia/doc gen/PBdocgen0013.pdf>
} 
conferida, hacemos públicos nuestros acuerdos en el carácter de simples proposiciones al pueblo de Chile, único titular del poder soberano de resolver sobre la materia."

Informe del Grupo de los 24. 1979

Con esto apuntan directamente a la propuesta constitucional de la dictadura, acusándola de estar lejos de la ciudadanía y en manos del poder autoritario. De esta manera declaran la necesidad de acceder a la democracia con libertad, el verdadero y único Régimen que debería existir en Chile, además critican duramente la constitución de Pinochet, acusándola de ilegal:

"Pensamos que sólo la democracia, sin apellido que la restrinjan, es compatible con la tradición histórica de Chile y con el espíritu libertario y justiciero que caracteriza a la inmensa mayoría de nuestro pueblo. Entendemos por la Democracia la forma de organización sociopolítica que se funda en el derecho del pueblo a gobernarse por sí mismo y asegura la efectiva vigencia y protección de los derechos humanos.

Nadie, sino el pueblo, tiene derecho a resolver sobre sus destinos, a definir los objetivos a tareas nacionales, ni a fijar marcos o limites a la voluntad popular.

(...) La historia prueba que la legitimidad y eficacia de una Constitución Política dependen del grado de acuerdo o adhesión consciente y voluntaria que concite en la comunidad nacional. Las Constituciones impuestas por regímenes de fuerza, aunque se valgan de plebiscitos para hacerlas aprobar, no perduran después de los gobiernos que con su fuerza se imponen."

Informe del Grupo de los 24. 1979

El grupo de los "24" por tanto reafirma que la Constitución propuesta por Pinochet y la Junta, y con ella el itinerario propuesto, sería ilegal, pero además señalan que no se necesitaría una Constitución nueva, sino más bien una reforma a la anterior. 
"Es absurdo menospreciar el acerbo de una tradición constitucional de más de siglo y medio. La Constitución de 1925, vigente con modificaciones al 11 de septiembre de 1973, nació como reforma a la Constitución llamada "portaliana" de 1833, la que a su vez fue reforma de la de 1828 . Por otra parte, rechazamos la tesis que atribuye a la crisis política que sufre nuestra Patria a un supuesto "fracaso" de las instituciones democráticas que consagraba nuestro régimen constitucional.

Pensamos que esa crisis tuvo causas políticas, sociales, económicas e ideológicas que imposibilitaron la estructuración de un proyecto social verdaderamente mayoritario en la comunidad nacional. La falta de esa mayoría agudizó el conflicto entre los intereses y concepciones en pugna y puso de relieve algunas deficiencias preceptivas de la Constitución vigente que es preciso corregir."

Informe del Grupo de los 24. 1979

Este grupo de estudios instaba, por tanto, a restaurar el orden democrático con una participación de la ciudadanía en elecciones y en orden a ejecutar la soberanía que le pertenece, también reconoce la necesidad de recuperar la política, los partidos y el parlamento, que hasta ese momento eran denostados y vetados por los militares. En economía se mantenía la idea de la planificación por parte del Estado en función de una mayor distribución, además de la participación directa de los trabajadores, aspecto que bajo el modelo neoliberal que se estaba instalando en dictadura era dejado de lado. Con todo, la oposición se abría lentamente al papel que jugaría el sector privado como un área importante para la economía nacional, ámbito que en los setenta había sido demonizado por la izquierda.

“Pensamos que dentro de ámbito de una economía esencialmente democrática, la acción del Estado y del sector privado son susceptibles de combinarse en grados y modalidades variadas de acuerdo a decisiones políticas respaldadas por mayoría popular. 
(...) el Estado podrá recurrir a la planificación económica y social para atender a las necesidades colectivas, equilibrar y armonizar el progreso regional, lograr un desarrollo económico y crecimiento del Producto Nacional más acelerados y promover una mejor distribución de la riqueza y del ingreso.

La democracia económica implica una activa participación del pueblo y en particular de los trabajadores, a través de mecanismos adecuados, en los procesos de planificación y en la formulación y evaluación de la estrategia nacional de desarrollo.”

Informe del Grupo de los 24. 1979

Pese a estas propuestas y la lucha realizada por este Grupo, la Constitución y su itinerario de transición fue instaurada en 1980, pese incluso al descontento de algunos miembros de la Comisión Ortúzar -grupo por régimen- que al ver como se desechaban algunas de sus propuestas renunciaron previamente, como es el caso del expresidente Jorge Alessandri. Con todo, los primeros años de los ochenta se iniciará en un escenario muy positivo para la oposición, gracias a la crisis económica de 1983 y el inicio de las grandes manifestaciones sociales.

Hacía marzo de ese año se presenta otro documento conocido como "Manifiesto Democrático"274 que reúne el pensamiento de la oposición, esta vez organizado en torno a la Alianza Democrática (1983-1988) creada al amparo de políticos de la democracia cristiana, grupos socialistas, social demócratas y de derecha republicana. Algunos de los miembros de esta alianza -entre los que estaba el primer presidente del retorno a la democracia, Patricio

\footnotetext{
274 VVAA. Manifiesto Democrático. [en línea] Santiago de Chile. 14 de marzo de 1983. [fecha de consulta 12 de octubre de

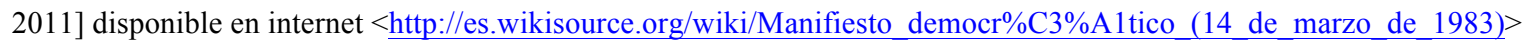


Aylwin- habrían participado de una agrupación precedente conocida como PRODEN (Proyecto de desarrollo para un Consenso Nacional, 1982) quienes habían realizado varias acciones contra el régimen. Sin embargo será la Alianza Democrática la que proyectará su rol hasta el retorno a la democracia.

En el manifiesto democrático se pone en claro el optimismo frente a la posible caída del régimen debido a la crisis económica, siendo un escrito muy duro en su critica al modelo de la Junta y a los abusos de la violencia de Estado:

“(...) Nuestra historia republicana no registra una crisis más profunda y prolongada que la que sufre el país. Ella afecta sus bases morales, políticas, sociales y económicas, abarca a todos los sectores de la comunidad, debilita la seguridad de la Nación y agudiza las injusticias y tensiones en su interior.

3. La crisis ha llegado a provocar el colapso del sistema financiero y de los grupos que lo dirigen, que constituya la máxima expresión del modelo en el que el Gobierno basaba su éxito $(\ldots)$

Desde el comienzo denunciamos el peligro que entrañaba aplicar en nuestro país un modelo económico que no se compadece con nuestra realidad y tiene por objeto imponer un sistema de sociedad contrario a los valores e intereses permanentes de la Nación.

(...) En el campo político interno se mantiene el régimen de arbitrariedades, principalmente originado por la aplicación del art. 24 transitorio de la Constitución. Las libertades básicas no tienen vigencia y constantemente se conocen nuevas denuncias por atropellos a los Derechos Humanos fundamentales"

Manifiesto Democrático. 1983

Con esta misma claridad se hace un llamado a la ciudadanía a tomar un papel protagónico, especialmente aprovechando el contexto de movilización popular, con el fin de acabar con la 
dictadura. Se nota el optimismo y se pone por escrito en dicho Manifiesto:

“ (...) Ha llegado el momento de reaccionar. Por ello hacemos un llamado a todos los hombres y mujeres que anhelan la libertad, la justicia y la paz para realizar un gran esfuerzo nacional que conduzca al restablecimiento de la Democracia.

Para lograr ese gran objetivo, se debe poner término inmediato a los regímenes de emergencia, que han enterado ms de nueve años sin interrupción y acaban de renovarse; restablecer la libertad y seguridad individuales y su efectivo resguardo por un Poder Judicial que asuma la tutela del respeto a las personas como corresponde en un Estado de Derecho.

Llamamos a encarar el futuro sin odios ni revanchismos, con espíritu generoso y voluntad de hacer justicia. Nuestro llamado persigue como fin reconstruir la democracia en Chile en el más breve lapso posible para lo cual creemos necesaria la unidad de todos los chilenos que acepten lealmente sus principios y sean capaces de actuar conformes a ellos."

Manifiesto Democrático. 1983

En temas económicos se mantiene la oposición al modelo impuesto por la Dictadura, refrendándose la idea de mayor participación de los trabajadores y el papel del Estado, esta vez apoyados por la grave situación que vivía el país producto de la crisis económica que no pudo evitar el modelo neoliberal:

“El Estado, desde el inicio de la República, ha desempeñado una misión vital en la sociedad chilena: Su acción dinámica y eficiente para orientar e impulsar la actividad económica, sin salirse de la órbita que le es propia, debe velar, también, por una equitativa distribución de la riqueza que contribuya a la satisfacción de las necesidades esenciales de la población, particularmente, en esta critica coyuntura en que la política económica implementada ha 
reducido gravemente el poder adquisitivo de los sectores de menores ingresos y su derecho a una vida digna. La participación activa de los trabajadores, sin la cual no podrá realizarse una recuperación económica ni establecer un régimen democrático salido, dignificar su esfuerzo e imprimirá un sentido social a la producción de los bienes.

A su vez, la participación empresarial desvinculada del propósito de concentración económica y sujeta a normas de bien colectivo, estimulará su capacidad creativa y la reactivación. De este modo, se contribuir a que la Democracia que se construya sea la expresión de toda la comunidad."

Manifiesto Democrático. 1983

Esta visión positiva que se imprimía en el documento ${ }^{275}$ que demandaba una salida rápida de la Dictadura se irá "congelando" poco a poco. En las negociaciones emprendidas entre los miembros de la Alianza Democrática y el régimen encabezado por el civil, don Sergio Onofre Jarpa se irá percibiendo una clara tensión entre la agenda del político pro régimen y la oposición. Por una parte, el representante de Pinochet no es escuchado en la Junta y se le da muy poco espacio de negociación, a la par que seguía la represión en las calles. Por otra parte, la oposición se encontraba dividida entre si ceder a la Constitución y su propuesta de transición o mantenerse firmes, como hasta ese momento, en no aceptar la Constitución y su itinerario y tratar de acceder a la democracia lo antes posible. El optimismo se difumina con los años y va ganando terreno la idea de la aceptación de la Constitución, la que se concretará un año más tarde en el conicido seminario del Hotel Tupahue.

Hay que mencionar también que en la moderación posterior del discurso de oposición estará implicada la mediación eclesiástica que también publicará un documento que ponía en

\footnotetext{
${ }^{275}$ El año 1983 se publica también las "Bases para un acuerdo Nacional” con similares características.
} 
entredicho a la dictadura (Conferencia Episcopal, 1982). ${ }^{276}$ En efecto, será con la participación de la Iglesia chilena que se presentará otro documento, esta vez, ya vislumbrando que la definitiva salida de la dictadura será más bien aceptando las reglas del régimen. Este documento se conocen como el "Acuerdo Nacional para la Transición a la Plena Democracia"277 publicado el año 1985.

En este documento surge el discurso mucho más conocido de la oposición a la Dictadura, el de la reconciliación, que implícitamente contiene la aceptación de que Pinochet solo saldrá previo triunfo de oposición en las urnas. A esta altura, el fervor de la crisis de los 80 que demandaba una salida inmediata de Pinochet comenzaba a menguar y entraba en juego la frialdad política y la necesidad de eludir deliberadamente la Constitución de 1980. Esto se verá reforzado en los consecutivos años, por la visita del Papa a Chile en 1987 y el fallido intento de asesinato de Pinochet en 1986, esto último terminará por hacer desaparecer la opción violenta de salida del régimen, por lo menos de algunos grupos de izquierda que aún estaban en duda y que se sumarán a la Alianza posteriormente. Se habla entonces de un retorno a la democracia "ordenado":

\begin{abstract}
“Como contribución al llamado a la reconciliación nacional formulado por S.E. el Cardenal Arzobispo de Santiago y como testimonio de la disposición de muy amplios sectores políticos del país a un gran acuerdo nacional que asegure la evolución pacífica hacia una democracia plena y auténtica, todos los que suscriben este documento, en un gesto positivo hacia la reconciliación que se desea, expresan su apoyo a los principios políticos, económicos y sociales que a continuación se enuncian.
\end{abstract}

(...) Los valores democráticos deben regir nuestra convivencia y para que ellos se alcancen

\footnotetext{
${ }^{276}$ Declaración del Episcopado de Chile. "La reconciliación en Chile". En: Mons. OVIEDO CAVADA, Carlos (ed), Documentos del Episcopado. Chile, 1974-1980. Ediciones Mundo, Santiago, 1982.

${ }^{277}$ VV.AA. “Acuerdo Nacional para la Transición a la Plena Democracia”, El Mercurio, 27 de agosto de 1985.
} 
se requiere una entrega ordenada del poder político a autoridades revestidas de plena e indiscutible legalidad democrática; un marco político-económico-social que garantice tanto la gobernabilidad del país como las condiciones básicas para el esfuerzo colectivo que los desafíos de hoy y del futuro plantean; y, también, el retorno de las Fuerzas Armadas a sus indispensables funciones permanentes (...)”

Acuerdo Nacional para la Transición a la Plena Democracia. 1985

En relación con esto, se declara explícitamente la aceptación de las "reglas del juego" institucional de Pinochet y se acepta la realización de "reformas" a la Constitución existente y no su eliminación completa- una vez retornada la democracia:

“Teniendo en consideración lo anterior, la estabilidad del sistema democrático que se establezca exige el compromiso solemne que contraen todos los que firmen o adhieran a este documento, de realizar la acción política del futuro dentro de un espíritu de lealtad democrática, aplicación efectiva de la ley y respeto mutuo, compatibilizándola con los principios institucionales, económicos y sociales aquí señalados. Sólo de esta manera se garantizará la gobernabilidad del país y la efectiva transición hacia una democracia plena $(\ldots)$

(...) El restablecimiento de la Democracia hace indispensable el que todos los chilenos tengan el derecho de expresar su pensamiento y asegurar sus libertades dentro de un régimen constitucional que contemple, al menos, los siguientes aspectos:

1. Elección por votación popular de la totalidad del Congreso Nacional, con claras facultades legislativas, fiscalizadoras y constituyentes.

2. Un procedimiento de Reforma Constitucional que, reconociendo la necesaria estabilidad que debe tener la Carta Fundamental, haga posible sus modificaciones y en caso de desacuerdo entre el Ejecutivo y el Congreso, someta la reforma a plebiscito. 
En términos económicos, se modera el discurso del Estado planificador -que desaparecerá en Democracia- y se acepta que el modelo debe mantenerse, a su vez que se asume que el Estado deberá asumir tareas cada vez más subsidiarias y reguladoras dejando libre paso al emprendimiento privado, en especialmente porque había que favorecer el crecimiento que comenzaba a experimentar el país. Junto a esto, se establecen las tareas prioritarias de los primeros gobiernos democráticos entre las que destaca la eliminación de la extrema pobreza:

"Es indispensable eliminar cualquier incertidumbre respecto al régimen socio-económico que imperará una vez restablecida la normalidad. La convivencia democrática, exige estabilidad en las reglas básicas para el funcionamiento de la economía, a fin de asegurar así armonía social y eficacia económica. Para lograrlo se requiere adecuado equilibrio entre el ejercicio de la libertad y la equidad.

El país debe proponerse simultáneamente una tasa de crecimiento alta y una sostenida reducción de las desigualdades en las oportunidades y los niveles de consumo.

Asimismo, el desarrollo dinámico y equitativo en Democracia requiere de normas claras, no sujetas a interpretación arbitraria, que impidan la dominación de un grupo social sobre otro y del Estado sobre la sociedad.

En virtud de lo expuesto, todos los que suscriben este documento comprometen su apoyo a las siguientes bases del orden económico-social futuro:

1. Serán metas prioritarias la superación de la extrema pobreza y la marginalidad, la creación de oportunidades de trabajo productivo y estable, y el logro de una tasa alta y sostenida de crecimiento, para lo cual será preciso superar las restricciones que impone la escasez de los recursos externos y aumentar sustancialmente el ahorro interno, tanto público como privado, principales limitaciones a la inversión y, por tanto, al crecimiento. 
2. Para el logro de los objetivos señalados, será necesario un propósito nacional de compartir equitativamente sacrificios y recompensas. Ello significa austeridad en los consumos, solidaridad y disciplina social.

3. Debe garantizarse constitucionalmente el derecho a la propiedad privada de los bienes corporales e incorporales, incluidos los medios de producción, condición necesaria para estimular la iniciativa individual bajo distintas formas de organización y actividades económicas. No se usará el sistema tributario como mecanismo expropiatorio. Debe reconocerse, también, la existencia de la propiedad estatal y mixta de medios de producción.

4. El Estado debe tener una función activa y le corresponde determinar los grandes objetivos nacionales, sobre la base de una planificación directa de su propia acción e indicativa para los demás agentes económicos, usando de preferencia instrumentos indirectos de persuasión e incentivo. Así coordinará y orientará la marcha de la economía, sin perjuicio de sus funciones reguladoras y redistributivas (...)"

Acuerdo Nacional para la Transición a la Plena Democracia. 1985

Como se observa, por tanto, hacia 1985 la oposición había perdido toda esperanza en una salida del dictador por otra vía que no fuese la que el propio itinerario había establecido. Pero, junto con eso, se aceptaba el modelo económico propio del régimen, donde el Estado se veía disminuido y la tasa de crecimiento se convirtió en el nuevo indicador de mejora del país. Se deja de hablar de un Estado planificador y se reconvierte en el Estado regulador.

En definitiva poco se habla de esta transformación del discurso de oposición y su transformación durante el proceso de transición, pero resulta muy relevante conocerlo para entender la democracia que se formó posteriormente, como veremos en las páginas que siguen en esta investigación. 


\section{6.- EL PLEBISCITO DE 1988 ¿PUNTO DE QUIEBRE?}

$\mathrm{Si}$ es que existe un hito reconocido internacionalmente que describa el retorno a la democracia en Chile, este es con toda seguridad el plebiscito de 1988. En el se conjugó la "mística" de la oposición a Pinochet que reunida en la Concertación de Partidos por la Democracia, bajo una bandera multicolor proyectaron comunicacionalmente que si ellos triunfaban la "alegría vendría”.

El impacto mundial que tuvo el resultado de la campaña del "No" a Pinochet ha sido por largos año aprovechado en el discurso político de la Concertación -hoy Nueva Mayoría- quiénes en ocasiones aparecen como los héroes del 5 de octubre. Esta fecha "simbólica" como se le ha calificado, evidentemente es un hito relevante para la historia reciente de Chile, con ella se acaba la dictadura en forma y Augusto Pinochet se retira de la presidencia, aunque sabemos que su poder permanecerá por mucho más tiempo vigente. Sin embargo, es necesario destacar que el Plebiscito, más allá de la relevancia mediática que tuvo nacional e internacionalmente, ${ }^{278}$ es un hito del largo proceso en el que se desarrolló la Transición. Pero, ¿puede ser considerado el hito más relevante? ¿Un punto de quiebre para la dictadura? Desde nuestro punto de vista el 5 de octubre de 1988, en un balance histórico global tiene más de agraz que de dulce.

En primer lugar, se debe decir que incluso en los estudios que precedieron al plebiscito, como el realizado por Manuel Antonio Garretón, importante intelectual de oposición, no desbordaba el optimismo y señalaba que debido a que no se había podido conseguir la transición "desde arriba ni desde abajo" debido en parte a que la oposición no había sido capaz de transformar su fuerza social en una propuesta de transición -ya vimos que más bien hubo un rendición a la

\footnotetext{
${ }^{278} \mathrm{El}$ acontecimiento ha sido últimamente reconsiderado en su imaginario, al punto que la más reciente película sobre el plebiscito, la película "No" de Pablo Larraín (2012), fue realizada alejada de la mística y el heroísmo y su propuesta es más bien en un tono de comedia. La película llego incluso a la nominación al Oscar como mejor película extranjera.
} 
propuesta de la dictadura- el plebiscito representaba de esta manera la mejor oportunidad para salir del régimen, incluso aunque ganara el Sí a Pinochet. Según él, si ganaba la oposición o el propio régimen se desencadenarían "dinámicas de transición” aunque ellas fueran reversibles, y enfatizaba, que esto era positivo aunque no se pudiese asegurar ningún resultado. ${ }^{279}$ En definitiva lo más positivo del plebiscito era la "oportunidad" para enfrentarse electoralmente en un espacio regulado institucionalmente.

Frente a esta "fragilidad" de la lucha en las urnas contra el dictador, el mejor mecanismo para asegurar que el régimen reconociera un triunfo del No -el cual era el mejor escenario posiblese requeriría del apoyo internacional o la iglesia como mediador externo. En el mejor de los casos se podría triunfar y se obligaría a hacer negociaciones que impliquen las reformas necesarias para "hacer funcionar" la democracia naciente y ceder en otro grandes temas, a lo cuál se debieron enfrentar efectivamente, no sin grandes tensiones.

El pragmatismo transmitido por Garretón evidencia claramente las razone de la alegría descollante de los miembros de la oposición -y de la ciudadanía- el año 1988 tras el triunfo del 5 de Octubre, ya que terminaron en el mejor escenario posible, pero oculta la realidad precedente e incluso oscurecen los propios resultados del plebiscito.

Varios acontecimientos previos marcaron el escenario del Plebiscito y fueron el marco para el “triunfo" de la oposición. Hay que enfatizar que el plebiscito de 1988 no es un logro de la Concertación, como ya vimos, sino el sometimiento a las reglas del juego de Pinochet, la oportunidad estratégica que aprovecharon y que fue catalizada por dos acontecimientos relevantes: la operación siglo XX en 1986 y la visita papal en 1987.

El primer escollo que debió saltar la oposición - tras asumir el itinerario de la dictadura- fue el

\footnotetext{
${ }^{279}$ GARRETON, Manuel Antonio. El plebiscito de 1988 y la transición a la democracia. FLACSO. Chile.1988.
} 
gran debate llevado a cabo en 1985 en torno a la Ley del Tribunal Calificador de Elecciones, que establecía en su primer artículo transitorio que entraría en funciones 60 días antes de celebrarse las parlamentarias del año 1990, es decir, en diciembre de 1989, no para el plebiscito.

Finalmente el Tribunal Constitucional se debe pronunciar sobre el asunto y el 24 de septiembre de 1985, en una reñida votación de cuatro votos contra tres, se estimó que dichas normas eran inconstitucionales, señalando que dicha "rígida interpretación del texto constitucional resulta inadmisible, porque ella está en pugna o contradice el artículo permanente y las disposiciones transitorias de la Carta Fundamental

“a) el artículo 18, que establece el "sistema electoral público;

b) la disposición transitoria vigésima séptima, inciso final, que dispone la realización de un plebiscito para que la ciudadanía se pronuncie sobre la proposición de la persona que desempeñará el cargo de Presidente de la República, en el próximo período presidencial;

c) las disposiciones transitorias decimoctava, letra A), y vigésima primera, letra d), al establecer que, durante el período a que se refiere la decimotercera disposición transitoria y hasta que entren en funciones el Senado y la Cámara de Diputados, las reformas constitucionales que se acuerden sólo tendrán eficacia si son aprobadas por un plebiscito. ${ }^{280}$

De esta manera, el 15 de noviembre de 1985, se pudo tener el marco regulatorio institucional necesario para la elecciones de 1988. El segundo escollo se superó en 1986 cuando se promulgo la ley 18556 Orgánica Constitucional sobre sistema de inscripciones electorales y Servicio Electoral. Esta ley permitió que se abrieran los registros electorales a partir de 1987, y se retomaba la institucionalidad perdida en 1973. Paradojalmente el primero en inscribirse en el

\footnotetext{
${ }^{280}$ Se puede ver la sentencia completa en: TRIBUNAL CONSTITUCIONAL. Sentencia Rol $N^{o}$ 33. 1988. en: < http://www.tribunalconstitucional.cl/wp/desent.php?id=33>
} 
registro electoral fue Pinochet en la comuna de Santiago, como acto simbólico y político, de aquí en adelante cualquier hombre o mujer y extranjeros residentes mayores de 18 años pudieron inscribirse en los registros electorales

Así describe el diario el País este acontecimiento, nótese que el vocero del régimen destaca que este hito es parte del cumplimiento de lo establecido en el itinerario y correspondía a la normalización institucional, mientras que la oposición insiste en llamar a la acción e inscribirse lo antes posible:

"Los registros electorales chilenos, destruidos por los militares tras el golpe de Estado de 1973, fueron reabiertos ayer en todo el país, como parte del proyecto de democratización limitada impulsado por el régimen. Esta vez, el general Augusto Pinochet fue uno de los primeros en inscribirse en una de las 514 juntas del censo instaladas en todo el país. La oposición, embarcada en una campaña para exigir elecciones libres, se ha dividido, sin embargo, frente a esta iniciativa: el centro-derecha alienta la inscripción, mientras la izquierda la rechaza.

De acuerdo con la nueva ley electoral aprobada por la Junta Militar de Gobierno, 8,2 millones de chilenos, mayores de 18 años, que no tengan antecedentes de conductas terroristas ni postulen doctrinas totalitarias basadas en la lucha de clases, podrán formalizar su derecho a voto. La masa de electores representa el $68 \%$ de la población total de Chile, calculada en 12 millones de acuerdo al censo de 1982. De esos electores, sólo 3,65 millones han votado alguna vez en su vida. Este hecho, calificado de "histórico" por el ministro del Interior, Ricardo García, constituye la primera cristalización de uno de los capítulos de las leyes políticas aprobadas el año pasado por el régimen militar, en el marco de lo que ha denominado "normalización institucional" (...)

A pesar de las fuertes críticas que la oposición en su conjunto ha formulado a las normas oficiales, los partidos de izquierda moderada, centro y derecha agrupados en la opositora Alianza Democrática pidieron a sus militantes y simpatizantes inscribirse en el censo. En 
un pronunciamiento oficial, este conglomerado, cuyo principal partido es la Democracia Cristiana, manifestó que ello constituía "un paso necesario en la lucha por las elecciones libres". Destacó, sin embargo, que tenía conciencia de que esta ley no representaba un "instrumento jurídico que conduzca a la democracia". El dirigente democristiano Ricardo Hormazábal justificó esta decisión afirmando que no basta quedarse en el rechazo y que la acción de inscribirse demostrará que se quiere "votar ahora" (...)"281

Tal como pensaba la oposición el candidato por el Sí, o sea la continuidad del régimen, sería con Pinochet a la cabeza, convirtiéndose en el candidato de la Junta. Por su parte la oposición organizó una férrea lucha mediática que "barrió" con la propuesta de oposición que destacaba fuertemente el pasado y el retorno del marxismo y la violencia terrorista de grupos de izquierda, mientras hacía ver el progreso económico. Por su parte, la oposición se apropio de un discurso de esperanza y alegría, donde destacaba la libertad y el futuro. ${ }^{282}$

Como dijimos antes, hay dos hitos que se deben destacar también como relevantes para comprender el periodo previo al plebiscito. En primer lugar el atentado frustrado contra el dictador conocida como la "Operación siglo XX" dirigida por el Frente Patriótico Manuel Rodríguez en 1986. Esta operación fue realizado por unos veinte miembros del FPMR en 1986 gracias a la internación ilegal de armas por carrizal bajo. La idea es asesinarlo en una emboscada en su retorno desde su casa de descanso en El Melocotón (Cajón del Maipo) junto con parte de su familia y protegido por su escolta.

En el atento murieron cinco escoltas y varios quedaron heridos. Por su parte, Pinochet gracias

\footnotetext{
${ }^{281}$ DIARIO EL PAÍS. "Los chilenos, por primera vez desde el golpe de Pinochet, pueden inscribirse para votar". 2 de febrero de 1987. [fecha de consulta: 3 de diciembre del 2015]. Disponible en internet: <http://elpais.com/diario/1987/02/26/internacional/541292415 850215.html >

282 ARRIAGADA Genaro y VALDÉS Juan Gabriel. Campaña del NO. Análisis y Perspectivas. CIS -CED-ILET-SUR. Santiago, 1988 .
} 
a una maniobra del conductor del auto en que venía junto a su nieto, logro retroceder y emprender la huida sin ningún rasguño. ${ }^{283}$

Este acontecimiento desató la furia represiva del régimen decretando una vez más el Estado de sitio en Chile. Este atentado responde a la declaración explícita de Pinochet que había realizado en 1986, meses antes del atentado, acerca de ser el candidato presidencial de la junta, proyectando así el régimen más allá de 1989, lo que oscurecía el panorama para la oposición. Sin embargo, el atentado tuvo varios efectos, por una parte reforzó la idea de la continuidad del régimen de la mano de Pinochet, y por otra, alineó a los inseguros en torno a la salida institucional del régimen -en especial miembros de partidos comunista- que vieron fracasado el intento por sacar al dictador de manera violenta, sumado así más actores a la oposición previamente al referéndum.

La visita del Papa en 1987 será relevante para la oposición y en una estrategia muy cuidada y engañosa también para Pinochet, sobre todo en el marco de la elecciones que se avecinaban. Para el caso de la oposición, Juan pablo II se encargó no sólo de visitar a los altos cargos de la iglesia, sino que estuvo reunido con los miembros de la Vicaría de la Solidaridad y asistiendo a reuniones en poblaciones emblemáticas de Santiago, lugar donde había una fuerte crítica al régimen y su represión. En relación a la visita oficial, Pinochet conversó con él en una reunión que, por una parte, se extendió más de la cuenta - de 10 minutos terminó en 40 minutos- y por otra parte, en un acto engañoso logro que el papa se asomará junto a él- vestido de civil- al balcón presidencial. Imagen que se proyectó en todo el mundo, con pesar para el Papa que manifestó en privado su molestia.

Pese a este "impasse" el Papa logró capturar en cada homilía que ofreció el sentir de la gente,

\footnotetext{
${ }^{283}$ VERDUGO, Patricia y HERTZ, Carmen. Operación Siglo XX. Ediciones del ornitorrinco. Chile. 1990 ;PEÑA, Cristóbal. Los fusileros: Crónica secreta de una guerrilla en Chile. Editorial Debate. Chile.2006
} 
apoyando fuertemente la democracia y la libertad y condenando duramente la violencia y el abuso. $^{284}$

Estos dos acontecimiento previos al plebiscito fueron catalizadores por una parte de un mayor consenso en torno a la salida institucional de Pinochet, por lo menos del grupo indeciso y por otra parte, animó a la ciudadanía a retomar la oposición contra Pinochet, pese a la fuerte represión iniciada tras el atentado al dictador. Por su parte, el intento de asesinato, entrega argumentos para mantener a Pinochet como candidato y muchos de sus seguidores de la necesidad de su continuidad, especialmente frente a los violentistas de izquierda.

En definitiva el resultado de la oposición será positivo para la oposición que termina triunfando con un $54,7 \%$ de los votos a favor del No a Pinochet, pero el dictador y el régimen obtuvo un no despreciable $43,1 \%$ de las votaciones. Este dato, es pocas veces considerado, ya que en la "mística" del triunfo de la Concertación se suele destacar la masividad del triunfo como si esta hubiese sido por una mayoría abismal de los chilenos -cuestión que permanece en el imaginario colectivo-. Sin embargo ni intelectuales, ni políticos estaban tan seguros, previamente a la votación, que habría un éxito asegurado o avallasador, lo cuál coincidió con la realidad de la votación. En estricto rigor, los acontecimientos previos daban cuenta que tanto la oposición como el régimen jugaban sus cartas de igual manera para triunfar en las urnas.

Las encuestas realizadas en ese momento (Centro de Estudios Públicos y Adimark) evidenciaron que la gente que votaba contra Pinochet, no lo hacía principalmente debido a la represión o la violación de los derechos humanos, sino que más bien considerando factores económicos, falta de trabajo principalmente $(72 \%)$. Por lo que el discurso político de la elite acerca de la libertad y la democracia, fue secundario para la población en general a la hora de votar. En efecto, lo que más dirimió finalmente era que se acabase el régimen y con él la miseria

\footnotetext{
${ }^{284}$ JUAN PABLO II. Mensajes de Juan Pablo II al pueblo de Chile. Editorial Salesiana. Santiago de Chile. 1987.
} 
económica producida por la desigualdad y el desempleo -muy contraria a la imagen de éxito económico que intentaba proyectar la dictadura. ${ }^{285}$

No es discutible que el plebiscito haya sido un "hito bisagra" en el retorno a la Democracia, pero ni el proceso histórico pone en evidencia que su resultado, a lo menos en el tiempo extendido, debe ser moderado. No puede seguir considerándose como un hito clave de manera aislada, allí confluyen decisiones de larga datación vinculadas al régimen, acontecimientos que catalizaron las decisiones de las élites, en uno y otro lado, e intenciones vinculadas al voto opositor de la ciudadanía que no siempre coincide con el discurso político y menos con la proyección casi mítica de éste. Ha quedado patente durante los últimos años de democracia que la apropiación "indebida" por parte de la Concertación del 5 de octubre ha llevado a un alejamiento de la ciudadanía de dicho discurso, de tal manera, que la celebración del retorno de la democracia es realizada principalmente por los partidos políticos, donde no participa la ciudadanía. Es más, hoy día se parodia, la potente frase del retorno a la democracia "Chile, la alegría ya viene” preguntándose cada vez más en diversas plataformas ciudadanas “¿cuándo llega?, haciendo mención a la desvinculación creciente que tiene la sociedad con la Concertación, que actúo como líder en el plebiscito de $1988 .{ }^{286}$

\footnotetext{
${ }^{285}$ MÉNDEZ GODOY, Roberto, Oscar BARROS , Enrique FONTAINE TALAVERA, Arturo. “iPOR QUE GANO EL NO?. Análisis y exposición de la encuesta CEP-Adimark de septiembre de 1988” [En línea]. Centro de Estudios Públicos. Chile. 10 de octubre de 1988. [fecha de consulta: 3 de diciembre del 2015]. Disponible en internet: < http://www.cepchile.cl/dms/archivo 1190 1158/rev33 mendez.pdf $>$

${ }^{286}$ SOTO, Eric. "Columna: La alegría que nunca llegó”. El quinto poder. [En línea 29 de junio del 2011. [fecha de consulta: 3 de diciembre del 2015]. Disponible en internet: < http://www.elquintopoder.cl/politica/la-alegria-que-nunca-llego/ >
} 


\section{7.-“EN LA MEDIDA DE LOS POSIBLE”: CHILE Y}

\section{LOS DERECHOS HUMANOS.}

Escribir acerca de los Derechos Humanos en Chile y su violación sistemática durante los años de la Dictadura es un tema que podría ocupar espacio importante de cualquier escrito. ${ }^{287} \mathrm{De}$ hecho la cantidad de investigaciones surgidas en los últimos años acerca del tema da cuenta de intentos por recuperar un tema que por mucho tiempo fue dejado de lado, sea a través de trabajos audiovisuales $^{288}$, educativos ${ }^{289}$, estudios legislativos, ${ }^{290}$ culturales, $^{291}$ históricos o sociológicos. $^{292}$

\footnotetext{
${ }^{287}$ Pese a que existe una larga lista de investigaciones al respecto, recomendamos la trilogía escrita por el historiador norteamericano Steve Stern: STERN, Steve. The Memory Box of Pinochet's Chile (3 vols.). Vol. 1: Remembering Pinochets's Chile. On the eve of London 1998. Vol. 2: Battling for Hearts and Minds. Memory Struggles in Pinochet's Chile, 1973-1988. Vol. 3: Reckoning with Pinochet: The Memory Question in Democratic Chile, 1989-2006.. Duke University Press. DurhamLondon. 2001-2006.

${ }^{288}$ Véase por ejemplo: "La memoria obstinada" (1997) de Patricio Guzman ; "Estadio Nacional” (2002) y "El derecho de vivir en paz" (1999) de Carmen Luz Parot; "El Mocito" (2010) de Marcela Said Cares y Jean de Certeau y el reciente "Habeas Corpus" (2015) de Claudia Barril y Sebastián Moreno; entre otros.

${ }^{289}$ Véase por ejemplo: MAGENDZO, Abraham, VENEROS, Diana, TOLEDO, María Isabel. Visita a un lugar de memoria. Guía para el trabajo en derechos humanos. Editorial LOM. Chile. 2010; MAGENDZO, Abraham. Educación en derechos humanos. Editorial LOM. Chile. 2006; Abraham MAGENDZO. De miradas y mensajes en la educación de derechos humanos. Editorial LOM. Chile. 2004.

${ }^{290}$ Véase por ejemplo: COLLINS, Cath. "Grounding global justice: International networks and domestic human right accountability in Chile and El Salvador.” Journal of latinoamerica studies. Vol. 38. No 4. 2006. pp. 711-738; COLLINS, Cath. "State terror and the law: The (Re) judicialization of human right accountability in Chile and El Salvador." Latinoamerican perspectives. Vol. 35, № 5, 2008. pp. 20-37.

${ }^{291}$ DEL ALCÁZAR, Joan. Chile en la pantalla. Cine para escribir y enseñar la historia (1970-1998). Publicacions de la Universitat de València - Centro de Investigaciones Diego Barros Arana, Valencia. 2013; DEL ALCÁZAR, Joan y VALLE, José E. "Los historiadores ante el cine y la literatura. Dos miradas distintas hacia la historia reciente de Chile." Revista de Historia social y de las Mentalidades Universidad de Santiago de Chile, Volumen: Año IX, Vol 1/2 2005. pp. 183- 212; ACEITUNO, David. "El cine de ficción como lectura crítica de la historia y su utilización en la enseñanza el caso de la transición a la democracia en Chile". En: DÍAZ MATARRANZ Juan José. Et. Al. Medios de comunicación y pensamiento crítico: nuevas formas de interacción social. Universidad de Alcalá, Servicio de Publicaciones. España. 2013, pp. 527-537

${ }^{292}$ Véase por ejemplo: Hiner, Hillary. "Voces soterradas, violencias ignoradas: Discurso, violencia política y género en los Informes Rettig y Valech.” Latin American Research Review. Vol. 44, Na. 3. 2009., pp. 50-74; COLLINS, Cath. HITE, Katherine y JOIGNANT, Alfredo. Las políticas de la memoria en Chile: desde Pinochet a Bachelet. Ed. UDP. Chile. 2013.
} 
En este capítulo no abordaremos cada uno de los detalles de la política de la memoria o el problema de los derechos humanos, lo cual serían una - o más- tesis por si sola, sino que más bien la analizaremos en el contexto del modelo de democracia heredada de la Transición. Esto porque cabe preguntarse si en un Chile "amarrado" constitucionalmente y además "cautivado" por la "revolución silenciosa" de los economistas de Chicago ¿sería posible abordar el problema de la violencia y muerte en Dictadura? el resultado es interesante, ya que si bien se ven avances, hasta el día de hoy resultan insatisfactorios para las familias y gran parte de la sociedad.

\section{1.- LOS MONSTRUOS Y LOS HORRORES.}

No es posible entender la política de derechos humanos si no se comprende el daño ocasionado a la sociedad que dejo tras de si la Dictadura que causó impacto incluso más allá de sus fronteras. ${ }^{293}$ De hecho si solamente nos quedásemos con el análisis de la políticas de reparación económica a las víctimas, la petición de perdón colectiva realizada por Patricio Aylwin, el estudio de los informes o la condena de algunos militares - casi nunca del alto mando- nos seguiríamos preguntando el por qué siguen existiendo grupos de familias de víctimas insatisfechas o las continúas demandas de justicia. En realidad, esto sucede porque el daño fue mucho más profundo y las soluciones, como veremos, más superficiales.

\footnotetext{
${ }^{293}$ DEL ALCÁZAR, Joan. Yo pisaré las calles nuevamente: Chile, revolución, dictadura, democracia (1970-2006). Santiago de Chile: Editorial Universidad Bolivariana, 2009; DEL ALCÁZAR, Joan. "Los historiadores y la consolidación democrática chilena: memoria, olvido e historia" Revista de Historia Actual Universidad de Cádiz, No 3 Páginas, 2005. pp.161- 171.
} 


\subsection{1.- Aplastar y Someter.}

Los golpes de estado son en sí mismo un acto de violencia, y no sólo de violencia contras las instituciones sino que fundamentalmente un tipo de violencia que afecta a la sociedad completa como señala Tilly, estos buscan infligir daños físicos inmediatos a personas u objetos lo que incluye la retención por la fuerza de personas u objetos pasando por encima de cualquier restricción o resistencia y además implica que existen autores de los daños y coordinación entre las personas que realizan los actos de daño o violencia. ${ }^{294}$

A su vez, esta forma de dañar a la sociedad tiene una propensión a realizar y cometer actos de violencia en el contexto de una crisis política, lo que implicaría el uso de la fuerza y de las amenazas de un grupo minoritario con recursos coercitivos. Estos grupos al asumir el control del poder por la vía violenta en cualquiera de sus formas se convierte a su vez en una acción ilegitima, porque viola y violenta la institucionalidad del mismo Estado. A este respecto, se debe señalar que pese a los intentos por demostrar, por parte de los políticos afines a la dictadura, que esta fue una acción política, un golpe nunca es una acción de verdadera política, una reacción violenta que permite un cambio de poder, hacia una determinada élite que cuenta con ciertos privilegios, ya sea el uso de las armas (el ejército) o el uso de ciertos mecanismos burocráticos que les permite hacerse del poder o recuperarlo (los colaboradores). Así, la implementación de un Golpe de Estado pasa por la necesaria existencia de un grupo dispuesto a derribar por la fuerza y que posee instrumentos coactivos y hombres dispuestos apoyarlos.

El 11 de septiembre de 1973 los militares no sólo terminan con el proyecto de la Unidad Popular instalando un régimen de terror, sino además le permite crear por la fuerza un nuevo orden, una nueva Constitución y una política orientada no hacia la sociedad civil, sino que con una clara

\footnotetext{
${ }^{294}$ TILLY, Charles. Violencia Colectiva. Editorial Hacer, Barcelona, 2007. p. 3.
} 
orientación alejada de la tradición republicana y con una tendencia neoliberal y de corte autoritario.

Pero esto no se dio por el uso exclusivo de la fuerza "bruta", ésta necesitó de una fuerza civil y tecnócrata que le colaborara para lograr su legitimación. En este sentido, la derecha, el empresariado y el liderazgo de Jaime Guzmán allanaron el camino legal para utilizar diversos mecanismos para legitimar la dictadura, de tal forma de consolidar una Estado con bases en el autoritarismo legal y así fue ejecutado en temprano Decreto Ley $\mathrm{N}^{\circ} 788$ que plantea la idea de un Poder Constituyente que recae sobre la Junta, diciendo: "Que la Junta de Gobierno ha asumido desde el 11 de Septiembre de 1973 el ejercicio de los Poderes Constituyente, Legislativo y Ejecutivo"295 De esta manera se destruye el anterior aparato constitucional de 1925 y se construye una nueva institucionalidad bajo una nueva forma de Estado, autoritario, mezcla entre el mundo civil y los militares. Unos aportaran con el conocimiento técnico-teórico y los otros entregarán las herramientas coactivas para llevar a cabo los planes necesarios para esta transformación.

La violencia fue entonces la garantía para el régimen de que no habría oposición a sus transformaciones sociales, económicas ni políticas. Les garantizó la total libertad de acción, la plena autonomía de los cuerpos sociales y además la plena seguridad que ante cualquier oposición o cuestionamiento a sus planes ellos se impondrían. Algunos comparan la Dictadura con el autoritarismo tradicional, ${ }^{296}$ pero este será distinto en diversas formas, principalmente porque posee una nueva configuración que incluyen elementos autoritarios, en la cual el terror sirvió de catalizadora de las transformaciones del Estado, que a su vez facilitó el trabajo de los

\footnotetext{
${ }^{295}$ LOVEMAN, Brian; LIRA, Elizabeth. Arquitectura política y seguridad interior del estado: Chile 1811-1990, Dibam, Santiago, 2002. p. 393

${ }^{296}$ CORVALÁN, Luis. Nacionalismo y Autoritarismo durante el siglo XX en Chile. Los orígenes, 1903-1931, Ediciones UCSH, Santiago, 2009. p. 35.
} 
economistas de Chicago, los Ingenieros y Políticos de derecha pro-golpe, a que aportaran en dicha transformación profunda. ${ }^{297}$ En resumen, la mano militar aplastó, el apoyo civil sometió y en un trabajo de corto y mediano plazo se obtuvo frutos en el largo plazo. ${ }^{298}$

\subsection{2.- Destruir}

No bastaba con aplastar y someter bajo los cambios políticos constitucionales realizados a partir de los años ochenta. Sino que había que destruir completamente el "germen marxista" de la sociedad. Quitar todo atisbo de estatismo, socialismo y purificar la política. Para esto había necesariamente que destruir.

Basta con dar una mirada rápida a los Informes Rettig y Valech ${ }^{299}$ para darse cuenta que la situación en la Dictadura era inhumana, las persecuciones, torturas y desapariciones fueron sistemáticas desde el primer día. Desde el mismo 11 de septiembre de 1973 varias unidades blindadas y de infantería del ejército atacaron el Palacio de La Moneda (sede de gobierno) mientras aviones de la Fuerza Aérea lo bombardearon, generando una imagen terrorífica en la población. En este escenario el Presidente Salvador Allende se suicidó con su propia arma.

Desde ese instante y decretado el toque de queda en todo Chile, varios Ministros de gobierno y colaboradores cercanos al Presidente fueron detenidos y llevados a centros ilegales de

\footnotetext{
${ }^{297}$ O’DONNELL, Guillermo. Contrapuntos, Ensayos escogidos sobre Autoritarismo y Democratización, Editorial Paidós, Buenos Aires, 1997. p. 104.

${ }^{298}$ Véase por ejemplo el trabajo de la periodista Naomi Klein, acerca de la política brutal de Shock para instalar la economía neoliberal, donde el Chile de Pinochet se presenta como el caso experimental en el mundo. KLEIN, Naomi. La doctrina del shock: El auge del capitalismo del desastre. Planeta, España. 2012.

${ }^{299}$ Para ver los informes completos véase: Informe de la Comisión Nacional de Verdad y Reconciliación (Informe Rettig) en: $<$ http://www.ddhh.gov.cl/ddhh rettig.html> y el Informe de la Comisión Nacional sobre Prisión Política y Tortura (Informe Valech) en: $<$ http://www.comisionvalech.gov.cl/InformeComision.html $>$
} 
detención. Se apagaron las antenas de las principales radios y las afines al Gobierno de la Unidad Popular incluso fueron allanadas. Sin mucha espera en los sectores rurales y urbanos se comenzaron a hacer arrestos a dirigentes de la Reforma Agraria y de los cordones industriales, algunos de ellos fueron ejecutados en el mismo lugar donde se les detenía.

Al día siguiente, el Bando Militar $\mathrm{N}^{\circ} 5$ declara unilateralmente el Estado de Guerra interna en Chile, con lo cual se abrían las puertas a cualquier tipo de acción, porque desde ese momento se consideraría de combate. Se proscribió el partido Comunista, Socialista y demás organizaciones de izquierda; a su vez el resto de partidos fueron suspendidos cuando se disolvió el Congreso Nacional. También fue disuelto el Tribunal Constitucional, los registros electorales fueron quemados y se ordenó el cese de funciones de Alcaldes, Regidores y Rectores de las universidades públicas. Para mantener la situación en mayor tensión se solicitó también a la población a denunciar a los líderes y adherentes de la Unidad Popular como «traidores a la Patria».

Los días siguientes no fueron menos terribles, se llamó a aquellos que tuvieran cargos y representatividades de grupos sociales a entregarse a las comisarías para regularizar su situación y se detuvieron a miles de personas y fueron conducidas el Estadio Chile y luego al Nacional. Algunas de las que fueron nombradas en ese lugar nunca más se les vio y fueron ejecutadas en el mismo estadio. Las poblaciones populares tales como La Legua, La Victoria y La Bandera fueron allanadas y sus pobladores detenidos en masa. Según los informes "las estimaciones acerca del número de gente muerta durante o inmediatamente después del golpe varían desde menos de 2.500 a más de 80.000 . Una lista de 3.000 a 10.000 muertos cubre las estimaciones más fiables." 300

\footnotetext{
${ }^{300}$ ROJAS, María Eugenia. Represión politica en Chile. [En línea] [fecha de consulta 12 de octubre de 2013] disponible en internet $<$ http://www.derechos.org/nizkor/chile/libros/represion/cifras.html>
} 
En junio de 1974 la Junta Militar crea la DINA, a cargo del teniente Coronel de ingenieros Manuel Contreras, todo esto pese a que el Jefe de Carabineros no estaba de acuerdo ya que se creaba una entidad ajena a todo control institucional, a las órdenes y que quedaría al mando directo del General Augusto Pinochet. De aquí en adelante la lista de los horrores es enorme, no sólo con los casos emblemáticos, como el caso Hornos de Lonquén, Caravana de la muerte, caso Quemados, Caso Letelier y el caso Degollados. ${ }^{301}$

Se crearon centros de detención y tortura, se aplicaron métodos de extorsión física y psicológica, se generó una serie de asesinatos o desapariciones, todos con total impunidad y en el mejor de los casos se inicio un proceso de exilio. En general para llevar a efecto esta tarea se coordinaron los servicios de inteligencia de las fuerzas armadas en colaboración con militantes del movimiento nacionalista "Patria y Libertad", particularmente en la persecución de miembros de movimientos de izquierda, por ejemplo el MIR (Movimiento de Izquierda Revolucionaria).

Posteriormente serán la DINA que luego se convertirá en la CNI, Central Nacional de Informaciones, las que comenzarán (1973-1990) a operar con efectivos provenientes de los otros departamentos de inteligencia, las cuales actuaran con total impunidad. Los documentos encontrados ${ }^{302}$ dan cuenta de sus tareas, entre las cuáles estaba espiar en toda unidad clave del Estado, fueran estos inclusos cercanos al régimen, pero además incluso investigar cada contratación hecha en estas mismas instituciones. Estas unidades de información, además entregaban información acerca de los detenidos o las acciones opositoras, coordinaban operaciones y nombramientos dentro y fuera de Chile. Estas organizaciones tuvo cuatro

\footnotetext{
${ }^{301}$ Se puede ver detales de varios de estos casos asociados a la investigación de la Vicaría de la Solidaridad en: INSUNZA, Andrea y ORTEGA, Javier (Eds.). Los archivos del cardenal. Casos reales. Editorial Catalonia-UDP. Chile. 2011; INSUNZA, Andrea y ORTEGA, Javier (Eds.). Los archivos del cardenal 2. Casos reales. Editorial Catalonia. Chile. 2014.

${ }^{302}$ DORAT, Carlos y WIBEL, Mauricio. Asociación ilícita. Los archivos secretos de la dictadura. CEIBO ediciones. 2012.
} 
personas a cargo, y se cuentan entre los más horribles perseguidores a Manuel Contreras, Odlanier Mena, Humberto Gordon (ya fallecido) y Hugo Salas, el primero y último siguen cumpliendo pena de cárcel, el segundó también fue acusado y condenado por crímenes de lesa humanidad y se suicidó en su casa, estando con permiso (dejó una carta donde condena la acción de la justicia hacia los que se consideraban salvadores de la patria).

Un respiro a las atrocidades era dado por el trabajo humanitario cumplido, en un primer momento, por organismos de diversas Iglesias -católicos, protestantes, judíos y ortodoxosagrupadas en el Comité Pro Paz que marcó el comienzo de un trabajo en defensa y promoción de los derechos humanos que quedo marcado para siempre en el trabajo de la Vicaría de la Solidaridad, la Comisión Chilena de Derechos Humanos, el Comité de Defensa de los Derechos del Pueblo, el Servicio Paz y Justicia, la Fundación de Ayuda Social de las Iglesias Cristianas y otras instituciones. ${ }^{303} \mathrm{Su}$ ayuda es un caso de estudio a nivel latinoamericano, ya que a través de ellos se pudo salvar mucha gente del asesinato, prestar ayuda judicial o incluso ayudar a escapar de la mano de los organismos represores.

No profundizaré en cada detalle de los horrores sufridos por miles de chilenos que fueron destruidos, unos literalmente, otros psicológicamente, ya que hay suficiente material testimonial que declara dichas vejaciones. Sin embargo, para dimensionar el daño generado en la población y específicamente entre los sobrevivientes se pude resumir en e el siguiente relato escogido aleatoriamente de la serie de testimonios entregados en México durante el año 1975 a la Tercera Sesión de la Comisión Internacional, de la Junta Investigadora de los Crímenes de la Junta Militar en Chile:

\footnotetext{
${ }^{303}$ HUTCHISON, Elizabeth y ORELLANA, Patricio. El movimiento de derechos humanos en Chile, 1973-1990. Centro de Estudios Políticos Latinoamericanos Simón Bolívar, Chile. 1991; VICARÍA. Vicaría de la Solidaridad : historia de su trabajo social. Eds. Paulinas, Chile. 1991
} 
Señores miembros de la Comisión Internacional, de la Junta Investigadora de los Crímenes de la Junta Militar en Chile - Ciudad de México 1975

A las 18,30 hrs. fuimos trasladados a la Escuela Militar y encerrados en habitaciones con guardia a la vista. Continuaban llegando más detenidos de diferentes partes de Santiago a la Escuela; estos eran Ministros, Jefes de Partidos de la UP, Subsecretarios, Senadores, etc.

(...)El sábado 15 de septiembre fuimos trasladados a la Base Aérea El Bosque. En la Base El Bosque fuimos nuevamente registrados, y nos robaron los relojes y encendedores. A los que reclamaban se les golpeaba brutalmente. Después nos embarcaron en un avión y nos llevaron a Punta Arenas. Un oficial del avión era brasileño. Llegamos a Punta Arenas como a las 20 hrs. Se nos amarraron las manos y se nos puso una capucha en la cabeza, fuertemente apretada en el lugar de los ojos, todo este entre golpes e insultos.(...). Al desembarcarnos de la tanqueta ya e el interior del Puerto Militar, le hicieron una pequeña curación al compañero Vergara. Para llegar a la barcaza que nos trasladaría a la isla Dawson nos hicieron pasar por más de 8 subiendo y bajando escaleras en un estúpido alarde de crueldad, mientras nos fotografiaban de todos los ángulos.

Ya en el interior del Campo fuimos llevados a presencia del Comandante, quien nos dijo que éramos prisioneros de guerra (?) y cualesquier insubordinación, intento de fuga, no cumplimiento de una orden que nos diera "un soldado del glorioso Ejército de Chile" sería castigado con el fusilamiento inmediato.

En la isla había un campamento con cinco barracas en las que estaban los detenidos de Punta Arenas y de la Tercera Zona Naval que creo abarca hasta Puerto Montt. Ellos eran más o menos 130. Una de estas barracas era de los condenados. Estos compañeros habían sido condenados por los Tribunales Militares. En la isla, el total de ellos ascendía a 52. Los demás presos estaban sujetos a sumario o prisión preventiva, de acuerdo a las leyes implantadas por la dictadura. El total de prisioneros en la isla ascendíamos más o menos a 160 hombres, incluyéndonos a nosotros que éramos 36. 
Sería conveniente solicitar en los organismos internacionales que se verifique visualmente si la isla fue totalmente evacuada. Nuestro grupo fue el primero en salir de ella el 8 de mayo de1974. Los demás detenidos quedaron en la isla.

El modo de operar en los interrogatorios era el siguiente: se encerraba a los detenidos en un calabozo inmundo, sin servicios higiénicos, con lo que nuestras necesidades físicas teníamos que hacerlas en el mismo calabozo. Muchos compañeros padecían de diarreas crónicas provocadas por la mala alimentación y las pésimas condiciones sanitarias de ese calabozo. Éramos sacados de uno por uno. A mí me desnudaron completamente, me amarraron fuertemente las manos y los pies y me vendaron los ojos. Todo esto lo hacía un cabo o sargento acompañados por dos o tres soldados, entre bromas soeces, insultos y los primeros golpes. En el ejército existen muchos individuos que componen estos grupos de interrogatorios que sufren desviaciones sexuales o son homosexuales, porque no se explica de otra manera el placer de tirarle los testículos y el miembro a los prisioneros, gozando estos degenerados con las exclamaciones de dolor de los atormentados. Una vez efectuando estos preámbulos, entraban al lugar dos o tres individuos que se identificaban diciendo que eran Fiscales de la Marina, Aviación, Ejército o Carabineros y que el prisionero debía decir la verdad y confesar todo lo que supiera, si no ellos se la sacarían de otra manera.

En mi caso ellos querían saber que estaba haciendo en La Moneda el día 11 y que cargo secreto tenía en la Presidencia y mi relación con el supuesto plan Z. Cuando yo les expliqué que era un profesional y que como tal me desempeñaba en el cargo de Jefe del Depto. de Cine y T.V. de la Presidencia, principiaron los golpes, culatazos, puntapiés, amenazas de fusilamiento, etc. Yo sufrí cuatro interrogatorios de esta especie. En uno de ellos me aplicaron corriente en los órganos genitales, en el ano y en la columna vertebral. En otro interrogatorio me dieron un culatazo feroz en la cara, botándome dos muelas y rompiéndome premolares y mandíbulas. Con ese sistema es sencillo hacer firmar cualquier confesión a un detenido. En mi caso, como yo no había hecho nada de 
las cosas que me imputaban, me mantuve en la negativa. Una vez perdí el conocimiento. De todas maneras el procedimiento que usan es tan cruel, inhumano y salvaje que es casi imposible resistirlo, porque si pasan al cuarto grado como ellos dicen y que consiste en golpear y atormentar al prisionero hasta que pierde el sentido, enseguida lo reaniman, le preguntan y vuelven a atormentarlo para que confiese. Es así como han muerto as manos de estos salvajes muchos compañeros nuestros; otros han confesado cosas que no existen o que no han hecho.

Para vergüenza de Chile, de la Humanidad, es así como aplica la justicia el ejército chileno. ${ }^{304}$

Los testimonios no se resumen a "ese lado de la vereda" también otros hombres valientes dieron dado cuenta de los brutales crímenes acontecidos en Chile durante la Dictadura, el mismo Juez René García Villegas quien fue uno de las primeras autoridades en reconocer que existía la tortura en Chile quien publicó en 1990 un libro testimonial acerca de sus vivencias en torno a la situación dramática que se vivía en Chile, señalando enfáticamente en sus páginas: “Quiero ser testigo. Testigo sobre mi país al que amo entrañablemente (...) Quiero ser testigo de los avatares de esta patria mía, de horas y días de sombra de más de 16 años (...) Falazmente se ha dicho que todas estas barbaridades se justificaban porque en Chile estábamos en guerra. Soy testigo de que en Villarrica y en mi extensa jurisdicción no vi ni oí hablar de ninguna guerra. Lo que me consta es , en cambio, el genocidio cometido." ${ }^{305}$

Las atrocidades vividas son incontables, sin embrago su objetivo es aun más dañino y perdurable.

\footnotetext{
${ }^{304}$ SILVA, Adolfo. Testimonio de Adolfo Silva González. Jefe del Depto. De Cine y T.V. de la Oficina de Informaciones y Radiodifusión de la Presidencia de la República-Chile. [En línea] [fecha de consulta 12 de diciembre de 2014] disponible en $<$ http://www.memoriaviva.com/testimonios/testimonio de adolfo silva gonzalez.htm $>$

${ }^{305}$ GARCIA, René. Soy testigo. Dictadura, tortura e injusticia. Editorial Amerinda. Santiago de Chile. 1990. pp. 17-33.
} 


\subsection{3.- Transformar}

Para algunos resultó y resulta difícil comprender el verdadero objetivo de la Dictadura ese 11 de septiembre de 1973. Como hemos visto, no era suficiente con aplastar y someter, sino que además debía aterrorizar, ¿con qué propósito? así lo resume Jaime Castillo Velasco en un libro que replica las memorias de Pinochet:

“...cabe concluir que el golpe de 1973 no fue para restablecer la institucionalidad democrática, quebrantada por el Gobierno de Allende. El propósito verdadero, se puede deducir, era el de establecer, por largo tiempo, un régimen autoritario de nuevo cuño, en desmedro de los valores y normas de la democracia tradicional. No se creía en esta clase de principios. La tesis fue nítidamente expuesta en las "apreciaciones" formuladas por los equipos de evaluación que funcionan en el Ejército y de los cuales documental libro "El Día Decisivo",todo bajo la dirección del mismo autor de las Memorias. El texto ha sido transcrito en el citado libro. Allí se dice, en efecto, lo que sigue: Estimamos que la acción militar que se realizará necesitará mantener el poder durante un número prolongado de años hasta la recuperación integral y total del pais." 306

De esta manera se pasó de ser una intervención militar por un lapso breve y hasta que las cosas se "normalizaran" a un periodo más extenso con un objetivo claro: transformar la sociedad. Y así lo señala el propio Pinochet en sus memorias:

"Mi idea al respecto era por cierto muy diferente. Si el Ejercito y las FFAA intervenían contra el Gobierno marxista, seria para producir cambios trascendentales en los más amplios y variados aspectos de la vida nacional, a fin de corregir las gravísimas deformaciones que la política tradicional había ocasionado con el correr de los años.

\footnotetext{
${ }^{306}$ CASTILlO VELASCO, Jaime. ¿Hubo en Chile violaciones a los derechos humanos?: comentario a las memorias del general Pinochet. Editora Nacional de Derechos Humanos. Chile. 1995. p. 21.
} 
Por lo tanto, las Fuerzas Armadas tenían que permanecer en el Poder un periodo indeterminado hasta modernizar la vida chilena, restablecer la convivencia, crear un régimen institucional acorde con los problemas y las amenazas de la época y dejar a la Nación en condiciones de defender su nueva democracia. De otra manera era preferible no hacer absolutamente nada, pues si todo fuera a culminar en el retorno de ciertos políticos, volvería el país a corto plazo aún peor de la que vivíamos ${ }^{307}$

Estas transformaciones como ya hemos ido delineando tiene que ver con cambios en la economía (neoliberalismo) y en el gobierno (autoritarismo) de la mano del uso de la fuerza, la violencia y el terror. Sin embargo, faltaba algo igual de relevante, penetrar en la cultura y la sociedad.

La Dictadura Militar es principalmente un régimen de tipo autoritario y aunque sus seguidores intenten demostrar que no existió ni existe lo que podríamos denominar un "pinochetismo" y por lo tanto fue un régimen libre de ideológica. Es claro, que el principal soporte de la Dictadura fueron las armas y la violencia, pero también, gracias al aporte de civiles, se va creando un entramado institucional y cultural. ${ }^{308}$ Sus ideas se fundamentarán principalmente en el antimarxismo, el autoritarismo, el sentido de patria, la importancia de las tradiciones y el conservadurismo cristiano (tanto de la Iglesia Católica como de la Iglesia Evangélica, especialmente la Metodista Pentecostal).

De hecho, ya en la Declaración de Principios de 1974 se plantea una idea de la concepción de hombre y el fin del Estado, esbozando una visión filosófica y doctrinaria. En el caso de la dictadura chilena esto es claro, ya que aunque los militares controlan el país de forma violenta, son los civiles aliados al régimen los que van orientando y estableciendo las pautas de la

\footnotetext{
${ }^{307}$ PINOCHET, Augusto. El Dia Decisivo: 11 de septiembre de 1973. Editorial Andrés Bello, Chile. 1979. p. 72

${ }^{308}$ DURÁN, Sergio. Ríe cuando todos estén tristes. El entretenimiento televisivo bajo la dictadura de Pinochet, Editorial LOM. Santiago. 2012.
} 
creación del nuevo sistema ${ }^{309}$. Con todo la dictadura en Chile quería hacer pensar que su intención no era transformar a la sociedad, por lo menos de manera patente, de hecho se señalaba con insistencia que la idea era justamente la contraria, la de despolitizar y desideologizar completamente el país (borrar el cáncer marxista).

En contra de lo que se podría pensar, fue justamente esa insistencia por des-ideologizar la que reformuló lo cánones de la sociedad, politizando "negativamente" a la población bajo la lógica de la condena a los políticos y la política y, en contraposición, exaltando a un líder que hace “cosas" y resuelve problemas. Esto se dio pese a los estallidos de violencia popular, especialmente en 1982 con las huelgas, y tras un breve periodo de recomposición civil en pro del apoyo al régimen o a la oposición tanto en el Plebiscito de 1988 como en las elecciones de 1989. El pueblo chileno, fuertemente marcada por esta despolitización ideológica buscada deliberadamente durante la dictadura y fortalecida con las políticas de la Concertación, se ha transformado profundamente no en propiamente una sociedad civil, sino en una sociedad mercantilizada y de consumo.

Esta transformación política de los chilenos sintoniza con las ideas del libre mercado que fueron sembradas durante los años ochenta. Esta forma de manipulación ideológica es clara y presente en los regímenes que Linz cataloga como totalitarios, porque utiliza el poder como "violencia legítima" para controlar la política y legitimarse. ${ }^{310}$ Los ciudadanos participan de esta legitimación, no sólo a través de la participación en la burocracia estatal, sino también por medio de una amplia base social que apoya al régimen. Patente de esto es el discurso de Pinochet el 9 de Julio de 1977 en Chacarillas. Evento que fue convocado por el Frente Juvenil

\footnotetext{
${ }^{309}$ RUBIO, Pablo. Los civiles de Pinochet. La derecha en el régimen militar chileno, 1983-1990. Dibam-Centro de Investigaciones Diego Barros Arana, Santiago, 2013.

${ }^{310}$ LINZ, Juan J. "Totalitarianism and Authoritarian Regimes”, 175-411, en GREENSTEIN, Fred y POLSBY, Nelson (eds.), Handbook of Political Science 3, Macropolitical Theory. Reading, Mass.: Addison-Wesley Press.. 1975.
} 
por la Unidad Nacional, donde según el periódico El Mercurio, en esta reunión los jóvenes eran la "representación simbólica de la juventud chilena en su compromiso permanente con la tradición y los valores fundamentales del país" ${ }^{311}$. Quienes participaron de esta reunión, cuya magnificencia y simbolismos eran una reminiscencia a los congresos del Partido Nacionalsocialista Alemán con una gran marcha con antorchas y banderas, fueron activos participantes y favorecidos por la Dictadura Militar y que lograron hacer un nicho político para el futuro, en plena democracia y hasta la actualidad.

En lo concreto el Régimen militar movilizó recursos que buscaron crear una imagen social de la dictadura a través de varias instituciones como el CEMA Chile, la Secretaría Nacional de la Mujer, el Frente Juvenil de la Unidad Nacional y la Dirección de Organizaciones Civiles, el uso de los medios de comunicación y toda una red de asistencialismo que sirvió como plataforma para instalar sus ideas. Como señala Verónica Valdivia

"La historia del Régimen militar chileno ha estado marcada por la represión, el carácter neoliberal del proyecto refundacional y el autoritarismo de su nueva institucionalidad. La imagen que ha emergido ha sido la de una dictadura asociada a una tecnocracia y los grandes grupos económicos, habiendo sido el instrumento para reimponer el capitalismo en Chile y lograr su integración al capitalismo transnacionalizado. Esta perspectiva ha oscurecido otros aspectos de esa experiencia, como su relación con actores sociales diferentes, desfavoreciendo una mirada más compleja que nos permita comprender el arraigo del general Augusto Pinochet y del régimen militar en grupos ajenos al empresariado y la clase alta. (...) Tal fenómeno pudo observarse durante el plebiscito sucesorio de 1988, donde Pinochet obtuvo el 43\% de los sufragios en un espectro social más amplio que el supuesto porcentaje.

\footnotetext{
${ }^{311}$ EL MERCURIO, Santiago de Chile, 9 de Julio de 1977.
} 
(...) La noche del 11 de septiembre de 1973, cuando la Junta Militar hizo su primera aparición pública, el comandante en jefe de la Fuerza Aérea, general Gustavo Leigh Guzmán, hizo explícita la naturaleza del nuevo gobierno. En esa oportunidad comunicó que el país estaba en guerra, aunque de un tipo particular, lo cual implicaba una misión específica. Esta se resumía en la frase: "Tenemos la certeza, la seguridad de que la mayoría del pueblo chileno está contra el marxismo" (...) La erradicación del "cáncer marxista" de la sociedad chilena fue enfrentada por las autoridades militares, en primer lugar, reconstruyendo los imaginarios sociales del enemigo. Si el marxismo y los marxistas habían sido parte de la vida nacional, integrantes plenos de la democracia chilena, ellos debían ser extirpados, considerando las características que las autoridades y sus partidarios les atribuyeron. Así, la izquierda fue transformada en una secta de criminales, asesinos, al servicio de intereses extranjeros totalitarios... En consecuencia, romper con el marxismo no significaba hacerlo con el "pueblo chileno", el que fue claramente redefinido. De el, como hemos apreciado, fueron expulsados los marxistas y sus colaboradores -calificados de antipatriotas-, quedando constituido por los sectores contrarios a la Unidad Popular. ${ }^{312}$

Claramente se puede señalar que la Dictadura allanó el camino, no sólo para instalar un modelo económico, sino que aparejado a esto para transformar a la sociedad. Visto así, el modelo de transición también mediatizado, como hemos visto, por la Dictadura y su legislación establecería ciertas pautas en base a la violencia, al horror, pero también a la creación de una nueva cultura. El resultado de esto, se verá en varios aspectos, como el que respecta a este capítulo, la política de derechos humanos y memoria.

\footnotetext{
${ }^{312}$ VALDIVIA, Verónica. "¡Estamos en guerra, señores!". el Régimen militar de Pinochet y el "pueblo", 1973-1980” Revista Historia. I. 43. 2010.
} 


\section{2.- EN LA MEDIDA DE LO POSIBLE.}

Hasta el año 2014, el total de causas que permanecen abiertas por crímenes de lesa humanidad ocurridos durante la dictadura cívico-militar, es según datos oficiales de 1.045. Hasta esa misma fecha el Programa de derechos Humanos (creado en 1997) es querellante en 903 causas por detenidos desaparecidos y ejecutados calificados, correspondiendo finalmente a 1.759 víctimas. Por otra parte, a ese mismo año el presupuesto gastado en Memoriales y otras obras de reparación simbólicas ascendió a \$ $103.523 .868 .{ }^{313}$ ¿Ha sido suficiente?

\subsubsection{La medida de lo posible.}

La frase más recordada y que enmarca la política en derechos humanos, fue la pronunciada por Patricio Aylwin a fines de 1990 y recogida por la prensa internacional que recordó y puso en el tapete la atadura de la Transición, cuando señaló que se debe proseguir: "la tarea ineludible de esclarecer la verdad y hacer justicia, en la medida de lo posible, respecto a situaciones del pasado aún pendientes, o que constituyen heridas abiertas en el alma nacional." ${ }^{314}$ Este afán de política real o de sinceridad simplemente marcará la pauta de las políticas vinculadas a las violaciones de los derechos humanos.

Si hacemos un recorrido por la historia reciente y la política de Derechos humanos, quizás la cuenta total no es tan alegre. Hacia 1990 con Patricio Aylwin como presidente y representante de la Concertación (Coalición de centro-izquierda). Este grupo gobernará desde 1990 hasta el

\footnotetext{
313 PROGRAMA DE DDHH-CHILE. Balance año 2014 Programa de DDHH. [En línea] [fecha de consulta 2 de marzo de 2015] disponible en internet $<$ http://www.ddhh.gov.cl/filesapp/balanceprensa.pdf $>$

${ }^{314}$ DIARIO EL PAÍS. “Aylwin reitera que investigará a fondo la violación de los derechos humanos en Chile”. 2 de Enero de 1991. [fecha de consulta: 5 de mayo del 2015]. Disponible en internet: $<\underline{\text { http://elpais.com/diario/1991/01/02/internacional/662770810 850215.html > }}$
} 
2010, aceptando la constitución de 1980 y la transición tendrá su base en lo que se conocerá como una política de los acuerdos. ${ }^{315} \mathrm{Si}$ bien, debemos reconocer el avance en el esclarecimiento de la verdad sobre los hechos ocurridos en dictadura, especialmente lo que guarda relación con las políticas de reparación adoptadas por el Estado. Como son por ejemplo la Comisión Nacional de Verdad y Reconciliación (Informe Rettig), la Corporación Nacional de Reparación y Reconciliación, la Mesa de Diálogo y la Comisión Nacional sobre Prisión Política y Tortura (Informe Valech), no es menor, como veremos más adelante que el principio sobre el que se basó la solución del problema fue el de los mínimos.

La primera Comisión (Rettig) fue creada en 1990 y tuvo como objetivo fundamental determinar la verdad: "La Comisión calificó 2.296 casos de graves violaciones a los derechos humanos: desapariciones de personas detenidas, ejecuciones, torturas con resultado de muerte cometidos por agentes del Estado o personas al servicio de éstos, secuestros y atentados contra la vida de

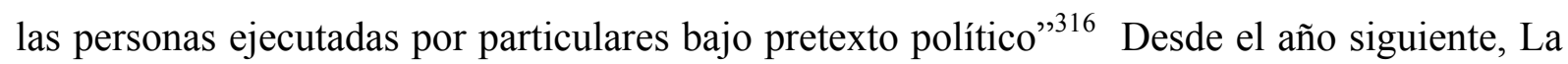
Corporación se encargó principalmente de coordinar, ejecutar y promocionar las acciones que dieran cumplimiento a las recomendaciones de la Comisión Rettig. También se investigaron nuevos casos, que sumaron hacia 1992 un total de 3195 personas ejecutadas, detenidas desaparecidas o torturadas hasta la muerte.

Por su parte, la denominada "Mesa de Dialogo" fue conformada por el segundo presidente de la Concertación, Eduardo Frei el año 1999. Esta mesa cumplió la función de recabar información sobre el destino de 200 detenidos desaparecidos; para esto se designaron jueces que investigarían exclusivamente los casos de violaciones a los derechos humanos y los altos

\footnotetext{
315 RICHARD, Nelly. "Recordar el olvido". En OLEA, R. \& GRAU, O. (Edits.), Volver a la memoria. Editorial LOM. Chile. 2001. pp. 15-21.

${ }^{316}$ INSTITUTO NACIONAL DE DERECHOS HUMANOS. Informe anual. Situación de los derechos humanos en Chile. [En línea] Gobierno de Chile. 2010. [fecha de consulta 2 de marzo de 2014] disponible en internet $<$ http://www.indh.cl/primerinforme-anual-2010-de-derechos humanos-en- chile>
} 
mandos de las Fuerzas Armadas aceptaron formalmente su responsabilidad ante estos hechos ocurridos en dictadura, quienes fueron parte de la Mesa de Diálogo (junto a representantes del gobierno, de las iglesias de Chile, juristas y psicólogos)

El año 2003 fue otro año clave para la política de los derechos humanos. Ricardo Lagos -tercer presidente consecutivo de la Concertación- propuso la formación de una Comisión que investigara los casos de prisión política y tortura por motivos políticos ocurridos entre 1973 y 1990, “(...) recogiendo así las demandas de las organizaciones de víctimas sobrevivientes y organizaciones de la sociedad civil. Nació así la Comisión Nacional sobre Prisión Política y Tortura (Comisión Valech), que entre el 13 de noviembre de 2003 y el 1 de junio de 2005 calificó 28.459 víctimas." ${ }^{317}$ En este caso, se entregaron testimonios de manera voluntaria y secreta por lo que algunos casos aún no son concoides por la opinión pública. La Comisión fue reabierta el año 2010 y su objetivo ha sido principalmente reparar el daño a las víctimas a través de una pensión mensual, gratuidad en la salud pública y beneficios para estudiar.

Por otra parte, un importante avance se dio el año 2009 cuando se creó el Instituto Nacional de Derechos Humanos, el año 2009 el cuál por objeto la promoción y protección de los derechos humanos reconocidos y protegidos por la Constitución de la República y las leyes, los tratados internacionales de derechos humanos vigentes en Chile y los principios generales de derecho, aceptados por la comunidad internacional. Como hito para la Memoria, la cuarta gobernante de la Concertación Michelle Bachelet inaugura el Museo de la Memoria y los Derechos Humanos.

Visto de esta manera, el Estado no aparece jugando un rol pasivo, lo cual es bastante cierto. Sin embargo los avances más profundos, especialmente los referidos a la Memoria, no han sido fruto de políticas gubernamentales sino que más bien gracias a la organización de la Sociedad

\footnotetext{
${ }^{317}$ INSTITUTO NACIONAL DE DERECHOS HUMANOS. Op. Cit. p. 60.
} 
civil. Quizás los avances, mediocres para algunos, han sido más bien el resultado de la política de los acuerdos perpetuados hasta el día de hoy.

\subsubsection{Más allá de lo posible}

Como hemos visto, si bien el Estado ha participado y avanzado en crear una política de derechos humanos, 1 búsqueda de verdad, reconciliación y memoria han sido más bien emprendimientos han sido impulsados desde la sociedad civil, como señala Collins: "Es importante resaltar que en Chile el impulso inicial a la "memorialización" no se originó desde el Estado sino desde la sociedad civil, por lo que no estaríamos hoy debatiendo los cómo, cuándo y contenidos de un museo nacional de la memoria si no fuera por la acción de los que han interpelado y exhortado al Estado para que así sea."318 En este sentido, diversas agrupaciones lucharon desde la dictadura hasta el día de hoy para mantener vivo el recuerdo de quienes, por su ideología y participación política, fueron vulnerados. Los ex centros de ejecución, desaparición y tortura que actualmente funcionan como sitios de memoria existen gracias a la gestión de estos grupos; entre ellos, se pueden destacar el Parque por la Paz y el espacio de memorias Londres $38 .^{319}$

De hecho el mismo Instituto Nacional de Derechos Humanos reconoce que gran parte de los avances en materia de justicia han llegado gracias a“(...) la lucha que durante más de 30 años han sostenido las víctimas, sus familiares, las organizaciones de derechos humanos y los defensores de derechos humanos. En efecto, desde una prescindencia que avaló la comisión de los crímenes primero y la impunidad después, los tribunales de justicia han ido cumpliendo

\footnotetext{
${ }^{318}$ COLLINS, Cath. (2009). "Exceso de profesionalización, exceso de privatización." Conferencia Experiencias nacionales e internacionales de Museos de la Memoria. Santiago de Chile. 2009. p.1.

${ }^{319}$ Las webs de dichos espacios de memoria son: http://villagrimaldi.cl y http://www.londres38.cl
} 
gradualmente con su obligación de investigar, juzgar y sancionar a los responsables por las violaciones cometidas en el pasado."320

La mayor crítica al proceso ha sido justamente la justicia que avanza muy levemente debido a que los militares en muchos casos tienen verdaderos pactos de silencio, como se ha comprobado últimamente, ${ }^{321}$ lo que impide avanzar en condena de los responsables. En este sentido, lo sitios de Memoria y centros de investigación (como los de la misma Vicaría de la Solidaridad) han aportado para construir caminos no oficiales a veces más lentos o diversos para emprender justicia. De esta manera se han podido llevar a la justicia a ex agentes de Estado vinculados a la represión, especialmente a partir de año 2000. Según estadísticas realizadas por el Observatorio de Derechos Humanos de la Universidad Diego Portales, ${ }^{322}$ desde el 2000 en adelante un total de 771 agentes fueron enjuiciados, de los cuales 526 han sido procesados o condenados sin sentencia definitiva, 173 fueron condenados con sentencia definitiva, nunca encarcelados por recibir beneficios, 66 se encuentran en prisión efectiva y 6 fueron condenados y liberados por reducción o conmutación de sentencia.

El quiebre definitivo con la sociedad civil en torno a hacer todo "en la medida de los posible" fue el arresto de Pinochet en Londres, ya que será el mismo gobierno de Chile quien pida la extradición por razones humanitarias, la que termina por ser acogida. Sin embargo, el ver llegar a Pinochet en sillas de ruedas y luego ponerse en pie en el aeropuerto en un claro gesto de cinismo (era traído justamente por su debilidad física para enfrentar un juicio) fue un insulto a las familias de detenidos desaparecidos. Finalmente, morirá en diciembre del 2006 sin ser

\footnotetext{
${ }^{320}$ INSTITUTO NACIONAL DE DERECHOS HUMANOS. Op. Cit. p. 15.

${ }^{321}$ DIARIO EMOL “Caso Quemados: PS valora fin de pacto de silencio e insta a uniformados a seguir actuar de ex conscripto". 22 de julio del 2015. [fecha de consulta: 23 de junio del 2015]. Disponible en internet: $<$ http://www.emol.com/noticias/Nacional/2015/07/22/735344/Caso-Quemados-PS-valora-fin-de-pacto-de-silencio-e-insta-auniformados-a-seguir-actuar-de-ex-conscripto.html>

${ }^{322}$ Se pueden ver los informes en: http://www.derechoshumanos.udp.cl
} 
condenado por sus crímenes. El pacto establecido en el modelo de democracia de Pinochet había dado resultado.

\section{3.- LA MEMORIA EN EL CHILE POST-PINOCHET. ${ }^{323}$}

La historia reciente de España coincide con la de Chile en haber recorrido un camino particularmente violento y traumático. Sin embargo, confluyen en la misma dos particularidades que la diferencian del caso chileno: una guerra civil fratricida y una fuerte represión durante una larguísima dictadura; pero también una característica que las une: una transición a la democracia pacífica (sin enfrentamiento armado) y negociada.

Para el caso de España existe un sorprendente acuerdo entre la historiografía en afirmar que el peso de esta memoria traumática fue gestionado en los años de transición por medio de lo que se ha venido a llamar un "pacto de silencio", ${ }^{324}$ una "voluntad de olvido",325 o, si se quiere, una "decisión de olvido" 326 con respecto a los hechos más traumáticos del enfrentamiento armado y la dictadura. La discusión existente actualmente, sin embargo, se centra en los matices entre olvido y silencio y, obviamente, en la justificación que se haga de la Ley de Amnistía de 1977. Mientras que para unos dicha ley y dicha gestión de la memoria fue una "artimaña" para evitar

\footnotetext{
${ }^{323}$ Partes de este capítulo han sido publicados en: ACEITUNO, David, et. al. "La memoria transicional en los profesores de Historia de España y Chile.” En: PAGEZ, Joan y SANTISTEBAN, Antoni. Una mirada al pasado y un proyecto de futuro. 25 años de Investigación e Innovación en Didáctica de las Ciencias Sociales. Vol 2. UAB. Barcelona. 2013. pp. 13-20; ACEITUNO, David. "Reflexiones en torno al Chile postpinochet: la memoria, el miedo y la didáctica de la historia". Revista Nuevas Dimensiones, № 4, Santiago, Chile, Diciembre del 2013.

${ }^{324}$ MATEOS LÓPEZ, Abdón. Historia y memoria democrática. Eneida. Madrid. 2007. p. 118.

${ }^{325}$ AGUILAR FERNÁNDEZ, Paloma. Memoria y olvido de la Guerra Civil. Alianza Editorial. Madrid. 1996. p 262.

326 JULIÁ DÍAZ, Santos. "Raíces y legado de la transición.” En SANTOS JULIÁ; PRADERA, J.; PRIETO, J. (coord.) Memoria de la transición (pp. 679-682). Madrid: E1 País. 1996. p. 680.
} 
que una posible justicia penal transicional pudiera caer sobre las filas del franquismo, ${ }^{327}$ para otros fue la solución que permitió el carácter consensuado y pacífico del proceso. ${ }^{328}$

A nivel político, el deseo de paz y las prioridades institucionales y económicas, marcarían el camino tibio de las políticas públicas de memoria durante la transición, y hasta la aprobación de la constitución de 1978 se mantuvo un pacto tácito de "silencio" entre la clase política 329 . Será fundamentalmente a partir de la segunda mitad de los años noventa, cuando empiece a quedar patente que la política de "reconciliación" había respondido más a una estrategia coyuntural que a una efectiva actitud de profundización, reconocimiento y superación. Tras la victoria socialista de 2004, ese mismo año se forma una comisión interministerial para el estudio de la situación de las víctimas de la guerra civil y el franquismo y, ya en 2007, nace la conocida como Ley de Memoria Histórica de 31 de octubre de $2007^{330}$, generándose desde entonces un debate político y social que llega hasta nuestros días.

En Chile la discusión acerca de la Historia Reciente esta en ciernes, si bien se ha avanzado en temas vinculados a la Memoria no estamos ni cerca de establecer un debate profundo acerca de las limitaciones de nuestra propia política (en Chile también existió una Ley de Amnistía de 1978, derogada recientemente el año 2014) ${ }^{331}$. Salvo, el caso del Museo de la Memoria, que

\footnotetext{
${ }^{327}$ MUNIESA BRITO, Bernat. Dictadura y Transición. La España lampedusiana. II: La monarquía parlamentaria. Universitat de Barcelona. Barcelona. 2005. pp. 16-17.

328 JULIÁ DÍAZ, Santos. Op. Cit. 1996 p. 681.

${ }^{329}$ Esto no significa que no se tomaran medidas ya entonces en materia de rehabilitaciones y compensaciones a las víctimas de la guerra civil y sus familias, con un importante desarrollo legal desde 1976. Entre otras: sobre la regulación de las pensiones a los mutilados de guerra civiles y excombatientes; sobre reconocimiento de pensiones, asistencia médico-farmacéutica y asistencia social en favor de familiares de fallecidos; indemnización por tiempo de prisión; o aquellas referidas a sindicatos y partidos políticos. $\quad$ En: http://www.clasespasivas.sepg.pap.minhap.gob.es/sitios/clasespasivas/es$\underline{\text { ES/PensionesPrestaciones/PrestacionesDerivadasGuerraCivil/Paginas/PrestacionesDerivadasGuerraCivil.aspx }}$

${ }^{330} \mathrm{El}$ nombre completo es el de "Ley por la que se reconocen y amplían derechos y se establecen medidas en favor de quienes padecieron persecución o violencia durante la Guerra Civil y la Dictadura”, más conocida como Ley de Memoria Histórica.

${ }^{331}$ El decreto ley 2.191 fue presentado en 1978 como una forma de "unir a la nación". Se anunció que se concedería el beneficio a todas las personas que cometieron delitos entre el 11 de septiembre de 1973 y el 10 de marzo de 1978, con una larga lista de excepciones en la que no estaba el homicidio. Recién será derogada en el año 2014.
} 
para algunos tuvo una función más política que concreta, especialmente para la derecha que veía en ella un encono contra la Dictadura de Pinochet o que en realidad, como señaló el mismo Historiador Sergio Villalobos, el relato presente en el museo es más bien una falsificación de la historia en cuanto se encuentra aislado del resto de la historia nacional. ${ }^{332}$

Con todo será el sociólogo Tomás Moulian quien entra a un debate similar al caso español al proponer que en Chile se forjó una especie de "compulsión del olvido" que fue creando una realidad típica de sociedades que han experimentado situaciones límites. Una especie de pérdida del discurso, una carencia de palabras comunes para narrar lo vivido, lo que reafirma discursivamente los antagonismos o dualidad de siempre: trauma o victoria. ${ }^{333}$ En este sentido, desde un punto de vista teórico, la historiografía nacional ha ido abordando el tema tardíamente. Las investigaciones se han centrado en los testimonios de algunos actores del proceso político, los efectos del régimen militar, los acomodamientos de la elite en la coyuntura, el impacto de las violaciones de los derechos humanos, la transición política pactada, el rol de los militares, el papel de la Iglesia Católica y el costo social de las modernizaciones económicas a raíz de la implementación del modelo neoliberal en los ochenta.

Quien más avanzado en este sentido para el caso chileno es el historiador norteamericano Steve Stern quien señala que la memoria no es solo el recuerdo de los acontecimientos y las emociones de una experiencia, sino que es también el significado que nosotros asociamos a esa experiencia. Por eso ha establecido que existe una interacción entre las memorias "sueltas", aquellas que son parte de las vivencias individuales, y la Memoria "emblemática", que es como "una gran carpa donde hay un show en el que se van incorporando y dando sentido y

\footnotetext{
${ }^{332}$ LA TERCERA. “Autoridades e historiadores polemizan sobre el rol del Museo de la Memoria” 26 de junio del 2012. [fecha de consulta: 1 de junio del 2015]. Disponible en internet: $<$ http://www.emol.com/noticias/Nacional/2015/07/22/735344/CasoQuemados-PS-valora-fin-de-pacto-de-silencio-e-insta-a-uniformados-a-seguir-actuar-de-ex-conscripto.html> ${ }^{333}$ MOULIAN. Tomás. Op. Cit. 2002.
} 
organizando varias Memorias, articulándolas al sentido mayor", las que configuran la Memoria colectiva. $^{334}$

La memoria emblemática, por tanto, va definiendo cuales son las memorias sueltas, lo que hay que recordar, dándoles la bienvenida a la carpa y su show, a su vez, que señala cuáles son las cosas que es mejor olvidar o empujar hacia los márgenes. Para comprender mejor esta construcción de la memoria colectiva, el mismo Steve Stern recurre al concepto de "nudos problemáticos", que son los que permiten construir el puente entre los recuerdos personales y los colectivos (las memorias sueltas y las colectivas). Estos nudos son multidimensionales, y en un contexto social son capaces de focalizar a los individuos en un aspecto de la realidad. ${ }^{335}$ Los nudos problemáticos que articulan las memorias en los diversos procesos históricos pueden ser:

Nudos humanos de la Memoria: que se refieren a personas o agrupaciones claves que representan el discurso colectivo.

Nudos temporales de la Memoria: Corresponden a hecho, fechas y aniversarios que convocan determinadas Memorias emblemáticas de la sociedad. Es como volver a vivir sentimentalmente un determinado fenómeno.

Nudos materiales de la Memoria: Son los espacios físicos (y a veces objetos y artefactos) a los que se asocia determinada Memoria emblemática, pueden ser por ejemplo monumentos, memoriales, museos.

Para el caso de la dictadura, ya se han ido reconstruyendo e identificando una serie de nudos problemáticos para entender la Memoria colectiva del periodo. Todo esto, gracias a la cantidad

\footnotetext{
${ }^{334}$ STERN, Steve. Op. Cit. 2002. pp.11-33

${ }^{335}$ STERN, Steve. Op. Cit. 2002. pp. 145-177
} 
de material testimonial que existe y que se sigue recogiendo. Actualmente se ha propuesto una serie de Memorias emblemáticas acerca de las cuales se pueden articular los discursos sociales, y en particular el de los docentes, en relación con el golpe de Estado y posterior Dictadura como son: la Memoria de la salvación, de la resistencia, la moral y ética y la del olvido. ${ }^{336}$

Nelly Richard, otra de las más importantes investigadoras sobre el tema con especial énfasis en la cultura, señala acerca de la existencia de los diversos nudos y memorias aún en construcción, para el caso de la Transición chilena, que serían aún un "proceso abierto de reinterpretación del pasado que deshace y rehace sus nudos para que se ensayen de nuevo sucesos y comprensiones [...] (remeciendo) el dato estático del pasado con nuevas significaciones sin clausurar que ponen su recuerdo a trabajar, llevando comienzos y finales a re-escribir nuevas hipótesis y conjeturas para desmontar con ellas el cierre explicativo de las totalidades demasiados seguras de sí mismas." $" 337$

En este sentido el Chile Post-Pinochet se ha caracterizado por tener una política errática ${ }^{338}$ en relación a la memoria e incluso, si se quiere ser más drástico, no ha existido una política estatal de Memoria como tal hasta entrado el año 2009, cuando se crea el Instituto de Nacional de Derechos Humanos que entrega recursos para mantener monumentos o lugares de memoria de manera sistemática. Antes de esto sólo existen acciones aisladas, vinculadas especialmente a la creación de comisiones que crean archivos testimoniales que puedan eventualmente ayudar a la justicia o una serie de normas que sirvan para compensar económicamente a las víctimas. Al igual que otros aspectos de la transición, el que Chile estuviese expuesto a los ojos del mundo

\footnotetext{
${ }^{336}$ VASQUEZ Nelson y IGLESIAS, Ricardo. "La construcción de la memoria colectiva en la historia reciente de Chile. Una tarea pendiente en el mundo escolar”, en: PAGÉS y GONZÁLEZ. Historia, memoria i ensenyament de la història, Universidad Autónoma de Barcelona. 2009. pp. 114-117

${ }^{337}$ RICHARD, Nelly. Ensayos de crítica cultural sobre el Chile de la Transición. Editorial Cuarto propio. Chile. 2001. p. 29.

${ }^{338}$ COLLINS, Cath. HITE, Katherine y JOIGNANT, Alfredo. Las politicas de la memoria en Chile: desde Pinochet a Bachelet. Ed. UDP. Chile. 2013. pp. 57-58.
} 
hizo que con algunos pocos avances alcanzara gran notoriedad, como por ejemplo que se creara una Comisión nacional de Verdad y Reconciliación o que se juzgara al principal cabecilla de la Dirección nacional de inteligencia (DINA), Manuel Contreras., encarcelado en 1995. Sin embargo, se pasa por alto el entramado de control y protección que se tenía alrededor del Dictador y que impidieron avanzar en más justicia, lo que llevó en más de una ocasión a que grupos de ciudadanos se manifestaran.

A partir de 1998, una vez retirado el Dictador del ejército ${ }^{339}$ pero perpetuado ahora en la política como Senador designado, la sociedad chilena inmediatamente se dividió, lo que da cuenta de que todo lo avanzado era demasiado vago como para sanar las heridas. El punto de quiebre se dio con la detención de Pinochet en Londres ese mismo año; a partir de aquí surgirá la segunda instancia o acción de DDHH humanos, la Mesa de Diálogo (1999-2000), debido a presiones internas y externas, y posteriormente tendría lugar la creación de una segunda Comisión Nacional que durará seis años, esta vez sobre prisión Política y Tortura (2000-2006). Hay que matizar que dicha Comisión no ha estado exenta de críticas debido a que todos los testimonios recogidos han sido protegidos bajo secreto y por lo tanto no sirven a la justicia. También vale la pena subrayar que este "recalentamiento memorialístico" en 1998 debido al arresto de Pinochet va a ser el periodo más álgido para el debate acerca de lo acontecido en dictadura, pero fue más bien un hecho coyuntural antes que motivado por la política estatal.

Durante este periodo de aproximadamente diez años se planteará públicamente la necesidad de reconocimiento del pasado y se llegará a cierto acuerdo acerca de la existencia- como memoria histórica- de que hubo violaciones contra los derechos humanos por parte del Estado; con esto se pasó del simple recuerdo o memoria de "algunos" a tomar en consideración lo que sufrió la sociedad en su conjunto. Se puede concluir que el Chile "modélico" frente a la defensa de los

\footnotetext{
${ }^{339}$ Para un análisis acerca del comportamiento de las Fuerzas Armadas en la Transición y su evolución se puede leer: FUENTES, Claudio. La transición de los militares. Editorial LOM. Chile. 2006
} 
Derechos Humanos conculcados bajo la dictadura no fue $\tan$ activo $^{340}$ como se ha difundido $^{341}$ y tardó varios años en imponerse la necesidad de una memoria histórica, con responsables concretos por lo que había ocurrido durante los años de plomo. De hecho, será el ex presidente Piñera -representante de la derecha- el que hablará de cómplices pasivos y el que motivará el cierre de cárceles exclusivas para violadores de los derechos humanos. ${ }^{342}$

Desde nuestro punto de vista, en la historiografía nacional y en el espacio público recién se inicia el debate sin tapujos, y siguen apareciendo voces críticas acerca del papel jugado por los políticos en la democracia a este respecto y los supuestos pactos secretos que habrían existido para proteger a militares, como señalará recientemente Héctor Salazar, abogado de uno de los casos más emblemáticos de Chile, el caso Quemados:

\begin{abstract}
“(...) hay que tener presente un factor clave: los pactos no escritos para hacer posible la transición de la dictadura a la democracia. Nunca han sido reconocidos pero hay manifestaciones concretas por ciertas actitudes. Uno tiene que ver con el sistema económico, donde no hubo mayores problemas en llegar a acuerdo entre el poder militar
\end{abstract}

\footnotetext{
340 "Según cifras del Poder Judicial, a marzo de este año, aún se mantienen vigentes 1.056 causas, de las cuales el 10\% ha sido fallada en primera instancia y 841 casos están en proceso de sumario" en: LA TERCERA. "El largo camino que recorren los casos de DD.HH. en tribunales". [En línea] 14 de agosto del 2015. [fecha de consulta: 16 de agosto del 2015]. Disponible en internet: $\quad<$ http://www.latercera.com/noticia/nacional/2015/08/680-642882-9-el-largo-camino-que-recorren-los-casos-deddhh-en-tribunales.shtml>

${ }^{341}$ En una noticia reciente se ha acusado al gobierno de sólo promover algunas iniciativas de justicia, a propósito del caso quemados Carmen Gloria Quintana, sobreviviente de un intento de asesinato por quemadura en la Dictadura señala que cuando visitó al Gobierno en plena democracia: "La primera gran decepción la tuve un día que fui a La Moneda, me acompañó el (abogado) Héctor Salazar y mi marido y hablamos con Enrique Correa y él nos dijo 'miren, aquí hay cosas bien claras, se va a hacer justicia con tres casos emblemáticos y nada más'. El caso Prats, el caso Degollados y no recuerdo cuál era el tercero". En: EL MOSTRADOR. "Héctor Salazar sobre supuesta cita de Carmen Gloria Quintana con Enrique Correa: "No me acuerdo" [En línea] 23 de julio del 2015. [fecha de consulta: 25 de julio del 2015]. Disponible en internet: < http://www.elmostrador.cl/noticias/pais/2015/07/23/hector-salazar-sobre-supuesta-cita-de-carmen-gloria-quintana-conenrique-correa-no-me-acuerdo/ $>$

${ }^{342}$ LA TERCERA. "Presidente Sebastián Piñera y su juicio a 40 años del Golpe: Hubo muchos que fueron cómplices pasivos: que sabían y no hicieron nada o no quisieron saber" [En línea] 31 de agosto del 2013. [fecha de consulta: 1 de junio del 2015]. Disponible en internet: <http://www.latercera.com/noticia/politica/2013/08/674-540379-9-pinera-y-los-40-anos-del-golpehubo-muchos-que-fueron-complices-pasivos.shtml >
} 
saliente apoyado por la derecha y el poder político entrante. El segundo pacto, que tiene que ver con el tratamiento a las violaciones de los DD.HH. cometidas durante la dictadura fue más difuso, ya que indudablemente el poder militar pugnaba por la impunidad absoluta mientras la Concertación tenía como bandera de lucha para llegar al poder precisamente enfrentar este tema. Fruto de eso es que el Presidente Aylwin acuñó ese concepto de 'justicia en la medida de lo posible",343

\footnotetext{
${ }^{343}$ EL MOSTRADOR "Las cuentas pendientes de la Concertación en DD.HH." 30 de agosto del 2015. [fecha de consulta: 1 de septiembre del 2015]. Disponible en internet: $<$ http://www.elmostrador.cl/noticias/pais/2015/07/30/las-cuentas-pendientesde-la-concertacion-en-dd-hh/>
} 


\section{8.-LA CONSTITUCIÓN DE PINOCHET COMO}

\section{MARCO PARA UNA NUEVA ¿DEMOCRACIA?}

Durante los últimos años el debate acerca del Chile post-dictadura ha girado en torno a la vigencia de la Constitución política de 1980 e incluso en torno a su legitimidad, ${ }^{344}$ cuestión que ni siquiera los cambios realizados en 2005 por el entonces presidente Ricardo Lagos pudo apaciguar, pese a haberle llamado "un piso institucional compartido." ${ }^{345}$ Estudiar o conocer el modelo de democracia en el que estamos y la transición que la alumbró necesita incorporar necesariamente el marco regulatorio que la delineó. Guste a algunos y a otros no, la Constitución de 1980 está en vigencia y sigue siendo el marco oficial de nuestra democracia actual. Es posible que al lector extranjero le resulte extraño que esto se haya mantenido firme durante los años de democracia, ${ }^{346}$ pero es una realidad que hasta el día de hoy sigue incólume y por más esfuerzos que se hayan hecho por derribarla no se ha ido más allá de la reforma. En los apartados que siguen veremos cómo se construyó el marco legal de nuestra nueva democracia sobre las costuras de un "traje" viejo.

\footnotetext{
${ }^{344}$ LA NACIÓN “Revelan fraude en plebiscito que aprobó constitución de 1980." 11 de Junio del 2012 [fecha de consulta: 1 de julio del 2015]. Disponible en internet: $<$ http://www.lanacion.cl/noticias/pais/politica/revelan-fraude-en-plebiscito-queaprobo-constitucion-de-1980/2012-06-11/115506.html>

${ }^{345}$ ESTEVEZ, Francisco Javier. "Columna: De la Constitución de 1980 y la Crisis de la República Elitista ” 28 de abril del 2015 [fecha de consulta: 1 de julio del 2015]. Disponible en internet: < http://radio.uchile.cl/2015/04/28/de-la-constitucion-de$\underline{1980-y-l a-c r i s i s-d e-l a-r e p u b l i c a-e l i t i s t a>~}$

${ }^{346}$ Para el destacado investigador español Joan de Alcázar, iniciado el Gobierno de Lagos y tras la detención de Pinochet en Londres, era un camino lógico el que se modificara la Constitución, cuestión que finalmente no se hizo. Ni se ha hecho. DE ALCÁZAR, Joan. Et. Al. Historia contemporánea de América. PUV. Valencia. 2002. p. 387.
} 


\section{1.- LA DICTADURA SE LEGITIMA.}

La Constitución de 1980 no fue un proyecto improvisado. Pasados un par de años del Golpe de Estado, la dictadura había decidido que la tarea que abordarían sería de largo aliento. Así el proyecto comenzó a gestarse hacia 1976 cuando se crea la Comisión de Estudios de la Nueva Constitución Política, conocida posteriormente como la Comisión Ortúzar ${ }^{347}$ debido a que quien la presidia era el abogado Enrique Ortúzar. En esta comisión participaron también el fundador de la Unión Demócrata Independiente (UDI de derechas), Jaime Guzmán Errázuriz y también Alejandro Silva Bascuñan, junto con Jorge Ovalle Quiroz, Alicia Romo, Enrique Evans de la Cuadra, Sergio Diez y Gustavo Lorca. El año 1977 se registraron algunas renuncias que fueron cubiertas por Luz Bulnes Aldunate, Raúl Bertelsen y Juan de Dios Carmona.

A su vez será el ex - presidente de derecha don Jorge Alessandri (hijo de Arturo Alesaandri, el presidente del anterior cambio Constitucional de 1925), quien introdujo entre 1978 y 1980 modificaciones al anteproyecto, que finalmente pasó a manos de la Junta de Gobierno, donde alcanzó su redacción final. Si bien la Comisión estaba al servicio de la dictadura, es cierto que esta estaba conformada principalmente por personas expertas en el ámbito del Derecho Constitucional o eran catedráticos en las universidades. El mismo Enrique Ortúzar, además de abogado, había sido Ministro de Estado del Presidente Jorge Alessandri Rodríguez.

La Comisión fue relevante para el estudio de la Constitución, pero no es innegable que la Dictadura fue mucho más audaz y no espero a que estuviese en vigor o que esta fuese votada universalmente y en la medida en que salían los capítulos estos fueron entrando en vigor mediante decretos. ${ }^{348}$

\footnotetext{
347 Todas las actas están disponibles on line en la Biblioteca del Congreso Nacional en: http://www.ben.cl/lc/cpolitica/actas oficiales-r

${ }^{348}$ HUNEEUS, Carlos. El Régimen de Pinochet. Editorial Sudamericana, Chile. 2000. p. 289.
} 
Así por ejemplo:

a.- Decreto Ley No 1.319, publicado en el Diario Oficial el 9 de enero de 1976.

b.- Decreto Ley $N^{\circ} 1.551$, publicado en el Diario Oficial el 13 de septiembre de 1976.

c.- Decreto Ley No 1.552, publicado en el Diario Oficial el 13 de septiembre de 1976.

d.- Decreto Ley $N^{o}$ 1.553, publicado en el Diario Oficial el 13 de septiembre de 1976.

e.- Decreto ley No 1.697 publicado en el Diario Oficial el 12 de marzo de 1977

En estos decretos se establecían cuestiones discutidas en las actas de la Comisión referidas a temas tales como la creación del Consejo de Estado, los regímenes de emergencia, bases institucionales, derechos y deberes constitucionales y la disolución de los partidos políticos.

Debido a esta decisión que pasaba por encima del estudio asignado, se dio la primera renuncia de la Comisión Ortúzar (Enrique Evans de la Cuadra, Alejandro Silva Bascuñán, estos dos Demócrata Cristianos, y Jorge Ovalle Quiroz). ${ }^{349}$ Finalmente la Comisión emitió dos documentos, un anteproyecto (encargado tempranamente en 1973) y un informe explicativo de aquél con varias ideas y propuestas.

Finalizado el trabajo de la Comisión Ortúzar, se entregó la información a Pinochet y éste la derivó al Consejo de Estado para que analizará la propuesta y redactara un proyecto de Constitución. Este nuevo órgano tenía carácter consultivo del Presidente de la República en asuntos de gobierno y administración civil. Lo conformaban los ex Presidentes de la República, un ex presidente de la Corte Suprema, un ex Contralor General de la República, un ex Comandante en Jefe del Ejército, de la Armada, de la Fuerza Aérea y un ex General Director

\footnotetext{
349 FERNÁNDEZ, Miguel Ángel. “Origen, legitimidad y consolidación de la Constitución.” Revista de Derecho de la Universidad Católica de Valparaíso XXII, 2001. pp. 321-323.
} 
de Carabineros; un ex Ministro de Estado, un ex diplomático con rango de embajador, un ex rector de universidad estatal o reconocida por el Estado, un profesor o ex profesor de una Facultad de Ciencias Jurídicas y un profesor o ex profesor de una Facultad de Ciencias Económicas de una Universidad Estatal o reconocida por el Estado; y por último, una persona representativa de actividades profesionales colegiadas, de la actividad empresarial, de la actividad laboral, de una organización femenina y un representante de la juventud. Estos participantes fueron todos designados por Augusto Pinochet.

Ambas instancias recogieron lo que el dictador solicitó, pese a que algunos miembros pensaron que podría hacerse alguna variación a la existente Constitución de 1925, pronto quedo claro que la tarea emprendida era adecuar la orgánica a los intereses del Régimen. De hecho quedó así estipulado en el acta de la primera reunión:

“El señor Diez señaló que a su juicio la comisión está abocada al estudio de una nueva Constitución y no sólo a introducirle enmiendas a la actualmente vigente y que considera que la exposición del señor Ortúzar constituye sólo una enumeración de alternativas que no solucionan el problema de fondo" 350

Fue tan claro esto que incluso el mismo ex - presidente Jorge Alessandri renunciará tras ver que las modificaciones propuestas por él no serían recogidas en el texto definitivo. El proyecto tuvo tal nivel de involucramiento de Pinochet que incluso su propia esposa censurará algunos cambios -por ejemplo los de 1979- porque, según ella, no estaban acordes a las ideas de su Padre, Osvaldo Hiriart, un abogado radical de viejo cuño. ${ }^{351}$

\footnotetext{
${ }^{350}$ ACTAS OFICIALES. Comisión de Estudios de la Nueva Constitución política de la República. Tomo I. Sesión primera. 24 de septiembre de 1973.

${ }^{351}$ DIEZ, Sergio. Reflexiones sobre la Constitución de 1980. 50 años de un actor y testigo de la vida política chilena. E1 Mercurio-Aguilar. Chile. 2013. pp. 2010-211.
} 
La preocupación fundamental sobre la que se basaba la necesidad de crear una nueva Constitución, por lo menos por parte de los estudiosos, era que la anterior carta (de 1925) había sido incapaz de absorber las problemáticas de su tiempo, volviéndose anticuada, neutra y por lo mismo habría permitido que entrara la amenaza del "totalitarismo marxista", como se llamaba entonces a todo atisbo de izquierdización en la política.

Los resultados de la Comisión no fueron tan profundos como se esperaba; de hecho no hubo aportes sustantivos, salvo los que mencionamos a continuación, entre los que llaman la atención el establecimiento de un periodo de transición:

a.- La supresión del preámbulo.

b.- El pago en efectivo y al contado de la indemnización por expropiación.

c.- La rebaja del periodo presidencial de ocho a seis años.

d.- La disminución del número de diputados de 150 a 120.

e.- La elección regional de los senadores.

f.-El Principio de Dominio Mínimo Legal.

g.-El carácter de funcionarios de la exclusiva confianza del Presidente de la Republica de los Comandantes en Jefe y del General Director de Carabineros.

g.-La modificación orgánica del Consejo de Seguridad Nacional.

h.-La inclusión de un periodo de transición desde el Gobierno iniciado en 1973 a otro de normalidad democrática. ${ }^{352}$

\footnotetext{
${ }^{352}$ FERNÁNDEZ, Miguel Ángel. Op. Cit. p. 325.
} 
Una vez que terminó de sesionar el Consejo, se hizo entrega del informe a Pinochet, quien a su vez lo hizo llegar a la Junta para que en virtud de su potestad constituyente procediera a redactar el texto final y aprobarlo. La Junta contó para esta tarea con una Comisión interna conformada por ministros de Estado y asesores. Finalmente se publicó en el Diario Oficial el 11 de agosto de 1980 el decreto (Decreto Ley No 3.464) que aprobaba el texto de la Nueva Constitución. Sin embargo, para que éste tuviera efecto sobre toda la población se sometió a plebiscito que, obviamente, fue ratificado por amplia mayoría. Por lo tanto, la Nueva Constitución fue promulgada el 11 de octubre de 1980 y entró en vigencia el 11 de marzo de 1981.

Con esto se cierra el capítulo de la legitimación de la dictadura, que veía la necesidad de consolidar su poder y hacerlo legal ante la ciudadanía y el exterior. Es menester señalar igualmente que en 1978 se conformó una Comisión paralela de oposición denominada "Grupo de los $24^{\prime 353}$, donde estaban connotados juristas y políticos, entre los que se cuentan Patricio Aylwin, Edgardo Böenniger, Jaime y Fernando Castillo y el mismo Alejandro Silva Bascuñán -una vez retirado de la Comisión de la Junta- (también se pronunciaron sobre la Constitución y su proyecto los colegios profesionales, las Escuelas de Derecho y personalidades a título individual como Pablo Rodríguez, abogado nacionalista).

La gran crítica al modelo emergente de la Constitución de 1980 es que la "Democracia protegida" que establecía requería altos quórum para su modificación, aunque sus autores afirmen que lo que busca en realidad la Constitución era más bien proteger los derechos naturales, ya que se impuso una alta votación para disminuir o modificar los derechos de las personas, lo cual es más bien positivo que negativo, como señala Diez. ${ }^{354}$

\footnotetext{
${ }^{353}$ QUINZIO, Jorge. “El Grupo de los 24 y su Critica a la Constitución Política de 1980”. Revista de Derecho de la Universidad Católica de Valparaíso XXIII, Valparaíso, Chile. 2002.

${ }^{354}$ DIEZ, Sergio. Op. Cit. pp. 219-220.
} 
En este sentido, la Constitución de 1980 afirma la superioridad del hombre frente al Estado, como persona y a través de los grupos intermedios, indicando que la familia es el núcleo fundamental de la sociedad, lo que queda establecido en el primer artículo de la Constitución política. Queda patente que este primer artículo está inspirado por el pensamiento de Maritain, ya que se establece que la finalidad del Estado es el "bien común", donde "poner al hombre a servicio de este instrumento es una perversión política", ${ }^{355}$ desestimando así la idea hegeliana de que el Estado es la encarnación suprema de la Idea o que el Estado es un superhombre colectivo. A partir de lo anterior se le dio carácter inamovible al artículo $5^{\circ}$ que se nutre del pensamiento de Jaime Guzmán y que señala que el “ejercicio de la soberanía reconoce como limitación el respeto de los derechos esenciales que nacen de la naturaleza humana". De esta manera se establece que la Constitución es una Ley Fundamental de la República.

Estos aspectos serán muy relevantes para entender el debate que se dará en torno a la legitimidad de la Constitución, en especial si se considera que la "esencia" de la misma consiste en cimentar la organización de la sociedad. Debido a esto es que no se puede desligar el pensamiento de Jaime Guzmán con la redacción del proyecto del Régimen.

Jaime Guzmán (1946-1991) ${ }^{356}$ será un cercano asesor de Pinochet, un joven y eximio jurista y fundador del gremialismo en Chile que se concretará en la conformación de la Unión Demócrata Independiente. Debido a su relevante rol en el Régimen será víctima del terrorismo de izquierda ya bajo la democracia. ${ }^{357}$ Para muchos él será el verdadero ideólogo tras la Constitución de 1980 que lleva la impronta de su pensamiento católico conservador. Su línea filosófica entronca con los juristas españoles Luis Sánchez Agesta y Luis Legaz y Lecambra, y por supuesto, remite al pensamiento jurídico del alemán Carl Schmitt. Con base en este último autor se puede

\footnotetext{
${ }^{355}$ MARITAIN, Jacques. El hombre y el estado. Ediciones Encuentro. España. 1983. pp. 27-28.

${ }^{356}$ Se pueden consultar datos biográficos en la web de su fundación: http://www.jaimeguzman.cl

${ }^{357}$ GAZMURI, Cristian. ¿Quién era Jaime Guzmán? Editorial RIL. Chile. 2013.
} 
entender que la Constitución de 1980 se plantea a sí misma como "revolucionaria" en el sentido que persigue destruir, y no sólo restaurar, la anterior Constitución con el fin de restituir el "Poder constituyente", esta vez en manos de los militares. ${ }^{358}$

En definitiva, queda claro que la Constitución de 1980 iba a cambiar sustancialmente la forma en que se lleva a cabo el control y el poder, así como legitimar y legalizar la autoridad del poder de facto. Cabe aclarar también que esta Constitución no fue la primera ni la única que no emanaba de la convocatoria a una Asamblea Constituyente: también lo fueron la de 1925 y, antes de ella, la de 1833. Por tanto, la originalidad fundacional de la Constitución es que implanta la legitimidad del Estado autoritario. Ya no es simplemente un gobierno de facto que utiliza la violencia para dominar y controlar las instituciones y a la población, sino que la Carta constitucional ofrece cobertura jurídica a un nuevo Chile, una nueva forma de actuar política y socialmente, lo que dará origen a su vez y caracterizará a una democracia protegida y autoritaria. ${ }^{359}$ Para la Junta Militar, había que eliminar la democracia liberal, responsable de lo que Pinochet había bautizado como la partidocracia ${ }^{360}$, es decir, el sistema representativo que había colapsado en 1973. Esta corrección en el sistema institucional devolvía también la posibilidad a la élite tradicional de regresar a la primera línea política y también la oportunidad de reformular completamente el sistema político y económico. De esta manera se irán delineando nuevos grupos, ahora imbricados en la dictadura, colaborando con ella o viéndose beneficiados por los cambios en las políticas sociales y económicas.

La Constitución de 1980 dejará marcado claramente que el Estado que emerge de sus normas es antimarxista, anti-totalitario y defensor de la libertad -económica principalmente- y que

\footnotetext{
${ }^{358}$ El debate ideológico y los límites de la teoría de Schmitt en la Constitución de 1980 y la influencia del gremialismo están recogidos en un muy buen libro del pensamiento político de Jaime Guzmán: CRISTI, Renato. El pensamiento politico de Jaime Guzmán. Una biografía intelectual. Editorial LOM. $3^{\circ}$ ed. Chile. 2014

${ }^{359}$ HUNEEUS, Carlos El Régimen de Pinochet. Editorial Sudamericana, Chile. 2000. p. 236.

${ }^{360}$ PINOCHET, Augusto Visión Futura de Chile. Dirección Nacional de Comunicaciones (DINACOS), Santiago, 1979. p. 32.
} 
busca extirpar de las sociedad todas las “doctrinas que atenten contra la familia, propugnen la violencia o una concepción de la sociedad, del Estado o del orden jurídico, de carácter totalitario o fundado en la lucha de clases"361. A su vez, el nuevo Estado rechaza el principio de voluntad popular y lo cambia por voluntad nacional, entendiendo que la voluntad popular reside solamente en los ciudadanos y en las autoridades de gobierno, o sea, los funcionarios superiores, las Fuerzas Armadas y la Corte Suprema que se corresponden con las instituciones creadas por derecho natural según la voluntad de Dios. ${ }^{362}$ Siguiendo esta misma lógica, la democracia que promueve la dictadura es aquella donde las personas quedan alejadas de la participación efectiva, siendo los depositarios de los beneficios que el Estado garantiza. En otras palabras, la democracia tiene como objetivo el progreso económico, garantiza la libertad y la propiedad privada. $^{363}$

Por último, para mayor seguridad, la Constitución expresará claramente que las Fuerzas Armadas asumen el papel de protectores del régimen político. Estas debían garantizar el orden institucional porque eran las únicas que poseían los recursos, el patriotismo y la disciplina necesarios para conseguirlo. Este poder omnipresente de las Fuerzas Armadas era ejercido por medio del Consejo de Seguridad Nacional-según el Capítulo XII de la Constitución de 1980-, pero los representantes de las Fuerzas Armadas en el Consejo de Seguridad Nacional no podían ser depuestos por el Presidente de la República. Así, el Estado va tornándose un Estado militarizado, puesto que las atribuciones de dicho Consejo son raramente superiores a las capacidades de sus miembros. Por su parte y contrariando el parecer de algunos miembros de la Junta original -el General Leigh de las Fuerzas Aéreas es retirado de la Junta por estar en desacuerdo- se va asumiendo que Pinochet se convierta en presidente, cargo que concentrará

\footnotetext{
${ }^{361}$ HONORABLE JUNTA DE GOBIERNO. Constitución Política de la República de Chile, Art. 8a, S. 1980.

${ }^{362}$ CRISTI, Renato. El pensamiento político de Jaime Guzmán. Autoridad y Libertad, Editorial LOM, Santiago, 2000. p. 56.

${ }^{363}$ CRISTI, Renato. Op. Cit. p. 34.
} 
las mayores atribuciones: mantiene una función superior de orden político, legislativo, el orden y la ley, debe ser el conductor del Estado y del Gobierno. En definitiva, el Presidente debía ser coherente con el ejercicio del poder pero superior a las diferentes ramas burocráticas del Estado.

En resumen, la Constitución de 1980 será la que dará sustento legal a la dictadura a partir de 1980, pero a su vez marcará las bases de la transición y la posterior democracia, al seguir aún en vigor. Pese a lo cual no ha estado exenta de fuertes críticas.

\section{2.- EL ¿PROBLEMA? DE LA ILEGITIMIDAD.}

Presentado de la forma hecha en el acápite anterior daría la impresión no sólo que la Constitución se instaló sin problemas sino que además fue bastante positiva para la ciudadanía. Pero en realidad, pese a los intentos de Junta Militar por dar una imagen favorable, de legalidad y paz para emprender los estudios constitucionales, la realidad fue que el contexto daba cuenta de una situación muy distinta.

Entre los años 1973 y 1978 -año en que se dicta la ley de amnistía- el país vivó la etapa más feroz de represión, persecución y asesinatos de su historia. El año 1976 fue creada la Vicaría de la Solidaridad con el fin de prestar asistencia judicial y social a las víctimas de la represión. Por otra parte, la DINA comienza la persecución de los miembros del Partido Comunista, algunos de cuyos integrantes apresados fueron torturados o asesinados (1976) en lo que se conoce como el caso "Calle Conferencia". 364

El mismo año en julio fue asesinado el diplomático español Carmelo Soria y en septiembre en Washington, el ex canciller de la Unidad Popular Orlando Letelier a manos de la DINA, en un

\footnotetext{
364 Todos los detalles del caso se pueden encontrar en el Archivo digital de Archivo Chile. En: http://www.archivochile.com/Derechos humanos/html/dd hh calle conferencia.html
} 
caso que va a levantar la presión de Estados Unidos y que desembocará en la disolución de la DINA y la creación de la Central Nacional de Inteligencia, CNI. Hacia 1976, las detenciones por organismos de represión aumentaron en un 92,5\%, al punto que en el mismo Ministerio del Interior había 41.359 personas detenidas por infracción al Estado de Sitio. En total, los detenidos por Carabineros o la Policía de Investigaciones llegaba a 1.024 .137 personas $^{365}$.

En este periodo también se disolvió el Congreso Nacional (Decreto Ley No 27 de 1973), se declaró la ilegalidad de los Partidos Políticos (Decreto Ley No 77 de 1973), se promulgó la caducidad de todos los Registros Electorales del país (Decreto Ley $N^{\mathrm{a}} 130$ de 1975), se estableció el control sobre los sindicatos (Decreto Ley No 198 de 1973), se prorrogó el Estado de Sitio en todo el territorio nacional (Decreto Ley No 364 del 16 de 1974), se creó la DINA (Decreto Ley No 521 de 1974), se ejerció la censura cinematográfica (Decreto Ley № 679 de 1974) y se entregó el poder a los Jefes Militares de las Zonas en los lugares que encontraban en Estado de Sitio o de Emergencia (Decreto Ley No 1.281 de 1975). ${ }^{366}$

Este fue el contexto en que se discutía la Constitución, con un poder desplegado para controlar la opinión disidente. Con todo, como ya señalamos hubo un fuerte debate acerca de las características de la Constitución, la legalidad del plebiscito que la puso en vigencia y su propuesta de democracia, aspectos que veremos a continuación.

\footnotetext{
${ }^{365}$ CARO, Isaac y KAUFMAN, Edy. El régimen militar chileno dentro del análisis de los patrones represivos en el Cono Sur. College Park, Maryland. 1991.

${ }^{366}$ LOVEMAN Brian y LIRA Elizabeth. Arquitectura politica y seguridad interior del estado. Chile, 1811-1990. Dirección de Bibliotecas, Archivos y Museos - Universidad Jesuita Alberto Hurtado, Centro de Investigaciones Diego Barros Arana, Chile. 2002. Pp. 345-444.
} 


\subsection{1.-La Crítica a la Constitución del "Grupo de los 24."}

El "grupo de los 24" -como se les conoció por la cantidad que integraban la agrupación- o el Grupo de Estudios Constitucional, se creó el 21 de julio de 1978 como un espacio donde estudiosos de distintas disciplinas y posiciones ideológicas buscaron hacer una propuesta alternativa y crítica a la que venía manifestando la dictadura.

Dos meses después de su creación se realiza la primera reunión del grupo, el día 12 de agosto de 1978 en el Hotel Las Acacias. En octubre de 1979 el "Grupo” ya disponía de un documento denominado "Bases Fundamentales de la Reforma Constitucional" donde manifestaba claramente que:

"Pensamos, en consecuencia, que el proceso de generación de la nueva Constitución debe orientarse esencialmente a lograr, el máximo acuerdo o consenso nacional, para lo cual debe cumplir las siguientes condiciones:

a) que se verifique bajo un régimen de plena vigencia del derecho y de las libertades públicas;

b) que una Asamblea Constituyente, ampliamente representativa de todos los sectores y tendencias nacionales, estudie el proyecto en público debate;

c) que el pueblo sea llamado a pronunciarse libre e informadamente sobre las principales alternativas que surjan de ese estudio; $y$

d) que tanto para la elección de la Asamblea Constituyente por sufragio universal, como para la realización del plebiscito en que el pueblo decida, se constituya previamente el Cuerpo Electoral mediante la apertura del Registro de Ciudadanos y se regulen, también previamente, los procedimientos de sufragio que garanticen la libertad y el secreto del 
voto y la corrección de los escrutinios, requisitos necesarios para la validez de dichos actos." 367

Queda claro con esta declaración que la opción propuesta por la oposición a la Junta distaba de lo que proponía la Comisión, en su fondo y en la forma en que se llegaría a un escrito final de la carta fundamental. En relación con la crítica posterior a la promulgación el Grupo de los 24 señaló:

“(...) la Constitución rechaza el sistema representativo de Gobierno, desconoce el derecho natural y exclusivo del pueblo para gobernarse, niega el pluralismo ideológico, establece un régimen político, autoritario-militarista, implanta un verdadero cesarismo presidencial, minimiza al Parlamento, transforma al Tribunal Constitucional en un organismo burocrático carente de representatividad popular y más poderoso que el Congreso, otorga un poder ilimitado a las FF. AA., subordina la vigencia de los derechos humanos fundamentales al arbitrio del gobierno y se identifica en lo económico con el capitalismo individualista de libre mercado. Además dadas las exigencias que impone para eventuales reformas constitucionales, perpetua un determinado régimen político, económico y social, que resulta prácticamente imposible de modificar. De esta manera, la Constitución de la Junta Militar niega la democracia y -lo que es más grave- cierra los caminos para instaurar la democracia dentro de la legalidad que ella consagra”,368

En dicho estudio se analiza artículo por artículo esta crítica y destaca las contradicciones que posee, tales como por ejemplo, la del artículo $5^{\circ}$ que consagra el principio de que "el ejercicio de la soberanía reconoce como limitación el respeto a los derechos esenciales que emanan de la naturaleza humana" que antes señalamos como central para el Régimen; pero el $N^{\circ} 26$ del artículo 19, en su inciso final, le coarta al señalar que existen "estados de excepción.” En este

\footnotetext{
${ }^{367}$ GRUPO DE LOS 24. "Bases Fundamentales de la Reforma Constitucional." Octubre de 1979 [fecha de consulta: 1 de julio del 2015]. Disponible en internet: < $\underline{\text { http://www.blest.eu/lex/grupo24.html }>~}$

${ }^{368}$ QUINZIO, Jorge. Op. Cit. p. 16.
} 
sentido, hay algunos autores que consideran que la Constitución es más bien un onjunto de leyes y no necesariamente una Constitución como tal. ${ }^{369}$

\subsection{2.-La Constitución de 1980. El pecado de origen.}

Uno de los debates más antiguos pone en el centro del debate la legalidad de la Constitución de 1980. Esta discusión girará en torno a cuestiones de forma y fondo. ${ }^{370}$ Las cuestiones de forma, por ejemplo, guardan relación con el procedimiento seguido para su elaboración, ya que según los detractores no se habría respetado el camino trazado por la anterior Constitución (1925) sino que se la asumió de hecho, como señalamos antes, como derogada, por lo que la Junta irá elaborando un derrotero propio, a veces improvisado, para construir la nueva Carta. Esto generó que la oposición al Régimen denunciara que los textos eran sesgados y propios de un grupo cerrado.

Por otra parte, el plebiscito que le dio validez y por el cual los ciudadanos debían manifestarse fue acusado de vicios y se terminó por considerar también ilegítimo por la oposición. Esto debido a que no existían registros electorales y, por lo tanto, no había una clara individualización del votante. Tampoco fue posible hacer reclamos ni una campaña informativa de oposición, en tanto todo el proceso se realizó en estado de emergencia y sin posibilidad real de confrontar los planteamientos gubernamentales. Como señala Cavallo:

"Los debates, iniciados esa noche y continuados al día siguiente en el edificio Carlos V, de calle Huérfanos, donde los miembros de la directiva de la DC tenían sus oficinas de abogados, concluyeron en una dura declaración, que calificó la convocatoria como "un acto de extrema

\footnotetext{
${ }^{369}$ ATRIA, Fernando. La Constitución Tramposa, Editorial LOM, Santiago, 2013. pp. 58-59

${ }^{370}$ RÍOS, Lautaro. “Razón y fuerza de la Constitución de 1980.” Revista Chilena de Derecho, 16, 1989. pp. 325 - 336.
} 
violencia y una afrenta a todos el país (...) En estas circunstancias, el supuesto plebiscito carece de toda validez y, en consecuencia, el texto que se vote, como todos los futuros actos que se ejecuten en el ejercicio de los poderes emanados de aquel, son igualmente ilegítimos y sin valor."371

Según esta perspectiva y como señala Atria, la Constitución de 1980 es fraudulenta en tanto fue aprobada en condiciones anormales. En un análisis "normativista", el autor apostilla que al tratarse de una norma que se dicta por un poder normativo -es decir un poder concedido o regulado por normas anteriores- , cuando dicho poder normativo se ejerce con infracción a las reglas que le confieren, la norma que se intenta crear es nula. ${ }^{372}$ En este caso, la medida de coacción ejercida durante su redacción, votación y posterior entrada en vigor la harían inválida, por lo que la dejarían en condición de nulidad o en posibilidad de dejarla nula tanto en 1982 como en el 2015; en el fondo, ese es su gran pecado de origen. A esto debería sumarse que los quórum fijados para su modificación, al ser tan altos, convierten a la Constitución en una verdadera celda y no en una norma que reúna y exprese la libertad de los ciudadanos. ${ }^{373}$

La denuncia se intentó ya en 1980, antes del plebiscito, y uno de los representantes de esta disidencia fue el ex presidente demócrata-cristiano Eduardo Frei Montalva, quien en un discurso realizado en una reunión del partido en el Arrayán señaló drásticamente:

"Porque toda esa Constitución del Consejo del Estado y toda esa Constitución está construida sobre la base del miedo. El miedo al pueblo. ¡Todas esas restricciones! ¡todas esas medidas defensivas! ¡todos son cercos para apretar a la gente para que no se exprese! (...) Yo quisiera decir que en esta batalla nosotros no debemos limitar a decir No. Porque

\footnotetext{
${ }^{371}$ CAVAllO, Ascanio; SALAZAR, Manuel y SEPÚLVEDA, Oscar; La historia oculta del régimen militar. Editorial Grijalbo, Chile, 1997. p. 276.

${ }^{372}$ ATRIA, Fernando. Op. Cit. 2013. p. 58.

${ }^{373}$ SUAREZ, Christian. "La constitución celda o straight jacket constitution y la dogmática constitucional”. Universum $N^{o} 24$. UTAL. 2009. pp. 248-271.
} 
esta batalla no termina el 11 de septiembre (...) Yo creo, mis amigos, que en este instante pesa sobre nosotros una responsabilidad moral.",374

Menos de un año después de esta reunión y de manifestar públicamente su oposición al Régimen (en lo que se conocerá como el "Caupolicanazo", por desarrollarse en el teatro Caupolicán en agosto de 1980) el ex presidente murió en extrañas circunstancias que hasta el día de hoy continúan investigándose.$^{375}$ Mientras tanto, la Constitución se mantuvo en vigor y la oposición debió aceptarla para abrirse a la transición estipulada por el dictador.

\section{3.-CONSTITUCIÓN Y TRANSICIÓN. LA ACEPTACIÓN.}

Como hemos visto, si por una parte el Régimen buscaba legitimarse a través de la Constitución, al mismo tiempo trazaba el itinerario que conduciría a la transición (ocho años para llamar a plebiscito acerca de la continuidad o no del Régimen), mientras se consolidaba en el poder Augusto Pinochet como Presidente hasta 1989. Desde la oposición, sin embargo, quedaba en el aire una sensación enrarecida respecto a qué hacer después del fracaso al pretender denunciar la ilegitimidad de la Carta fundamental y la propuesta del itinerario lanzado desde el oficialismo. En este punto se registra un quiebre importante en relación a la futura evolución del Régimen: los opositores tenían que decidir de manera urgente si estaban dispuestos a jugar con las reglas impuestas por la dictadura o darían un puñetazo sobre la mesa para expulsar a Pinochet.

\footnotetext{
${ }^{374}$ FUENTES, Claudio. El Fraude. Crónica sobre el plebiscito de la constitución 1980. Editorial Hueders. Chile. 2013. pp.3334.

${ }^{375}$ El Ex presidente inicialmente estará a favor del Golpe, pero luego se vuelve un férreo opositor. Su muerte se da en extrañas circunstancias, se irá a operar una hernia y fallece, en 2008 se encontraron rastros de químicos en la exhumación del cuerpo (Mostaza sulfúrica y Talio) que validan en involucramiento de terceros en su muerte.
} 
El año crucial sería 1984. El 27 de julio miembros de distintas esferas políticas y profesionales fueron convocados al Seminario que llevaba por título "Un sistema jurídico político constitucional para Chile”, que tuvo lugar en el Hotel Tupahue. El Chile de 1984 era muy distinto al de años anteriores: ya había cesado la crisis de los primeros años de esa década que desencadenaron las grandes movilizaciones ciudadanas, alimentadas también por la profunda crisis bancaria que había puesto en entredicho por un tiempo la política económica neoliberal; con lo cual, los políticos sentían que la sociedad era capaz de acometer nuevos desafíos y que las bases estaban más maduras para enfrentarse al dictador. El año anterior (1983) se había creado la primera Alianza de oposición (Alianza Democrática) con la participación del Partido Socialista (que por primera vez no se unía al Partido Comunista, a lo menos una parte), el Partido Radical y el Demócrata Cristiano. La Alianza Democrática insistía en pedir la devolución de la soberanía popular por encima de la del jefe de Estado y la eliminación de las disposiciones transitorias que regulaban el paso del régimen autoritario a una democracia restringida. Los esfuerzos de la Alianza en 1983, pese a que las condiciones económicas y sociales le eran favorables, se vieron disminuidas debido a la capacidad negociadora impulsada por Pinochet a través de Sergio Onofre Jarpa, un político civil seguidor del Régimen. Con todo Jarpa, intentó hacer algún acercamiento, proponiendo el adelanto de las elecciones y así poner en vigor plena la Constitución, pero el propio Pinochet frenaría los avances drásticamente.

Por su parte, seguía la represión a las movilizaciones ciudadanas mientras las alas más radicales del Partido Comunista, el Partido Socialista (Almeyda), el MIR y la izquierda Cristiana conformaron el Movimiento Democrático Popular (MDP), que postulaba una estrategia mucho más confrontacional. El 13 de diciembre de 1983 se creó el Frente Patriótico Manuel 
Rodríguez, que inició una serie de atentados presentándose como "el brazo armado del pueblo". 376

En vista de este panorama, la realización del Seminario del Hotel Tupahue resultaba un verdadero desafío para trazar una nueva estrategia. La gran pregunta que debía ser respondida era: ¿Era posible salir de la dictadura con la misma Constitución de 1980? Patricio Aylwin uno de los participantes- declarará con convicción que sólo habría dos salidas, por la vía pacífica o la lucha armada. La vía pacífica representaba la vía jurídico-política, como así lo señalaba en ese entonces el ex - presidente:

“(...) personalmente- argumentaba- yo soy de los que consideran ilegítima la Constitución de 1980. Pero así como exijo que se respete mi opinión, respeto a los que opinan de otro modo. Ni yo puedo pretender que el general Pinochet reconozca que su Constitución es ilegítima, ni él puede exigirme que yo la reconozca como legítima. La única ventaja que él tiene sobre mí a este respecto es que esta Constitución - me guste o no- está rigiendo Éste es un hecho que forma parte de la realidad y que yo acato. ¿Cómo superar este impasse sin que nadie sufra humillación? Solo hay una manera: eludir deliberadamente el tema de la legitimidad" 377

Esta tesis marcó definitivamente el punto de quiebre para la futura estrategia de la oposición (se desestima lo propuesto por el "grupo de los 24" y la Alianza Democrática de Gabriel Valdés, que ponía su foco en una Asamblea Constituyente), no sólo en lo que se refería a la Constitución sino también frente a la propia transición y a la democracia que surgiría de ella. De esta manera, en 1984 se decidió que el único camino posible era la aceptación y la reforma de la Carta en la medida de lo posible.

\footnotetext{
${ }^{376}$ OTANO, Rafael. Op. Cit. 2006. pp. 16-18.

${ }^{377}$ OTANO, Rafael. Op. Cit.2006. p. 21.
} 
Esta transición a la chilena -o a lo Pinochet- se convierte en una experiencia única, alejada de los cánones propuestos por la Ciencia Política, centrada en el legalismo y la decisión pragmática. En sucesivas reuniones y seminarios Patricio Aylwin irá señalando y reafirmando esta misma idea, que permitirá hablar cada vez con más claridad de una la salida negociada y de la imperiosa necesidad de consenso. Inicialmente, no toda la Democracia Cristiana ni mucho menos la oposición en general estuvo de acuerdo, mucho menos sabiendo que "la calle" tenía fuerza propia; pero se llegó finalmente a lo que se conocerá como el “Acuerdo Nacional para la Transición", donde participaron tanto políticos de diversas bancadas como representantes de la Iglesia. El acuerdo finalmente no dio resultados tangibles, siendo rechazado por el propio Pinochet en una visita del Cardenal Fresno; la situación llegaría a un clímax de tensión en los años sucesivos, incluyendo un intento de asesinato frustrado contra Pinochet y una reactivación de la represión debido a este episodio. Esos serán los principales acontecimientos que condicionarán el derrotero que seguirá la estrategia de avance hacia la democracia por parte de la oposición.

El año 1987 comenzarían los preparativos para la gran salida -aún cuando continuaban operativos grupos radicales que seguirán practicando la violencia hasta bien entrada la democracia-: se trabajó en reunir y completar las firmas y se designó quiénes serían los contendientes una vez superado el plebiscito del "Si" o "No" a Pinochet. El desenlace es conocido: el dictador fue derrotado y así consiguió acceder al poder la coalición denominada “Concertación de Partidos por la Democracia”, donde Patricio Aylwin sería responsable de asumir la dirección ejecutiva del Estado. Sin embargo, la aceptación del itinerario y de la Constitución quedarían como un tema pendiente hasta el día de hoy.

Será incluso durante la campaña presidencial que la derecha presionará a Aylwin para que decida a reformar la Constitución, con el fin de dejar todo "solucionado" antes porque, como señalaba Allamand -representante de Renovación Nacional, el ala más aperturista de la derecha 
de Pinochet-: "Si usted asume el gobierno sin el problema constitucional resuelto, se va a gastar los dos primeros años en una discusión inútil. Es mucho mejor entrar con una normativa menos perfecta, pero tener el problema medular solucionado." ${ }^{378}$ Lo que se pensaba en ese momento era que las tibias reformas constitucionales podrían representar el equivalente en España de los "Pactos de la Moncloa.” En la práctica, era aprovechar la instancia para arrebatar previamente de las manos de Aylwin el control para cambiar la Constitución ya que, una vez en el poder, el nuevo presidente dejaría en desventaja al Régimen y sus políticos. El objetivo se logró y, antes que asumiera el primer mandatario, se amarró desembozadamente la Constitución, mediante reformas que satisfacían el empate -igual que vimos en un apartado anterior que sucedió con los enclaves- y garantizaban la tranquilidad en el traspaso presidencial. Se aprobaron 54 reformas que fueron votadas en un plebiscito (30 de julio de 1989) que poca gente entendió.

La Constitución fue administrada con apenas retoques durante toda la democracia -alrededor de 15 leyes modificadas de diversa índole- entre 1990 y 2005. Con todo, la modificación más importante hasta ahora ha sido la realizada durante el Gobierno de Ricardo Lagos. En dicha ocasión se realizaron 54 modificaciones (Ley 20050, del 26 de agosto de 2005). Entre los principales cambios vinculados a los amarres constitucionales figuraban:

a.- Eliminación de los senadores designados y vitalicios.

b.- Reducción del mandato presidencial (a 4 años).

c.- Facultad de remoción de los Comandantes en Jefe.

d.- Modificación del Consejo de Seguridad Nacional (Será desde este momento un organismo asesor del presidente de la República y solo podrá ser convocado por éste).

\footnotetext{
${ }^{378}$ OTANO, Rafael. Op. Cit. 2006. p. 95.
} 
En años posteriores y hasta el día de hoy se han ido haciendo otras reformas diversas vinculadas a educación o algún aspecto vinculado al parlamento, por ejemplo, la entrega de cuentas públicas, fecha de elecciones, etc.

Las modificaciones a la Constitución realizadas el año 2005 fueron para algunos un signo de un cambio fundamental de la Constitución original; de hecho, el propio ex Presidente Lagos señalará que:

"Ahora podemos decir que la transición en Chile ha concluido. Ahora tenemos un cuerpo constitucional que está acorde con la tradición histórica de Chile y lo más importante, un cuerpo constitucional que fue aceptado por la unanimidad en el Congreso Nacional”379

Sin embargo, otros autores y políticos siguen considerando que, en esencia, la Constitución vigente sigue siendo por lo menos ilegítima y debe ser cambiada. Durante el segundo Gobierno de Michelle Bachelet asumiendo esta tesis, se reinició el debate acerca de la necesidad de un cambio en base a una Asamblea Constituyente, ${ }^{380}$ pero debido a las propias condiciones políticas del Gobierno esta idea se desestimó. ${ }^{381}$ Con todo, en la actualidad la Constitución de Pinochet sigue siendo la Carta Fundamental de nuestra democracia.

\footnotetext{
${ }^{379}$ RADIO COOPERATIVA. "Presidente Lagos: Reformas constitucionales marcan el fin de la transición” 14 de Julio de 2005 [fecha de consulta: 10 de junio del 2015]. Disponible en internet: $<$ http://www.cooperativa.cl/noticias/pais/politica/reformasconstitucionales/presidente-lagos-reformas-constitucionales-marcan-el-fin-de-la-transicion/2005-07-14/100948.html >

380 SOTO, Francisco. "Asamblea constituyente: la experiencia latinoamericana y el actual debate en Chile. Estudios constitucionales, 2014. V. 12, No 1, pp. 397-428,. [fecha de consulta: 10 de junio del 2015]. Disponible en internet: < http://www.scielo.cl/scielo.php?script=sci arttext\&pid=S0718-52002014000100010\&lng=es\&nrm=iso>

${ }^{381}$ RADIO UDECHILE. "Presidenta anuncia nueva Constitución pero sin asamblea constituyente" 28 de abril de 2015 [fecha de consulta: 10 de junio del 2015]. Disponible en internet: $<$ http://radio.uchile.cl/2015/04/28/presidenta-anuncia-nuevaconstitucion-pero-sin-asamblea-constituyente >
} 


\section{9.-LA DEMOCRACIA ADMINISTRA LA}

\section{ECONOMÍA DE PINOCHET: LAS GARRAS DEL}

\section{JAGUAR.}

Si hay un ámbito que tuvo mayor continuidad entre la dictadura y los Gobiernos democráticos éste es el de la Economía. Esta esfera se ha utilizado continuamente por algunos grupos cercanos al Régimen para reafirmar la obra "positiva" de Pinochet, quien habría entregado a sus sucesores un país en alza, rico y con amplias proyecciones de futuro. En este sentido, la promesa de Pinochet de abundancia y desarrollo se habría cumplido; por lo tanto, la propia razón mandaba que no se implementasen cambios de fondo respecto al camino emprendido por los Chicago Boys: no había que tocar el diseño económico recibido de manos de la dictadura.

Sin embargo, durante los últimos años este modelo económico no ha sido sólo un factor más incluido en el paquete de la transición, sino que ha terminado por convertirse en uno de los puntos más dramáticos de controversia, inundando todos los ámbitos de la vida social. Ya lo señalamos anteriormente, esta "revolución silenciosa" es la que ha terminado por cooptar la democracia de ciudadanos, dando una mayor preponderancia a un tipo de democracia distinto, donde lo más importante es la "libertad individual", entendida ésta como emprendimiento y competencia. Así, el Estado y la sociedad se han acostumbrado -o casi- a que sea el sector privado que marque la pauta, no sólo en el plano de los negocios sino también en los servicios sociales claves. A continuación abordamos la gestación de este modelo y sus consecuencias para la "democracia a la chilena". 


\section{1.-DICTADURA Y LOS CHICAGO BOYS: FRACASO Y DEFINITIVO ÉXITO.}

Hay un hecho que nunca conviene soslayar: a lo largo de la dictadura hubo civiles que colaboraron con ella. Desde el plano político con la Comisión Ortúzar y, de manera particular, quien será reconocido como el ideólogo de la "Democracia protegida", Jaime Guzmán. Sin embargo, hubo otro grupo de civiles que desde otra vereda actuarán y respaldarán al Régimen, esta vez en el plano económico. Se trata de un grupo de jóvenes economistas de la Pontificia Universidad Católica de Chile que realizaron sus postgrados en Estados Unidos, en la Universidad de Chicago, donde fueron fuertemente influenciados por las nacientes teorías neoliberales que impulsaban Milton Friedman y Friedrich Hayeck. ${ }^{382}$ Entre los principales líderes de este grupo figuran Sergio de Castro, José Piñera, Rolf Lüders, Hernán Büchi, Pablo Baraona y Álvaro Bardón, entre otros, quienes redactaron sus postulados en el libro conocido como El Ladrillo. ${ }^{383}$

Ahora bien, tanto el ala política como la económica tenían vínculos y no actuaban separadamente; por el contrario, se generó bastante entendimiento acerca de lo que sería construir una nueva sociedad. ${ }^{384}$ Las investigaciones acerca de las reformas emprendidas por los economistas de Chicago son abundantes ${ }^{385}$ y cada arista es demasiado amplia como para

\footnotetext{
${ }^{382}$ FONTAINE, Arturo. La historia no contada de los Economistas y el Presidente Pinochet. Editorial Zig-Zag. Chile 1988.

383 CENTRO DE ESTUDIOS PÚBLICOS. El ladrillo. Bases de la politica económica del gobierno militar chileno. CEP. (Reedición). Santiago de Chile. 1992.

${ }^{384}$ HUNEEUS, Carlos. "Tecnócratas y políticos en un régimen autoritario. Los Odeplan boys y los Gremialistas en el Chile de Pinochet." Revista Ciencia Politica. V. XIX. 1998.

${ }^{385}$ Recomendamos especialmente: FOXLEY, Alejandro. "Experimentos neoliberales en América Latina.” Estudios CIEPLAN. 7. 1982; BUCHI, Hernán. La transformación económica de Chile. De estatismo a la libertad económica. Editorial Norma. Bogotá. 1993; MELLER, Patricio. Un siglo de economía política chilena (1890-1990). Editorial Andrés Bello. Chile 1996; VALDES, Juan Gabriel. La escuela de Chicago: Operación Chile. Grupo Editorial Zeta, Argentina. 1989; DELANO, Manuel y TRASLAVIÑA, Hugo. La herencia de los Chicago boys. Ediciones del Ornitorrinco. Santiago 1989; BARDÓN, Álvaro, CARRASCO Camilo y VIAL, Álvaro. Una década de cambios económicos: la experiencia chilena: 1973-1983. Alfabeta. Santiago. 1985.
} 
abordar cada una de ellas en este apartado; sin embargo intentaremos dejar en claro cuáles fueron los principales logros y fracasos alcanzados por este grupo.

\subsection{1.- De la politica de Shock al traspiés.}

La interpretación más ortodoxa que se hacía en la época acerca de la crisis económica chilena profundizada con la Unidad Popular, era que la causa fundamental estaba en el progresivo papel que el Estado habría ido asumiendo en la economía. El epítome de dicho recorrido que se terminó con Allende, se habría iniciado en 1930 después del poderoso efecto de las crisis del 29 que habría llevado a Chile a optar por un modelo de Industrialización por Substitución de Importaciones, en el cual Estado poco a poco habría asumido un rol relevante, creando empleo como beneficiando a los ciudadanos con una fuerte política empresarial, social y educativa, especialmente con el Frente Popular. Esta visión de decadencia es reafirmada por uno de los líderes de los Chicago Boys, como es Sergio De Castro quien señala que “el caos sembrado por el gobierno marxista de Allende solamente aceleró los cambios socializantes graduales que se fueron introduciendo en Chile ininterrumpidamente desde mediados de la década del 30."386

Esta visión crítica acerca de la política económica de Chile, cercana a la corriente keynesiana era una réplica de lo que venían discutiendo estos economistas monetaristas en Estados Unidos a propósito del modelo generado a partir de la gran depresión norteamericana. ${ }^{387}$ Es por esto que la respuesta que surgiría a la crisis económica vivida en 1973 (agravada por la ausencia de préstamos externos, la enorme inflación, fuga de capitales, el desabastecimiento, industrias estresadas financieramente, agotamientos de las reservas internacionales, mercado negro y con

\footnotetext{
${ }^{386}$ MELLER, Patricio. Un siglo de economía politica chilena (1890-1990). Editorial Andrés Bello. Chile 1996. p. 174.

${ }^{387}$ MARTíNEZ, Gerardo. “Causas de la gran depresión de los años treinta: Aportes recientes.” Revista Universitaria. PUC. Abril No 9. 1983.
} 
un déficit fiscal de casi el 25\%) era bastante clara: se debía hacer una política de shock o contrarevolucionaria para cambiar el rumbo. Esto, en condiciones democráticas no es fácil, pero la dictadura y el poder que poseía facilitó que se instalasen sin cortapisas.

¿Cuáles eran estos aspectos a “frenar”? Fundamentalmente que el Estado deje de manipular las variables económicas (control de precios, determinación de la tasa de interés, fijación del tipo de cambio, etc.); que se acabe con la burocracia estatal; que se acaben las actividades estatales paralelas a la actividad privada con los sectores productivos o de servicios; que se terminen con las nacionalizaciones y el estatismo progresivo de la economía; que no siga funcionando el sistema de planificación; disminuir la inversión estatal en áreas de reducida rentabilidad social y que se termine la politización de las instituciones públicas.

El golpe asestado fue brutal, ya que mientras se reprimía y violentaba a la ciudadanía, se volvía el control sobre las empresas y campos tomados en el periodo anterior, se desarmaban los sindicatos y casi 100 mil funcionarios fueron separados del Estado en sólo un año. En un principio, Pinochet “coqueteo" con grupos nacionalistas, pero una vez decidido por los Chicago Boys, estos comenzaron su tarea:

a.- Abolieron el control de precios.

b.- Desregularizaron los mercados.

c.-Redujeron las tarifas de importación.

d.- Devaluaron la moneda para impulsar las exportaciones.

e.- Comenzaron una política brutal para disminuir la inflación, por medio de un reajuste fiscal. 
f.- Se comenzó a restituir propiedades a sus dueños y generar créditos. (Salvo la industria de Cobre, astutamente).

Milton Friedman en su visita a Chile en 1975, fue bastante enfático al analizar los principales problemas del país, efectuar su diagnóstico y determinar su cura:

"Estoy en Chile por primera vez, desde hace una semana exactamente. Sería difícil juzgar sobre sus problemas como un experto. Sin embargo, curiosamente, después de los primeros tres días me pareció que podía hacerlo, pero en los días subsiguientes comprobé lo poco que sabía.

Sin embargo, considero que Chile tiene hoy dos problemas básicos: el primero, y muy obvio, es contener la inflación; el segundo, establecer una economía social de mercado vigorosa, que permita al país "despegar" en un crecimiento económico sostenido, cuyos beneficios sean compartidos por todos los ciudadanos. Estos dos problemas están vinculados entre sí, aunque en rigor se trata de problemas diferentes.

(...)No creo que para Chile una política de gradualismo tenga sentido. Temo que el "paciente" puede llegar a morirse antes que el "tratamiento" surta efecto.

Creo que Chile puede ganar mucho si examina los ejemplos relacionados con el tratamiento de "shock" para el problema de la inflación y de la desorganización.

(...) Me referiré ahora a los problemas más inmediatos. Si Chile tratara de enfrentar sus dificultades utilizando el tratamiento de "shock", ¿qué pasos debería dar? Sin duda no me encuentro en posición de detallarlos en forma precisa. Sin embargo, quiero anotar lo que estimo son las etapas más importantes y más convenientes.

En primer lugar, debe hacerse como si se tratara de un "paquete" de medidas, anunciarlas en forma pública y explicar claramente lo que se hará. 
Una de estas etapas consiste en "liberarse" de esos ceros "extras" que están ahogando a las computadoras para eliminar 3, 4 o más de estos ceros.

(...) La segunda y más importante etapa estaría representa- da por un compromiso de gobierno de reducir todos sus gastos en 20 a $25 \%$ en un periodo determinado de tiempo. No puedo decir, en forma exacta, cómo y dónde reducir los gastos, aunque puedo decir que creo que realmente hay una sola manera de hacerlo: la que afecta en el largo y en el ancho a todos los gastos, es decir $20 \%$ de todo presupuesto, cualquiera que sea.

(...) el gobierno debe adoptar un compromiso firme de reducir el presupuesto gubernamental en un periodo determina- do, para lograr una reducción de 20 a 25\%.

Una tercera etapa debe consistir en un "paquete" de medidas destinadas a eliminar los obstáculos que actualmente existen para obtener eficaz operación del mercado privado, a fin de absorber, lo más rápidamente posible, a la gente que estará cesante o quedará desocupada a causa de las reducciones del gobierno."388

\subsection{2.- El repunte y la herencia.}

Lo que se estaba en Chile no podía ser algo a medias ni gradual, se debía cambiar todo. De este modo en la etapa que va desde 1974 a 1982, que será la primera, los Chicago Boys serán partidarios de una férrea ortodoxia de los postulados liberales, aunque inicialmente no surta los efectos esperados, como por ejemplo bajar la inflación de manera radical (el PGB cayó en un $12 \%$, la tasa de desempleo creció hasta el 16\%, y el valor de las exportaciones se redujo en un

\footnotetext{
${ }^{388}$ FRIEDMAN, Milton. "Bases para un el desarrollo económico. Versión de la conferencia publica ofrecida por el Dr. Milton Friedman en el Edificio Diego Portales de Santiago, el 26 de marzo de 1975." En: VVAA. Un legado de libertad. Milton Friedman en Chile. Instituto Democracia y Mercado /Atlas Economic Research Foundation / Fundación para el Progreso, 2012. pp. 17-62.
} 
40\%). Sin embargo hacia 1977 se iniciará el verdadero boom de las políticas neoliberales, manejadas desde el ODEPLAN (Oficina de planificación Nacional) y se gestará lo que el propio Friedman denominará el "Milagro Chileno", aunque continuaba la alta tasa de desempleo (20\%), producto de la política de despidos masivos desde el Estado, la reducción del gasto público y a causa de la privatización de empresas.

Sin embargo, el éxito inicial se vio alterado por la crisis desatada en 1982, pero el modo en que se enfrentó marcará todo el segundo periodo y la propia Democracia, como señalan Larraín y Vergara:

"En un principio el énfasis estuvo en la estabilización fiscal, y ya en 1976 se logró un superávit en el sector público. Se contrajo fuertemente tanto la inversión como el consumo del gobierno, a la vez que se reestructuraron las empresas públicas que hasta ese entonces eran fuente importante del déficit fiscal. En 1975 también se produjo un cambio de radical importancia en la institucionalidad fis cal con la ley de administración financiera del estado, que permitió ordenar la: cuentas públicas y definir claramente las responsabilidades respecto del presupuesto de la nación y su ejecuci6n.

La reforma tributaria de 1975 fue otro elemento clave en esta primera fase. Sus objetivos básicos fueron corregir los efectos inflacionarios en la recaudación tributaria, implantar el IVA (que pasó a ser por lejos el impuesto mis importante) y eliminar los regímenes especiales que dominaban el panorama tributario.

Con la crisis de 1982-83 retomaron los déficit fiscales, pero rápidamente, a partir de 1987, se retomaron los superávit, que se mantendrían a nivel del sector público no financiero por mis de una década. Ésta crisis fue también un revés para el programa privatizador en cuanto a diversos activos volvieron a manos del Estado. No obstante, este proceso se reinició con más fuerza en 1985.

En 1984 se implementó una nueva reforma tributaria, pero esta vez dirigida a1 impuesto a la renta. Es así como se integró el impuesto a1 ingreso de personas y empresas. Se bajó el 
impuesto corporativo, quedando su tasa bastante por debajo de las tasas marginales máximas del impuesto a las personas. El objetivo era evitar la doble tributación e incentivar el ahorro. En los 90 se mantuvo el sistema tributario con modificaciones menores (...)»389

La crisis cambiaria de 1982-1983 se convertirá en la peor crisis económica que enfrentó Chile desde la Crisis de 1929, y el Régimen deberá enfrentar dos desafíos, enfrentar su política neoliberal y hacer los ajustes necesarios y hacer frente a las grandes movilizaciones sociales, que de manera inédita enfrentaron a la Dictadura. Esta crisis fue originada por la devaluación del tipo de cambio real, la duplicación de la deuda externa y por un retroceso de las exportaciones, lo que provocó que el PIB se redujera en un 14,3\% y el desempleo aumentará al 23,7\%. Muchos bancos debieron ser rescatados y el mismo Régimen hará un llamado a "salvar" al país donando sus joyas.

Las soluciones inmediatas adoptadas por el Régimen fueron la liquidación de las instituciones insolventes o traspaso de activos y pasivos a instituciones solventes y la compra de cartera riesgosa sin recursos líquidos con compromiso de recompra. Pero lo que más impactará la Economía y Sociedad serán los cambios que se harán a la ortodoxia adoptada en la primera etapa neoliberal, y que estará marcado por el ingreso al Ministerio de Hacienda en 1985 de un joven economista quien luego será candidato a la presidencia, Hernán Büchi. En el prólogo de uno de sus libros, Cristian Larroulet quien será Ministro de Piñera, hace la siguiente "laudatio" a su obra:

¿Cuándo se salvó Chile? EN qué momento de su historia nuestro país viró ciento ochenta grados para escaparse del hasta entonces oscuro destino de la mayoría de las naciones de Latinoamérica? El modelo económico chileno es motivo de admiración y estudio en todas

\footnotetext{
${ }^{389}$ LARRAÍN, Felipe y VERGARA Rodrigo (ed.). La transformación económica de Chile. Centro de Estudios Públicos, Chile. 2001. pp.10-12
} 
partes del mundo; hay por supuesto también detractores, pero son los menos, porque la realidad es demasiado elocuente: Chile pasó a la cabeza del desarrollo económico del continente y es difícil por ahora quien pueda desbancarlo de esa posición.

A la hora de buscar explicaciones y protagonistas, los candidatos son muchos, aparecen por cientos. Pero todos sabemos que entre éstos hay algunos cuya labor, sobresaliente hace la diferencia. Hernán Büchi es uno de ellos. ${ }^{390}$

Los cambios introducidos al sistema neoliberal, conformarán el núcleo de lo que hoy se conoce como el "modelo económico chileno" obteniendo importantes resultados económicos en cuanto al crecimiento. Büchi iniciará la etapa de flexibilización de las políticas económicas con un fuerte pragmatismo. Su rol fundamental será acelerar las privatizaciones e intensificarlas, pero ahora agrega la privatización de los servicios sociales con el objetivo de reactivar la economía. En este sentido, el estado comenzó a ser cada vez más subsidiario, dejando su función principal como controlador de los desequilibrios macroeconómicos. Todos estos cambios serán posible gracias al buen precio con que se vende en la época el cobre y a una reestructuración sustancial de la política fiscal, a las reformas comerciales y financieras y a las reformas sociales. Estos cambios serán también los que administrarán los Gobiernos de la Concertación.

Tras un pequeño retroceso en el modelo debido a la crisis, se comenzó lo que se ha denominado un segundo milagro chileno. Entre las políticas concretas emprendidas esta:

a.- Reducción del gasto en el sector público y rebajas del gasto social y las jubilaciones.

b.- Política de devaluación del peso en función del dólar que sobrepasasen la inflación, favoreciendo así las exportaciones y se restringían las importaciones.

\footnotetext{
${ }^{390}$ BÜCHI, Hernán. La transformación económica de Chile. (Reedición) Aguilar-El Mercurio. Chile. 2008.
} 
c.- Privatizaciones de las empresas que continuaban siendo estatales (Acero (CAP), Eléctricas (Enersis, Endesa), Comunicaciones (Entel, CTC), Azúcar (IANSA), Aeronáutica (LAN Chile,), entre otras).

d.- Privatización de los bancos intervenidos en la crisis de 1982.

e.- Se deja en manos del Banco central el control de las tasas de interés.

Cada una de estas privatizaciones no ha estado exento de polémicas, ya que no hubo control en sus ventas, lo que ha llegado a que se denomine el "gran saqueo de Chile". 391 Sin descontar que, tanto el sistema de salud (ISAPRES, Instituciones de Salud Previsional) ${ }^{392}$ y pensiones (AFP, Asociación de Fondos de Pensiones) ${ }^{393}$ paso a convertirse en un negocio tan rentable que hasta el día de hoy permanece inamovible. En definitiva el modelo económico instalado por Pinochet se vio reforzado, los resultados le avalarán una vez llegada la Democracia, en ese contexto ¿Por qué cambiar?

\section{2.-LA GARRAS DEL JAGUAR: LA TRANSICIÓN Y LA DEMOCRACIA}

El modelo económico instalado por Pinochet será consolidado por los Gobiernos de la democracia hasta la actualidad. La razón de esta continuidad es indiscutible si se observan los datos generales hacia 1988-89 (Cuadro 1).

\footnotetext{
${ }^{391}$ MONCKEBERG, María Olivia. El saqueo de los grupos económicos al Estado chileno. Grupo ZETA. Chile. 2001.

392 TETELBOIN, Carolina. La Transformación Neoliberal Del Sistema de Salud, Chile: 1973-1990: Reformas de Primera Generación. Universidad Autónoma Metropolitana, México. 2003

${ }^{393}$ ELTER, Doris. Sistema de A.F.P. chileno: injusticia de un modelo. Editorial LOM. 1999.
} 


\section{CUADRO 1}

VARIABLE MACROENÓMICAS 1984-1997
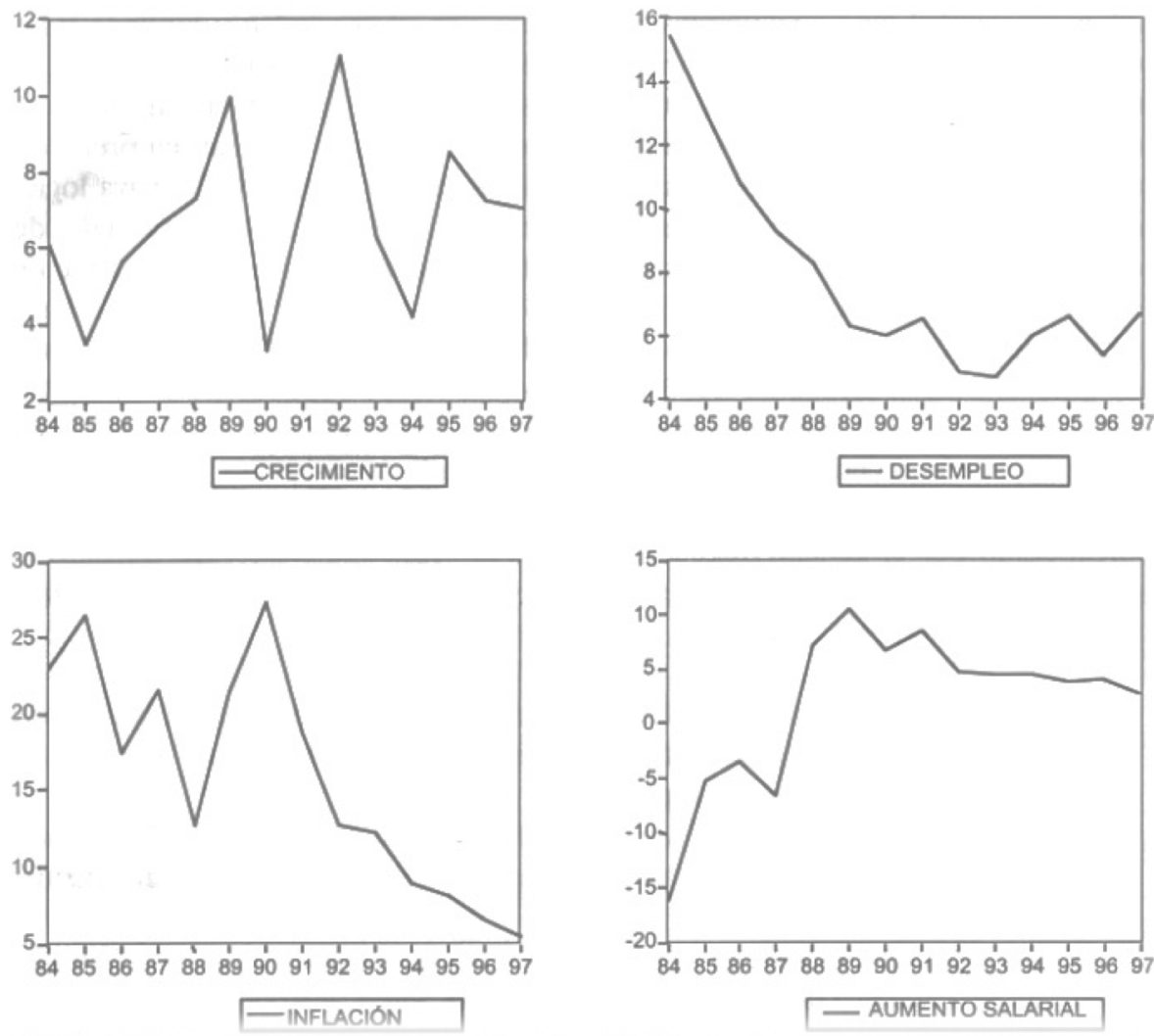

Elaborado por: LARRAÍN, Felipe y VERGARA Rodrigo (ed.). La transformación económica de Chile. Centro de Estudios Públicos, Chile. 2001. p. 30.

Un auspicioso futuro se proyectaba si se seguía con estas políticas, en especial si ya estaban consolidadas y habían llevado a Chile desde una economía de mercado a una sociedad de mercado con la instalación definitiva en la práctica cotidiana de los shopping, los mall, las multi-tiendas, la compra a crédito, etc. Ya lo anunciaba el dictador cuando en tono optimista 
hacia 1980 señalaba que “( ...) de cada siete chilenos, uno tendrá automóvil; de cada cinco, uno tendrá televisor, y de cada siete, uno dispondrá de teléfono." ${ }^{394}$

Y así fue: entre 1986 y 1998 se creció con tasas exorbitantes por sobre el 7\% (en 1992 llegó incuso al 10\%), estos años de abundancias llevaron a que Chile se transformara a poco de andar la democracia en todo un modelo de desarrollo, un "Jaguar de Latinoamérica" como le comenzaron a calificar en el exterior. ${ }^{395}$. Obviamente, se pasaba por alto que una elevada dosis de la violencia y represión lo habían hecho posible. Con todo, los datos macroeconómicos -en especial el PIB por habitante- eran bastante útiles para presumir internacionalmente de que la democracia era exitosa; para mantenerla bastaba con ciertos ajustes, bastante menores, al sistema neoliberal ya implantado. ${ }^{396} \mathrm{El}$ ahorro se vio incrementado, se compraron más autos, se establecieron records en construcción de viviendas, en exportaciones, en inversión, en ocupación laboral, y además las encuestas favorecían positivamente al gobierno al señalar mayoritariamente que Chile progresaba. El éxito estaba consolidado y era la mejor carta de presentación de la nueva democracia.

Las políticas de los años noventa fueron fundamentalmente gradualistas en el ámbito antiinflacionario, mientras la política fiscal fue bastante prudente; siguiendo las pautas y recomendaciones del Congreso de Washington para economías emergentes, se estableció una tasa de cambio flexible y se suspendieron los impuestos a las entradas de capitales de corto plazo. La austeridad fue la regla de los primeros gobiernos democráticos, siguiendo la ortodoxia macroeconómica en su manejo. Aunque en la primera década del siglo XXI el crecimiento fue

\footnotetext{
${ }^{394}$ EMOL. "La historia de Pinochet en algunas de sus más célebres frases." 10 de diciembre de 2006 [fecha de consulta: 10 de diciembre del 2013]. Disponible en internet: <http://www.emol.com/noticias/nacional/2006/12/10/238587/la-historia-depinochet-en-algunas-de-sus-mas-celebres-frases.html>

${ }^{395}$ OTANO, Rafael. Op. Cit. 2006. pp. 346-347.

${ }^{396}$ SOLIMANO, Andrés. Capitalismo a la chilena y la prosperidad de las élites. Editorial Catalonia.2a edición. Chile. 2013. pp. $77-78$.
} 
menor respecto a la de los 90 (marcada por la inversión, apoyada por una política de ahorros, una rápida expansión de las exportaciones, un clima de calma social, salarios moderados, y un sector laboral con sindicatos debilitados por la reforma laboral de Pinochet, que no fue ni ha sido modificada). De esta manera se pudo enfrentar con acierto las recesiones de 1999 y 2009, siguiendo los parámetros del FMI y basados en la ortodoxia norteamericana, que funda sus orientaciones en el rol del Banco Central y su independencia, tipos de cambios flexibles y metas de inflación. ${ }^{397}$

Hasta aquí parece una "tarea" bastante bien hecha -la incuestionable economía de Pinochet, bien administrada tanto por demócrata-cristianos y socialistas durante la democracia-, que permitió alcanzar importantes logros macroeconómicos. ¿Pero fue posible hacer esto sin costos? ¿Fue posible hacer esto en una sociedad civil que esperaba más igualdad y equidad en democracia? Aquí surge el núcleo de lo que algunos llaman "la traición de la democracia": la consolidación de una deuda donde la construcción de una ciudadanía de calidad, con derechos asegurados, ha sacado la peor parte. Analizaremos a continuación algunas de esta críticas al modelo de transición que puso en primer lugar los logros económicos por sobre los sociales y políticos.

\section{3.-¿SE CAE EL MODELO? EL DEBATE ACTUAL.}

En este apartado no analizaremos cada uno de los aspectos centrales de la economía de la transición o la democracia, ya que hemos elegido algunos aspectos que tocaremos en capítulos aparte para dar mayor énfasis a las características de nuestra particular democracia. Lo que

\footnotetext{
${ }^{397}$ MARTNER, Gonzalo y RIVERA, Eugenio (Editores). Radiografia crítica al modelo chileno. Balances y propuestas. LOM ediciones-USACH. 2013.
} 
haremos más bien será analizar y reflexionar en torno al modelo económico administrado por la democracia y que es, en lo "grueso", la herencia de Pinochet. Nos detendremos en las críticas surgidas en los últimos años respecto a algo que hasta hace poco era alabado por su éxito. Un modelo que, como veremos, no sólo continúa con los principios de la dictadura sino que ha creado los suyos propios en base a los anteriores.

En este sentido, compartimos la tesis de Siavelis, quien señala que no sólo existen enclaves de la dictadura, sino que la democracia tiene los suyos propios:

"Los enclaves de la transición, en la mayoría de los casos, no fueron impuestos por el régimen militar. En este sentido, gozan de una mayor legitimidad democrática y son cualitativamente diferentes de enclaves autoritarios. Sin embargo, existen ciertas similitudes entre los dos tipos de enclaves. Los enclaves de transición, al igual que los autoritarios, son multidimensionales (ellos constan de instituciones, formas de pensar y maneras de actuar, etc.). Además, ambos tipos no son totalmente negativos $\mathrm{y}$, en cierto modo, hacen una contribución positiva a la consolidación de la democracia. Por ejemplo, se podría argumentar, en algunos sentidos, que la presencia y la influencia de los militares durante la transición en realidad contribuyeron a la democratización garantizando los intereses fundamentales de los posibles actores de veto. Del mismo modo, es importante reconocer que muchos de los enclaves de transición jugaron un papel muy positivo en el éxito de los compromisos de transición democrática." ${ }^{, 398}$

Obviamente, no compartimos el optimismo de Siavelis respecto de lo positivo de estos enclaves, ni los de la dictadura ni los de la democracia, cuestión que podemos hacer porque la Historia Reciente de Chile nos ha demostrado que el malestar incubado por esto ha ido reflotando fuertes movilizaciones durante los últimos seis años. Con todo, además de lo que el

\footnotetext{
${ }^{398}$ SIAVELIS, Peter. "Enclaves de la transición y democracia chilena." [en línea] Revista Ciencia Política. Vol. 29, No 1 , 2009. pp. 3-21. [fecha de consulta 12 de mayo de 2015] Disponible en internet: $<\underline{\text { http://www.scielo.cl/scielo.php?script=sci arttext\&pid=S0718-090X2009000100001\&lng=es\&nrm=iso }>}$
} 
autor denomina "enclaves políticos", como son la elaborada distribución del poder mediante cuotas ("el cuoteo"), el control que ha tenido la elite en la selección de candidatos y la política electoral, la dominación de los partidos, la formulación de políticas elitistas y extrainstitucionales surge como uno de los bastiones de este modelo de democracia "a la chilena" la intocabilidad de la economía y su modelo. Aquí radicaría justamente el núcleo de su triunfo, la definitiva victoria de la clase media tan buscada desde mediados de siglo. ¿Es así?

\subsection{1.- El sueño chileno. La riqueza que no llegó a todos.}

Recuerda Rafael Otano, cronista de la Transición, que en 1992 se celebró el XIV Encuentro Nacional de las Empresas titulado "Ad portas: en el umbral de la prosperidad". En esta oportunidad Jeffery Sachs, de la Universidad de Harvard, quien había trabajado en un programa de estabilización en Bolivia de mediados de los 80 con gran éxito y que en ese momento asesoraba a Boris Yeltisn sobre la reconversión de la economía rusa, destacó como uno de los ponentes. Que este prestigioso economista estuviese en Chile era un halago para los empresarios de la época que veían que su país llamaba la atención en el extranjero. El "milagro" chileno no pudo ser menos que alabado por el investigador norteamericano, quien señaló: "Chile tiene mucho que enseñar a esta región y al mundo entero. Me parece que Chile puede proporcionar una gran lección en el sentido de que la democracia y la economía van de la mano.” 399

En la misma reunión hablaron los que eran los líderes del momento - y que lo siguen siendo en muchos casos-, como Ricardo lagos, José Piñera, Eduardo Frei, Jovino Nova, entre otros. Entre dichas presentaciones destacó la de Ricardo Lagos -por ese momento ya anunciando su candidatura- que puso en palabras lo que muchos empresarios querían que dijera un socialista:

\footnotetext{
${ }^{399}$ OTANO, Rafael. Op. Cit.2006. p. 344-345.
} 
que se seguiría de manera pragmática en lo económico y se agregarían en un plano muy secundario algunos tópicos de interés como el desarrollo con equidad, la mejor cobertura social y desarrollar un nuevo trato social. Se había pasado la prueba: en el fondo el Chile del crecimiento con una economía de mercado se mantendría igual, no sólo con los Demócrata Cristianos sino que también con un posible presidente socialista.

Entonces, el "mantra" repetido hasta la saciedad por la concertación se había instalado definitivamente: Chile estaba dando el salto al desarrollo. El optimismo era tal que durante el Gobierno de Piñera se llegó a afirmar que Chile sería un país desarrollado el año 2018 con USD 22000 de crecimiento del producto. Obviamente, aquí no se distinguen crecimiento de desarrollo, asumiendo una posición netamente neoclásica: lo importante era que continuara existiendo un proceso de acumulación y progreso técnico, el resto se daría por "chorreo.” Si a esto le sumamos que las exportaciones a partir del regreso a la democracia se diversificaron, propiciada a su vez una mayor apertura comercial mediante tratados regionales, bilaterales o acuerdos multilaterales, abandonando definitivamente el camino "cepalino" de desarrollo industrial interno, ${ }^{400}$ los objetivos de la economía estaban logrados. En efecto, se había generado más riqueza, pero ¿para quienes?

En realidad, los verdaderos logros de la economía de mercado de la democracia son otros, y así lo reafirma Siavelis:

\footnotetext{
“Tempranamente los líderes democráticos reconocieron que la economía era el talón de Aquiles de la transición. Un cambio sustancial en la economía había ocurrido, y la integridad de la transición democrática podría haberse visto comprometida. El compromiso de los presidentes de dejar intacto el modelo económico tranquilizó a las poderosas elites económicas cuya reacción a un posible cambio en la política podría haber
}

\footnotetext{
${ }^{400}$ MARTNER, Gonzalo y RIVERA, Eugenio (Editores). Op. Cit. 2013. pp. 137-139
} 
sido extraordinariamente desestabilizadora. Inversionistas internacionales fueron asegurados de la estabilidad económica y de un panorama confiable de inversión. Finalmente, el proceso de consulta de actores de veto sobre la economía facilitó un acuerdo posterior más amplio sobre otros asuntos con los grupos que simpatizaban con la derecha. En suma, este enclave, al igual que los anteriores, fue central en el mantenimiento de la transición democrática. Sin embargo, la falta de voluntad de los gobiernos democráticos para poner en discusión los fundamentos del modelo económico (más allá de algunas pequeñas reformas parciales, como el plan AUGE -una reforma limitada del sistema de salud emprendida por el Presidente Ricardo Lagos para hacer frente a las más graves desigualdades en el sistema de salud) ha dejado a la Concertación abierta a las críticas de que nada ha cambiado con la democracia. A pesar del éxito en la lucha contra la pobreza, los niveles de desigualdad en Chile se encuentran entre los más altos del mundo, y las debilidades en la representación ciudadana, subrayadas en este trabajo, dejan a los ciudadanos con escasas posibilidades de influir en la política económica del país. Una vez más, las negociaciones de alto nivel, en desmedro de las consultas populares o legislativas, han sido la norma en la construcción de la política económica." ${ }^{401}$

Si bien en los años noventa se propuso la necesidad de generar un "crecimiento con equidad" ésta no tuvo suficiente apoyo en el congreso en un primer momento y cuando lo hubo, había poca convicción para ejecutar los cambios, de modo que se continuó con un modelo que Martner denomina "híbrido", es decir, con un fuerte neoliberalismo con toques de desarrollo equitativo y sustentable; ${ }^{402}$ que por una parte generó mejoras en los servicios públicos y las condiciones sociales (así lo señalan los indicadores del PNUD) ${ }^{403}$, pero que no atacó la

\footnotetext{
${ }^{401}$ SIAVELIS, Peter. Op. Cit. 2009. pp. 15-17

${ }^{402}$ MARTNER, Gonzalo. Remodelar el modelo. Editorial LOM. 2007

${ }^{403}$ Se pueden ver en: http://desarrollohumano.cl
} 
desigualdad $^{404}$ o que se ha diversificado en sus exportaciones al precio de sobreexplotar los recursos naturales. ${ }^{405}$

El triunfo del reformismo de baja intensidad ha generado que al día de hoy Chile sea el país de la OCDE con mayor desigualdad de ingreso. Los ingresos del 10\% más rico en Chile son 26 veces más altos que los del 10\% más pobre (proporciones similares registran países como Colombia y México). La cantidad de súper-ricos que ingresan a la revista Forbes ha ido en aumento durante todos estos años, contándose entre 12 y 14 e incluso alguno entre los top 100, lo cual es insólito para un país con 17 millones de habitantes. ${ }^{406}$

Durante los últimos gobiernos se ha impulsado una serie de estrategias para disminuir la brecha, en especial avanzando en la igualdad de "oportunidades", una idea adoptada por los Gobiernos democráticos de Chile de tinte liberal, que intenta "emparejar la cancha" para que funcione la meritocracia. Pero han abandonado la idea de los "derechos" asegurados por el Estado y adoptan más bien la lógica de la competencia donde los “mejores" llegarán lejos y podrán emprender, obviando que en contextos tan desiguales como el nuestro el apellido y la "cuna" son aspectos cruciales, como ha quedado demostrado en varios estudios respecto al tema, como el realizado por Nuñez y Pérez:

\footnotetext{
${ }^{404}$ Los datos más recientes en el informe: OECD. “Todos Juntos ¿Por qué reducir la desigualdad nos beneficia?”. [en línea] Mayo del 2015. [fecha de consulta 12 de junio de 2015] Disponible en internet: <http://www.oecd.org/chile/OECD2015-InIt-Together-Highlights-Chile.pdf>

${ }^{405}$ Son varios los casos en que se han visto envueltos los privados respecto a la sobre-explotación e incluso casos donde el Estado ha jugado un rol importante como protector del emprendimiento, por el ejemplo el caso de los Cisnes y la celuloso Arauco, las Termoeléctricas o el intento fallido de construir una Hidroeléctrica en plena Patagonia chilena. Se puede leer: CLAUDE, Marcel. Una vez más la miseria: ¿Es Chile un país sustentable?. Editorial LOM. 1997.

${ }^{406}$ EL MOSTRADOR. "Ranking Forbes: Familia Luksic nuevamente lidera chilenos entre las mayores fortunas del mundo" [en línea]. 2 marzo 2015. [fecha de consulta 12 de mayo de 2015] Disponible en internet: $<$ http://www.elmostrador.cl/mercados/2015/03/02/ranking-forbes-familia-luksic-nuevamente-lidera-chilenos-entre-las$\underline{\text { mayores-fortunas-del-mundo/> }}$
} 
"Este resultado sugiere que habría existido un escaso grado de movilidad socioeconómica en el pasado, de modo tal que la estratificación social y económica que ha imperado en Chile durante ya siglos ha persistido en una magnitud importante hasta el Chile contemporáneo. Por otra parte, el trabajo también muestra empíricamente que el denominado "juego de los apellidos" tiene plena vigencia en el presente; existe un amplio y significativo consenso respecto del estrato socioeconómico que los individuos deducen subjetivamente a partir de los apellidos. El consenso subjetivo que concitan los apellidos es consistente con el rol que las diversas formas de ascendencia han jugado en la estratificación social y económica de Chile en el pasado. Además, las percepciones comunes representadas por los apellidos son "correctas", en el sentido que predicen acertada y significativamente el estrato socioeconómico efectivo de quienes portan tales apellidos."

Durante los últimos años e independiente de los estudios que muestran el éxito económico de Chile, se han divulgado investigaciones que recogiendo datos oficiales, muestran la verdadera cara del "desarrollo de Chile" con datos sobre empleo, salarios y movilidad social. Por ejemplo, en un informe del 2013 la fundación Sol señala alguno de los siguientes datos:

a.- "Quienes ganan el Salario Mínimo no son un grupo minoritario. Al considerar el total de trabajadores dependientes que se desempeñan en el sector privado (incluye servicio doméstico y asalariados de empresas externas en el sector público) (...) Si se incluyen todas las categorías ocupacionales (asalariados, cuenta propia y empleadores), el total de

\footnotetext{
${ }^{407}$ NÚÑEZ, Javier y PÉREZ, Graciela. "Dime cómo te llamas y te diré quién eres: la Ascendencia como mecanismo de diferenciación social en Chile”. Serie Documentos de Trabajo $N^{\circ}$ 269. Departamento de Economía, Universidad de Chile. 2007. pp. 18-19. También se puede ver: NÚÑEZ, Javier y PÉREZ, Graciela. "Classism, meritocracy and discrimination in the labor market: The case of Chile". Serie Documentos de Trabajo No 208. Departamento de Economía, Universidad de Chile. 2004.
} 
personas que ganan el Salario Mínimo o menos alcanza a 1.681.213, un 24,5 \% del total. Vale decir, prácticamente 1 de cada 4 trabajadores chilenos se encuentra en esta situación.

b.-Los bajos salarios es un problema generalizado en Chile. La política del Salario Mínimo, no sólo afecta a quienes lo reciben, sino que a gran parte de los trabajadores chilenos, a través de un Efecto Faro, que ilumina e impacta la distribución salarial. Por ejemplo, el 74 $\%$ de los trabajadores dependientes del sector privado gana menos de \$357.000 líquidos.

c.-50 \% de los trabajadores que ganan el Salario Mínimo o menos, se encuentran en la Agricultura, Industria Manufacturera y el Comercio. En las grandes empresas también se paga el Mínimo. Mientras en las micro empresas cerca del 30 \% ganan el Salario Mínimo o menos, en la gran empresa el 17,7 \% de los trabajadores se encuentra en igual situación, una proporción mucho más alta a la esperada. A nivel global, 1 de cada 3 trabajadores dependientes en el sector privado que recibe el Salario Mínimo o menos es contratado por grandes empresas.

d.-Los trabajadores que ganan el Salario Mínimo no sólo pertenecen a los hogares más pobres. 2 de cada 3 trabajadores que ganan el Salario Mínimo o menos, viven en hogares que se ubican entre el tercer y el séptimo decir de ingresos, lo que generalmente se tipifica como los sectores medios de la sociedad.

e.- La dieta de un parlamentario chileno equivale a 37,2 Salarios Mínimos. Mientras, el promedio en los países de la OCDE es 9,3 veces y en países como Portugal, Alemania, Reino Unido y Francia no supera las 6 veces.

f.- El actual valor del Salario Mínimo no cumple su objetivo. El Salario Mínimo de \$241.000, al descontar el pago de las leyes sociales, sólo alcanza para 1 kilo de pan al día, 2 pasajes diarios para ir y retornar del trabajo y para arrendar una pieza por $\$ 129.680$. Para 
el caso de los trabajadores que también reciben gratificación legal junto al Salario Mínimo, podrán arrendar una pieza por $\$ 177.880 .{ }^{, 408}$

Este y otros informes pueden ser corroborados con datos específicos, nosotros sólo hemos transcrito las conclusiones, no por esto menos ciertas. Por una parte, están los súper ricos y una economía creciendo de manera estable (en torno al 5\% anual) y por otra la promesa incumplida del desarrollo para la clase media. De hecho, existe mayor oportunidad para comprar y la clase media ha sido beneficiaría de esto, pero al costo de un asfixiante endeudamiento; otro de los logros de la economía de Pinochet como ha sido instalar un sector financiero brutal que hoy empapa no sólo los bancos sino incluso las empresas del retail que actúan como prestamistas o banqueros. Como señalan los mismos economistas de la Fundación Sol en una reciente columna:

“Según la Universidad San Sebastián, a partir de la información proveniente de DICOMEquifax, el número de endeudados a marzo 2015 en Chile es de 10,6 millones de personas. Si comparamos ese número con los 7,9 millones de ocupados que indica la Nueva Encuesta Nacional de Empleo del INE (en su trimestre enero-marzo 2015), nos encontramos con que existen 1,3 endeudados por cada ocupado. En septiembre 2011, según la misma fuente, el número de endeudados era de 9,5 millones y se daba el mismo indicador de 1,3 endeudados por cada ocupado.

Además, el número de endeudados creció en un 12\%, mientras que el número de ocupados lo hizo en un 6,5\%. En el mismo período la desocupación disminuyó en un 13,2\%. Es decir,

\footnotetext{
${ }^{408}$ DURÁN, Gonzalo y KREMERMAN Marco. Salario Mínimo y CASEN 2013 Trabajadores ganando el salario mínimo o menos en Chile. [en línea]. Documento Fundación SOL. Julio 2015. [fecha de consulta 12 de julio de 2015]. Disponible en internet: <http://www.fundacionsol.cl/wp-content/uploads/2015/07/estudiosalariominimo.pdf $>$
} 
el crecimiento de deudores no guarda relación con los niveles de desocupación, o, en otras palabras no necesariamente disminuye el número de deudores si crece la ocupación." ${ }^{409}$

Según este dato, casi todos los chilenos están endeudados y, lo que es peor, el crecimiento de la ocupación no es mayor que la del endeudamiento. La pregunta entonces es cómo se ha aguantado tanto, no sólo en temas referidos al constante abuso sobre las materias primas, la desigualdad en el crecimiento, la ausencia de derechos mínimos en salud, educación o pensiones e incluso la desmejorada situación de los salarios y la "falsedad" de la calidad de vida en base al endeudamiento. La respuesta no es fácil y se ha querido interpretar, en base a las manifestaciones sociales recientes en especial la del año 2011, como una crisis del modelo. Sin embargo, al parecer el modelo sigue con buena salud.

\subsection{2.- La pesadilla chilena. El debate actual sobre el modelo.}

Es cierto que el convencimiento acerca de la existencia de un modelo chileno de economía e incluso de sociedad era mal visto, incluso se asignaba inmediatamente ese análisis a personas vinculadas con la izquierda más radical. En el fondo, la crítica estaba marginada del quehacer nacional. Sin embargo, será la propia ciudadanía la que pondrá en el tapete el debate cuando comience a salir a las calles a exigir derechos que hasta ese estaban-y siguen en muchos casosmediatizados por la oferta y la demanda.

\footnotetext{
${ }^{409}$ CIPER. "Trabajar en una economía de la deuda" [en línea]. 20 de julio de 2015 [fecha de consulta 12 de agosto de 2015] Disponible en internet: < http://ciperchile.cl/2015/07/20/trabajar-en-una-economia-de-la-deuda/>
} 
El primer resquebrajamiento se vivió con la conocida "crisis asiática" en $1998^{410}$ que puso en entredicho en exitosos modelo de crecimiento que hasta ese momento vivía Chile. El caso modelo dio paso a la figura del "alumno aplicado" metáfora utilizada cunado Chile entraba a la OCDE y a la de los “problemas reales de la gente” que se transformó en frase cliché. Pero el modelo seguía ahí presente, ese conjunto de principios que rigen la relación entre la dimensión económica de la sociedad y el resto de sus dimensiones (política, social, cultural, etc.).

En el caso chileno queda claro, que tanto las relaciones sociales, la entretención y la cultura (los mall, los shopping, organización del territorio, etc.) esta mediatizada por la economía, así como las transacciones (la monopólica "redcompra", única empresa a cargo de la compra con tarjea de débito), la salud, pensiones y educación (redes privadas o subsidiadas por el Estado a la demanda) están insertas en la cotidianeidad a tal punto que Chile parece, como señala el geógrafo Sebastián Monnier, más bien un país estafa:

"Este país es una estafa. Yo no hablo del "otro Chile", de estos uno por ciento más ricos, viviendo en los "barrios altos", yo hablo de la gran mayoría del país. El costo de la vida en Chile es alto, cerca de, si no superior (especialmente en los dominios de la educación y de la salud) a lo que puede ser en países desarrollados de Europa. Pero Chile no es un país desarrollado; es solamente un país económicamente crecido, donde el poder de comprar y la calidad de vida de la mayoría están desfasados relativamente a los precios. La gente vive en un estrés y una inseguridad financieros permanentes, en la cortapisa del endeudamiento -qué maravillosa invención que estás tarjetas tipo Cencosud para controlar a una población criada en la incitación al consumo-. En los supermercados, el chileno camina lentamente, como obligado, abovedado y echado encima de su carro -

\footnotetext{
${ }^{410}$ DEL VILLAR Rafael, MURILLO José Antonio y BACKAL Daniel. "La crisis financiera en Asia: orígenes y evolución en 1997 y 1998”. Documento de Investigación N 9807 Dirección General de Investigación Económica Banco de México. Diciembre de 1998
} 
¿cómo no ver en esta imagen el símbolo de una forma de represión?- antes de llegar a la caja para pagar sus compras en cuotas. Es solamente un ejemplo, entre otros." ${ }^{411}$

En otras palabras, Chile es un país que posee un crecimiento importante pero éste no llega a la gente, o lo hace a cuenta-gotas. En definitiva, las mejoras son para el escaparate, sólo al alcance de aquellos individuos (privilegiados) que tiene el dinero para comprar o la valentía para endeudarse. En general, se cultiva una vida de apariencias.

Por ejemplo, el trabajo no tiene protección alguna, sólo un $11 \%$ de los asalariados están sindicalizados, ha habido un incremento de la subcontratación y cada tanto cuando se habla de mejora en el sueldo mínimo, a la par aparecen empresarios señalando de la posible recesión o como esto afectaría la dinámica de la economía. ${ }^{412}$ Pese a esto, un motor de la economía es el consumo, donde el Estado resulta subsidiario, de aquí que en Chile exista un mercado de automóviles muy dinámico, de tecnología, de retail, etc. El Estado en este contexto actúa más bien como controlador de conflictos que pueden derivar de la insatisfacción de necesidades sociales o que pueden derivar de empleos de mala calidad o precarios. De aquí que en los últimos años se otorguen constantemente bonos al ingreso familiar, a la mujer, al adulto mayor, etc. En este mismo sentido, la mayor cantidad de dinero captado por el fisco se obtiene a través del IVA, cuya recaudación es mucho mayor que el impuesto a la Renta; con lo cual continúan beneficiándose los que más tienen. En Chile se paga el impuesto que se paga (con todo los

\footnotetext{
${ }^{411}$ EL MOSTRADOR. “Chile, un país-estafa.” [en línea]. 6 de julio de 2014 [fecha de consulta 12 de mayo de 2015] Disponible en internet: $\quad<$ http://www.elmostrador.cl/noticias/opinion/2014/07/06/chile-un-pais-

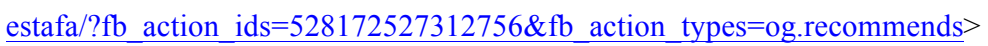
412 MAYOL Alberto. Op. Cit. 2013. pp. 40-43.
} 
subterfugios para tributar menos al servicio de los ricos), por lo que no resulta excepcional que una mega-empresa de retail puede pagar menos impuestos que un pequeño kiosco. ${ }^{413}$

Por otra parte, Chile es quizás uno de los países más interconectado con el mundo, con unos 60 tratados de comercio que lo ponen en relación con cerca del $80 \%$ de la economía mundial. Pero ¿qué quiere nuestro país del resto? La respuesta es sencilla: más mercancías. Y ¿qué quieren los demás de Chile? La respuesta también es fácil: minerales. De esta manera el futuro no está muy claro, ya que nadie asegura ni el precio de venta, ni que siga existiendo por veinte años más la necesidad de seguir comprando (quizás un descubrimiento como el del salitre sintético en los años 30 nos deje otra vez "fuera de carrera" con el cobre) o que existan suficientes yacimientos para satisfacer esa presunta demanda. Con todo, el peso de la minería en una década se ha duplicado en el PIB, consolidando la lógica de la explotación de recursos como sustento del presupuesto de la República (el modelo de "nuevo extractivismo").

Debido a todo esto -y mucho más- el malestar debía aflorar en algún momento y así sucedió a partir del 2011, con algunos atisbos previos. Para Salazar, los movimientos ciudadanos -como les denomina- tardaron en aparecer debido a ciertas características de la transición que él lista de la siguiente manera:

a.- Había que disfrutar de la satisfacción ("la alegría ya viene”) del fin de la fase dictatorial.

b.- Había que esperar que los hechos demostraran el olvido total, por parte de los partidos concertados, de su pasado democrático-populista ("la traición”).

\footnotetext{
${ }^{413}$ SOYCHILE. "El Jumbo del Costanera Center paga menos que un kiosko por patente comercial" [en línea]. 30 de junio del 2012. [fecha de consulta 12 de MAYO de 2015] Disponible en internet: < http://www.soychile.cl/Santiago/Economia-yNegocios/2012/06/30/102085/El-Jumbo-del-Costanera-Center-paga-menos-impuestos-que-un-kiosko.aspx $>$
} 
c.- La inyección desarrollista que inoculó el capital extranjero en el modelo neoliberal de Pinochet -produciendo el boom consumista- ocultó en primera instancia las contradicciones intrínseca de este modelo.

d.- Muerto el modelo populista (izquierda parlamentaria incluida) y notoriamente debilitado en el mundo el marxismo-leninismo (caída del muro, etc.) no existía una propuesta alternativa tradicional para oponerse al neoliberalismo triunfante.

e.- Después de 1990 se produjo el eclipse progresivo de los centros de acción alternativa que habían surgido en los años ochenta (ONG, grupos de lucha armada, redes de educación popular, Iglesia de los pobres, etc.) ${ }^{414}$

Este malestar incubado, aparece en el momento en que la Democracia, en especial la coalición de centro izquierda, celebraba sus éxitos y se autodenominaba la "coalición que más tiempo había liderado el país” o que era "el mejor gobierno chileno en un siglo.” Obviamente, el castillo de naipes cedió a la presión y al siguiente turno el gobierno se trasladaría a la derecha (hablaremos en el capítulo final de este tema), perdiendo la Concertación el poder después de más de veinte años de ostentarlo.

La interpretación de estas movilizaciones -principalmente la de los estudiantes- es interpretada por algunos pensadores cercanos a la Concertación como un signo de los "tiempos" no muy diferente a lo vivido en otros lugares del mundo. En otras palabras, sería el efecto del mismo desarrollo y no un defecto de éste:

"Las simetrías entre lo que está pasando en Chile con lo que sucedió en los Estados Unidos y Francia de los sesenta son sorprendentes. La primera y más obvia es lo que

\footnotetext{
${ }^{414}$ SALAZAR, Gabriel. Movimientos sociales en Chile: Trayectoria histórica y proyección politica. Editorial Uqbar. Chile. 2012. p. 37.
} 
podríamos denominar el "virus 15M": ese que germina cuando un país supera el umbral de los 15 mil dólares per cápita, y los "valores pos materiales" empiezan a ser tan valorizados como los materiales. La generación que sale hoy a las calles de Chile no vivió la guerra de sus padres contra la escasez y el autoritarismo"

Sin embargo la indignación era mucho más profunda, era contra de la propia transición y todo lo construido por ésta. Como señala uno de los líderes del movimiento, Giorgo Jackson, actualmente diputado:

“(...) En mi caso, egresado de un colegio particular, sentía esa angustia del privilegiado; y a cada universidad a la que asistí, para explicar el sentido del movimiento, desde la Universidad de Los Andes o Adolfo Ibáñez hasta los más diversos colegios particulares, siempre me interesó plantear ese tema con fuerza. Creo que una de las funciones que tuvimos los universitarios este año —en particular los de las mejores universidades de Chile - fue el buscar que los estudiantes privilegiados tomaran conciencia de su situación, y les generara angustia, culpa y rabia. No es fácil para nadie aceptar que los privilegios de los que goza son a costa de la discriminación de otros. Y fue un signo alentador darme cuenta de que éramos cada vez más — de verdad muchos - quienes queríamos desprendernos de dichos privilegios, o al menos ponerlos en juego para vivir en un país más justo.

(...) el esfuerzo de los secundarios de 2006 no fue en vano. En este 2011 muchos de los que participaron en ese movimiento y en el de 2008 entraron a la educación superior. Tenían la invaluable experiencia de la derrota, pues tras decenas de comisiones y mesas de trabajo, su esfuerzo culminó sin las reformas buscadas (el fin al lucro en la educación era una de ellas). La recordada fotografía que se sacó la presidenta Bachelet con los

\footnotetext{
415 TIRONI, Eugenio. “¿Vivimos una revolución cultural?” [en línea]. Columna Diario. EL MERCURIO. Noviembre del 2011. [fecha de consulta 12 de MAYO de 2015] Disponible en internet: $<$ http://www.cieplan.org/opinion/detalle.tpl?id=220>
} 
dirigentes de la derecha y de la Concertación, todos con las manos entrelazadas y en alto, fue el triste final para un movimiento que terminó doblegado, mientras la clase política hacía creer que la educación había dado un gran salto (por esos las manos entrelazadas) cuando no se habían movido las estructuras. Esa experiencia, sin embargo, hizo que esta generación entendiera mejor dónde estaban las trampas del sistema político y alimentara la desconfianza necesaria para no caer en ellas nuevamente.

(...) Hay que ir hacia las reformas constitucionales. El hecho de que tengamos una demanda que apoya tanta gente —un $80 \%$ en algún momento- y que el Gobierno haya podido hacer caso omiso de esta, demuestra que hay una contradicción profunda en nuestra democracia. El hecho que un Parlamento no pueda hacer mucho contra un presupuesto mezquino también muestra las limitaciones de un régimen tan presidencialista como el nuestro. Todo eso se suma a la ya conocida "política de los consensos" entre los dos bloques hegemónicos que mantienen sus niveles de poder gracias al sistema binominal. Los dirigentes de la CONFECH tratamos de instalar esa contradicción en el debate público y siento que a la gente le quedó dando vuelta el tema; creo que ahí está el germen para que la ciudadanía se active, y para que la siguiente tarea deba ser explicar muy claramente los lugares comunes con los que se defiende un sistema que no es del todo democrático."

En realidad, lo que proponían los estudiantes, queda claro, era algo más profundo. No era una rabieta de "nuevos ricos" como lo querían hacer pasar algunos investigadores cercanos al Gobierno, ni mucho menos la rabia de antisociales o anarquistas ${ }^{417}$, sino que eran una élite

\footnotetext{
${ }^{416}$ JAKSON, Giorgo. "La Mala Educación: ideas que inspiran al movimiento estudiantil en Chile. [en línea]. Revista on line Paradigmas del siglo XXI. 12 de junio 2012. [fecha de consulta 12 de mayo de 2015] Disponible en internet: $<$ http://paradigmasenelsigloxxi.wordpress.com/2012/06/12/la-mala-educacion-ideas-que-inspiran-al-movimiento-estudiantil$\underline{\text { en-chile-giorgio-jackson/> }}$

${ }^{417}$ Una parte de la derecha interpeló d ela manera más dura al movimiento, tratándolo de inconformista, o que con esto se podía destruir el consenso o que era si se llegaba a plebiscito era peligrosísimo: LARRAÍn Carlos. "Carlos Larraín: "No nos va a doblar la mano una manga de inútiles subversivos” [en línea]. Publicado en La Tercera 6 de agosto 2011. [fecha de consulta
} 
intelectual que se había visto traicionada, pero que además despertaba de una pesadilla que habían vivido sus padres. Una sociedad democrática con pocos derechos asegurados, con mucha libertad pero sólo para comprar o emprender; un sociedad de clientes más que de ciudadanos. Y eso era justamente lo que quedaba por revertir. Sin embargo, la presión dejó en claro que sería difícil lograrlo y pronto se pondrá de manifiesto que hay otras fuerzas actuando para que todo cambie sin cambiar nada.

\subsection{3.-¿De la democracia protegida a la controlada?}

En capítulos anteriores establecimos que la democracia con que cuenta Chile, mediada por la Constitución de 1980, ha funcionado con la vigilancia de las Fuerzas Armadas como garantes de ella, al punto que se le califica como una "Democracia Protegida", lo cual es de sobra evidente especialmente para los primeros años de la transición. A su vez, se ha establecido que el proyecto económico ha sido heredado de la dictadura con pocos cambios, por lo tanto sigue vigente e instalado profundamente en la sociedad chilena.

Ahora bien, podría decirse que el andamiaje que apuntalaba la "Democracia protegida" se fue desarmando lentamente desde los primeros años de la transición hasta el 2005, cuando se le extirparon una buena parte de sus enclaves. Pero esto no significa haber conquistado una nueva Constitución, sino más bien que en la carta reformada siguen vigentes los altos quórum para

12 de mayo de 2015] Disponible en internet: < http://www.latercera.com/noticia/politica/2011/08/674-384606-9-carloslarrain-no-nos-va-a-doblar-la-mano-una-manga-de-inutiles-subversivos.shtml>;

LARRAÍN, Felipe. "Nada es suficiente para los estudiantes" [en línea]. 22 de octubre 2011. Publicado en Soychile. . [fecha de consulta 12 de mayo de 2015] Disponible en internet: $<$ http://www.soychile.cl/Santiago/Sociedad/2011/08/22/33635/Larrain-Nada-es-suficiente-para-los-estudiantes.aspx> ; BAYER, Harald. “¿El fin de la democracia de consenso?” [en línea]. Publicado en El Mercurio, 16 de agosto de 2013 . [fecha de consulta 12 de mayo de 2015] Disponible en internet: < http://www.elmercurio.com/blogs/2013/08/16/14402/El-fin-de-lademocracia-de-consenso.aspx $>$ 
su modificación que la hacen inamovible; por lo tanto, la crítica hacia la misma sigue en pie. No obstante, algo ha cambiado y el eje crítico ha ido girando hacia otros actores, ocultos hasta hace muy poco, pero que han contado con un poder enorme en el Chile reciente: los empresarios.

Si bien lo que señalaré a continuación es una hipótesis que debe corroborarse con mucho más estudio acerca del desarrollo del empresariado en Chile, disponemos de ciertos indicios sobre su certeza en el Chile actual. Como explica Thomas Piketty explica en El Capital en el siglo $X X I$, la riqueza acumulada crece más rápido que los ingresos del trabajo. Es por esto que los ricos, que ya posee la mayoría de los bienes, se hacen más ricos aún, mientras que todos los demás, que dependen principalmente de los ingresos de su trabajo, quedan desplazados. Esto vendría a cronificar la desigualdad en los países capitalistas. ${ }^{418}$ Ahora bien, estos ricos lo son gracias a que sus padres lo fueron y, en esencia, su riqueza no es fruto necesariamente del trabajo sino de la acumulación. Así sucede que con el tiempo los ricos se han ido haciendo más ricos, y salvo algunos grupos de clase media que han logrado ir acumulando en coyunturas muy específicas, la norma es que la brecha entre unos y otros sólo ha disminuido en momentos excepcionales de la historia.

La teoría de Piketty parece ser válida en general, puede aplicarse provechosamente para describir algunos casos en Latinoamérica y quizás en el caso chileno funciona sobre aquellas fortunas de siglos XIX amasadas por chilenos $\mathrm{y}$, principalmente por capitalistas extranjeros, que han conseguido conservar e incluso incrementar su patrimonio a lo largo del tiempo (como Edwards, Errázuriz o Subercausaux). ${ }^{419}$ Sin embargo, este patrón de acumulación no logra explicar la situación del Chile reciente y la apropiación de bienes en manos, por ejemplo, de los

\footnotetext{
${ }^{418}$ PIKETTY, Thomas. El capital en el siglo XXI. Fondo de Cultura Económica de España. España. 2014.

${ }^{419}$ NAZER, Ricardo. "El surgimiento de una nueva élite empresarial en Chile: 1830-80” En: BONELLI, Franco y STABILI María Rosaria. Minoranze e culture imprenditoriali. Cile e Italia (secoli XIX-XX). Editorial Carocci. Italia. 2000.
} 
Piñera, Lerou, Délano y tantos otros como ellos, que representan a los actuales super- ricos del país. En realidad, estas nuevas riquezas se crearon bajo la dictadura a partir de favores que se iniciaron en los ochenta (con Pinochet entregando las empresas públicas a bajo precio a sus allegados, como a su entonces yerno, Ponce Lerou), pero que incluso se extienden a los noventa. También se vivió una transición de los líderes civiles de la dictadura, ${ }^{420}$ que vieron su espacio natural de continuidad en el mundo empresarial, como fue el caso de Hernán Büchi (ex Ministro de Hacienda), miembro por lo menos de ocho directorios de empresas de distintas características; o Sergio de Castro (ex Ministro de Economía y de Hacienda), socio de una empresa inmobiliaria, o Carlos Cáceres (también él ex Ministro de Hacienda), quien formó parte de tres directorios. El listado podría alargarse con otros tantos antiguos miembros del Régimen. $^{421}$

Por su parte, algunos conspicuos integrantes de la Concertación y ex -políticos de izquierda también reorientaron sus labores al mundo privado. Los casos más emblemáticos son los de Enrique Correa, quien formó parte del primer Gobierno democrático y hoy es el lobbysta más reconocido de Chile y un asesor de empresas; y Oscar Guillermo Garretón -socialista y colaborador de Allende y luego de Aylwin-, quien llegó a director de dos empresas privadas de mucha relevancia (telecomunicaciones y azúcar). Como se puede observar, el mundo privado, financiero y empresarial ha seducido a los ex -colaboradores de Pinochet, pero también a gente cercana a la democracia. El por qué?... La respuesta está en el viento, o en el espíritu de época.

\footnotetext{
${ }^{420}$ THE CLINIC. "La Maldición de Pinochet: empresarios que se enriquecieron en dictadura y que cayeron en desgracia" [en línea]. 14 de octubre del 2014. [fecha de consulta 12 de julio de 2015] Disponible en internet:

http://www.theclinic.cl/2014/10/14/la-maldicion-de-pinochet-empresarios-que-se-enriquecieron-en-dictadura-y-quecayeron-en-desgracia/

${ }^{421}$ Se pueden ver estudios acuciosos del tema en: MONCKEBERG, María Olivia. El saqueo de los grupos económicos al Estado chileno. Grupo ZETA. Chile. 2001; MONCKEBERG, María Olivia. Con fines de lucro, Random House Mondadori. Chile. 2013; MONCKEBERG, María Olivia . El negocio de las universidades en Chile, Random House Mondadori. Chile. 2007
} 
Si hace años atrás alguien hubiese denunciado que en Chile existían poderes fácticos que controlaban la toma de decisiones en democracia, lo más seguro es que hubiese sido descalificado y silenciado; tratado como un demagogo que agitaba una crítica trasnochada y sin fundamentos. Sin embargo, en estos últimos años han quedado a la intemperie los estrechos vínculos entre economía y político en desmedro de la salud de una democracia de tal nombre. A continuación una lista de los ejemplos más sangrantes:

a.- Colusión de farmacias.

El año 2008 el Fiscal Nacional Económico Enrique Vergara Vial comenzó una investigación por una colusión de precios entre las mayores cadenas farmacéuticas chilenas tras una denuncia de la Subsecretaría de Salud Pública. La polémica mayor se dio cuando se supo que Sebastián Piñera, candidato a la presidencia, era accionista de Farmacias Ahumada, recibiendo críticas de parte del oficialismo. Éste declaró sobre las acciones que "no sabía que las tenía."422

\section{b.- Caso Cascada:}

Entre 2008 y 2011, la Superintendencia estableció la existencia de un esquema en el que el ex yerno de Pinochet, Ponce Lerou, se veía beneficiado. Las sociedades realizaron una serie de operaciones sociales, tanto de inversión como de financiamiento, que tuvieron por objeto dejar disponibles importantes paquetes de acciones para su remate en el mercado, para después recomprar los títulos a precios mayores a los de su venta inicial. La utilidad estimada de Julio Ponce Lerou ascendió a 128 millones de dólares. La Superintendencia de Valores y Seguros terminó por señalar que había habido una falta grave.

\footnotetext{
${ }^{422}$ DIARIO UDECHILE. "Consumidores por caso Farmacias: "Los delitos de cuello y corbata siempre quedan en la impunidad" [en línea]. 23 de junio 2015. [fecha de consulta 12 de julio de 2015] Disponible en internet: $<\underline{\text { http://radio.uchile.cl/2015/06/23/consumidores-por-caso-farmacias-los-delitos-de-cuello-y-corbata-siempre-quedan-en-la- }}$ $\underline{\text { impunidad }>}$
} 
Una de las hipótesis de la defensa del Julio Ponce Lerou durante el caso fue que tras las acusaciones del ex superintendente Coloma estaba la influencia del ex presidente Sebastián Piñera quien invirtió, a través de Axxion y Bancard en matrices de SQM (Norte Grande, Oro Blanco y Calicchera), acciones que, según indicó en 2013, mantuvo hasta el año 2008 cuando vendió parte de sus activos financieros. También se dieron varios casos de asesorías no realizadas de políticos a la empresa. ${ }^{423}$

c.- Ley de Pesca.

Esta ley, conocida como Ley de Límites Máximos de Captura por Armador y que entró en vigor en 2001, fue impulsada por el Gobierno de Ricardo Lagos. Establecía un sistema de cuotas individuales transferibles que duraría dos años; en 2002, a través de una ley corta, el Congreso aprobó extender estas licencias por diez años. Sin embargo, este reparto favoreció finalmente a un puñado de empresarios que tiene la concesión exclusiva, marginando y afectando a los pequeños pescadores. Nueve grupos económicos son dueños del 90\% de la pesca industrial de jurel, sardina y anchoveta. El proyecto, formulado por el ex ministro de la cartera Andrés Fontaine, consideraba dejar el 50 por ciento de las cuotas para licitación, dándole mayor competencia al sector con el ingreso de nuevos actores y así, generar mayores recursos para el Estado. La llegada de Pablo Longueira a Economía en el Gobierno de Piñera desestimó esta posibilidad. $^{424}$

\footnotetext{
${ }^{423}$ EL MOSTRADOR. "SQM: Conflicto de interés llega al Congreso y piden inhabilitarse a parlamentarios en votación del caso Cascadas" [en línea]. 7 abril 2015. [fecha de consulta 12 de julio de 2015] Disponible en internet: $<$ http://www.elmostrador.cl/noticias/pais/2015/04/07/sqm-conflicto-de-interes-llega-al-congreso-y-piden-inhabilitarse-aparlamentarios-en-comision-del-caso-cascadas/>

${ }^{424}$ LA TERCERA. "Las cinco claves de la Ley de Pesca que genera protestas en las ciudades portuarias de Chile” [en línea]. 11 de julio del 2012. [fecha de consulta 12 de julio de 2015] Disponible en internet: $<$ http://www.latercera.com/noticia/nacional/2012/07/680-471587-9-las-cinco-claves-de-la-ley-de-pesca-que-generaprotestas-en-las-ciudades.shtml>
} 


\section{d.- Caso Caval.}

El Caso Caval (2015) es un escándalo político y un caso judicial de carácter penal, referido a un supuesto tráfico de influencias ejercido por Sebastián Dávalos, hijo de la presidenta Michelle Bachelet, quien habría ayudado a la obtención de un crédito (con el mismo dueño del Banco y uno de los hombres más ricos de Chile, Andrónico Luksic) por más de US\$ 10 millones, que finalmente fue aprobado días antes que su madre ganara la elección presidencial; crédito que habría sido utilizado para comprar un terreno en Machalí, en la VI Región, cuyo suelo era de uso agrícola. $^{425}$

\section{E.-Caso Penta.}

El caso Penta (2015) es un caso judicial de carácter penal, referido principalmente, a un supuesto fraude al fisco de Chile por parte de Empresas PENTA, mediante la utilización de facturas y boletas de honorarios falsas que, entre otros aspectos, habrían permitido el financiamiento irregular de campañas electorales de varios políticos. Actualmente el caso está en plena investigación por delitos tributarios y por soborno, lavado de dinero y cohecho. En él se han visto involucrados tanto políticos de derecha como del Gobierno; tal vez el más sonado entre los involucrados haya sido el ex Ministro de Bachelet, Rodrigo Peñailillo. ${ }^{426}$

\footnotetext{
${ }^{425}$ LA TERCERA. "Caso Caval: Ejecutivo del Banco de Chile testifica que "en mis 16 años de experiencia primera vez que veo la concesión de un crédito de éstas características" [en línea]. 4 de agosto del 2015. [fecha de consulta 12 de agosto de 2015] Disponible en internet: < http://www.elmostrador.cl/noticias/pais/2015/08/04/caso-caval-ejecutivo-del-banco-de-chiletestifica-que-en-mis-16-anos-de-experiencia-primera-vez-que-veo-la-concesion-de-un-credito-de-estas-caracteristicas/>

${ }^{426}$ ADNRADIO. "Investigan a fiscal por supuestas filtraciones del caso Penta-SQM a Rodrigo Peñailillo" [en línea]. 3 de agosto del 2015. [fecha de consulta 12 de agosto de 2015] Disponible en internet: $<$ http://www.adnradio.cl/noticias/nacional/investigan-a-fiscal-por-supuestas-filtraciones-del-caso-pentasqm-a-rodrigopenailillo/20150803/nota/2878877.aspx $>$
} 
Estos son sólo algunos ejemplos que han impactado en la sociedad por los abusos de ciertos sectores económicos que actúan con impunidad. Pero hay otros tan graves como el del retail, el de la Empresa "La Polar" o el millonario "perdonazo" por impuestos internos a la tienda “Johnson". La "normalidad" y cantidad de estos episodios han terminado por minar la confianza de la ciudadanía en los políticos y en la propia política, al ser testigos impotentes del grado de impunidad frente a todo tipo de delitos económicos.

Esta relación incestuosa entre política y economía neoliberal fue muy bien articulada durante la democracia y generó el control necesario para seguir manteniendo el statu quo necesario para los negocios entregados por Pinochet. En adelante, los militares ya no necesitabarían seguir protegiendo, ahora estaban los empresarios controlando, como sintetizan muy bien los abogados Briones y Bosselin:

"Escarbando en la historia se observa que la obra de la dictadura en materia económica tuvo dos aspectos: por un lado, libertad en los precios, libertad de contratación, apertura al comercio exterior y un poco de competencia en los mercados; y, por el otro, traspasar el aparato económico productivo del Estado a personas leales y afines a la dictadura y eso se hizo concienzudamente y sin pausa bajo la era de Büchi, el gran arquitecto. Para ello se desarrolló un proceso de una audacia impresionante. Primeramente se pusieron a la venta por gotas las compañías, entregando a personas que trabajaban en el Estado sus derechos a fondos por retiros y jubilaciones. Eso se llamó capitalismo popular. Mientras tanto, unos pocos conseguían créditos oportunamente, incluso del banco estatal, para adquirir paquetes que pudieran darles el control político de las empresas.

Hecha esa primera etapa era necesario capitalizar las compañías, para lo cual se les permitió a las empresas que controlaban los fondos previsionales, que son en el fondo impuestos específicos, comprar acciones y, como aquellas empresas estaban controladas a su vez por personas del mismo signo político, se conformó una perfecta dupla privada 
con un componente público, los fondos previsionales; pero aún faltaba otra ayuda del Estado, la que consistió en que las empresas pagaran impuestos sólo por aquellos dineros que no se reinvertían, lo que unido a un impuesto a la renta muy bajo catapultó el proceso de acumulación a niveles exorbitantes como los que se conocen hoy. Para este fin se creó el famoso FUT o Fondo de Utilidades Tributables, que acaba de ser objeto de una reforma parcial en la última reforma tributaria.

Cuando llegó la democracia estos grupos necesitaban verdaderos seguros de vida y evitar que gobiernos de centro izquierda, dirigidos por "peligrosos" democratacristianos o socialistas, afectaran sus intereses vitales y para ello hicieron dos cosas que les parecieron muy inteligentes. Primero fundaron, desarrollaron y consolidaron un partido político que es hoy el más grande, con el objetivo preciso de defender el proceso privatizador bajo el ropaje de defender un supuesto modelo de libertad económica. Pero como los votos no daban para entregar seguridades, concurrieron a la vereda opuesta y también procedieron a efectuar jugosos aportes a un grupo selectivo, pero muy influyente de personeros que pudiesen definir políticas públicas tanto a nivel ejecutivo como parlamentario. Así el dinero pasó a controlar la política." ${ }^{427}$

Esto será en gran parte el germen del malestar social y lo que alimenta la crítica al régimen político y económico actual. Una democracia que no sólo estaría atada legalmente a la dictadura, sino que se siente cómoda en su modelo de sociedad y economía, a tal punto que le defiende cuando es necesario. En este sentido, los últimos informes que pulsan la opinión pública recogen este malestar señalando que un $47 \%$ de los chilenos piensan que es necesario que las cosas cambien radicalmente, mientras sólo un 20\% (identificado con las elites) opina lo contrario; lo que deja en claro que esta situación es un mal muy profundo en el Chile actual

\footnotetext{
${ }^{427}$ EL MOSTRADOR. "Columna: De la democracia protegida a la controlada" [en línea]. 1 de abril del 2015. [fecha de consulta 12 de agosto de 2015] Disponible en internet: < http://www.elmostrador.cl/noticias/opinion/2015/04/01/de-la-democraciaprotegida-a-la-controlada/>
} 
que ha iniciado un nuevo periodo de demandas y politización. ${ }^{428}$ Además, se trasluce que la diferencia entre la apreciación de un Chile Modélico y un Chile en Crisis ${ }^{429}$ corresponde a la opinión de aquellos que se han visto beneficiados frente a quienes se han quedado al margen del crecimiento y el desarrollo.

${ }^{428}$ PNUD. Informe de desarrollo humano: Los tiempos de la politización en Chile. Programa de desarrollo humano en Chile. 2015.

${ }^{429}$ MAYOL, Alberto y AHUMADA, José M. Economía política del fracaso: la falsa modernización del modelo neoliberal. Editorial el Desconcierto. Chile. 2015. 


\section{0.-EDUCACIÓN PARA (CASI) TODOS: EL DESAFÍO DE LA CONCERTACIÓN DE LOS 90.}

El tema educativo ha sido el "disparador" para que los investigadores sociales comenzaran a fijarse en el Chile democrático con una mirada distinta. En movilizaciones consecutivas que se viene realizando en los último diez años los estudiantes han ido profundizando en sus demandas dejando en claro que no se trata del tema solamente educativo, sino que con en ello se ponen de manifiesto los errores de la dictadura y el mantenimiento de los mismos bajo la democracia. Así lo señala de manera clara el actual diputado y ex dirigente estudiantil Gabriel Boric:

"Ricardo Lagos y Sergio Bitar crearon el 2005 el sistema de los créditos CAE, que tiene endeudado hasta no poder más a miles de familias chilenas, y a los que nos opusimos en su momento a dicha reforma nos dijeron que éramos egoístas.

Michelle Bachelet, a quien cientos de miles de estudiantes le pedimos en las calles el año 2006 que cambiara nuestro sistema educativo, nos dio la espalda, y acordó con la derecha aprobar la LGE, traicionando a un movimiento que quería derribar el legado de la dictadura.

La respuesta es muy simple: Los estudiantes no podemos creer ni en Piñera, ni en la derecha, ni en Bachelet, ni en la Concertación. Sería atentar contra nuestra inteligencia, nuestra historia y nuestro sentido común. El desafío de todo movimiento como el nuestro es entender su momento histórico. Es entender qué es lo que representamos, y por ende, qué es lo que podemos hacer. Cuáles son los muros que podemos derribar y cuáles son las realidades que podemos construir. 
A nosotros, como generación, no nos tocó experimentar la dictadura. Algunos éramos muy pequeños para entender lo que pasaba y la mayoría no había siquiera nacido. Pero sí nos tocó ver la esperanza de nuestros padres, hermanos, y vecinos de que con el retorno a la democracia iba a significar un cambio profundo en sus vidas, y nos tocó estar ahí cuando dicho anhelo fue lentamente cayéndose a pedazos. Tuvimos, a la vez, nuestra propia historia de sinsabores. También hicimos nuestro camino para tratar de cambiar este sistema, y descubrimos las nuevas murallas que se habían trazado, aquellas que impedían salirse del modelo acordado durante la dictadura.

Fue en ese camino, sin embargo, donde aprendimos que sí había cosas en las que creer. Aprendimos a creer en nosotros mismos, en que a pesar de que la televisión nos dijera que estábamos equivocados, esa sensación en la guata de que esto podía cambiar estaba en lo correcto. Aprendimos a creer en nuestros compañeros, aquellos que sufrían los mismos abusos que nosotros, y en que la fuerza y radicalidad de nuestro movimiento se encontraba en nuestra unidad y cohesión. Aprendimos a creer en los chilenos y chilenas, aquellos que parecían llevar vidas tan grises y tristes, pero que en el fondo de sus corazones seguía vivo el deseo de vivir en una sociedad más justa, más igualitaria y más democrática.

Nuestra convicción es que los que marchamos hoy, y todos aquellos que siguen con esperanza esta marcha desde sus casas y trabajos, tenemos una gran responsabilidad a cuestas. No se trata de que seamos grandes iluminados o de que tengamos una verdad que nadie conoce. Se trata del momento que nos toca vivir y la posibilidad de avanzar en una dirección que hasta hace unos años era impensable. Es nuestra responsabilidad, como generación, acabar con la transición." ${ }^{430}$

\footnotetext{
${ }^{430}$ BORIC, Gabriel. ¿Podemos los estudiantes creer en el Presidente? [en línea]. Discurso realizado en la marcha en Santiago de Chile el 16 de mayo del 2012. En: Diario "THE CLINIC" [fecha de consulta 3 de mayo del 2011]. Disponible en internet: <http://www.theclinic.cl/2012/05/16/discurso-de-gabriel-boric-podemos-los-estudiantes-creer-en-el-presidente/>
} 
En el fondo, como deja en claro la larga cita anterior, el problema es la forma en que se ha desarrollado la democracia actual, donde la educación se ha transformado en un "tambor de resonancia" de los graves problemas de desigualdad, inequidad y segregación. Asumiendo que la educación es uno de los factores más importantes de desarrollo de los países es insólito que en el Chile democrático aún no esté asegurada de manera igualitaria para todos y, por el contrario, que la de mejor calidad esté en manos del mejor “cliente•" Una muestra más de cómo la dictadura permeó la sociedad en su totalidad, incluyendo este ámbito tan relevante.

En los siguientes apartados analizaremos la génesis del modelo educativo bajo la dictadura y cómo se ha ido profundizando en democracia.

\section{1.-LA ESCUELA COMO CAMPO DE BATALLA.}

La educación es un espacio donde los diversos Gobiernos imprimen su sello, en ella aplican y ponen en práctica sus convicciones, subrayando los aspectos que consideran más relevantes como el currículum y los contenidos, la formación inicial o continua, el aprendizaje, las infraestructuras, etc. También suele ocurrir que la educación y su sistema se convierten en un verdadero campo de batalla ideológico, que en la mayoría de los casos no va más allá de suprimir algunos programas específicos o dar énfasis a otros, entendiendo que la estructura general es una preocupación profunda y por tanto del Estado.

Sin embargo, en el contexto de los años 70 en América Latina y de manera particular en Chile, la educación no sólo se convirtió en un campo de batalla en términos ideológicos sino que se llegó al terreno práctico, con persecución y asesinatos. Para los militares éste fue un campo donde se estaba decidiendo el futuro del país, donde confrontaban el pensamiento marxista internacional frente a otro de carácter nacional-conservador. 


\subsection{1.-La revolución inconclusa de Allende en Educación.}

Entre las causas que llevaron a la crisis de 1973 y el posterior Golpe de Estado, el nuevo proyecto educativo no pude ser soslayado. La educación era un campo que estuvo en la diana de los sectores más reaccionarios desde el primer momento porque ella también estuvo expuesta a los cambios profundos que propuso la Unidad Popular en toda la estructura de la sociedad y la economía chilena.

Como señalan muchos investigadores, la educación bajo el Gobierno de la Unidad Popular vivía su propia tensión frente a las demandas de la sociedad que ya desde la década de los 60 solicitaba que se hicieran cambios estructurales. Bajo el Gobierno de Allende se dio un salto adelante en el crecimiento del sistema educacional, en los esfuerzos igualitarios y en la participación popular para proponer una política educativa. Efectivamente, en la estructura del sistema educacional se incorpora un grupo de directores que provienen del sector sindical y político, dejando a la burocracia técnica fuera. Estos nuevos grupos, como ocurriera también en otros campos, van a estrechar vínculos con obreros, sectores medios y grupos de campesinos, además de grupos urbanos marginales. Los lineamientos para la transformación de la educación durante la Unidad Popular se iniciaron con las conversaciones con la Central Única de Trabajadores y el Sindicato Único de trabajadores, y alcanzaron su culminación en el Congreso Nacional de Educación de 1971. ${ }^{431}$

Los datos evidencian cambios profundos operados bajo el corto mandato del Gobierno de Allende, guiados por este vínculo con los sectores populares y de trabajadores. Según datos recabados por Núñez y otros autores, la atención pre-escolar subió de 58.990 a 90.295 niños, con un promedio de crecimiento anual de $15,2 \%$, elevando la tasa de atención desde 4,1 a

${ }^{431}$ NUÑEZ, Ramón. Et. Al. Las transformaciones educacionales bajo el régimen militar. Vol. 1. (reimpresión) PIIE. Chile. 1991. 
6,4\% . Además se habría logrado la plena cobertura de la población de 6 a 14 años, al subir la matrícula de la educación básica desde 2.044.591 a 2.316.874 niños, con un promedio de incremento anual de 4,3\%. En la educación secundaria (Ed. media) el promedio de crecimiento fue de un $11,8 \%$ anual y en la técnico profesional de un 17,6\% de aumento anual, elevando así la tasa de escolarización de la población de 15 a 19 de un 33,5 a un 42,9\%. Por su parte, la Educación Superior creció en un promedio anual del 22\% anual. ${ }^{432}$ Para mejorar la calidad de estos procesos también se incrementó la contratación de profesores, se les dio participación en la gestión, aumentó la sindicalización, se generaron nuevas instancias de capacitación y mejoraron los salarios reales.

Con el fin de favorecer a los estudiantes más pobres se hicieron fuertes inversiones con el objeto de entregar textos escolares gratuitos y mejorar el equipamiento de escuelas técnicoprofesionales. Hacia 1971 se duplicó la superficie edificada destinada a instituciones educativas. Para lograr este increíble crecimiento y mejoras sustanciales en el sector se debieron aumentar los programas de asistencialidad en volumen de población favorecida y calidad de las prestaciones. Con todo, los esfuerzos no cosecharon resultados tan satisfactorios como los esperados y los estudiantes de más bajos recursos continuaron desertando de la Educación Superior.

Aparejado con esto e inevitablemente, el gasto público en Educación aumentó vertiginosamente pese a las restricciones que ya se vivían en los años 70. Algunos costos se amortizaron exprimiendo el sistema al máximo, lo que mermó en muchos casos la calidad. En este sentido, la estrategia educacional gubernamental implicó, inicialmente, una profundización de la política de ampliación e igualdad de las oportunidades educativas y un cierre de los aspectos inacabados de la reforma iniciada por el gobierno anterior. Sin embargo, pronto se inició la

\footnotetext{
${ }^{432}$ Ídem. p. 25.
} 
discusión acerca de un camino propio con una nueva definición política e ideológica. En 1971 se comienza ya a hablar de la necesidad de transformaciones revolucionarias o un esquema global de avance del socialismo en el plano educacional, en lo cual incidió la polarización que estaba viviendo el país en este momento. Para estos planes se recibió colaboración de la UNESCO y de especialistas con un marcado enfoque marxista, de donde nació el proyecto de Escuela Nacional Unificada (ENU) en $1972 .{ }^{433}$

Este ambicioso proyecto tenía como objetivo general la formación integrada de la personalidad de los estudiantes mediante la educación general y politécnica. Específicamente, se querían desarrollar las habilidades, conceptos, actitudes y valores favorables al trabajo productivo, a la convivencia democrática y al compromiso social. Promovía la formación de una conciencia nacional, de una concepción científica de la sociedad, del hombre y la naturaleza y el cambio de la mentalidad consumidora hacia otra productiva y solidaria. A principios de 1973 se presentó el informe del proyecto ENU, el cual fue un motivo más para criticar el Gobierno de Allende, acusándolo de ideológico e instrumentalizador de la educación con el fin de inculcar el marxismo en los niños y jóvenes. Este fuerte rechazo por parte de grupos conservadores, incluyendo a la Iglesia y los militares, obligó a retirar el proyecto. El 11 de septiembre los militares liquidarían definitivamente el proyecto e iniciarían su propia contrarrevolución.

\footnotetext{
${ }^{433}$ Véase: MINISTERIO DE EDUCACIÓN. Antecedentes para la fundamentación de la ENU. Santiago. 1973; NUÑEZ, Iván. 2003. La ENU entre dos siglos PIIE-Editorial LOM. Santiago 2003; RUBILAR, Luis. "La Escuela Nacional Unificada (ENU, febrero de 1973)”. Revista Extramuros. UMCE. Año 3 Número 3. 2004.
} 


\title{
10.1.2.-La contra-revolución concluida e instalada de Pinochet.
}

Con la llegada de la Junta Militar al poder tras el Golpe de Estado sucedería con la educación lo mismo que con otras áreas de la sociedad, como la política y la economía: debía ser transformada radicalmente, como señalaba Pinochet en 1974:

\begin{abstract}
"Un esfuerzo consistente por superarlo (la crisis) debe fundarse principalmente en una educación que fomente una escala de valores morales y espirituales propios de nuestra tradición chilena y cristiana, que jerarquice cada cosa en función del fin último del hombre. En esa perspectiva, una educación que respete la libertad de enseñanza y el fuero íntimo de la conciencia de cada cual, y que alcance a todos, tendrá que robustecer el conocimiento y amor de cada uno de nuestros compatriotas hacia Chile, su geografía, su historia y su pueblo",434
\end{abstract}

La intervención sobre la educación como proyecto es más bien tardía, pese a que ya desde 1973 se habían registrado algunas actuaciones; pero será en 1979 cuando se ponga en marcha lo que se denominará "Directiva Presidencial sobre Educación Nacional”, con un breve paréntesis en 1981-82, producto de la recesión económica que sufrió el país. Es evidente que los cambios operados en educación estarán en sintonía con la reorientación económica que vivirá el país, pasando de una economía de industrialización por sustitución de importaciones a una basada a en el modelo capitalista con base en la Escuela de Chicago. A su vez, en política y administración se finiquitará el Estado benefactor para pasar a uno subsidiario, reduciendo drásticamente el empleo público, decisión que afectará directamente al profesorado y cambiará radicalmente su fisonomía hasta el día de hoy.

Con estos principios orientadores más el aparato represivo establecido por el régimen, se

\footnotetext{
${ }^{434}$ JUNTA MILITAR. Declaración de principios. 11 de Marzo de 1974.
} 
comienza la transformación económica, que como vimos líneas más arriba será de corte nacionalista y con un fuerte componente moral cristiano, esto debido a que actuará como contrarevolución de la propuesta de la Unidad Popular considerada marxista e ideológica. En 1975, en el documento conocido como el Objetivo Nacional de Chile, se reafirma lo planteado en 1974 y se deja en claro fehacientemente que no se aceptará “(...) la difusión proselitista de ninguna doctrina o idea que atente contra la tradición o la unidad nacional, contra el sentido libertario y democrático de la institucionalidad chilena, o contra la integridad de la familia o de la nación." 435

De manera específica el año 1979 se establecen los principios para la educación en el documento titulado “Directiva Presidencial sobre Educación”, enviado por Pinochet al entonces Ministro de Educación, el historiador Gonzalo Vial Correa, señalando que:

1.- "Todo el sistema educacional estará guiado por el humanismo cristiano, que se expresa en la Declaración de principios de la Junta Nacional de Gobierno y en los Objetivos nacionales."436

2.-El régimen establecería los contenidos de estudio. También señala con claridad que el objetivo será la formación de buenos trabajadores, buenos ciudadanos y buenos patriotas.

3.- El Régimen asegura la educación básica para todos, pero la educación media (secundaria) y la Superior (Universitaria) es excepcional y más bien un privilegio.

4.- Se establece que el Régimen detendrá cualquier expansión de la educación, en tanto pública, y que de ahí en adelante esta labor será transferida al sector privado detener toda expansión de la labor educativa del estado y de transferir las posibilidades de ampliación del sistema

\footnotetext{
435 JUNTA MILITAR. Objetivo nacional del Gobierno de Chile. Resolución 3102. 23 de diciembre de 1975

${ }^{436}$ Véase: PINOCHET. AUGUSTO. Directiva Presidencial sobre Educación. (Carta al Ministro de Educación, Gonzalo Vial). 5 de Marzo de 1979.
} 
educacional al sector privado, quien será la encargada de ampliarla. El estado sería el garante y fiscalizador. Para la educación técnico-profesional esto se expresa aún más claramente, ya que intenta vincularla a la empresa privada, lo que a medio plazo terminará casi por hacerla desparecer.

5.- En el documento se establecen lineamientos generales sobre Educación Superior y su gestión.

6.- Se busca revitalizar los centros de padres y apoderados, pero estableciendo que deben estar alejados de la política. Así también sucederá con los profesores.

Junto con restar al Estado su capacidad para asegurar la educación como un derecho para todos y entregarla al sector privado, se consolida otro de los principios más relevantes y que perdurará hasta el día de hoy: la libertad de enseñanza. En 1982, un libro de Hernán y José Vera Lamperein favorable al régimen que hablaba acerca de la Municipalización de la Educación, -directriz lanzada por la dictadura que terminará por desvincular a la educación del Estado-, señalaba: "la municipalización de los servicios básicos de educación y salud es la última y más concreta de las etapas en el proceso de lograr que cada chileno pueda llegar a ser actor de su propio destino personal y familiar, dentro del marco del principio de subsidiariedad. ${ }^{\text {437 }}$ De esta manera se consolidaba lo individual por sobre lo estatal, y se otorgaba preponderancia a la libre iniciativa por sobre los derechos sociales. ${ }^{438}$

En concreto, además de una transformación ideológica se inició una desarticulación de la educación chilena. Esta se puso en marcha, por ejemplo, con un proceso de designación y

${ }^{437}$ VERA LAMPEREIN, Hernán y VERA LAMPEREIN, José. La municipalización de la enseñanza. Editorial Andrés Bello. Chile. 1982. p. 7

${ }^{438}$ Véase: OLIVA, María. A. "Política educativa y profundización de la desigualdad en Chile." Revista Estudios Pedagógico, XXXIV(2), 2008. pp. 207-226 y OLIVA, María A. "Política educativa chilena 1965 - 2009 ¿Qué oculta esa trama?” Revista Brasileira de Educaçao, 15(44), 2010. pp. 311-410. 
“limpieza" de los Rectores que encabezaban las ocho universidades del país (Decreto-Ley N ${ }^{\circ}$ 50), lo que significó en la práctica el control de todo el sistema educativo. Estos “(...) cumplirán las funciones y ejercerán todas las atribuciones que corresponden a los Rectores de las Universidades en conformidad con las normas legales vigentes y demás acuerdos o resoluciones universitarias dictadas en su virtud." ${ }^{439}$ Todo debido a que como señalaba el dictador: "La situación académica, administrativa y de relaciones humanas hasta el 11 de septiembre de 1973 en la mayoría de las universidades era caótica; en las restantes, las menos, conflictiva; era reflejo agudizado del clima reinante en el país. Existía total desinterés respecto del trabajo universitario, las huelgas y los paros malograban cualquier planeamiento académico. Incluso se llegó a lo delictual." ${ }^{440}$ Junto a esto, también comenzó la persecución, detención y asesinato de profesores vinculados a la izquierda y la Unidad Popular.

En resumen, las dos medidas más relevantes del Régimen para instalar su ideología y desligar la educación del Estado fueron la descentralización de la administración educacional, cediéndola a las Municipalidades (generando lo que denominó Brunner, el "Estado Docente Mínimo" ${ }^{, 41}$ ) -proyecto que formó parte de la iniciativa de regionalización dirigida por la Comisión Nacional de Reforma Administrativa a partir de 1974; y la racionalización del gasto público, que generó condiciones cada vez más deprimidas para los docentes, desincentivando el desarrollo profesional y aumentado la denominada "deuda histórica de los profesores." 442

\footnotetext{
${ }^{439}$ Diario Oficial, 2 de octubre de 1973

${ }^{440}$ PINOCHET, Augusto. Un año de reconstrucción. 11 de septiembre 1973 - 11 de septiembre 1974: el Jefe Supremo de la nación General de Ejército Augusto Pinochet Ugarte informa al país. Santiago. Chile. 1974.

${ }^{441}$ BRUNNER, José Joaquín. El Diseño Autoritario de la Educación en Chile. Flacso. Santiago. 1980

${ }^{442}$ Corresponde a la deuda generada a partir de la transferencia de colegios a los municipios en 1981, cuando al profesorado no se le reconoció el reajuste especial de entre 50 y 90 por ciento del sueldo base, que se les había entregado pocos meses antes. (Artículo 40 del DL No 3.551). En base a los cálculos del Colegio de Profesores, habría 93.089 docente afectados por la deuda histórica, 61.353 de la enseñanza básica y 31.736 de la enseñanza media, y sus pérdidas por el incumplimiento en el pago de la asignación serían del orden del 30\% de sus sueldos. El monto adeudado a los profesores alcanzaría los 14 mil millones de dólares. Al día de hoy esta deuda sigue impaga. Más información: AVALOS, Beatrice. Profesores para Chile: historia de un
} 
También se creó el Colegio de Profesores para tener mayor control y la formación de docentes pasó a ser universitaria.

A partir de 1979 y hasta el año 1990 el Régimen consolidará los principios antes señalados, instalando políticas tendentes cada vez más a la privatización, dejando en condiciones paupérrimas la educación pública. Por ejemplo, en relación con la Educación Universitaria se estableció por Decreto (Decreto-Ley N 4, del 14 de enero) en 1981 que la contribución estatal al financiamiento de las instituciones de educación superior iría disminuyendo gradualmente hasta 1986, momento en cuál solo recibirían el 50\%. A su vez estableció lo que se conocerá como Crédito Fiscal para el financiamiento de estudios para los estudiantes. La idea de fondo era agregar competitividad al sistema, favoreciendo los vínculos con el sector privado en busca de recursos, o que surgieran Universidades Privadas, haciendo así que fuese el mercado y el juego entre oferta y demanda el verdadero regulador del sistema.

En educación secundaria sucedió lo mismo, ya que cuando se traspasaron los establecimientos educacionales a municipalidades y corporaciones empresariales (Decreto- Ley $n^{\circ} 1-3.063$ ) la idea era que existiera competencia entre sostenedores. La etapa culminante del proyecto educativo de la dictadura se alcanzó en 1990, con el Gobierno Pinochet en plena retirada, cuando se consolidó la política de mercantilización de la educación mediante la Ley Orgánica Constitucional de Educación de 1990, que se basa en diferentes decretos publicados durante los años 80 y establece:

proyecto. Santiago, Chile: Ministerio de Educación, 2002 y COX, Cristián; GYSLING, Jacqueline. La formación del profesorado en Chile, 1842-1987. CIDE, 1990. 
1.- Se reafirma el rol Subsidiario del Estado. Señala que el rol principal de la educación es responsabilidad de la Familia y el Estado, por su parte, debe “otorgar especial protección al ejercicio de este derecho"

2.- Sigue presente la relevancia del principio de Libertad de Enseñanza: En el artículo $2^{\circ}$ explicita: que el fin del Estado es "resguardar especialmente la libertad de enseñanza."

3.- El Estado sigue siendo garante sólo de la Educación Básica. Se creó el Consejo Superior de Educación, organismo encargado de aprobar los marcos curriculares (Objetivos Fundamentales y Contenidos Mínimos Obligatorios para la educación básica y media), decretar planes y programas de estudio y aprobar un sistema periódico de evaluación del currículum nacional.

4.- Se consagraron los principios de descentralización y flexibilidad curricular, posibilitando la autonomía de los establecimientos educacionales para construir y ofertar planes y programas de estudio propios, lo que favorecía a los colegios confesionales y evitaba que todos los colegios tuviesen que estar sometido a la centralización por parte de Estado. Con este punto y el anterior se aseguraba la libertad y se mantenía cierto control.

A este panorama se vieron enfrentados los primeros Gobiernos de la democracia. Lo esperable era que en aras de la equidad, igualdad y mejora de las condiciones de los docentes, el problema fuese rápidamente solucionado; sin embrago, como veremos, la situación se arrastra hasta nuestros días como una de las tantas deudas pendientes de la actual democracia. Podemos señalar sin temor a equivocarnos que en Educación, uno de los principales motores del desarrollo, no sólo no hubo transición sino que el ideario de la dictadura se impuso en todos los frentes. 


\section{2.-UNA HERENCIA MÁS: LA (MALA) EDUCACIÓN.}

No todo es negativo y esto es cierto si analizamos los datos educativos de los años de democracia. Hoy casi el $90 \%$ de las personas entre 25 y 30 años ha terminado la educación secundaria o media como se le denomina en Chile, en comparación con el 40\% de las personas entre 55 y 64 años. Por otra parte, el número de estudiantes en la educación superior es cuatro veces mayor que hace veinte años y siete de cada diez chilenos son primera generación en estos centros de estudio. Por último, las pruebas internacionales muestran notables mejoras en nuestro sistema educativo, que destaca como uno de los mejores de Latinoamérica. ${ }^{443}$ Sin embargo, a la par de estas mejoras se han registrado las más fuertes movilizaciones estudiantiles posiblemente del siglo XX ¿Por qué el descontento? ¿Es injusto o desagradecido?

Como hemos visto, el Chile modélico siempre esconde una cara menos agradable cuando hurgamos en los avances que exhiben pomposamente los datos "macro". En este caso, el lado oscuro de la realidad es la aberrante desigualdad y segregación educativa y la despiadada mercantilización de la educación en general, consentida e incluso ensanchada en democracia por un costo de la educación que supera a la de cualquier país miembro de la OCDE. ${ }^{444} \mathrm{~A}$ su vez, la percepción que se tiene de la educación es de que existe un excesivo afán de lucro en el sector y que esto propicia una brecha enorme, avalada por el mismo Estado, entre educación pública y privada.

Como pudimos ver, la educación chilena transitó de ser un modelo casi completamente centralizada, con casi un $80 \%$ de estudiantes en educación pública más unas pocas escuelas

\footnotetext{
${ }^{443}$ MINEDUC. "Equidad en los aprendizajes escolares en Chile en la ultima década." Serie Evidencias. Ministerio de Educación. Año 2, No 17. CHILE. Mayo de 2013

${ }^{444}$ BELLEI, Cristián. "El estudio de la segregación socioeconómica y académica de la educación chilena.” [en línea]. Estudios pedagógicos. Valdivia, V. 39, №. 1. 2013. pp. 325-345. [fecha de consulta 12 de octubre del 2014]. Disponible en internet en $<$ http://www.scielo.cl/scielo.php?script=sci arttext\&pid=S0718-07052013000100019\&lng=es\&nrm=iso $>$
} 
privadas donde asistían las elites, y un grupo muy limitado de escuelas subvencionadas. A partir de los años 70, la Dictadura, no sólo estableció un proyecto que cambiaría radicalmente ese tipo de educación sino que en lo concreto aplicó una política de shock que modificó el sistema. Así se adoptaron políticas que terminaron con la educación pública y la colocaron en el mercado, donde la despolitización y la "libertad" (para quienes pudieran pagarla) pasaron a ser los paradigmas principales.

Durante los ochenta, entre los investigadores en educación y los grupos que se convertirían posteriormente en los verdaderos policy makers, ${ }^{445}$ irán construyendo consensos en torno a los cambios que deberían hacerse una vez retornada la democracia. Aunque se criticaron aspectos de la política educativa de la dictadura, también se comenzó valorizar otros con el fin de mantenerlos. Como sucedió por ejemplo con el Sistema de Medición Educacional (SIMCE) creado en 1988 que es una prueba estandarizada para medir el rendimiento escolar, pero que en últimos años se ha ido transformando en un verdadero ranking de colegios, donde claramente los más perjudicadas son los públicas. Entre los cambios más relevantes propuestos por estos grupos, está la idea de la focalización de la intervención educativa que, en resumen, se tradujo en ejecutar políticas de discriminación positiva a favor de los que tienen más déficit, surgiendo así el programa de las 900 escuelas, ${ }^{446}$ con lo cual se va desplazando la idea de recuperar la educación pública con igualdad para todos. A su vez se promueve la idea de "aprender a aprender", que busca eliminar el verticalismo en la sala de clases y transformar las relaciones sociales en la escuela, un proceso positivo de cambio. ${ }^{447}$ Sumado a esto se debe mencionar que

\footnotetext{
${ }^{445}$ Los centros de investigación más relevantes fueron el CIDE (Centro de Investigación y Desarrollo de la Educación http://www.cide.cl ), el PIIE (Programa interdisciplinar de Investigaciones en Educación http://www.piie.cl ) y el CPU (corporación de promoción universitaria http://www.cpu.cl)

${ }^{446}$ GUTTMAN, Cynthia. Todos los niños pueden aprender. El programa de las escuelas para lo sectores pobres de Chile. UNESCO. 1994

${ }^{447}$ PICAZO, María Inés. Las políticas escolares de la concertación durante la transición democrática. Ediciones UDP. Chile. 2013. pp. 111-118.
} 
a nivel internacional se genera un movimiento que surge en los debates del FMI y el Banco Mundial por desarrollar el capital humano, ${ }^{448}$ el cual señalarán era de importancia decisiva para alcanzar el desarrollo, aliviar la pobreza y dar un "salto" tecnológico.

Gracias a esto, el Chile de los noventa se sumó a la propuesta internacional y se desarrollaron varios trabajos en conjunto con el Banco Mundial que impactaron la política educativa, como fue el programa MECE (mejoramiento de la calidad y la equidad), esto era también un espaldarazo a la política de la democracia chilena que había decidido mantener el componente neoliberal heredado de la dictadura, por lo que se le consideraba un contexto bastante favorable para desarrollar políticas conjuntas con estos organizamos internacionales. En la práctica el Banco Mundial le "ofreció" su apoyó a cambio justamente del mantenimiento de las políticas heredadas, además de que las nuevas tuviesen duración en el tiempo, que se siguiera favoreciendo la educación básica o primaria y que no se tocara al sector privado.

De esta manera se mantenían en pie las políticas relativas al mercado en la educación chilena que afectaban directamente a la educación pública, como señala Donoso:

“En el marco país, el cambio de modelo de financiamiento del año 1981 y la entrada en operación del enfoque de mercado implicó una alteración relevante en la composición de la matrícula escolar según dependencia escolar. Antes de iniciado este proceso, el sector fiscal representa el $80 \%$ de la matricula total, el particular subvencionado el $15 \%$ y el privado sin subvención un 5\%. Cinco años después (1986), el sector municipal (ex fiscal) había reducido al 63\%, el subvencionado se elevaba al 30\% y el privado sin subvención seguía en un 5,1\%. Diez años después de la última cifra (1996) el sector municipal agrupaba el 56,6\% de la matrícula, el subvencionado el 33\% y el particular el 8,7\%. Al año 2000 los

\footnotetext{
${ }^{448}$ BRUNNER, José Joaquín y ELACQUA, Gregory. Capital Humano en Chile. Editorial Universidad Adolfo Ibáñez y La Araucana, Santiago de Chile, 2003.
} 
cambios persisten, pero cada vez con mayor fuerza. Los municipales reúnen el 54,2\%, los subvencionados el 35,8\% y los privados el 8,2\%",449

El resto de políticas implementadas en los años 90, como queda claro en los datos antes señalados, mejorarán las condiciones materiales de los colegios públicos, pero de ninguna manera han logrado recuperarlos y mejorar su prestigio, al punto que continúa el descrédito y migración al sector privado -por lo menos de aquellos grupos con dinero suficiente para hacerlo- que, sumado a las constantes movilizaciones de estudiantes y docentes, harán que la situación se siga agravando. Esto es aún más grave si se considera que Chile está entre los países más segregados de hecho según el índice Duncan; ${ }^{450}$ junto a Perú, es el país donde los ricos estudian con los ricos, los menos ricos con los menos ricos, los pobres con los pobres, etc.; con las obvias consecuencias para la convivencia y la democracia. ${ }^{451}$ En definitiva, el sistema de vouchers (financiamiento a la demanda), así como el modelo con lucro (no permitido legalmente en algunos niveles educativos, pero sostenido tramposamente) y la posibilidad de los padres de enviar a sus hijos a escuelas que exigen un cobro adicional de acuerdo con su estrato económico, aunque en algún sentido ha estimulado el crecimiento de la cobertura y mejorado la calidad y la equidad de resultados del sistema educativo chileno (como se puede ver en datos de pruebas internacionales ${ }^{452}$ ), también han profundizado la segregación social y el malestar general hacia la ausencia de un derecho a la educación asegurado y promovido.

\footnotetext{
449 DONOSO, Sebastián. "Reforma y política educacional en Chile 1990-2004: El neoliberalismo en crisis.” [En línea]. Estudios pedagógicos vol.31, Nº.1. 2005. p.113-135. [fecha de consulta 3 de mayo del 2011]. Disponible en internet::

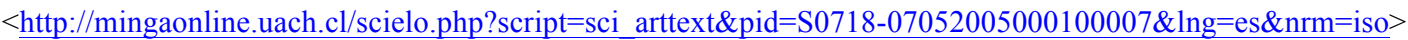

${ }^{450}$ WAISSBLUTH, Mario. "Manifestaciones estudiantiles en Chile”, Foreign Affairs Latinoamérica, Vol. 11: Nº 4. 2011. p. 35

${ }^{451}$ GARCIA-HUIDOBRO, Juan E. y BELLEI, Cristián. Desigualdad educativa en Chile. Santiago: Universidad Alberto Hurtado. Chile. 2003.

${ }^{452}$ CLARO, Susana. "Chile lidera ranking educacional en América Latina. Avances y desafíos para Chile de acuerdo a TERCE”. Puntos de referencia CEP Chile. 2013.
} 
En este sentido, los gobiernos de la democracia han preferido "parchar" la educación pública en vez de apostar por cambios estructurales, creando una serie de programas como los MECE, liceos prioritarios, P-900, Escuelas y Liceos para todos, Perfeccionamiento y apropiación curricular para docentes, pasantías en el extranjero, etc., la mayoría con políticas de intervención focalizadas, que han tenido evaluaciones no siempre positivas o que impacten sustantivamente en el rendimiento escolar y su calidad. En 1995 y en vista de que los efectos de estas propuestas no tenían el impacto esperado, se retoman planes más ambiciosos, esta vez de manera centralizada proponiendo una Reforma al Sistema Educacional. ${ }^{453}$ Sin embargo, como sucedería con la mayoría de los cambios implementados, la Reforma fue criticada por sus fines políticos y carencia de sustento técnico por no tomar en cuenta a los docentes como actores relevantes. En el fondo, esto significaba seguir re-haciendo un traje a la medida de la herencia de la dictadura, sin apostar por cambios profundos, como señala Oliva:
“(... la política actual no sólo muestra una coexistencia entre Estado y Mercado, sino que intenta vanamente hacerlos compatibles. El resultado de ello es una preeminencia del libre mercado, del sistema privado, consecuente con la permanencia de los ejes de la política educativa de la Dictadura y su orden neoliberal con ello se produce el desplazamiento del concepto de democracia, desde su dimensión política a una económica con consecuencias nefastas para el derecho a la educación."

Justamente esta imbricación es la que ha estado en la palestra en la discusión pública acerca de la educación, ${ }^{455}$ en especial con relación a la Educación Superior donde la situación es

\footnotetext{
${ }^{453}$ Véase: GARCÍA-HUIDOBRO Juan E. (Ed.). La Reforma Educacional Chilena. Editorial Popular. Madrid. 1999; COX, Cristián. (Ed.). Politicas Educacionales en el cambio de siglo. La reforma del sistema escolar en Chile. Santiago: Editorial Universitaria. 2003

${ }^{454}$ OLIVA, María A. "Política educativa chilena 1965 - 2009 ¿Qué oculta esa trama?.” Revista Brasileira de Educaçao, 15(44), 2010. p. 324

${ }^{455}$ Se puede ver el debate en los libros y columnas publicadas por el Director de Educación 20/20 (ONG enfocada en temas de educación y política pública), Mario Waissbluth: WAISSBLUTH, Mario. La educasión esta vien: Un ensayo preocupado y
} 
realmente dramática. En este sector, la proliferación de Universidades privadas en lo últimos años -bajo el supuesto de que la competencia mejoraría la calidad-, la mayoría de las cuales con escasa acreditación de sus programas y que atienden principalmente a estudiantes de bajos recursos sin necesidad de solicitar un puntaje mínimo de ingreso, ha generado un nivel de endeudamiento tal que ha terminado con estudiante embargados. Esto ocurrió porque la educación superior es financiada por las familias en un $80 \%$ del costo o mediante créditos bancarios, con el supuesto de que los mayores ingresos percibidos cuando obtuvieran su título les permitiría a los egresados pagar las deudas contraídas durante los años que cursaron la carrera. En este punto sería oportuno recordar que el crecimiento desproporcionado del sector privado en educación superior y la posterior creación de un sistema "bancarizado" (CAE, Crédito con Aval del Estado) de financiamiento no fue creación de la dictadura sino que fue diseñado en plena democracia durante el Gobierno del socialista Ricardo Lagos. ${ }^{456}$

El año 2006 se inició lo que se considera como uno de los más importantes movimientos sociales liderados por estudiantes. Hacia el año 2011 ya estaban bien instaladas en la sociedad las demandas solicitadas por jóvenes y adolescentes, a tal punto que el grado de desacuerdo con las políticas estudiantiles alcanzaba el $81 \%$, con un $76 \%$ de chilenos apoyando las demandas estudiantiles. ${ }^{457}$ Si bien la situación no ha cambiado sustancialmente en los últimos años la discusión se mantiene en tensión. Se estudia una reforma de la carrera docente que terminó una vez más por marginar a los profesores de su elaboración y generó un paro de dos meses el año 2015 (se encuentra todavía en fase legislativa); aún no se definen criterios claros acerca de la

posiblemente propositivo. Educación 20/20 libre de derechos. Chile. 2014; WAISSBLUTH, Mario. Se acabó el recreo. Editorial Debate. 2011.

${ }^{456}$ CIPERCHILE. “CAE: Cómo se creó y opera el crédito que le deja a los bancos ganancias por \$150 mil millones” [En línea] 20 de Diciembre del 2011. [fecha de consulta 3 de mayo del 2012]. Disponible en internet:: $<$ http://ciperchile.cl/2011/12/20/cae-como-se-creo-y-opera-el-credito-que-le-deja-a-los-bancos-ganancias-por-150-milmillones/>

${ }^{457}$ WAISSBLUTH, Mario. "Manifestaciones estudiantiles en Chile”, Foreign Affairs Latinoamérica, Vol. 11: No. 4, 2011. pp. 32-39 
acreditación de Universidades, el lucro en la educación escolar o la promoción de la educación pública; continúa la municipalización de la educación y la Reforma Educativa -impulsada por los movimientos estudiantiles- que promueva el derecho a la educación por sobre la libertad de enseñanza sigue en lista de espera. ${ }^{458}$ Mientras tanto, se repiten año tras año protestas y paros en escuelas y universidades. Existen algunos avances, como la creación de programas de acceso equitativo a la educación superior (PACE, Propedéuticos ${ }^{459}$ ), el cierre o intervención de Universidades privadas con graves problemas o la creación de normativas que regulan el lucro en educación subvencionada. Con todo, si hay algo que está claro es que la discusión recién comienza. $^{460}$

\footnotetext{
${ }^{458}$ Proyecto de Reforma Educacional 2015: http://reformaeducacional.gob.cl

${ }^{459}$ Programa de Acompañamiento y Acceso Efectivo (PACE) http://www.pace.mineduc.cl; Red de Propedéuticos UNESCO $\underline{\text { http://Www.propedeutico.cl }}$

${ }^{460}$ WALKER, Horacio. (Senador Oficialista) "Educación superior: el debate que viene” [En línea] Columna El Mercurio. Martes 18 de agosto de 2015. [fecha de consulta 23 de agosto del 2015]. Disponible en internet:: $<$ http://www.elmercurio.com/blogs/2015/08/18/34449/Educacion-superior-el-debate-que-viene.aspx $>$
} 


\section{1.-CHILE Y SUS DOS SISTEMA DE SALUD: LA}

\section{CRISIS DORMIDA.}

En una reciente entrevista (agosto del 2015) el presidente de la asociación de Isapres de Chile, Rafael Caviedes, señalaba que "hay espacio para llegar a un acuerdo histórico que cambie radicalmente el modelo de salud." Continúa la nota de prensa enfatizando que "en la industria aseguran que hay consenso sobre la necesidad de hacer cambios profundos, pero se quejan de que todo lo que saben sobre la reforma que se viene ha sido a través de trascendidos y advierten que, si los cambios incluyen un Fondo Mancomunado con Fonasa, un techo sobre gasto máximo de afiliados y la eliminación de la declaración de salud -como se rumorea-, la industria dejaría de ser viable. ${ }^{461}$ Para un lector ajeno al contexto chileno este debate resultará extraño, ya que la reforma de la salud o la gran reforma que modificará el modelo de salud nacional no nace de una propuesta estatal de manera unilateral sino del convenio o acuerdo entre el Estado y la empresa privada: representación palmaria de las dos "almas" del sistema de salud en Chile. ${ }^{462}$ En los siguientes apartados expondremos otro de los pilares básicos del Chile heredero de la dictadura, que sigue en pie en democracia y que sitúa a nuestro modelo como un caso sui generis en el panorama internacional.

\footnotetext{
${ }^{461}$ EL MOSTRADOR. "Rafael Caviedes: "Hay espacio para llegar a un acuerdo histórico que cambie radicalmente el modelo de salud" [En línea] 19 agosto 2015. [fecha de consulta 23 de agosto del 2015]. Disponible en internet: < http://www.elmostrador.cl/mercados/2015/08/19/rafael-caviedes-hay-espacio-para-llegar-a-un-acuerdo-historico-que-cambie$\underline{\text { radicalmente-el-modelo-de-salud/> }}$

${ }^{462}$ ANNICK, Manuel "The Chilean Health System: 20 Years of Reforms". Salud pública de México. vol.44, No.1, enerofebrero de 2002.
} 


\section{1.- EI ADIÓS A LA SALUD PÚBLICA.}

Como hemos señalado en capítulos anteriores, antes de 1973 y del Golpe el Estado era el titular y responsable máximo de los bienes y servicios básicos como la educación, la salud o el desarrollo de viviendas y, a la vez, se preocupaba por incentivar la demanda de estos bienes y servicios mediante la toma de conciencia de la población acerca de la importancia social de los mismos, remarcando que estos eran un derecho de la ciudadanía frente al cual el Estado jugaba un rol relevante, en especial hacia las clases menos favorecidas. Durante el gobierno de Salvador Allende se propuso instalar un Sistema Unificado de Salud que sería financiado completamente por los recursos públicos, con el fin de terminar con la segregación en el acceso a la salud que incluiría la participación comunitaria. El proyecto no fue bien recibido por el Colegio Médico, que se sumó a la reacción contraria a la Unidad Popular, exigiendo su cancelación. Con el Golpe de Estado y la incorporación de los Chicago Boys al elenco dictatorial, el eje conceptual del desarrollo se movió drásticamente. Ya en 1974 la “intelligenzia” del Régimen había formulado lo que se conoció como las siete modernizaciones:

1. El Plan de Reforma Laboral.

2. La Reforma Previsional.

3. Cambios en los planes de la salud.

4. Municipalización de la Educación.

5. Modernización Judicial.

6. Cambios en la Agricultura. 
7. Regionalización y Cambios en la Administración Pública. ${ }^{463}$

En la práctica, lo que harían sería fortalecer el sector privado en detrimento del papel que hasta ese momento había jugado el Estado. En 1975 los militares en el poder de la mano del Colegio Médico -contrario como señalamos a la política de Allende- comenzaron a desarrollar un proyecto de salud para el "nuevo Chile" que emergía con el respaldo de la represión dictatorial 464. Los resultados de estas políticas hicieron que el Ministerio de Salud (MINSAL) fuese fortalecido asumiendo un rol más político-técnico y que desapareciera el antiguo Servicio Nacional de Salud (SNS); a su vez, se creó el Sistema Nacional de Servicios de Salud (SNSS).

A través de este nuevo organigrama se inició el mismo proceso que en educación, comenzando por la regionalización de los servicios, y la municipalización de la atención primaria; lo que desemboco en la disminución de funcionarios, pero que a su vez generó una baja en el estatus de los que permanecieron y una merma en sus salarios. Al quedar en manos de la Municipalidad también generó otras dificultades como congestionamiento de atención, desorganización y otras series de falencias que impactaron fuertemente en los sectores menos favorecidos.

En términos de administración fueron separadas las funciones del Ministerio de salud, que se encargó de las cuestiones relativas a la gestión y la creación de normativa, y todos los aspectos financieros fueron trasladados al Fondo Nacional de Salud (FONASA). Esta institución se transformó en la alternativa pública para el otro sistema privado que estaba en ciernes, pero que caería en el descuido, generando una segregación brutal.

\footnotetext{
${ }^{463}$ MENANTEAU-HORTA, Darío. "El rol del Estado en el desarrollo social y la Reforma de la previsión en Chile y EE.UU." Revista Austral de Ciencias Sociales. No 10. 2006. pp. 5-22.

${ }^{464}$ MINSAL. Sistema Nacional de Servicios de Salud. MINSAL. Chile. 1975.
} 
Para consolidar un sistema privado de prestación de salud, se crearon dos iniciativas, una fue la introducción de un segmento comercial para la salud privada novedoso y hasta ese momento único en Latinoamérica y por otra parte se estableció un sistema de financiamiento original y útil al sistema privado en creación. Sobre el primer aspecto se creó por decreto ley de 1981 las Instituciones de salud previsional (ISAPRES), las cuales son empresas privadas con fines de lucro, que cumplen la función de realizar intermediación financiera en la compra y venta de “planes" de salud. La Dictadura les favoreció enormemente y la industria de salud privada creció de manera exponencial, pasando de ser sólo 6 en 1981 a 23 en 1989, abarcando al 21\% de la población, el 10\% de la cual está cubierta por contratos colectivos. ${ }^{465}$

El crecimiento no terminó por reemplazar a la cobertura pública, por razones económicas fundamentalmente y el propio razonamiento de las ISAPRES que dar preferencia a ciertos "públicos” que son más rentables, tanto por su capacidad de pago, como por su "salud" que evita el hacer uso de los planes. De hecho establecen planes diferenciados para mujeres en edad fértil (más caros) de hombres solteros, normalmente a personas de la tercera edad, por su tendencia a enfermar, suelen ser marginados y desviados a FONASA. ${ }^{466}$

La segunda iniciativa significó cambiar al aporte tripartito (Empleador, Empleado y Estado) que con anterioridad se realizaba a la salud pública por medio del Servicio Nacional de Salud. Con la reforma efectuada en dictadura se omite el aporte del Empleador mientras que al empleado se le carga con el costo de dicho servicio (Desde 1986 en adelante se va aumentando

\footnotetext{
${ }^{465}$ MENANTEAU-HORTA, Darío. Op. Cit. 2006.

${ }^{466}$ LA TERCERA. "Las isapres generan situaciones de segregación y discriminación que no parecen aceptables" [En línea] 15 de marzo del 2015. [fecha de consulta 23 de agosto del 2015]. Disponible en internet: $<\underline{\text { http://diario.latercera.com/2014/03/15/01/contenido/pais/31-159911-9-las-isapres-generan-situaciones-de-segregacion-y- }}$ discriminacion-que-no-parecen.shtml >
} 
llegando a la imposición actual del 7\% obligatorio de la renta tributable). Se asume la lógica de libertad de mercado, similar al del sistema de pensiones (como veremos en otro capítulo más adelante) y educación señalando que no debe existir discriminación en el libre acceso a la oferta de servicios de salud, sean públicos o privados. ${ }^{467}$ Por su parte, el aporte del Estado la idea era que desapareciese finalmente, peor esto no se pudo concretar, aunque disminuyo de un $64 \%$ en 1974 a un $35 \%$ en 1989. A su vez con el fin de promover el desarrollo de Isapre el Estado, además debió subsidiar a los jubilados que estaban en sus sistema con un 1,5\% extra y asumir el auxilio de maternidad y la concesión de un $2 \%$ adicional para que grupos de trabajadores de baja renta con el fin de que pudiesen comprar un plan de salud. En resumen, el financiamiento no sólo se recortó, cargando el peso en el empleador, sino que además durante la Dictadura se subvencionó fuertemente la empresa privada de salud.

Todo esto generó una verdadera estratificación social en Salud, como señala Menanteau-Horta: a.- Los segmentos con mayores rendimientos deben comprar planes de salud en el mercado según la opción individual.

b.- Los sectores medios pueden optar por el régimen de libre elección del FONASA, con copagos variables según el nivel del profesional.

c.- Los estratos de bajas rentas son atendidos en los servicios estatales de forma gratuita mediante comprobante de la condición de pobreza, pagando, en caso contrario, un porcentaje de acuerdo a los ingresos. ${ }^{468}$

\footnotetext{
${ }^{467}$ PIÑERA, José. El Cascabel al Gato. La Batalla por la Reforma Previsional. Editora Zig-Zag. Chile. 1991 ${ }^{468}$ MENANTEAU-HORTA, Darío. Op. Cit. 2006.
} 
Junto con esto, el sistema de financiamiento evita que los ciudadanos se puedan ayudar entre sí, ya que los que pagan su salud privada a través de ISAPRE quedan exentos de pagar en FONASA y, como en las primeras están las personas con mejores rentas, el sistema público o el que está vinculado al Estado y a los sectores más vulnerables ven mermados su presupuesto, lo que afecta directamente en la atención. De hecho, es evidente la calidad de las Clínicas y profesionales vinculadas a la atención privada y el sistema de ISAPRES en comparación con los alicaídos hospitales públicos.

Por lo tanto, la misma realidad educativa de segregación y desconexión entre el mundo privado y público, donde prima la competencia y el emprendimiento personal, se replica en el campo de la salud, aunque con resultados aún más graves para la población. Esta clara discriminación podría haber sido neutralizada en democracia. Podríamos imaginar que bajo una dictadura se consigue instalar un modelo que atenta contra un derecho tan básico como la salud doblegando la voluntad de los ciudadanos a través de la represión; sin embargo el sistema pinochetista, también en este campo, pervivió y se perfeccionó con sus sucesores.

\section{2.-UNA CRISIS DORMIDA.}

Una vez retornada la democracia, el Gobierno entrante se debió enfrentar a las dificultades acumuladas en el sector sanitario, además de intentar conciliar el modelo de libre mercado con políticas tendientes a garantizar mayor equidad. Una de estas cuestiones se relaciona con las demandas de los trabajadores de la salud, quienes fueron sometidos a condiciones laborales muy precarias. En general, las políticas en democracia van a adoptar la misma lógica que en el tratamiento de la educación: se apostará por cambios focalizados más que estructurales y sólo en los últimos años se ha abierto el debate en torno a una gran reforma del sistema sanitario en 
su conjunto.

Teóricamente el gobierno se ha replanteado -con el respaldo del Colegio Médico- los nuevos objetivos de la salud chilena, estableciendo que se trata de un derecho universal donde se requiere acceso igualitario, un financiamiento solidario, más eficiencia en la gestión y mayor equidad para los usuarios. Con esto se hace una declaración de interés que se distancia de los objetivos del periodo anterior. Los resultados fueron alentadores, como señala Labra: “en términos de la mejoría de los indicadores de salud (en particular mortalidad infantil y enfermedades asociadas al alcoholismo), en 1994 el MINSAL definió la equidad como un principio básico de las políticas, tomando varias iniciativas tópicas en el ámbito de la ampliación de la cobertura del SNSS. Por ejemplo, primero pasó la atención primaria a ser gratuita; $\mathrm{y}$, recientemente, fue determinado prestar atención gratuita y otros beneficios a los mayores de 60 años inscritos en el FONASA, después de constatarse que de un total de 1,3 millones de adultos mayores, solamente el 10,9\% estaba afiliado a una Isapre.”469

Estas medidas focalizadas intentarían amortiguar el daño que estaba generando el alto precio y la baja cobertura de las ISAPRE, lo que se tradujo en una migración al sector público. Otro de los graves problemas de la salud pública ha sido- y sigue siendo- las listas de espera generadas en el sistema público, problema que se ha afrontado tercerizando la atención y derivándola a servicios privados, lo cual ha generado más de un crítica. ${ }^{470}$ Recientemente también se adoptó la "Carta de Deberes y Derechos de los Pacientes" en los hospitales y fue publicado un Estatuto

\footnotetext{
${ }^{469}$ LABRA, María E. "La reinvención neoliberal de la inequidad en Chile. El caso de la salud” Cadernos Saúde Pública, Ri 18 (4), jul-ago, 2002. pp. 1041-1052

${ }^{470}$ CHILE B "Listas de espera: el túnel sin salida de la salud pública en Chile. [En línea] 25 de julio del 2015. [fecha de consulta 23 de agosto del 2015]. Disponible en internet: < http://www.chileb.cl/reporteros/listas-de-espera-el-tunel-sin-salidade-la-salud-publica-en-chile/>
} 
de Atención Primaria, y actualizado el Estatuto para los profesionales de la salud pública, lo que repercutió moderadamente en los salarios.

Por su parte, el aumento del aporte fiscal ascendió de manera considerable, incrementándose en casi un 50\% en relación al copago, que a su vez disminuyó de manera importante también. Se fortaleció la política de focalización iniciada en el periodo dictatorial, especialmente con el grupo materno-infantil, y el trabajo de saneamiento básico y prevención. Será Ricardo Lagos el primer presidente de la democracia en intentar una reforma de la salud profunda con más equidad en la atención; sin embrago el sistema de ISAPRE y la dualidad y segregación sobrevivieron al talante reformista del presidente socialista y aún perviven (por ejemplo, el gasto anual per cápita del sector público en salud es de US\$210, mientras que el sector privado gasta US\$ 500).

Uno de los avances más importantes estuvo dado por el Plan AUGE (Plan de Acceso Universal de Garantías Explícitas, establecido por la Ley No 19.966), luego denominado GES (Garantías Explícitas de Salud), en una reglamentación que cada tres años se modifica agregando nuevas patologías al sistema sanitario que garantiza el acceso a las acciones de promoción, protección y recuperación de la salud. Las Garantías Explícitas ${ }^{471}$ que están vigentes desde julio del 2005 para cotizantes o afiliados a FONASA o una ISAPRE son:

a.-Acceso: Obligación de Fonasa y las Isapres de asegurar las prestaciones de salud.

b.-Oportunidad en la atención: Existencia de un plazo máximo para el otorgamiento de las prestaciones de salud garantizadas.

\footnotetext{
${ }^{471}$ Véase: Listado de enfermedades cubiertas en MINSAL: http://www.supersalud.gob.cl/difusion/572/w3-propertyname$\underline{501 . h t m l}$
} 
c.- Calidad: Otorgar la atención de salud garantizada por un prestador registrado o acreditado. Protección financiera: Contribución, pago o copago que deberá efectuar el afiliado por prestación o grupo de prestaciones. ${ }^{472}$

Pese a que el Plan GES suena como un avance relevante, es el punto más alto de la focalización, que resuelve el problema apenas de algunas patologías garantizando su atención. Pero que genera una exclusión de aquellos que no serían beneficiarios o que no cumplen con los requisitos técnicos para utilizar dicho beneficio. Además, con la justificación de que el sector público no podría responder a la demandas de la atención GES, se traspasan millones al sector privado, utilizando una vez más el sistema de voucher a la demanda. Con esto el daño a la salud pública es enorme, como señala una investigación reciente de CIPER Chile:

"Un área que ha sido particularmente dañada son los hospitales públicos. Durante la dictadura la inversión en ellos fue prácticamente cero. Con la Concertación hubo mayor inversión, pero fue insuficiente: entre 1999 y el 2009 la capacidad hospitalaria del sistema público (medida en camas) se redujo en $12 \%$. Por otra parte, la deuda hospitalaria no ha parado de crecer a pesar de que cada año se cancelen grandes sumas. En abril del 2013 ésta superó los \$103.948 millones.

(...) Un ejemplo: Fonasa paga un día cama en Unidad de Tratamiento Intensivo a un "precio" de \$126 mil. Sin embargo, el costo promedio es de \$300 mil. Esto deteriora la red pública y genera incentivos para que los hospitales ofrezcan aquellas prestaciones mejor pagadas (GES) en detrimento del resto (no GES).

472 Véase: "Guía legal sobre: Plan GES o AUGE" En: Ley fácil de la Biblioteca Nacional, En línea: http://www.bcn.cl/leyfacil/recurso/plan-ges-(ex-auge) 
Sin embargo, Fonasa actúa distinto cuando compra centralizadamente "días camas" en las clínicas privadas. A la Clínica Las Condes le paga por un día cama básico \$ 827 mil, mientras que a un hospital público solo le paga $\$ 60$ mil. Durante 2012 el gasto por esta vía fue de \$19.521 millones, cifra que perfectamente podría haber sido utilizada en ampliar la oferta de camas públicas cuyo déficit histórico era de 3.000 camas en 2010.

Para hacer frente a la falta de camas, el gobierno de Ricardo Lagos inició una política de concesiones hospitalarias a través de la cual se adjudicaron dos hospitales -uno en La Florida y otro en Maipú- a un consorcio español. La solución no puede calificarse de conveniente para el Fisco chileno. El Estado deberá pagar aproximadamente U\$600 millones por dos hospitales que cuestan menos de U\$300, es decir, hay más de U\$300 millones que quedan como ganancia para el concesionario. Esta utilidad se genera fundamentalmente por dos mecanismos: el subsidio fijo a la construcción y el subsidio fijo a la operación.”473

Obviamente, los avances en materia de salud se pueden relativizar tanto como los de educación, profundizando gravemente el modelo de libre mercado instalado en dictadura; especialmente bajo el modelo de libre elección (MLE) instalado en 1985 y mantenido durante la democracia, que ha llevado dinero "fresco" a los privados que tienen el negocio de la salud, profundizando un sistema basado en la demanda. Por su parte, las ISAPRES logran ganancias extraordinarias año tras año, subiendo los planes mediante mecanismos y tecnicismos elaborados para acaparar los recursos de los "clientes" con poco gasto. Como ejemplo, el año 2014 sus ganancias se elevaron más de un 50\%, ascendiendo a 60 mil millones de dólares; esto en medio de las críticas

\footnotetext{
${ }^{473}$ CIPER CHILE. "Cómo se ha desmantelado la salud pública." [En línea] 25 de mayo del 2005. [fecha de consulta 23 de agosto del 2015]. Disponible en internet: <http://ciperchile.cl/2013/05/27/como-se-ha-desmantelado-la-salud-publica/>
} 
por las alzas constantes de precio en los planes de salud ${ }^{474}$ y los mecanismos entramados para beneficiarse de los ingresos de sus cotizantes. ${ }^{475}$

Lo que parece más extraño es que pese a la desigualdad en la atención de salud no haya habido manifestaciones importantes, salvo la de enfermos catastróficos o de enfermedades de alto costo-en especial por el abandono de las ISAPRES de estos "clientes"-, que abogó por que la Salud Pública incluyese su financiamiento, cuestión que parecía insólita, pero era muy real en el Chile democrático. La presencia en estas manifestaciones de un popular periodista de Chile, Ricarte Soto, les concedió repercusión nacional, lo que derivó en la aprobación de la llamada la Ley Ricarte Soto de $2015 .{ }^{476}$ Con estas situaciones aún a cuesta, cabe preguntarse con mayor fuerza qué tipo de democracia impera todavía en Chile y entender con mayor claridad por qué una reforma del sistema sanitario como la que se busca implementar durante este año necesita “negociar" con el sector privado para llegar a buen fin.

\footnotetext{
${ }^{474}$ LA TERCERA. "Utilidades del sistema isapres suben 56\% y bordean los \$ 60 mil millones en 2014”. [En línea] 13 de marzo del 2005. [fecha de consulta 23 de agosto del 2015]. Disponible en internet: $<\underline{\text { http://www.latercera.com/noticia/nacional/2015/03/680-620609-9-utilidades-del-sistema-isapres-suben-56-y-bordean-los-- }}$ 60-mil-millones-en-2014.shtml>

${ }^{475}$ ELQUINTOPODER. “Clínicas Privadas e Isapres: El Negocio de la Salud”. [En línea] 11 de febrero del 2011. [fecha de consulta 23 de agosto del 2015]. Disponible en internet: < negocio-de-la-salud/>

${ }^{476}$ Ley que establece un Sistema de Protección Financiera para Diagnósticos y Tratamientos de Alto Costo (2015). Véase: MINSAL: http://web.minsal.cl/leyricarte
} 


\section{2.- LAS PENSIONES SE VAN A LA BOLSA O EL GRAN NEGOCIO DE LAS AFP.}

La Educación, la Salud y las Pensiones son pilares fundamentales para el desarrollo social de los países democráticos. Hemos analizado en perspectiva histórica dos de estos, con resultados que son sorprendentes para el contexto actual que vive Chile. Sin embargo, así como existe un problema latente en Salud, una crisis ya desatada en Educación, el sistema de Pensiones chileno oculta realidades dramáticas aún poco investigadas desde una perspectiva histórica del tiempo presente.

Como hemos visto, tanto en Educación como en Salud, en Chile se mantuvo la herencia de la Dictadura en relación a la provisión mixta en ambos servicios que ha agudizado la segregación. Por lo mismo podría pensarse que en Pensiones la tendencia sería algo similar, sin embargo para este caso la situación es aún más grave ya que sólo existe el sistema privado de pensiones. En las líneas que vienen analizaremos desde una perspectiva histórica, su nacimiento y profundización, además reflexionaremos sobre sus efectos sobre el Chile actual.

\section{1.- SISTEMA PRIVADO PARA ¿TODOS?}

El Sistema de pensiones chileno no es reciente, de hecho hacia 1924 cubría casi el 54\% de la población, por lo que se puede señalar que posee larga datación. Entre los años 1935 y 1955 en pleno apogeo del Estado Benefactor su crecimiento se de manera importante -con tasas sobre el 2,5\% anual- su máximo lo alcanzará en 1974 con el $79 \%$ por ciento de la fuerza de trabajo 
cubierta. ${ }^{477}$ En este sistema eran los afiliados activos los que financiaban las pensiones de los pasivos, por lo que el sistema se sustentaba en esta relación trabajador y pensionado.

Este sistema tenía características muy distintas al actual, ya que era un sistema de reparto y de pago tripartito (Estado-empleador y empleado), realizado a través de la existencia de "cajas" o Instituciones de Previsión que se nace el marco de la "Cuestión Social” y la serie de demandas que en el contexto de los movimientos obreros de principio del siglo XX se generaron. ${ }^{478}$ Será ya en 1924 con el primer Gobierno "mesocrático" liderado por Arturo Alessandri, que se legislará en materias referidas a la protección social, mediante la promulgación de leyes sociales y laborales que son el resultado del largo proceso de demandas que se inicia en el norte salitrero y los centros urbanos. Al año siguiente se promulga la Nueva Constitución de Chile (1925) que consolidaba un sistema presidencial, y que ponía en manos del Estado la protección social a la par que se instalaba el modelo de industrialización por sustitución de importaciones, apoyando el desarrollo nacional y creando más empleo público.

Es en este contexto, y cómo herencia también de las primeras organizaciones de trabajadores que se crean las primeras Cajas de Previsión, de Compensación, Mutualidades. Entre las más relevantes está el Servicio de Seguro Social, la Caja de Empleados Particulares y la de Empleados Públicos. Durante los años 40 y 50 se profundizó el papel del Estado, mientras estaba en el gobierno la coalición de partidos que formaban el Frente Popular (P. Socialista, P. Comunista y P. Radical). Superado los años 50 y pese al aumento de la inflación heredada de los gobiernos del Frente Popular, en la década de los 60 el gobierno Demócrata Cristiano mantuvo la política de bienestar que tendrá como objetivo fundamental la redistribución del

\footnotetext{
${ }^{477}$ MARCEL, Mario y ARENAS, Alberto. "Social security reform in Chile”, Inter-American Development Bank, Occasional Papers, No 5, 1992.

${ }^{478}$ LARRAGAÑA, Osvaldo. El Estado Bienestar en Chile: 1910-2010. Programa de las Naciones Unidas para el Desarrollo, Chile. 2010; ORTIZ LETELIER, Fernando. El movimiento obrero en Chile (1891-1919), Ediciones Michay S.A , España. 1985
} 
ingreso, pero integrando esta vez a grupos desplazados hasta ese momento como campesinado y sectores urbanos pobres.

Debido a esto el gasto público en el área social se duplicó, por lo que se debieron aumentar los ingresos e imposiciones tributarias. En paralelo, se inician otras políticas que buscaban ampliar los beneficios del Estado y de los ciudadanos, mediante la Reforma Agraria y la nacionalización del cobre, incipiente en el gobierno de Eduardo Frei (60s) y profundizada con Allende (UP). A comienzos de los años 70 se sigue un modelo de planificación económica, donde el Estado actuaba como regulador y estimulador de la economía, pero que coordinaba y estimulaba a los distintos actores económicos. Así no se eliminaba completamente al sector privado, sino que convivía con el sector público que tenía una actividad de intervención; de hecho, el sistema de previsión estaba administrado en parte por privado (cajas) o de administración semi-estatal.

Pese a los avances logrados en relación con la previsión social, antes del Gobierno de Allende el sistema estaba agrupado por empleo, diferenciado el trabajo manual del intelectual, de esta forma las Cajas entregaban beneficios diferenciados a artesanos, obreros, empleados particulares o privados. También existían ciertas diferencias a nivel regional en el reparto. De esta manera se repartían los trabajadores en un $45 \%$ que participaba del Servicio de Seguro Social, un $11 \%$ que formaba parte de la Caja de Empleados y un 7\% pertenecía la Caja de Empleados Públicos y Periodistas. El resto de Cajas -sobre 30- afiliaban al 12\% restante de trabajadores.

En la década del 70, pese a que se generó una disminución en la cobertura debido a la evasión del pago o el aumento del desempleo, se propició un reparto más equitativo que fue destacado entre las 40 medidas de la Unidad Popular, que además reconocía las dificultades que poseía el sistema de reparto al favorecer a algunos por sobre otros: 


\section{“7. JUBILACIONES JUSTAS NO MILLONARIAS}

Terminaremos con las jubilaciones millonarias, sean parlamentarias o de cualquier sector público o privado, y utilizaremos esos recursos en mejorar las pensiones más bajas.

\section{DESCANSO JUSTO Y OPORTUNO}

Daremos derecho a jubilación a todas las personas mayores de 60 años, que no han podido jubilar debido a que no se les han hecho imposiciones.

\section{PREVISION PARA TODOS}

Incorporaremos al sistema provisional a los pequeños y medianos comerciantes, industriales y agricultores, trabajadores independientes, artesanos, pescadores, pequeños mineros, pirquineros y dueñas de casa.

\section{PAGO INMEDIATO Y TOTAL A LOS JUBILADOS Y PENSIONADOS}

Pagaremos de una sola vez los reajustes del personal en retiro de las Fuerzas Armadas, y haremos justicia en el pago de pensionados y montepiadas del Servicio de Seguro Social. ${ }^{, 479}$

Así desde la época de Eduardo Frei, pero particularmente en los años 70 con Salvador Allende, se intentó perfeccionar el sistema y ambos “(...) encaminan sus esfuerzos hacia la aprobación de reformas tendientes a universalizar el sistema de seguridad social, a uniformidad la multiplicidad de regímenes que lo integraban, eliminando sus distorsiones y privilegios, y a sanear los problemas financieros que lo aquejaban. El éxito obtenido sólo fue parcial. En

\footnotetext{
${ }^{479}$ UNIDAD POPULAR. Programa de la Unidad Popular. Las primeras 40 medidas del gobierno popular [En línea] 1970. [fecha de consulta 23 de agosto del 2015]. Disponible en internet: $<\underline{\text { http://www.abacq.net/imagineria/medidas.htm }>}$
} 
materia de pensiones, ni Frei ni Allende lograron el consenso necesario para emprender el duro saneamiento que se requería para ordenar una multiplicidad de regímenes anárquicos, muchos de ellos excesivos." $" 480$

Estos intentos de ampliación de la cobertura va a ser duramente criticada por la dictadura y el comité de expertos vinculada a ella. De hecho, la mayor justificación para modificar el sistema -pese a que había común acuerdo en el mundo de que era un sistema que funcionaba- era que sería imposible mantener un sistema de reparto considerando que la relación entre "activos" y “pasivos" había ido disminuyendo, en gran parte también por la "permisividad" del Estado y la política de Allende, como señalan Iglesia y Acuña: “(...) hacia 1979 la relación entre activos y pasivos cayó desde 12,2 a 2,5, lo que no puede explicarse sólo por tendencias demográficas y corresponde más bien a los efectos de una extrema generosidad para conceder beneficios." ${ }^{481}$

Además, hacia fines de los 70 para algunos el sistema ya estaba desfinanciado y en colapso debido al desempleo y al exorbitante aporte estatal que requería para su mantenimiento, como señala Gaete: “(...) Chile había vivido una larga historia de desocupación sostenida y crónica, con un sistema previsional colapsado, que entregaba malos beneficios y encarecía significativamente la mano de obra empleada con tasas de cotización que habían llegado a estar por sobre el $50 \%$ de los salarios. Aun así, este financiamiento era insuficiente y requería de aportes fiscales crecientes" ${ }^{482}$ Estos serán argumentos suficientes, sumados a las políticas de shock instaladas en dictadura por los "Chicago Boys", para modificar el sistema de manera radical.

\footnotetext{
${ }^{480}$ ARENAS DE MESA, Alberto. Cobertura previsional en Chile: Lecciones y desafios del sistema de pensiones administrado por el sector privado. Cepal. Chile. 2000. p. 12.

${ }^{481}$ ACUÑA Rodrigo. e IGLESIAS, Augusto. "La Reforma a las Pensiones" En. LARRAÍN Felipe y VERGARA Rodrigo. La transformación económica de Chile. Centro de Estudios Públicos. Santiago. 2001. p. 434.

${ }^{482}$ GAETE, María Elena. "La Transición del Régimen de Reparto al de Ahorro Individual.” En: ARIZTÍA. Juan AFP: Las tres letras que revolucionan América. CIEDESS. Chile. 1997. p. 235.
} 
La reforma al sistema de pensiones es otra de las política de "modernización" que emprendió la Junta Militar de la mano de los economistas de Chicago y queda declarado como un pilar fundamental de su política en el libro conocido como El Ladrillo, que inicia su diagnóstico sobre este aspecto señalando que el sistema de pensiones precedente está en crisis:

"Puede sostenerse sin temor a errar, que hay conciencia generalizada de que el sistema previsional está en crisis, de que es injusto, discriminatorio e ineficiente.

(...) Las críticas más claras al sistema de seguridad social se refieren a:

1. Alto costo.

2. Discriminación o injusticias del sistema.

3. Baja eficiencia, que crea una gran discrepancia entre los fondos aportados y los beneficios recibidos." 483

Los argumentos utilizados son los ya conocidos, pero la finalidad no es aplicar una reforma para ajustar dichos errores sino cambiarlos de "raíz" por un sistema que traería más "justicia", como es el sistema de capitalización individual, donde el sector privado es fundamental. El sistema es explicado de la siguiente manera:

“- El nuevo sistema previsional constará de dos subsistemas: uno de carácter estatal, financiado por la vía tributaria, que establecería una previsión mínima (1 vital o menos) igual para todos los chilenos que cumplieran más de 65 años y que hubieran trabajado un número mínimo de años (25 6 30); y el otro, que sería en base a un sistema de ahorro que

\footnotetext{
${ }^{483}$ CENTRO DE ESTUdIOS PÚBLICOS. El ladrillo. Bases de la política económica del gobierno militar chileno. CEP. (Reedición). Santiago de Chile. 1992. p. 118.
} 
se depositaria mensualmente en una institución especializada, de acuerdo a un mecanismo contractual de administración delega- da de esos fondos, los que podrían ser cobrados en forma de una pensión vitalicia sólo cuando se alcance la edad de retiro. La entidad administradora de estos ahorros tendría la obligación de invertirlos de manera tal, que asegurara que estos mantendrán su valor real a través del tiempo (reajustabilidad), y que devengarán un interés. Estas entidades, similares a los Fondos de Pensión y Mutualidad que existen en otros países, pagarán las jubilaciones a sus asociados y cobrarán al Gobierno la pensión mínima que corresponderá a cada chileno, de manera de simplificar la operatoria fiscal, abaratar sus costos y dar un mejor servicio a sus asociados.

(...) El nuevo sistema de previsión se concibe en términos de organización semejante a1 que existe actualmente para las Asociaciones de Ahorro y Préstamo, esto es, entidades autónomas, administradas por representantes de los ahorrantes y con una Unidad Central Coordinadora que podría, eventualmente, otorgar respaldo y seguridad financiera a1 resto de las entidades.

Estas nuevas entidades, que para diferenciarlas de las actuales "cajas" las llamaremos Fondos de Pensión, tendrán por objeto administrar los ahorros de sus depositantes, invertirlos en valores reajustables del mercado de capitales que se ira creando (ver capitulo respectivo), o en acciones cuya rentabilidad sea equivalente al retorno de un valor reajustable; los beneficios que los Fondos otorguen serán contractuales o no podrán recibirse si no se cumplen los requisitos mínimos de edad y número de años trabajados." ${ }^{484}$

Varias cosas resultan de este cambio y se observan fácilmente. El Estado se vuelve subsidiario, las pensiones dependerán de la capacidad de capitalización del individuo, las cajas son

\footnotetext{
${ }^{484}$ CENTRO DE ESTUDIOS PÚBLICOS. Op. Cit. 1992. pp. 130-131.
} 
reemplazadas por los Fondos de Pensiones administradas de manera privada completamente. El dinero depositado en estos fondos dependerá de la capacidad que tenga cada uno de ellos para transar el dinero en el mercado y particularmente en la bolsa, por lo que las jubilaciones quedarán en situación de inestabilidad constante y favorecerán a los que tiene mejores trabajos y mayor capital. De esta manera el trabajador se convertiría en un verdadero emprendedor, ya que en la medida que más dinero entregue a los fondos mejor pensión tendrá:

\begin{abstract}
"Un sistema previsional basado en "Fondos" de ahorro efectivo de los participantes no sólo es una solución eficiente a1 problema previsional, sino que además creará un mecanismo de acumulación de riqueza en manos de los trabajadores. Ellos pasarían a ser, con el tiempo, una de las principales fuentes de ahorro para financiar inversiones, pudiendo alcanzar un papel prominente como poseedores de capital. Si esta posibilidad se materializa, podrían desaparecer o aminorarse las tensiones entre el capital y el trabajo, ya que este último seria a su vez poseedor de importantes recursos de capital." 485
\end{abstract}

La política de los Fondos de Pensiones se presentaba de una manera muy optimista: ya no se dependería de escaso dinero del Estado sino que el propio trabajo podría aumentar las arcas personales. Además, el reparto dejaría de ser “desigual” ya que no habría reparto solidario, todo el dinero sería para cada uno. Se comenzó el traspaso al nuevo sistema ya a partir de 1974 y se hizo obligatorio a partir de 1983, algunos se mantuvieron en el antiguo, los menos, pero lo que llamó más la atención es que este supuestamente exitoso modelo de capitalización fue impuesto a la ciudadanía, al no haber alternativa al sistema de fondos de pensiones. Pero las Fuerzas Armadas no se sumarán y mantendrán un sistema propio de reparto (Caja de Previsión de la Defensa Nacional (CAPREDENA) y la Dirección Previsional de Carabineros de Chile

\footnotetext{
${ }^{485}$ CENTRO DE ESTUdiOS PÚBLICOS. Op. Cit. 1992. p. 134.
} 
(DIPRECA)) hasta la actualidad, viéndose beneficiados con jubilaciones de muy buena calidad y mucho mejores que los que forman parte del sistema de pensiones. ${ }^{486}$

En definitiva, un modelo solidario con fallas y debilidades pero que reconocía el aporte de las personas, los empleadores y el Estado fue cambiado radicalmente por uno en que es el mercado el verdadero articulador. El cambio en la práctica fue más bien forzado que real, ya que como señala Arellano, el análisis de los defectos del sistema de reparto: "no se derivaba la conveniencia de reemplazarlo por un sistema privado de capitalización como insistentemente ha sido planteado por los economistas del gobierno militar. Los defectos indicaban que era necesario uniformar las disposiciones que determinaban los beneficios y aportes al sistema, modernizar su administración, extender la indexación para neutralizar la inflación y recuperar la cobertura perdida en los últimos años."487

Con todo, triunfó el neoliberalismo y se instaló el sistema de capitalización de la mano del terror de la dictadura. Sin embargo, esta propuesta "innovadora" no fue para todos, como si los militares previeran el daño que en el largo plazo podrían generar a las pensiones y marginaron a sus miembros. Un sistema tan imbricado con el neoliberalismo y que beneficiaba a los militares dándole una condición distinta debería haber sido modificada en democracia; sin embargo, una vez más el sistema de profundizó y sigue dañando el derecho a los adultos a tener un buen "vivir" tras una larga vida de esfuerzo.

\footnotetext{
${ }^{486}$ RADIO UCHILE. "Pensiones de uniformados muestran amplia diferencia con jubilación por AFP" [En línea] 3 de agosto del 2013. [fecha de consulta 23 de agosto del 2015]. Disponible en internet: < http://radio.uchile.cl/2013/08/03/pensiones-deuniformados-muestran-amplia-diferencia-con-jubilacion-por-afp>

${ }^{487}$ RELLANO, José Pablo. Políticas sociales y desarrollo. Chile 1924-1980. Cieplan, Santiago. 1985
} 


\section{2.-EL DRAMA DE JUBILARSE EN CHILE}

En Chile, a diferencia de la Educación y la salud, no existe una alternativa al sistema privado de pensiones. Es obligatorio imponer a las AFP (Administradoras de Fondos de Pensiones) el $10 \%$ del sueldo más gastos de administración que van entre los $0,50 \%$ o el 1,5\% extra. Por lo tanto, todo chileno está sometido a los beneficios que pueda entregar la administradoras de fondos de pensiones y los vaivenes de la bolsa, lo cual ha generado una situación dramática para muchos chilenos que trabajando e imponiendo dinero reciben pensiones que quedan muy por debajo de sus sueldos, e incluso llegando algunos a quedar en la miseria o buscando alternativas de asesorías privadas para manejar el dinero de los fondos, cuestión que sube el costo y que excluye por tanto a gran parte de los chilenos. ${ }^{488}$

Los estudios realizados por la Fundación $\mathrm{Sol}^{489}$ durante los últimos años ha comprobado que el Sistema de Pensiones bajo la capitalización individual no sólo es injusto sino que además atenta contra los derechos de los trabajadores establecidos por OIT (Pacto Internacional de Derechos Económicos, Sociales y Culturales (PIDESC) de las Naciones Unidas, que reconoce el derecho de toda persona a la seguridad social y al seguro social de 1966) y además no habría cumplido las promesas hechas en los 80 acerca de los beneficios de este sistema de pensiones; por ejemplo, en cuanto a la cobertura de la población económicamente activa que se habría reducido desde 1973 a 1980 de un $73 \%$ a un 64 \%. Podría pensarse en un repunte una vez instalado el sistema, pero con datos del 2013 la cobertura sólo alcanza el 63,7 \%.

Como mencionamos, existe además desigualdad ya que las Fuerzas Armadas están en un sistema de reparto que en la actualidad es deficiente, a tal punto que hacia el año 2013 el Estado

\footnotetext{
${ }^{488}$ CNN CHILE. "El drama de las pensiones de jubilación” [En línea] 13 de junio del 2013. [fecha de consulta 23 de agosto del 2015]. Disponible en internet: < http://www.cnnchile.com/noticia/2013/06/13/el-drama-de-las-pensiones-de-jubilacion->

${ }^{489}$ http://www.fundacionsol.cl Fundación Sol, según sus objetivos, es un centro estudios para cuestiones de trabajo, sindicalismo y educación, que busca discutir las "verdades instaladas" que sostienen al modelo económico actual.
} 
debió cubrir un déficit de $\$ 1,03$ billones. Tampoco existe un pilar solidario en el sistema (salvo un exiguo aporte del Estado) y desfavorece a las mujeres que, en general, reciben peores salarios que los hombres y por lo tanto, disfrutan de menos posibilidades de capitalización.

Un punto crucial respecto a la eficiencia del sistema es justamente los resultados de las pensiones que -como mencionamos anteriormente- dan resultados de baja calidad y que no necesariamente cubren la vejez con dignidad. Según los datos de la Superintendencia de pensiones citados por la Fundación Sol, “a diciembre de 2013, el sistema privado chileno pagó 1.031.207 pensiones y el monto promedio ( $\sin$ incluir APS) fue de $\$ 183.213$ (87\% del Salario Mínimo). En el caso de las pensiones de Vejez que pagan las AFP (Modalidad retiro programado), el 91,2 \% son menores a $\$ 139.857$ (6 UF), lo que significa que 9 de cada 10 pensionados bajo esta modalidad reciben una pensión menor a $66,6 \%$ del Salario Mínimo nacional. En el caso de las mujeres, la situación es aún más alarmante, ya que 94,2 \% recibe menos de esta cifra." 490

Como se observa, la situación es dramática pero toma tintes de absurdo cuando, además de ser ineficiente se puede corroborar que los beneficios recibidos por las AFP son inmensos, además de lo que recibe directamente desde el Estado, que se ha ido transformando poco a poco en un Estado "subsidiador" más que subsidiario como se proponía originalmente. Por ejemplo, el año 2013, de cada $\$ 5$ que se pagaron por concepto de pensiones civiles (sin contar a las Fuerzas Armadas), \$4 provenía de las arcas fiscales y sólo $1 \$$ de las AFP y Compañías de Seguro. Las ganancias que son percibidas por los fondos son enormes, superando con creces sus egresos. Así encontramos, por ejemplo, que el año 2013 se recibieron ingresos por casi $\$ 6,6$ billones y

\footnotetext{
${ }^{490}$ FUNDACION SOL. Presentación Fundación SOL para Comisión Asesora Presidencial sobre el Sistema de Pensiones. Cuaderno de Trabajo. Chile. 2014. p.5
} 
se generaron egresos por sólo $\$ 2,5$ billones, arrojando un excedente de $\$ 4,05$ billones que equivale al $62 \%$ de los ingresos. ${ }^{491}$

Con estos datos queda claro que la política adoptada en los años 90 -en pleno retorno de la democracia- en relación con el sistema de pensiones ha sido la de perpetuar, profundizar y hasta exportar $^{492}$ el sistema creado en dictadura. Teóricamente los gobiernos de la democracia se plantearon como objetivo aliviar la "deuda social" $" 493$ heredada de la dictadura; en la práctica esto se llevó a cabo aumentando los recursos de manera focalizada. La gran limitación habría sido la base de recaudación tributaria que sólo permitió solventar el costo de aumentar ciertos derechos en el sector pensiones o salud financiados por el Fisco- que en este caso se van directo a los bolsillos de privados-pero no permitirían reinstalar un Estado de bienestar. Tras más de veinte años de democracia se considera que el modelo de pensiones favorece al sector privado y ha sido exitoso, pero para el propio beneficio de los dueños de aseguradoras, no para el trabajador. En este sentido una reforma importante fue aplicada en los últimos años bajo el gobierno de Bachelet (en 2009), que fijó una Pensión Básica Solidaria ${ }^{494}$-el monto a pagar es mucho menor al sueldo mínimo- para todos los ciudadanos de la tercera edad sin necesidad de haber contribuido al sistema. El problema es que el Estado sigue haciéndose cargo de las deficiencias del modelo. ${ }^{495}$

\footnotetext{
${ }^{491}$ FUNDACION SOL. Op. Cit. 2014. p.7

${ }^{492}$ GESTION. "Las AFP en el Perú y el nuevo enfoque de las pensiones" [En línea] 28 de mayo del 2015 [fecha de consulta 13 de junio del 2015]. Disponible en internet: <http://gestion.pe/economia/afp-peru-y-nuevo-enfoque-pensiones-2132834>; SURA. Contribución del sistema privado de pensiones al desarrollo económico de Latinoamérica. Experiencias de Colombia, México, Chile y Perú. Asset Management Impreso en Chile. Chile. 2013

${ }^{493}$ HARDY. Clarisa. La reforma social pendiente. Ediciones de Chile 21. Chile 1997.

494 “Es un beneficio monetario mensual, de cargo fiscal, al que pueden acceder todas aquellas personas mayores de 65 años de edad, que no tengan derecho a una pensión en un régimen previsional y que cumplen con los requisitos establecidos en la Ley $\mathrm{N}^{\circ} 20.255$ (2009) A partir del 1 de julio de 2015: \$89.514 mensuales.” Ver: < http://www.previsionsocial.gob.cl/subprev/?page id=7430>

${ }^{495}$ SEHNBRUCH, Kirsten y SIAVELIS, Peter. El balance: política y políticas de la concertación 1990-2010. Editorial Catalonia. Chile. 2014. pp. 238-239.
} 
En la actualidad se ha generado un amplio debate ${ }^{496}$ acerca de qué se debe hacer con el sistema de pensiones, en la medida en que se ha ido comprobando la ineficacia y desigualdad que genera. Se ha propuesto regresar a un sistema de reparto que no ha dado fruto, debido al importante lobby de las aseguradoras y se ha instalado la idea "intermedia" de agregar una AFP Estatal como opción a las privadas, de tal manera que se agrega competencia al sistema. Esto sería otro aporte "sui generis" del modelo chileno de democracia, que pone las pensiones de sus ciudadanos a disposición del negocio de la especulación financiera entrando directamente en el juego del mercado. ${ }^{497}$

\footnotetext{
${ }^{496}$ ACUÑA, Rodrigo e IGLESIAS, Augusto. "Chile's Pension Reform After 20 Years” Social Protection Discussion Paper Series $N^{\circ}$ 0129. 2001.

497 LATERCERA. AFP "Estatal: mala idea.” [En línea] 2 de septiembre del 2014 [fecha de consulta 13 de junio del 2015]. Disponible en internet: < http://www.latercera.com/noticia/opinion/ideas-y-debates/2014/09/895-593986-9-afp-estatal-malaidea.shtml>; RADIO UCHILE. "Debate por AFP Estatal: "Nos dan una aspirina para el cáncer en el modelo previsional” [En línea] 2 de mayo del 2014 [fecha de consulta 13 de junio del 2015]. Disponible en internet:

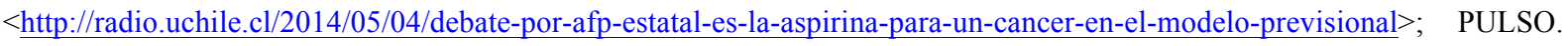
"Los 5 mitos sobre la AFP estatal. ¿Es posible hoy en Chile?. [En línea] 2 de mayo del 2015 [fecha de consulta 13 de junio del 2015]. Disponible en internet: $<$ http://www.pulso.cl/noticia/economia/economia/2013/04/7-21191-9-los-5-mitos-sobre-la-afpestatal-es-posible-hoy-en-chile.shtml $>$
} 


\title{
13.-LA ESTRATEgIA POLÍTICA DEL ORDEN:
}

\section{EL SISTEMA BINOMINAL.}

"Aquí estoy, cumpliendo mi compromiso e iniciando un nuevo tiempo para la democracia" señala la cita de la página del Gobierno de Bachelet que da cuenta de la nueva legislación que elimina el Sistema Binominal. Esta iniciativa esperada durante muchos años, se propone como un paso adelante en la construcción de un sistema electoral más democrático. Este nuevo sistema sería mucho más inclusivo al ampliar la representatividad, también se agregan factores de discriminación positiva al género, como un monto en dinero extra por cada mujer elegida, como se señala en la misma web informativa:

\begin{abstract}
"Esta mañana, luego de 25 años de un sistema electoral poco representativo, la Presidenta Michelle Bachelet promulgó la Ley que sustituye el sistema electoral binominal por uno de carácter proporcional inclusivo.
\end{abstract}

Este nuevo sistema aumenta la cantidad de diputados de 120 a 155 con el fin de mejorar la representatividad, disminuyendo de 60 a 28 los distritos. En cuanto a senadores, estos pasan de ser 38 a 50, y se establece una sola circunscripción senatorial por región. Lo que aumenta es cuántos candidatos pueden elegirse en cada caso, que varía de acuerdo a la población.” 498

Obviamente la propuesta, que aún no es puesta en ejercicio, ha sido duramente criticada justamente porque propone un aumento de los integrantes en la cámara en momentos en que

\footnotetext{
${ }^{498}$ GOBIERNO DE CHILE. "Fin al binominal: Conoce el nuevo sistema electoral” [En línea] 27 de abril del 2015. [fecha de consulta 13 de junio del 2015]. Disponible en internet: < http://www.gob.cl/2015/04/27/fin-al-binominal-conoce-el-nuevo$\underline{\text { sistema-electoral/> }}$
} 
los políticos sufren un alto desprestigio. ${ }^{499}$ Los resultados de dicho sistema están por verse en los próximos años, pero lo que está claro es que el sistema precedente marcó el actuar del sistema político durante gran parte de la democracia y será a través de él que se cautelará el orden y la representación de una política que hizo prevalecer el equilibro durante más de veinte años. Esta fue otra herencia de la dictadura que delineó el actuar político de la democracia a la “chilena" con una ley promulgada los últimos meses del Régimen. ${ }^{500}$ En las siguientes líneas explicamos sus características y efectos.

\section{1.- HISTORIA Y CARACTERÍSTICAS DEL SISTEMA BINOMINAL.}

Los sistemas políticos y sus definiciones son relevantes porque a través de ellos se puede determinar lo que sucederá en el mediano o largo plazo con la gobernabilidad. En este sentido, un sistema político determinado podría generar incentivos para la cooperación, penalizando a aquellos sectores que no sean capaces de llegar a acuerdos entre sí. O también el sistema podría tensionarse al punto de que no se logren acuerdos y el sistema entre en crisis.

Este sencillo análisis va a determinar la decisión de los años 90 para mantener o corregir el sistema. ${ }^{501}$ Es menester mencionar que en el periodo previo al Golpe de Estado estaba en vigor

\footnotetext{
${ }^{499}$ RADIO UCHILE. "Los desafíos e interrogantes que plantea el fin del binominal”. En línea] 27 de abril del 2015. [fecha de consulta 13 de junio del 2015]. Disponible en internet: < http://radio.uchile.cl/2015/04/27/los-desafios-e-interrogantes-queplantea-el-fin-del-binominal>

${ }^{500}$ SQUELLA, Agustín y SUNKEL, Osvaldo . Democratizar la democracia. Reformas pendientes. Editorial LOM. Chile. 2000.

${ }^{501}$ Para conocer el sistema de partidos chileno en perspectiva histórica se puede ver: ARRIAGADA, Genaro. ¿Hacia un "Big Bang" del Sistema de Partidos?. Editorial Los Andes, 1997; SCULLY, Timothy y VALENZUELA, Samuel, "De la democracia a la democracia: Continuidad y variaciones en las preferencias del electorado y en el sistema de partidos en Chile", Estudios Públicos, 51. 1993; CAVAROZZI, Marcelo y GARRETÓN, Manuel A. (Ed.), Muerte y resurrección: Los partidos políticos en el autoritarismo y las transiciones en el Cono Sur. FLACSO, Chile. 1989; CRUZ-COKE, Ricardo. Historia electoral de Chile 1925-1973. Editorial Jurídica. Chile. 1984.
} 
la Constitución de 1925, la cual -como expone Valenzuela- había propiciado cierta flexibilidad para que se llegara a acuerdos durante los años en que estuvo vigente mediante un sistema proporcional que facilitaba la competencia de partidos más pequeños, hasta que se introdujeron cambios en los años sesenta que terminaron por polarizar y tensionar el sistema llevándolo a un quiebre, que será interpretado por la dictadura como el germen de los males nacionales. El autor lo resume de la siguiente manera:

“Los partidos pequeños se vieron afectados por un cambio importante en la legislación electoral en 1958 y 1962, a saber, la prohibición de los pactos electorales que habían generado las listas hibridas de candidatos (...) Los pactos daban ventajas considerables a los partidos menores, porque permitían la elección de algunos de sus miembros en distritos donde eran relativamente fuertes y, al mismo tiempo, el Servicio Electoral sumaba sus votos en forma separada, aislándolos de la lista en que se presentaban, haciendo así la sumatoria total de su votación nacional bajo su propia etiqueta partidaria. De este modo, el partido tenía la posibilidad de conservar su existencia legal siempre y cuando apareciera con más del apoyo mínimo a nivel nacional requerido con este fin y, simultáneamente, obtenía el impulso necesario en ciertos distritos para elegir a sus candidatos al compartir una lista más apta para captar los votos necesarios para sobrepasar el cociente electoral del sistema D'Hondt.

(...) La única forma de hacer pactos con las nuevas normas imperantes era que los partidos acordaran —a la vez que se mantenían cada uno como una organización distinta con una identidad propia - registrar una denominación partidaria ficticia de alcance nacional en el Servicio Electoral, con listas hibridas de candidatos. Pero difícilmente podían los partidos pequeños esperar que los grandes se acomodaran a ellos al punto de sacrificar su denominación partidaria.

(La Democracia Cristiana...) Pese a adoptar por lo general una actitud de apoyo al gobierno de Allende al comienzo de su periodo, los democratacristianos se vieron pronto 
impulsados a hacer una alianza electoral con la derecha, en un intento por evitar un drenaje de los votos opositores a costa de su partido. Esta alianza se desarrolló primero en elecciones complementarias para llenar vacantes en la Cámara de Diputados y se estableció también para las elecciones parlamentarias de marzo de 1973. Por primera vez, el electorado debía optar entre candidatos organizados en dos "partidos" inscritos como tales con fines electorales, la Confederación Democrática a la derecha y la Unidad Popular a la izquierda. Nunca antes había estado el sistema de partidos tan polarizado, puesto que las fuerzas extremas en los dos bloques pudieron imponer en gran medida los términos del debate político." ${ }^{502}$

La década de los sesenta representará para Chile lo que se conocerá como el periodo de Gobiernos de proyectos excluyentes, en el cual la Democracia Cristiana se consolidará como un partido de centro - en reemplazo del tradicional Partido Radical- pero que asumirá un papel distinto al que tradicionalmente tenían los partidos de centro, buscando alianzas con la derecha o la izquierda. En su caso, llegando al poder se margina de los pactos y proyecta un gobierno de tercera vía, lo que llevará a quebrar el sistema en los años setenta, sumado a la ampliación del electorado -el campo, las mujeres y los sectores marginales urbanos- y demandas crecientes que presionaban al poder político. El resto de la historia es bastante conocida: la Unidad Popular se queda sola en el poder, confrontada por los partidos de derecha y la propia Democracia Cristiana y sin capacidad para tomar decisiones en el Congreso.

Esta imagen quedó plasmada en la retina de los militares, quienes calificaban el periodo político precedente al Golpe como uno de caos y anarquía donde el juego político era manipulado por

\footnotetext{
${ }^{502}$ VALENZUELA, Samuel. "Orígenes y transformaciones del sistema de partidos en Chile”. Estudios Públicos. 58. 1995. pp. 67-68
} 
políticos sin interés en lo nacional o vinculados al marxismo internacional. Pinochet lo describía de la siguiente manera:

"La vida militar me preparó, primero, para entender cabalmente, que ninguna institución puede funcionar en buena forma si existen en su seno el caos y la anarquía. Deben, en efecto, darse jerarquías, funciones y responsabilidades. En una palabra: orden. Aprendí que ese es un requisito fundamental para que la organización sea eficaz, y aprendí, también, que cada componente de esa estructura, idealmente, no debe fallar en la ejecución de sus responsabilidades. Es decir, en la vida militar se vive, quizás con mayor claridad formal que en otra parte, en permanente dinámica de mandar y obedecer. ¿Y acaso sucede algo demasiado diferente en cualquier otra actividad? En todo caso, quien manda debe saber hacerlo. A su vez, quien obedece, en consecuencia, no puede escapar a la misma dinámica.

Todo esto tiene que establecerse en la comprensión cierta de qué es la organización militar. En ella, quien no sepa mandar, no sirve. Y quien no sepa obedecer, tampoco sirve. Por lo demás, y aunque resulte un tanto drástico decirlo así, en la vida, la persona que resulta más inútil es aquella que no sabe ni mandar ni obedecer, Creo que para poder ejecutar bien el mando es imprescindible haber aprendido a obedecer. Y a obedecer en plenitud, en forma comprometida, sin vacilaciones. Es mal jefe, por lo tanto, quien haya sido mal subalterno.

En resumidas cuentas, el saber mandar y saber obedecer son instancias de la vida militar que pueden diferir sólo en meras cuestiones de forma en su proyección a la sociedad en general. En todas partes deben darse jerarquías y mando. Y en todas partes, por lo tanto, existirán personas con mayor o menor capacidad para ser útiles según su función. Así, cualquiera que sea la organización social; básicamente debe conformarse con una cierta jerarquía. Jerarquía que debe estar en función de un real consenso, con una búsqueda auténtica del bien común. 
No debe repetirse el hecho de que minorías controlen y manejen decisiones- como aconteció en el pasado- o que éstas provengan desde el exterior. Una democracia debe sustentarse en un respeto jerárquico. Valgan estos alcances previos para referirme a algunas cuestiones que han ocurrido en Chile, y que he visto aflorar desde que asumí la función de gobernante.

Sufrimos en Chile todo un proceso movido por la demagogia de uno u otro estilo. Proceso cuyo fin era siempre el mismo, a saber: el permanente cuestionamiento de las jerarquías, de la autoridad y sobre todo el sistema mismo, para finalmente intentar destruirlo. O sea, emergió un "pensamiento crítico" - más exactamente, un pseudo pensamiento críticodestinado a crear las condiciones propicias para el avance del Partido Comunista. Esto pudo llevarse a cabo bajo la inspiración de los comunistas, la complicidad tácita de otros y la ingenuidad de terceros. La consigna era que todo debía ser cambiado. Y para ello, de modo no tan subliminal ni delicado, se dejaba vislumbrar la idea amenazante de que previamente era imprescindible aniquilar lo existente. De ahí toda efervescencia, que los marxistas procuraron propagar, no sólo en las universidades, sino que también en la Educación Media y quizás más abajo, llegándose incluso al intento de convertir la educación nacional en un adoctrinamiento socialista. El Partido Comunista y otras colectividades dispusieron de un número suficiente de activistas para impulsar inquietudes en la juventud, muchas de ellas absolutamente legítimas, que ellos se encargaron de desviar hacia los intereses y fines partidistas.

Así fue desarrollándose el proceso chileno al que nuestro Gobierno puso término. A cualquier hombre que vista uniforme no le resulta difícil reconocer los elementos estratégicos de la acción política. Y, de ese modo especialmente claro, la ofensiva del Partido Comunista, que obedece a las instrucciones que Moscú proyecta por el mundo."

\footnotetext{
${ }^{503}$ PINOCHET, Augusto. Politica, Politiquería, Demagogia. La Nación. Chile. 1983.
} 
Esta imagen de descontrol y falta de orden permaneció durante casi toda la dictadura y marcará fuertemente la definición política previa a la llegada de la democracia. Durante la dictadura no se permitía el ejercicio político y se mantiene la estructura política autoritaria, el congreso está suspendido y el poder legislativo será ejecutado por la Junta de Gobierno. Durante los ochentas se incorporaron civiles en cargos claves del Régimen Militar, pero no existe ninguna instancia concreta que haya permitido -salvo el plebiscito que corroboró la implantación de la Constitución de 1980- preparar a la ciudadanía para la democracia que se preveía llegar a fines de los ochenta. ${ }^{504}$

En 1988 y a pocos meses de retornar la democracia se establecerá un sistema que reemplazará al proporcional de los años 1973 en relación con los senadores y diputados (ley 18.799, del 26 de mayo de 1989, que modificó la ley orgánica constitucional sobre votaciones populares y escrutinios, la ley 18.700, del 6 de mayo de 1988). En este caso se consolidará la Democracia Protegida, mediante un sistema que se conocerá como "Sistema Binominal”, diseñado con el fin de establecer un sistema bipartidista que favoreciera a la derecha -especialmente- y el centro, excluyendo así a los sectores de izquierda. ${ }^{505}$

Estas leyes electorales actuarán a su vez como un factor que ejercerá presión a los partidos políticos generando que se formen pactos electorales al tener que presentarse por listas, como señala el artículo 109 bis:

\footnotetext{
${ }^{504}$ CAÑAS KIRBY, Enrique. Proceso político en Chile: 1973-1990. Editorial Andrés Bello. Chile. 1997.

${ }^{505}$ FERNÁNDEZ, Mario. "El proyecto de ley electoral chilena de agosto de 1988. Análisis de algunos de sus fundamentos y alcances". Estudios Sociales. 59. 1988. pp. 45-61.
} 
“Artículo 109 bis.- En caso de elecciones de Parlamentarios, el Tribunal proclamará elegidos Senadores o Diputados a los dos candidatos de una misma lista, cuando ésta alcanzare el mayor número de sufragios y tuviere un total de votos que excediere el doble de los que alcanzare la lista o nómina que le siguiere en número de sufragios.

Si alguna lista obtuviere los dos cargos, elegirá un cargo cada una de las listas o nóminas que obtengan las dos más altas mayorías de votos totales de lista o nómina, debiendo el Tribunal proclamar elegidos Senadores o Diputados a aquellos candidatos que, dentro de cada lista o nómina, hubieren obtenido las más altas mayorías.

Si el segundo cargo por llenar correspondiere con igual derecho a dos o más listas o nóminas, el Tribunal proclamará electo al candidato que hubiere reunido mayor cantidad de preferencias individuales.

En caso de empate entre candidatos de una misma lista o entre candidatos de distintas listas o nóminas, que a su vez estuviesen empatadas, el Tribunal procederá, en audiencia pública, a efectuar un sorteo entre ellos, y proclamará electo al que salga favorecido."506

Un buen resumen del funcionamiento del sistema y sus efectos son expuestos por Valenzuela de la siguiente manera: "se establece que los distritos para el Senado y la Cámara baja cuenten con dos representantes y los partidos pueden incluir en su lista un máximo de dos candidatos para llenar los cargos. Los electores emiten sus preferencias por candidatos individuales, pero los votos se cuentan primero por lista partidaria. Si la lista ganadora obtiene más del doble de los votos de la próxima lista más votada, la mejor situada elige a ambos candidatos. De no ser así, elige a solo uno, con la segunda posición yendo al candidato que obtiene la más alta votación en la segunda lista más votada. De este modo se hace posible, como ha ocurrido

506 MINISTERIO DEL INTERIOR. Ley 18.799: "Modifica leyes orgánicas constitucionales N Nos. 18.603 y 18.700 ”. 26 de mayo de 1989. 
frecuentemente, que el segundo candidato elegido gane pese a haber obtenido menos votos que el candidato ubicado en segundo lugar en la lista ganadora. Si hay solo dos listas, basta que una de ellas tenga un tercio de los votos para asegurarse de elegir a un candidato. Por ende, la ley electoral fue diseñada para favorecer a los partidos de derecha, puesto que se esperaba generalmente de ellos, vistos los resultados del plebiscito de 1988, que obtuvieran un voto combinado de menos de la mitad, pero más de un tercio, del total. Esto se ha visto corroborado por los resultados electorales."

Los intentos por reformar el sistema binominal durante la democracia han sido ocho en total, pero solo el año 2015, gracias a un acuerdo común, se decidió por terminar con él después de un extenso debate que había durado bastantes años. ${ }^{508}$ Cabe preguntarse entonces si este sistema de sobrerrepresentación que favorecía a la derecha, la formación de coaliciones y “empantanaba” las decisiones políticas generando equilibrios difíciles de romper, ¿Por qué no se modificó durante todos estos años? ¿Por qué no mejorar el sistema electoral con fines democráticos en plena democracia? Al parecer nos encontramos con otras de las características particulares de la democracia a la chilena.

\section{2.- EL SISTEMA BINOMINAL ¿PARTICIPACIÓN O CONTROL?}

La mejor o peor calidad de una democracia está vinculada, entre otras cosas, a que su sistema político y electoral facilite o permita mayores grados de representatividad, competitividad, gobernabilidad y un mejor rendimiento de cuentas. Obviamente, el ajuste de estos "ideales" no es siempre posible y en la medida que se mejore uno, decrece otro. Por estas mismas razones

\footnotetext{
${ }^{507}$ VALENZUELA, Samuel. Op. Cit. 1995. p. 73

${ }^{508}$ FUENTES, Claudio y RÍOS, Marcela. (Ed.). Una Reforma Necesaria. Efectos del Sistema Binominal. FLACSO. Chile. 2006.
} 
existen posiciones que aseguran que el sistema binominal ha sido positivo para Chile, como señala Carey:

"No obstante, es importante señalar que las elecciones chilenas celebradas desde el restablecimiento de la democracia en 1989 han generado una combinación respetable de los ideales representativos fundamentales (...) y que este resultado ha sido ampliamente reconocido fuera del país. Al margen de las motivaciones iniciales que hubiera para instaurar un sistema binominal, las elecciones chilenas producen coaliciones fácilmente identificables por los votantes antes de las elecciones; que, en líneas generales, han puesto en práctica las políticas y programas con los que hicieron campaña para llegar al poder, y que han gobernado con eficiencia.

Además, el sistema binominal ha mejorado considerablemente la representación de las minorías que han querido y podido entrar en alianzas electorales amplias. Las elecciones legislativas chilenas también han proporcionado un foro para el desarrollo de una oposición electoral viable, así como un marco institucional en el que esta coalición puede operar. Finalmente, las listas abiertas conceden a los votantes chilenos la oportunidad de recompensar o castigar, mediante una simple marca en la lista, la actuación en el poder o en una campaña de cada uno de los candidatos a parlamentarios. El reducido número de candidatos en cada una de las circunscripciones impide que las campañas se conviertan en cacofonías de propuestas individuales que podrían confundir más que informar a los votantes.

(...) Desde un punto de vista comparado, estos elementos suponen una impresionante lista de virtudes para cualquier sistema electoral. Los posibles reformadores deberían considerarlas con detenimiento antes de propugnar cambios 
en un sistema que tan buenos resultados ha reportado. Y si hay consenso para la reforma, bien podría pensarse en un cambio cuantitativo, no fundamental. Un ligero incremento de $\mathrm{M}$ que dejara intacto el resto del sistema electoral proporcionaría ventajas considerables en cuanto a representatividad, quizá limitando al mismo tiempo las concesiones relativas a los otros ideales." 509

Como queda claro, las "virtudes" a las que se apela parten omitiendo las "razones" que le dieron origen, que como se sabe son las de una dictadura que buscaba "proteger" la democracia. Dicho esto se sitúa una vez más a la "vanidad" del Chile de los 90, un país con proyecciones internacionales donde su estabilidad es símbolo de progreso. Entre los argumentos del autor figura justamente que no haya "movimientos" bruscos en el sistema de partidos, que la gente puede reconocer "fácilmente" las grandes coaliciones evitando la "demagogia" individual. En el fondo los mismos argumentos de Pinochet: generar una política del orden, evitando los males de la hiper-representatividad o el surgimiento de los "caudillos" que podrían traer "caos". ¿Pero ha funcionado así realmente? ¿Si ha generado tanto debate, por qué siguió en vigor hasta el día de hoy?

En un interesante estudio del Centro de Estudios para el Desarrollo del año 2008 donde se hace un análisis crítico del sistema, ${ }^{510}$ se mencionan aquellos aspectos que ponen en evidencia las verdaderas razones del funcionamiento del sistema binominal y sus limitaciones, siguiendo el pensamiento de Nohlen acerca de los beneficios de los sistemas mayoritarios ${ }^{511}$ y lo que realmente sucede en Chile:

\footnotetext{
${ }^{509}$ CAREY, John M. “Las virtudes del sistema binominal.” Revista Ciencia. política. V 26, No 1, 2006. pp. 226-235.

${ }^{510}$ CED. Informe XII. Repasando las críticas al sistema binominal. CED. Chile. 2008

${ }^{511}$ NOHLEN, Dieter. Elecciones y sistemas electorales. Nueva Sociedad, Caracas. 1995.
} 


\begin{tabular}{|c|c|}
\hline \multicolumn{2}{|c|}{ Cuadro Comparativo Sistema Mayoritario y Sistema Binominal chileno } \\
\hline Beneficios & Chile \\
\hline $\begin{array}{l}\text { Impide la fragmentación partidaria al sancionar a } \\
\text { los partidos pequeños políticos. }\end{array}$ & $\begin{array}{l}\text { No, en Chile actualmente existen más partidos } \\
\text { relevantes que en } 1973\end{array}$ \\
\hline $\begin{array}{l}\text { Fomenta la concentración partidaria, debido a su } \\
\text { tendencia a formar un sistema bipartidista }\end{array}$ & $\begin{array}{l}\text { No, en Chile existen a lo menos cinco partidos } \\
\text { relevantes que concentran menos votación que en } \\
1973\end{array}$ \\
\hline $\begin{array}{l}\text { Fomenta la estabilidad del gobierno mediante la } \\
\text { formación de mayorías parlamentarias } \\
\text { monopartidista. }\end{array}$ & $\begin{array}{l}\text { No, en Chile ha impedido que el Gobierno tenga } \\
\text { mayoría en el Parlamento a pesar de sus } \\
\text { resultados electorales superiores al } 50 \% \text {. }\end{array}$ \\
\hline $\begin{array}{l}\text { Fomenta la moderación política, pues hace que } \\
\text { los partidos más grandes compitan por ganar el } \\
\text { apoyo del electorado ubicado en el centro del } \\
\text { espectro ideológico. }\end{array}$ & $\begin{array}{l}\text { Discutible. La experiencia chilena demuestra que } \\
\text { la competencia tiende a trasladarse al interior de } \\
\text { cada pacto electoral (UDI vs. RN; y PDC vs. PS } \\
\text { y PPD). }\end{array}$ \\
\hline $\begin{array}{l}\text { Fomenta la alternativa en el poder, pues una } \\
\text { variación pequeña en la relación de votos puede } \\
\text { dar lugar a una gran variación en la relación de } \\
\text { escaños parlamentarios. }\end{array}$ & $\begin{array}{l}\text { No. En el caso chileno una variación pequeña } \\
\text { puede dar como resultado un gran cambio } \\
\text { político, pero no a nivel de gobierno debido al } \\
\text { tipo presidencial del mismo. }\end{array}$ \\
\hline $\begin{array}{l}\text { Permite al elector decidir directamente, a través } \\
\text { de su voto, quienes deben gobernar, sin delegar } \\
\text { tal decisión a las negociaciones entre los partidos } \\
\text { después de las elecciones. }\end{array}$ & $\begin{array}{l}\text { No, por el contrario -y como se verá el grueso de } \\
\text { la composición del Parlamento- se decide a la } \\
\text { hora de la negociación en y entre los partidos } \\
\text { políticos. }\end{array}$ \\
\hline
\end{tabular}


Los casos que refuerzan lo señalado en el cuadro comparativo acerca del comportamiento del sistema electoral son abundantes, a la vez que dejan en claro que el sistema binominal no es de tipo mayoritario. En general, la alternancia ha sido muy baja -el primer caso se dio recién con el Gobierno de Piñera el año 2010-, desde el inicio de la Democracia ha gobernado la coalición de centro-izquierda y la pérdida del poder se ha dado debido a una situación de desprestigio de dicho grupo; sin embargo, en el Congreso la representación del centro izquierda y la derecha han sido casi equitativas. Las negociaciones son casi siempre entre los partidos, mediante votaciones primarias, casi nunca universales y cuando ha surgido la necesidad de reemplazar a miembros de la cámara se hace internamente por decisión de los partidos. Por últimos los partidos independientes tienen casi nula posibilidad de estar en el poder si no están en alguna coalición aglutinante.

En relación con la representación proporcional, el sistema binominal establece distorsiones serias. Para evitar que se genere una desproporcionalidad grave, los propios partidos han asumido estrategias que ayudan a evitarlas: por ejemplo mediante exclusiones, concesiones de "cupos" o simplemente los partidos mayoritarios no presentan candidatos en algunos distritos con el fin de dejar que los partidos pequeños lleguen al Congreso. Con lo cual gran parte de la política para asegurar la proporcionalidad se debe hacer antes, mediante negociaciones intraparlamentarias. $^{512}$

\footnotetext{
${ }^{512}$ ARRIAGADA, Genaro. ¿Hacia un "big bang" del sistema de partidos? Editorial Los Andes, Santiago de Chile. 1997. p. 67.
} 
A su vez, el sistema binominal pensado por la dictadura generó una tendencia en la conformación de los distritos y circunscripciones -espacios electorales para diputados y senadores- que no favorece la integración electoral de los ciudadanos de manera equitativa. Para esto se utilizó la división administrativa de Chile con base en las elecciones del plebiscito de 1988, manipulando dichos espacios y considerando los valores de votación que aquellos partidos que votaron por el NO o el Sí a Pinochet. Así por ejemplo en Santiago, donde triunfó el "No" se redujo su representación (26\% de diputados) siendo que allí vive casi el $40 \%$ de la población de Chile. A su vez, en distritos menores se llegan a elegir 40 diputados para una población de 1,5 millones de habitantes, o en otros con la misma población se eligen solo 14 diputados. Estas distinciones no responden a representatividad sino que se establecieron de manera arbitraria buscando una mayor representación de los grupos pro-régimen que elegirían a sus candidatos durante la dictadura.

Por su parte, el que las representatividad y proporcionalidad estén hábilmente manipuladas, deja en exclusión al propio elector evitando su real participación, ya que se ha llegado a predecir con gran exactitud los resultados de las elecciones, con lo cual el candidato se negocia antes de los comicios y casi se da la relación de "candidato propuesto-candidato electo", quedando la ciudadanía reducida a la calidad de ratificador de las propuestas de los partidos políticos. ${ }^{513}$

Analizándolo de esta manera el Sistema Binominal no se ha cambiado porque no es un mal modelo; de hecho es muy funcional al "juego" de los partidos" independiente de su posición ideológica, especialmente si está dentro de las dos grande colaciones. Puede que haya generado una sobre-representación de los partidos de derecha -como lo quería el dictador y sus aliados al crear el sistema- pero esto también ha favorecido a los partidos de centro-izquierda agrupados

\footnotetext{
${ }^{513}$ ARRIAGADA, Genaro. Op. Cit. 1997. p. 68
} 
en la Concertación de Partidos por la Democracia -actual Nueva Mayoría-, manteniéndoles el en poder por casi 20 años. Como señala Carey:

"En Chile, se critica con frecuencia al sistema electoral binominal, porque concede una ventaja indebida a la coalición electoral situada en segunda posición -que, desde 1989, ha sido la de derecha-, al otorgarle la misma representación que a la lista más votada en casi todas las circunscripciones, a pesar que la derecha va siempre por detrás de la Concertación en porcentaje de votos. De hecho, puede que la expectativa de que el sistema $\mathrm{M}=2$ tuviera esa consecuencia fuese uno de los principales alicientes para quienes lo concibieron y, en sentido estricto, ha resultado beneficioso para la derecha. La alianza de derecha ha estado más sobre-representada que ningún otro sector político en las elecciones legislativas, obteniendo un promedio de número de escaños un 4,6\% superior a su cuota de sufragios. Sin embargo, la Concertación ha obtenido un promedio de número de escaños un $4,4 \%$ mayor que su propia cuota de sufragios, de manera que la diferencia agregada entre la bonificación obtenida por la derecha y la de la Concertación es mínima (...) Es evidente que tanto la Concertación como la derecha se han beneficiado del sistema $\mathrm{M}=2$, y ambas más o menos en igual medida, a costa de todas las demás listas."

Queda en claro, entonces, que durante los años en que estuvo en vigor el sistema binominal cumplió el papel para el que fue establecido: "proteger" la democracia, evitar el caos y mantener el "orden”. De lo cual salió favorecida la Coalición de oposición al Régimen durante casi veinte años, ya que aseguraba sus cupos en el congreso y daba tranquilidad a la hora de mantenerse en el poder sin contratiempos. Por tanto, los beneficiados por el sistema han sido los partidos y los perdedores, los ciudadanos, quienes sólo son observadores del juego de pactos y acuerdos previos a la elecciones. Así se ha visto durante años trastocado el derecho de cada ciudadano a

\footnotetext{
${ }^{514}$ CAREY, John M. Op. Cit. 2006. pp. 226-235.
} 
ser representado por quienes ganan fehacientemente -al establecerse listas, que son previamente negociadas- o a tener un voto de igual valor que otro ciudadano, debido a la manipulación de las circunscripciones y distritos.

Se espera que el nuevo sistema establecido este año 2015, que incluye la incorporación de más parlamentarios, dibuje un nuevo mapa electoral (con nuevos distritos y circunscripciones), mayor representación con una ley de cuota que favorecerá el género y con medidas que apuntan a la creación de nuevos partidos. ${ }^{515}$ Las respuestas sobre estos avances no las tendremos aún, pero sí sabemos que la Historia quedó marcada por un sistema electoral que mantuvo la democracia a la chilena al servicio del régimen en pos del orden que tanto añoraba el dictador. ${ }^{516}$

\footnotetext{
${ }^{515}$ BCN. "Nuevo sistema electoral para elecciones parlamentarias (Fin del sistema binominal)" [En línea] Ley fácil. Biblioteca del Congreso de Chile. [fecha de consulta 13 de junio del 2015]. Disponible en internet: $<\underline{\text { http://www.bcn.cl/leyfacil/recurso/nuevo-sistema-electoral-para-elecciones-parlamentarias-(fin-del-sistema-binominal)> }}$ ${ }^{516}$ HUNEEUS Carlos. El Régimen de Pinochet. Editorial Sudamericana. Chile. 2000 y HUNEEUS, Carlos. La democracia semisoberana: Chile después de Pinochet. Editorial Taurus. Chile. 2014.
} 


\section{4.-LA DERECHA VUELVE AL PODER:}

\section{ENCARNAR EL LEGADO O ROMPERLO.}

Parece fácil referirse a la derecha y su reciente llegada al poder, entender su pensamiento ya resulta complejo y su éxito -o fracaso, dependiendo del punto de vista que se mire- está más bien en lograr que la centro izquierda se sumara a los postulados de libertad económica y actuará dentro del capitalismo a partir de los años 90 como fueron postulando desde los años 60 y 70 en contraposición al modelo de intervención estatal. ${ }^{517}$

Sus postulados tampoco son fáciles de seguir y en el último año se ha iniciado una especie de crisis, ${ }^{518}$ reescribiendo sus orígenes al tratar de alejarse cada vez más del Pinochetismo ${ }^{519}$ o surgiendo nuevas escisiones. Con todo, la llegada de Piñera, militante del partido Renovación Nacional (RN, de derecha, más "moderado" que la UDI (Unión Demócrata Independiente), el otro partido de derecha, flagrantemente Pinochetista desde sus orígenes ${ }^{520}$ - marcará un punto de inflexión en la historia política reciente y dará señales interesantes de analizar acerca de esta

\footnotetext{
${ }^{517}$ CORREA, Sofía. Con las Riendas del Poder. La Derecha Chilena en el Siglo XX. Editorial Sudamericana. Chile. 2005.

${ }^{518}$ HERRERA, Hugo. La derecha en la crisis del bicentenario. Ediciones UDP. Chile. 2015.

${ }^{519}$ LA NACION. “Jaime Bellolio, el UDI que se desmarcó del minuto de silencio a Pinochet.” [En línea] 10 de diciembre del 2014. [fecha de consulta 12 de marzo del 2015]. Disponible en internet: < http://www.lanacion.cl/noticias/pais/politica/jaimebellolio-el-udi-que-se-desmarco-del-minuto-de-silencio-a-pinochet/2014-12-10/130326.html >

520 "Después de casi dos meses de polémica, el tribunal de disciplina de RN expulsó a Guzmán del partido, y éste se retiró con dirigentes y militantes afines para formar la "UDI por el sí" (en el plebiscito). La división, concretada la semana pasada, se debió a diferencias sobre cómo enfrentar la sucesión presidencial. Mientras Guzmán pide un sí incondicional a Pinochet como candidato en el plebiscito, Jarpa, aliado con el político de derecha Andrés Allamand, que hace dos años firmó el acuerdo nacional para la transición a la democracia, ofrece un sí, pero al candidato que designen los comandantes en jefe, y estima que Pinochet tendría más posibilidades en una elección abierta. Esta diferencia fue suficiente para la división” EN: EL PAIÍS. "Ruptura en la derecha chilena pinochetista" [En línea]. 25 de abril de 1988. [fecha de consulta 12 de marzo del 2015]. Disponible en internet: < http://elpais.com/diario/1988/04/25/internacional/577922411 850215.html>
} 
vía chilena a la democracia que ve en la derecha la salida a las promesas no cumplidas del centro izquierda. Sin embargo ¿Qué derecha llega al poder en 2009? ¿Llega la derecha al poder o Sebastián Piñera es un caso excepcional?

\section{1.- PIÑERA, EL POLÍTICO Y ECONOMISTA PRÓFUGO.}

La historia del ex presidente no está exenta de polémicas y de hecho será justamente su trayectoria previa a la elecciones el lastre más difícil de llevar para poder triunfar en la urnas el año 2009, aunque paradójicamente también su mayor fortaleza. Un hombre cercano a la derecha, pero lejos del estereotipo de hombre de derecha: él será el arquetipo de "self-made man."

\subsection{1.- Trayectoria empresarial.}

Una biografía general de su trayectoria nos da indicaciones claras acerca de quién fue y es Piñera en la política nacional. Sebastián Piñera -nacido en 1949- es hijo de Magdalena Echenique Rozas ${ }^{521}$ y José Piñera Carvallo, quien fuese embajador en Bélgica (1965-1966), en Estados Unidos ante la ONU (1966-1970) -todos bajo el Gobierno democratacristiano- y ocupara diversos cargos en la CORFO (corporación de Fomento). De esta manera, entre el apellido aristócrata de su madre y los cargos de su padre, lo sitúan en un hogar privilegiado para el Chile de la época. Entre sus familiares, como consta en la reseña biográfica del Congreso

\footnotetext{
521 "Fue conocida la historia cuando en una visita presidencial le cuenta a Ollanta Humala que él es descendiente del emperador inca Huayna Capac. Haciendo notar como su descendencia estaba vinculada a la alta alcurnia que pobló el su de américa.” Véase: ELQUINTOPODER. "Los secretos del árbol genealógico de Piñera” [En línea] 16 de junio del 2011. [fecha de consulta 12 de marzo del 2015]. Disponible en internet: $<$ http://www.elquintopoder.cl/politica/los-secretos-del-arbol-genealogico-depinera/>
} 
Nacional, hay un sobrino monseñor, arzobispo, y presidente de la Conferencia Episcopal de Chile (1984-1987), don Bernardino Piñera Carvallo. Por lo que no sólo está ligado al poder político y oligárquico sino también al religioso, tan importante en Chile. ${ }^{522}$

Piñera está casado con Cecilia Morel Montes, orientadora familiar y juvenil del Instituto Carlos Casanueva y Licenciada en Familia y Relaciones Humanas de la Universidad Mayor y tiene . cuatro hijos: Magdalena (profesora de Historia); Cecilia (médico); Sebastián (ingeniero comercial; y Cristóbal (psicólogo).

Sebastián no sólo se ligó al poder por su padre, también por su hermano y primo, fieles seguidores de Pinochet. Su hermano José Piñera Echeñique fue ministro de Trabajo y Previsión Social y de Minería durante en el gobierno de Augusto Pinochet y candidato independiente a la Presidencia de la República, en 1993. Su primo Andrés Chadwick es militante de la Unión Democrática Independiente, partido fundado por Jaime Guzmán y fue parte posteriormente del equipo de Piñera en el gobierno. Su otro hermano, Pablo Piñera, fue subsecretario de Hacienda durante el gobierno de Patricio Aylwin, consejero del Banco Central, director ejecutivo de Televisión Nacional de Chile, director general de Administración y Finanzas del Ministerio de Relaciones Exteriores y gerente general de Banco-Estado durante el gobierno de Michelle Bachelet. La veta política familiar es transversal.

Piñera estudió en uno de los colegios de la élite santiaguina, el Verbo Divino y en la estancia en el extranjero de su padre lo hizo en Bruselas. Sus estudios universitarios los realizó también en la Universidad preferida por la élite en esos años, la Pontificia Universidad Católica de Chile, en especial en un lugar que alcanzará fama internacional con sus vínculos con Chicago, como

\footnotetext{
${ }^{522}$ CONGRESO NACIONAL. "Reseña Biográfica Parlamentaria: Sebastián Piñera Echenique”. [En línea] [fecha de consulta 12 de marzo del 2015]. Disponible en internet:
} $<\underline{\text { http:/historiapolitica.bcn.cl/resenas parlamentarias/wiki/Sebastián Piñera Echenique }>}$ 
es la Facultad de Economía. En 1971 se tituló como mejor alumno en ingeniería comercial. El año del Golpe de Estado viajó a Estados Unidos para continuar sus estudios de posgrado en el área económica en la Universidad de Harvard, estudiando temas vinculados a la Economía de la educación.

Profesionalmente se ha desempañado tanto como catedrático -en la misma facultad donde egresó y otras más- y como empresario. A mediados de los setenta se desempeñó como consultor del Banco Interamericano de Desarrollo y del Banco Mundial. Incluso durante el año 1976, trabajó en la CEPAL en un proyecto sobre pobreza en América Latina.

En 1977 ingresa a los negocios como miembro de Ingeniería Financiera y Comercial Ltda., empresa que realizaba asesorías financieras y evaluación de proyectos. Posteriormente irá ampliando sus negocios al sector inmobiliario, la banca, librerías, empresa postales, etc. Al año siguiente asumirá la gerencia general del Banco de Talca. Desde los años ochenta se vinculará a la empresa Citicorp Chile, un banco de inversión formado por Citibank y el Banco Santiago. Y en este mismo periodo iniciará su periodo más fructífero en relación a los negocios cuando crea Bancard S.A., sociedad que trajo a Chile las tarjetas de crédito Visa y MasterCard, encargada además de la emisión de tarjetas.

Su negocio se consolidó en los años noventa, mediante la adquisición de acciones de empresas inmobiliarias, telecomunicaciones (ENTEL), farmacéutica (FASA), de energía (Colbún) y de transporte, como será la compra de un porcentaje (16\%) de acciones de aerolíneas LAN Chile. Se expande también al negocio minero, compra de terrenos en la zona central y sur. Como si esto fuera poco, inició el proyecto de conservación y ecoturismo denominado "Parque Tantauco" tras adquirir 115.000 hectáreas de bosque nativo en la isla Grande de Chiloé. El año 2005, compró el canal de televisión Chile-Visión, el tercero más grande de Chile e ingresó al 
negocio del fútbol comprando acciones de Colo-Colo y Azul, los dos equipos más grandes del país y rivales.

Con estas y otras inversiones más, la revista Forbes lo sitúa actualmente como uno de los hombres más ricos de Latinoamérica con un patrimonio de 735 billones de dólares en su haber. $^{523}$

\subsection{2.- Trayectoria política.}

Los recuerdos que se tiene de Piñera y su vínculo con la política antes de 1990 es el de una persona cercana a la Democracia Cristiana, ${ }^{524}$ pero que nunca se decidió por su militancia porque económicamente no se sentía acorde a sus directrices.

Con el plebiscito de 1988 se marcará su definición política, señalando públicamente que se inclina por la opción del NO a Pinochet. Y aunque no se define inicialmente por el centro o por la derecha $(\mathrm{RN})$, su vinculación con la derecha pinochetista será estrecha -participará en las protestas contra el apresamiento de Pinochet en Londres y destacará su labor en economía- al punto que será jefe de campaña del candidato de la UDI, Hernán Büchi, ex ministro del dictador, por un breve momento, lo que terminará por acercarlo a la derecha. En este mismo periodo lanza su campaña como senador independiente cercano a RN para la Región Metropolitana, donde ganó (1990-1998) y terminó por inscribirse definitivamente en el partido de Renovación Nacional (RN, de derecha).

\footnotetext{
${ }^{523}$ Se puede consultar el perfil de S. Piñera en Forbes en: http://www.forbes.com/profile/sebastian-pinera/ [En línea] [fecha de consulta 12 de marzo del 2015].

${ }^{524}$ ALLAMAND, Andrés. La Travesía Del Desierto. Editorial Aguilar. Chile. 1999
} 
Este triunfo le llevará posteriormente (1992) a ser proclamado precandidato de Renovación Nacional para las Elecciones Presidenciales de 1993, aspiración que se verá frustrada por uno de los más grandes impasses de la política en democracia, conocida como el "kiotazo" o el "piñeragate", ${ }^{525}$ debido a que se expone una grabación en televisión en vivo donde se le escucha intentando hacer presión sobre Evelyn Matthei -compañera de partido y precandidata presidencial paralela-. Debido a esto ambos renuncian a la carrera presidencial.

Pese a este turbio caso, no deja de lado su ambición por ser presidente y en 1999 es proclamado precandidato en representación de Renovación Nacional (RN), lanzando una candidatura paralela al representante de la Unión Demócrata Independiente (UDI), Joaquín Lavín. Pero viendo las bajas posibilidades que tenía se retira de la carrera y apoya al candidato de UDI. Pese a esto, el año 2001 vuelve a ser electo presidente de Renovación Nacional, aunque ese mismo año desistió presentarse al senado. En 2005 vuelve a ser precandidato presidencial por RN. En esta elección presidencial logra ganar Michelle Bachelet en segunda vuelta. Sin embargo, será el año 2009 el que logra finalmente conquistar el poder, como candidato de la Coalición de Derecha (Coalición “por el cambio”), ganándole en segunda vuelta al candidato de centro izquierda y ex presidente Eduardo Frei Ruiz-Tagle. Ejercerá el cargo de presidente hasta marzo

\footnotetext{
${ }^{525}$ Se denomina "Kiotazo" por la marca en que se reproduce la grabación en televisión y "Piñeragate" como un juego de palabras que hace referencia al "watergate". Se puede ver la grabación completa del acontecimiento en: "Muy bien guardada en una bodega de vinos en Viluco, mantuvo Francisco Ignacio Ossa la cinta que el capitán Diez les entregó a él y a Evelyn Matthei, la mañana del 23 de agosto en el [Restaurante] Coppelia. La que sigue a continuación es la grabación de parte del diálogo telefónico [a través de teléfonos celulares]-entre Sebastián Piñera y Pedro Pablo Díaz- que el militar [Capitán Fernando Diez] proporcionó a la diputada y su acompañante y que dura cerca de 4 minutos. Este diálogo fue cortado por Ossa hasta dejarlo en los 2 minutos y 32 segundos que se dieron a conocer en [el programa de televisión] "A eso de..". Según un informe de la Compañía de Teléfonos [de Chile], la conversación entre el senador y su amigo tuvo una duración total de 8 minutos y 30 segundos. Existe la hipótesis de que el diálogo que sigue fue editado por alguien, quien habría realizado cortes e intercalado frases, con la intención de dejar un compendio de garabatos y sin sentidos. El orden de la conversación está alterado.”En: "La grabación de Sebastián Piñera (Kiotazo), el Piñeragate de 1992". < https://www.youtube.com/watch?v=8W ZhpQAx w $>[$ En línea] [fecha de consulta 12 de marzo del 2015].
} 
del año 2014, lo que marcará el retorno de la derecha al poder después de varias décadas "fuera" del poder, por lo menos del que depende del voto ciudadano. ${ }^{526}$

\subsection{2.- Piñera prófugo: costos y beneficios de la política y el dinero.}

Con esta biografía casi impecable, parece claro que sea un verdadero ejemplo para el país. Con características que lo hacen ser ejemplo para generaciones: emprendedor, luchador de los derechos ciudadanos y contrario al Régimen. Un liberal y demócrata que de la mano del esfuerzo ha llegado lejos.

Sin embargo esto no ha sido así, sino que figura en la lista de los políticos que menos popularidad llegó a tener en medio de su gobierno, ${ }^{527}$ superando incluso la de Allende y sólo superado en la actualidad por Bachelet. Esto porque en su historial también se cuentan relatos terribles de abuso de poder, corrupción y "juego sucio” político. El verdadero Piñera, el que rechazaba la gente, era el de la impunidad del que se enriqueció en dictadura a costa de información privilegiada y de favores una sombra de abusos que ni en pleno mandato presidencial le abandonó.

Ya mencionamos el complejo caso en el que se vio involucrado en plena campaña como precandidato presidencial con una de sus “compañeras" de partido. En aquella ocasión Piñera se presentó a la ciudadanía como un competidor voraz, capaz de cualquier cosa por ganar, incluso de presionar mediante el engaño. Este acontecimiento puso de manifiesto otro conflicto, el de

\footnotetext{
${ }^{526}$ Se puede leer una biografía autorizada en: DAZA, Loreto y DE SOLAR, Bernardita. Piñera. Historia de ascenso. Editorial Debate. Chile. 2011.

${ }^{527}$ EMOL. "Encuesta CERC refleja nueva caída en popularidad de Presidente Piñera”. [En línea] 27 de septiembre de 2011 [fecha de consulta 12 de marzo del 2015]. Disponible en internet: $<\underline{\text { http://www.emol.com/noticias/nacional/2011/09/27/505240/encuesta-cerc-refleja-nueva-caida-de-popularidad-del- }}$ presidente.html >
} 
Piñera empresario, ya que en esa ocasión será el propio Ricardo Claro --su ex amigo, empresario y dueño del canal en que se exhibe la acusación- el que le acusará ante las cámaras. No será un periodista quien lo pone en la tribuna, sino otro empresario ¿Por qué? Según se ha especulado, lo de Ricardo Claro será la venganza contra la traición cometida por Piñera años atrás en un negocio donde este último era gerente general. ${ }^{528}$

Este no será el único problema en que se verá envuelto Piñera por temas financieros y políticos. Uno de los casos más graves se dio tempranamente en 1982 cuando se acusó a Piñera y sus socios por infracción a la ley de bancos e incluso aquel fue declarado reo; de lo cual se salvó huyendo de la justicia y desapareciendo por un tiempo, hasta que se revirtió la situación. La acusación señalaba que Piñera y sus socios -a través del Banco de Talca- habían prestado más de 200 millones de dólares a sociedades relacionadas que no necesariamente tenían existencia legal y sin ningún tipo de garantía, además de transgredir otras normativas sobre límite de préstamos. Como se señala en una de las investigaciones del caso, "según reconocieron los propios involucrados, estos créditos a empresas relacionadas estaban destinados a comprar con ese dinero acciones del propio banco." ${ }^{, 529}$ Sin embargo, en un caso con tanta información sobre el delito y pese a haber estado prófugo de la justicia, fue declarado inocente gracias a la ayuda y presión de personas cercanas al Régimen, donde incluso la propia Ministra de Justicia Mónica Madariaga declaró haber intervenido a su favor y el juez Luis Correa Bulo que llevaba la causa reconoció presiones recibidas por la dictadura. ${ }^{530}$

\footnotetext{
${ }^{528}$ THE CLINIC. "El vengativo señor Claro" [En línea] 28 de octubre de 2008 [fecha de consulta 12 de marzo del 2015]. Disponible en internet: < http://www.theclinic.cl/2008/10/28/el-vengativo-senor-claro/>

${ }^{529}$ LA NACION. "Inversionista en fuga: cuando Piñera arrancó de la justicia” [En línea] 19 de abril de 2009 [fecha de consulta 12 de marzo del 2015]. Disponible internet:
} <http://www.lanacion.cl/noticias/site/artic/20090418/pags/20090418205903.html >

${ }^{530}$ EL MOSTRADOR. "Exclusivo: todas las verdades del expediente de la quiebra del Banco de Talca" [En línea] 19 de julio de 2009 [fecha de consulta 12 de abril del 2014]. Disponible en internet: < http://www.elmostrador.cl/noticias/pais/2009/07/29/exclusivo-todas-las-verdades-del-expediente-de-la-quiebra-del-banco-de$\underline{\text { talca/s }}$ 
Se podría pensar que después de esta serie de casos no habría ninguno más. Pero la ambición del empresario era insaciable y en 1997 se vería involucrado en lo que se conocerá como el “Caso Chispas" o el "Negocio del Siglo". Esta vez y ocupaba una plaza de senador cuando se vio envuelto en un conflicto de intereses: consiguió que Endesa-España le pagara por sus acciones de Enersis un precio mayor que el que se ofreció a otros accionistas que se encontraban en las mismas condiciones que él, por lo que fue acusado de hacer negocios con información privilegiada. $^{531}$

Increíblemente, no sería ese tampoco el último caso en que se verá envuelto: le seguirá el caso de Colusión de farmacias (FASA) en relación con los precios de los medicamentos el año 2008, lo que terminó con el reconocimiento de la ilegalidad y el pago de fuertes multas. Piñera era dueño de acciones de una de las farmacias (Ahumada) involucradas, cuando se le consultó señaló que no "sabía que las tenía”.532 Últimamente se le ha visto envuelto en uno de los casos más dramáticos de financiamiento de la política y su vínculo con la empresa, conocido como Caso Soquimich. .533

Como se puede observar, las vidas ejemplares del Piñera "Político y Empresario" están teñidas y manchadas por casos de oscuro origen. A final de cuentas, Piñera no sólo era un hombre de derecha, sino que pertenecía a la "nueva derecha", aquella que aprovechó los vínculos con la Dictadura para enriquecerse y dar el salto para acceder al poder.

\footnotetext{
${ }^{531}$ COOPERATIVA. "EL caso Chispas" [En línea] 12 de enero de 2006 [fecha de consulta 12 de abril del 2014]. Disponible en internet: < http://www.cooperativa.cl/noticias/pais/sebastian-pinera/el-caso-chispas/2006-01-12/080740.html>

${ }^{532}$ EMOL. "Piñera y sus acciones en FASA: "No sabía que las tenía" [En línea] 27 de marzo del 2009 [fecha de consulta 12 de abril del 2014]. Disponible en internet: $<$ http://www.emol.com/noticias/nacional/detalle/detallenoticias.asp?idnoticia=350965>

${ }^{533}$ CIPER CHILE. "Hijos de Piñera y de Pizarro y sur consultores. Los nombres y conexiones políticas detrás de las empresas que facturaron a SQM" [En línea] 2 de abril del 2015. [fecha de consulta 12 de abril del 2014]. Disponible en internet: < http://ciperchile.cl/2015/04/02/los-nombres-y-conexiones-politicas-detras-de-las-empresas-que-facturaron-a-sqm/>
} 


\section{2.- LA DERECHA EN EL PODER O EL EXITOSO EMPRESARIO DE "CLASE} MEDIA."

Después de veinte años alejada del poder la derecha retornó al gobierno de la mano de Sebastián Piñera, personaje al que hemos descrito en su complejidad y contradicciones, quien supo canalizar el malestar que se tenía por promesas incumplidas del centro izquierda y se proyectó como una derecha "nueva", lo cual le traería beneficios y problemas.

A continuación describiremos someramente la coyuntura que atravesaba el país para comprender mejor las circunstancias del cambio político. El gobierno precedente, el primero de Michelle Bachelet, debió enfrentar conflictos asociados a la educación con el inicio de las grandes movilizaciones estudiantiles y la conocida revolución "pingüina,"; 534 movilizaciones en el sector de la salud, producto del brote de influenza AH1N1 que fue en general bien controlado y la controversia ocasionada por la píldora del "día después", que fue aprobada en el Congreso tras un largo debate.

El conflicto educativo, a diferencia del sanitario, escaló rápidamente, al punto que hacia el año 2009 se había ampliado a los docentes, lo que desembocó en un paro de casi treinta días durante el mes de octubre. Estas manifestaciones incluso retrasaron la aprobación del presupuesto de educación para el año 2010. Por otra parte, estallaron conflictos sociales en el sur, producto del asesinato de un comunero mapuche a manos de un carabinero. La situación tomó tintes dramáticos cuando la acusación demostró que la muerte no fue en defensa propia por parte de la policía sino que la víctima habría sido muerto de un disparo por la espalda.

\footnotetext{
${ }^{534}$ GUTIÉRREZ, Tamara y CAVIEDES, Cristina. Revolución Pingüina: la primera gran movilización del siglo XXI en Chile. Editorial Ayun, Chile. 2006; CEP. “Tema especial: Evaluación del Conflicto Estudiantil” . Estudio Nacional de Opinión Pública, $\mathrm{N}^{\circ}$ 52, Chile, junio-julio 2006.
} 
El tema se espesó tras un intento del gobierno por mejorar la situación, siguiendo lo propuesto por la OIT en el Convenio 169, para lo cual se envió un proyecto de ley que crearía una nueva situación jurídica para el pueblo mapuche; sin embargo, el proyecto fue rechazado porque lo líderes del pueblo originario argumentaron que no habían sido consultados incumpliendo el gobierno la letra del propio Convenio de la OIT.

En economía el año 2009 no fue particularmente positivo. El producto interno bruto cayó 1,5\% respecto del año anterior, mientras la demanda interna y las exportaciones de bienes y servicios también experimentaron contracciones. Por lo mismo fue necesario fortalecer la Ley de seguro de cesantía, que pasó de cubrir a 50 mil a 250 mil personas. En materia internacional tampoco fue un año tan provechoso. La presidenta Bachelet fue criticada por su viaje a Cuba, primer viaje de un jefe de Estado a ese país después de Allende. Chile a su vez fue demandado ante la Haya por Perú, cuestión agravada por un ejercicio militar chileno realizado en la frontera con el país vecino. Pese a lo referido no todo fue tan negativo ya que en 2009 se invitó a Chile a ser parte de la OCDE, lo que provocó el inicio de un proceso de mejoras como requerimiento básico para pertenecer a esta "liga" de países.

Con este escenario de fuerte tensión que habría trocado el éxito inicial de Michelle Bachelet en un fracaso de la Concertación, la coalición de centro izquierda se vio desafiada políticamente por un adversario que apostaba al cambio. En la competencia del año 2009 se presentarían cuatro candidatos: Jorge Arrate, por el partido Comunista, Eduardo Frei, ex presidente de la Concertación, Marcos Enríquez-Ominami, ex miembro de la Concertación y uno de los más grandes críticos de la misma y Sebastián Piñera, al frente de la Alianza por Chile -luego renombrada como Coalición por el Cambio-, conglomerado de la derecha . Los resultados fueron clarísimos: Jorge Arrate cosechó el 6,21\% de los sufragios; Marco Enríquez-Ominami 
el 20,13\%; Sebastián Piñera se alzó con el 44,05\% y Eduardo Frei obtuvo el 29,6\%; de esta manera, Piñera pasó a la segunda vuelta junto a Frei y terminó alzándose con el triunfo.

El eslogan utilizado por Piñera será “Así queremos Chile”,donde propondrá los pilares para el cambio desarrollados por un conjunto de expertos que denominó Grupo “Tantauco,” el “think tank" de la derecha que contando con más de 1200 profesionales, le vino ofreciendo ideas desde el año 2006 para lo que sería el nuevo Gobierno . Este grupo se mantendrá en el poder durante el todo el mandato de Piñera y ocupará cargos relevantes: por ejemplo, María Luisa Brahm será asesora de Piñera en La Moneda; el ministro de la Segpres, Cristián Larroulet; el de Hacienda, Felipe Larraín; otros colaboradores muy próximos fueron el senador por Renovación Nacional (RN), Alberto Espina, Felipe Larraín, Felipe Morandé -quien ocupó el Ministerio de Obras Públicas-, Harald Beyer -quien fue Ministro de Educación- y Rodrigo Hinzpeter que ocuparía el Ministerio del Interior. Pero el grupo más amplio se desplegó también en la segunda línea política y particularmente técnica. ${ }^{535}$

El grupo asesor y el propio Piñera reforzaron la idea que apuntaba a una especie de "frenazo" del desarrollo, una especie de crisis de ideas que paralizaba el centro izquierda y era necesario cambiar, como señala enfáticamente en su programa:

\begin{abstract}
"Hace más de 100 años, cuando Chile se aprontaba a celebrar su primer Centenario de vida independiente, Enrique Mac Iver, desde las tribunas del Ateneo de Santiago, pronunció un discurso que quedó grabado a fuego en nuestra historia. El destacado político denunciaba entonces: «Me parece que no somos felices»; y agregaba: «La holgura se ha trocado en estrechez; la energía en laxitud; la confianza en temor; las expectativas en decepciones».
\end{abstract}

\footnotetext{
${ }^{535}$ CAMBIO 21. “¿Qué fue de los Tantauco? El “Think tank” de Piñera que elaboró los famosos pendrive que se le entregó a cada ministro hoy no se encuentran en ninguna parte. Como que no hubieran existido nunca" [En línea] 5 de agosto del 2011. [fecha de consulta 12 de abril del 2014]. Disponible en internet: $<\underline{\text { http://www.cambio21.cl/cambio21/site/artic/20110805/pags/20110805190340.html> }}$
} 
¿Por qué Chile parecía haberse detenido? ¿Y qué había atajado el poderoso vuelo que había tomado la República?, se preguntaba. Poco más de un siglo después, y a punto de celebrar el Bicentenario, nos asaltan interrogantes similares: ¿Qué ha sucedido con la promesa de llegar al año 2010 como un país desarrollado y sin pobreza? ¿Dónde está el crecimiento sólido y las promesas de promover la innovación y el emprendimiento? ¿Qué ha ocurrido en Chile que los delincuentes nos atemorizan día a día arrebatándonos calles, plazas y parques? ¿Dónde ha quedado nuestra admirada tradición de eficiencia y probidad en el servicio público? ¿Cuándo las envenenó la incompetencia y la corrupción?¿Cuándo y por qué Chile perdió el liderazgo? ¿Por qué volvemos a tener un desempleo que afecta a casi 750.000 compatriotas?" ${ }^{536}$

El discurso será en este tenor: el bicentenario nos sorprende como un país que no ha terminado por desarrollarse, con limitaciones y tareas incumplidas. Así, la derecha podría concretar de una vez por todas el sueño de Chile de alcanzar a los países más desarrollados. Además, la promesa del centro izquierda ha sido incumplida y su proyecto político está agotado:

"La respuesta a todas estas interrogantes es una sola. La Concertación, que nos ha gobernado en los últimos 20 años se agotó, perdió las ideas, la fuerza y la voluntad. La Concertación de hoy no es la de ayer. La Concertación de ayer tenía una misión, tenía ideales, principios, proyectos y unidad. Era una opción válida y sin duda cumplió un rol importante. Sin embargo, los 20 años en el poder le arrugaron el rostro y el alma. Donde hubo una misión, hoy solo queda la voluntad de aferrarse al poder. Donde había proyectos, hoy campea la improvisación. Donde había principios, hoy prevalece el oportunismo.

Basta mirar cómo se comportan muchos de sus integrantes. Los que eran demócratas no trepidan en pactar con el comunismo. Los que abrazaban los valores del humanismo

\footnotetext{
${ }^{536}$ PIÑERA, Sebastián. Programa de Gobierno para el cambio, el futuro y la esperanza. 2010-2014. Alianza por Chile. Chile. 2009. p.3
} 
cristiano hoy le abren solapadamente las puertas al aborto. Los que lucharon por elecciones libres son ahora los campeones de la intervención electoral. Nos prometieron un sistema moderno de transporte público y nos dieron el Transantiago. Inauguraron con bombos y platillos un tren hasta Puerto Montt y nos legaron un tren fantasma. Inauguraron hospitales en que hasta los enfermos eran de utilería. Cuando construyeron puentes se cayeron y cuando quisieron botarlos no pudieron. Por estas razones, son millones las chilenas y chilenos que, cansados de un Gobierno con fatiga de material y promesas incumplidas, están optando por un cambio. Hay razones para agradecer a la Concertación lo que hizo por Chile en el pasado, pero ahora los chilenos desean emprender un rumbo nuevo." 537

Se trata en el fondo una serie de Gobiernos ineficientes, que atentan contra los principios fundamentales de la moralidad, cercanos al comunismo - aún discursivamente la fuente de todos los males- y donde la política de los "arreglos" y la improvisación ha hecho daño al país. Pese a la aún vigente demonización de la izquierda por parte de la derecha más tradicional, en quien se sostendrá este cambio será principalmente en la figura de Sebastián Piñera. Será él la persona que buscará encarnar un nuevo Chile, un político que pese a ser de derecha no apoyó a la dictadura, sino que dijo "No" a Pinochet; hijo de una familia esforzada como la mayoría de los chilenos y que gracias a ese mismo esfuerzo ha podido tener un "buen pasar" económico. 538 En otras palabras, discursivamente Piñera busca encarnar a la "clase media" chilena, la que con esfuerzo había podido surgir y quería mantener y "proteger" su "buen pasar." Un chileno promedio "moderado" políticamente, mal que mal su padre -como destacaba siempre el

\footnotetext{
${ }^{537}$ PIÑERA, Sebastián. Op. Cit. 2009. p. 4

${ }^{538}$ CLARIN. "Sebastián Piñera: cuna de clase media y una fortuna de US\$1.200 millones” [En línea] 18 de enero del 2010. [fecha de consulta 12 de abril del 2014]. Disponible en internet: < http://www.ieco.clarin.com/economia/Sebastian-millonesfortuna-clase-media 0 191980815.html>
} 
aspirante a presidente, era un demócrata cristiano. ${ }^{539}$ En este sentido, junto al malestar que sentía la gente por los Gobiernos de la Concertación y sus veinte años en el poder, aparece un candidato que representaba el Chile que siempre se ha querido, el del hombre exitoso, emprendedor y que podría ser capaz de solucionar las cosas; el candidato que podría- de la mano de la tecnocracia y la eficiencia llevar a Chile al desarrollo. Visto así, Piñera no era de derecha, aunque lo fuera: él era el chileno que quiere ascender socialmente y que entra en política porque la cosa no "da para más". Piñera era un empresario de esos que tienen concentrado el poder económico en Chile, pero no lo representaba porque tenía un discurso de esfuerzo que daba la impresión que no tenía tanto dinero y ocultaba cada vez que podía los problemas que se echó encima por sus negocios "turbios" de años anteriores.

En definitiva, en apariencia no triunfaba la derecha el año 2009 sino más bien se dejaba atrás la ineficiencia y el "cuoteo" político de la Concertación, por un Gobierno que -personalizado en Piñera- hacía bien las cosas: el "Chilean way" como bautizará su política, tras el triunfo sobre la naturaleza logrado en el rescate de los 33 mineros.

\section{3.- "CHILEAN WAY" O EL "PIÑERA WAY"}

En el programa de Gobierno Piñera deja claro que su liderazgo será distinto, alejado de la política tradicional:

“El cambio al que aspiramos va mucho más allá del reemplazo en el Gobierno de un grupo político por otro y que todo siga igual, como en «El Gatopardo» de Lampedusa. Postulamos cambiar de verdad la forma de gobernar Chile. Veamos en qué consiste tal

\footnotetext{
${ }^{539}$ EL MUNDO. "Piñera un hombre forjado a si mismo.” [En línea] 11 de marzo del 2010. [fecha de consulta 12 de abril del 2014]. Disponible en internet: < $\underline{\text { http://archivo.eluniversal.com.mx/notas/665339.html }>}$
} 
cambio. En primer lugar, en la forma de ejercer la Presidencia de la República. Los problemas y desafíos de hoy exigen un Presidente todo terreno, un Presidente las 24 horas del día por 7 días a la semana. Que se arremangue las mangas, se haga cargo de los problemas y lidere las soluciones. En el Gobierno de la Coalición por el Cambio, por ejemplo, la responsabilidad de ganarle la batalla a la delincuencia no será delegada en un subsecretario, sino que será asumida por el propio Presidente de la República." ${ }^{450}$

Esta especie de imagen del presidente ejecutivo y ejecutor de las políticas, del 24/7 o del Gobierno que soluciona los problemas rápidamente, le pasará factura desde el inicio de su gestión. No sólo porque su discurso casi "mesiánico" e hiperbólico no se corresponde con la realidad sino porque será la propia realidad la encargada de mostrarle que gobernar un país no es lo mismo que una empresa, que el pragmatismo no es suficiente para tener satisfechos a sus compañeros de partido y que la carga histórica de la derecha y su propio vínculo con la empresa privada le traerán constantes dificultades a su quehacer. En el fondo, no basta con proponer un "Chilean way" si éste se asemeja demasiado a un "Piñera way." El resultado político final será que Piñera terminará por ser uno de los factores de quiebre al interior de la derecha y "pavimentará el piso" para el retorno de la Concertación, esta vez denominada "Nueva mayoría" con Bachelet a la cabeza.

Una de las primeras frases dichas por Sebastián Piñera estando ya en el gobierno fue: “(...) en 20 días hemos avanzado más que otros en 20 años", 541 con lo que inicia un Gobierno que se proponía borrar todo rastro de la Concertación en el modo de hacer las cosas. Es menester señalar que el comienzo del Gobierno de Piñera no fue fácil, ya que una de las primeras tareas emprendidas fue la de la reconstrucción post-terremoto (acaecido en febrero del año 2010, justo

\footnotetext{
${ }^{540}$ PIÑERA, Sebastián. Op. Cit. 2009. p. 6

${ }^{541}$ COOPERATIVA. "Sebastián Piñera: En 20 días hemos avanzado más que otros en 20 años” [En línea] 1 de abril del 2010. [fecha de consulta 12 de abril del 2014]. Disponible en internet: < http://www.cooperativa.cl/noticias/pais/sismos/catastrofeen-chile/sebastian-pinera-en-20-dias-hemos-avanzado-mas-que-otros-en-20-anos/2010-04-01/133613.html>
} 
antes de iniciar su mandato, y que destruyó parte de la zona sur del país), por lo que la planificación inicial se vio dominada por esta agenda. Pese a esto se mantuvo la estructura central basada en la "delivery unit" o la Unidad Presidencial de Gestión del Cumplimiento (UPGC) que buscaba “transformar la gestión del Estado de Chile hacia una gestión enfocada en indicadores de resultados para las personas." ${ }^{242}$

Su modo de hacer las cosas subrayaban en su quehacer el sesgo técnico que imprimió Piñera, un liderazgo fuerte con un acentuado protagonismo mediático del presidente, de mucho pragmatismo $^{543}$ y con un estilo alejado de las formas y riesgos que le trajo bastantes incomodidades a nivel mediático, por ejemplo, cometiendo errores al comunicar ideas, utilizando palabras equivocadas o queriendo acometer acciones que se veían fuera de lugarcomo el interés que tuvo en entrar a la mina en el caso de los 33 mineros rescatados, su insistencia por mostrar en el extranjero el papel escrito por los mineros, o las caídas en la zona del terremoto. ${ }^{544}$ Todo esto, recogido en redes sociales, generaba burlas constantes, desfavoreciéndole comunicacionalmente y atentando contra la lógica del gobierno de "excelencia" que quería transmitir.

Por otra parte, la oposición insistió en destacar el conflicto de intereses que se abría para un empresario de su calado ejerciendo la presidencia, lo que lo llevó a entregar y hacer público que dejaba sus negocios en fideicomiso ciego. Sus colegas de partido a su vez criticaban su

\footnotetext{
${ }^{542}$ PIÑERA, Sebastián. Rindiendo cuenta: Balance de cuatro años de Gobierno del Presidente Sebastián Piñera. Informe de avance de los siete ejes prioritarios del gobierno y de la reconstrucción” Secretaría de Gobierno. Chile. 2014. p.12

${ }^{543}$ Según algunos sería el rasgo típico de su formación en Harvard: LA TERCERA. "Lo que aprendió Piñera en Boston” [En línea] 9 de junio de febrero del 2015. [fecha de consulta 12 de agosto del 2015]. Disponible en internet: $<$ http://diario.latercera.com/2011/09/24/01/contenido/reportajes/25-84592-9-lo-que-aprendio-pinera-enboston.shtml>

${ }^{544}$ EL MOSTRADOR. “"Tusunami": La lista de errores y lapsus de Piñera a un año del terremoto” [En línea] 28 de febrero del 2011. [fecha de consulta 12 de abril del 2014]. Disponible en internet:
} $<$ http://www.elmostrador.cl/noticias/pais/2011/02/28/tusunami-la-lista-de-errores-y-lapsus-de-pinera-a-un-ano-delterremoto/> 
interés constante por estar involucrado en cada toma de decisión y tener un pequeño grupo asesor alejado de los partidos. Por otra parte, Piñera incluyó en su gobierno -por lo menos inicialmente- a ministros que representaban capacidades técnicas más que políticas,con el fin de hacer notar que lo importante era "abocarse a la tarea." Cuestión que trajo más de un problema, tanto por el conflicto de intereses de algunos ministros con empresas privadas como por la incapacidad para entender los ritmos de la política y la ciudadanía.

El primer año de Piñera fue bastante equilibrado, se podría decir que tuvo un inicio bastante exitoso, había expectativas de cambio y se percibía al gobierno de "técnicos" como algo positivo respecto al periodo anterior, considerado un Gobierno de "politiqueros." Con esto se vio la posibilidad de que se encarnara la promesa del Gobierno 24/7, sustentado en el exitoso rescate de los mineros del Norte chileno, que generó una nueva “imagen-país” en el exterior. ${ }^{545}$ En economía también fue un periodo prometedor, alcanzando una tasa de crecimiento del $6 \%$ . En cuanto a educación se creó la "Beca vocación de profesor" para estimular la formación docente y se crearon los liceos de "excelencia académica", en ámbito de salud y pensiones se elimina el 7\% de cotización para jubilados, se da un bono bodas de oro y se aumenta el posnatal a 6 meses. Estas medidas sirvieron para dar un lavado de imagen a las políticas de la derecha, que hasta ese momento se consideraba que sólo se preocuparía del crecimiento; sin embargo, Piñera asume tareas que parecían innovadoras, aunque queda la sensación general de que pese a que son medidas atractivas, siempre había alguna "letra chica" impuesta por la derecha o los empresarios para que estas medidas tuviesen siempre alguna limitación.

Junto a esto, al final del primer año se fue observando que la velocidad de los cambios no era tal, y que el Gobierno de "excelencia" comenzaba a demorar más de lo prometido en tareas

\footnotetext{
${ }^{545}$ EL PAÍS. "Chile conmueve al mundo con el rescate de los 33 mineros" [En línea] 14 de octubre del 2010. [fecha de consulta

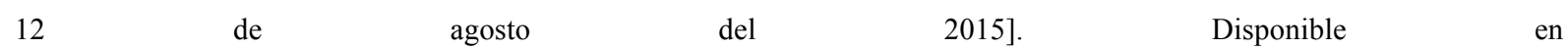
internet: $<$ http://internacional.elpais.com/internacional/2010/10/12/actualidad/1286834409 850215.html>
} 
básicas, por ejemplo, la reconstrucción pos- terremoto. A su vez pese a los cambios propuestos en Educación y Salud, estos se percibieron como pequeños ajustes y no cambiaban sustancialmente el modelo existente. A su vez se resintió en los grupos menos favorecidos la perdida de los bonos que antes había otorgado la ex presidenta Bachelet, el que se diera una alza en el transporte en un $40 \%$ y un fuerte alza en los precios de los productos y servicios.

De esta manera se comenzaba a diluir el efecto del "chilean way" y comenzaba a aparecer una vez más la sombra de la ineficiencia y las promesas incumplidas. El segundo año (2011) será el más dramático, ya que se generan importantes movilizaciones estudiantiles y regionales como sucedió con la región extrema de Magallanes, que se sentía abandonada de las políticas públicas- a su vez que paros en sectores claves como la industria cuprífera. Este mismo año resurgen los problemas vinculados al dinero y la corrupción con dos sucesos relevantes como son el caso "La Polar" " 546 -una multitienda que hacía cobros excesivos a sus clientes y terminó con ejecutivos enjuiciados- y el de colusión de Farmacias donde se vio envuelto el presidente. Por otra parte el tema de la delincuencia será un tema que se proyectará por varios años de su gobierno. Durante el 2011 Piñera alcanzará los niveles más bajos aprobación nunca antes visto en un Gobierno en pos dictadura con un $24 \%$.

El año 2012 será un poco más tranquilo, aunque resurgirá el problema de la salud y las largas esperas para la atención, la educación ahora continuará con el debate acerca del endeudamiento producto de los créditos con aval del Estado creado bajo el Gobierno de Lagos. Reaparece a su vez el problema Mapuche y surgen los primeros casos de abusos sexuales en la Iglesia chilena, que removerán a la élite cercana a la derecha.

\footnotetext{
${ }^{546}$ AMERICA ECONOMÍA. "La Polar: estafa financiera en Chile" [En línea] 21 de junio de 2011. [fecha de consulta 12 de agosto del 2015]. Disponible en internet: $<$ http://www.americaeconomia.com/analisis-opinion/la-polar-estafa-financiera-en$\underline{\text { chile> }}$
} 
Los dos últimos años de Piñera irá revirtiendo el malestar que se generó con su Gobierno, instalando la idea de que pese a las "dificultades" se pudo avanzar. En un sondeo hecho el año 2014, Piñera obtendrá un 50\% de aprobación igualando la del primer año. ${ }^{547}$ Se destacará en la evaluación final varios hitos vinculados a su política y a su personalidad. Se destaca el fortalecimiento de la imagen del país en el exterior, la creación de empleo, la reconstrucción post-terremoto, la creación de hospitales -aunque en realidad se concesionan-, promoción de la vida sana y saludable -creación de nuevos parques, programa elige vivir sano, kioscos saludables en escuelas, ley anti tabaco y ley de tolerancia cero de alcohol y creación del Ministerio del deporte- y la defensa de los consumidores fortaleciendo mecanismos de defensa no sólo para el comercio sino también en el sector financiero.

Lo que más llama la atención es que al finalizar su Gobierno, pese a los escándalos y las fuertes críticas a su Gobierno debido a estar vinculada a la derecha política, se siga viendo en él un político distinto, aquel que es "emprendedor y trabajador", de "terreno", eficiente, de "buenas intenciones y de "familia". Todos es principios encarnan por una parte, el Chile de los noventa, donde todos quieren ascender socialmente, donde la clase media esforzada es el ideal, donde el éxito económico es un logro relevante. Pero además siguen vigentes los principios más conservadores de Chile, por lo que se destaque en el ser un hombre de "buen corazón" y de "Familia."

Pese a todo, una vez terminado el mandato de Piñera, este abandona Renovación Nacional y se inicia una oleada de retiros de la derecha tradicional para crear nuevos partidos, creándose así

\footnotetext{
${ }^{547}$ LA TERCERA. "Piñera culmina gobierno con un 50\% de aprobación y 36\% de rechazo según la encuesta Adimark de febrero". [En línea] 3 de marzo del 2014. [fecha de consulta 12 de agosto del 2015]. Disponible en internet: $<\underline{\text { http://www.latercera.com/noticia/politica/2014/03/674-567703-9-pinera-culmina-gobierno-con-un-50-de-aprobacion-y-36- }}$ de-rechazo-segun-la.shtml>
} 
lo que algunos han llamado la tercera vía de Piñera ${ }^{548}$ ¿Por qué el quiebre de la Derecha tras su salida del poder si se tuvo un gobierno exitoso? Una idea inicial que no surge es que el Gobierno de Piñera, elegido por la ciudadanía debido al malestar contra la Concertación y sus 20 años de Gobierno, se transforma poco a poco no en el Gobierno de la derecha, sino el Gobierno de Piñera, hecho a su medida y bajo sus lógicas, una especia de "Piñera way" lo que será resentido al interior de la Derecha tradicional, en temas sensibles, como son los temas valóricos, de Memoria y Derechos Humanos y derechos sociales.

En temas sociales, ya hemos visto cómo Piñera instala el interés por la Educación, la salud y las pensiones y realiza políticas que tradicionalmente se podrían asociar a gobiernos progresistas, donde el Estado actúa de manera relevante (apoyo estatal a los jubilados y al post natal por ejemplo). En temas valóricos fue especialmente resentido por la derecha la política de Unión Civil para personas del mismo sexo iniciada en el Gobierno de Piñera el año 2011 (“Acuerdo de Vida en Pareja”) y convertida en ley el año 2015. En temas de Memoria y Derechos Humanos Sebastián Piñera mencionó por primera vez en democracia y de manera pública desde la Presidencia que existía culpabilidad civil -los cómplices pasivos-en el Golpe de Estado $^{549}$, pero además fue sumamente criticado por el cierre del penal Cordillera, una cárcel “de lujo" para militares violadores de derechos humanos que fueron trasladados a otro penal con características de reclusión normal, cuestión que nunca fue abordada por los Gobiernos de centro izquierda anteriormente. ${ }^{550}$ De esta manera Piñera se aleja de la derecha pinochetista y de lo que se conoce como la "familia militar."

\footnotetext{
${ }^{548}$ EL MOSTRADOR. "La "tercera vía” de Piñera". [En línea] 16 de octubre del 2013 [fecha de consulta 12 de agosto del 2015]. Disponible en internet: <http://www.elmostrador.cl/noticias/pais/2013/10/16/la-tercera-via-de-pinera/>

${ }^{549}$ EL QUINTO PODER. “Los “cómplices pasivos” [En línea] 11 de septiembre del 2013 [fecha de consulta 12 de agosto del

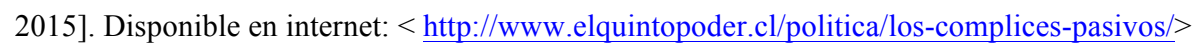

${ }^{550}$ LA TERCERA. "Piñera anuncia cierre definitivo del penal Cordillera y traslado de los condenados a Punta Peuco" [En línea] 26 de septiembre del 2013 [fecha de consulta 12 de agosto del 2015]. Disponible en internet:
} 
Esta forma de hacer política llevó, por una parte, a que la derecha más tradicional le acusará de ser más bien la continuación de los Gobiernos de la Concertación ${ }^{551}$-de centro izquierda-; por otra parte, gran parte de la oposición le siguió acusando de ser un gobierno vinculado al empresariado y los poderes "fácticos de derecha." Mientras tanto la ciudadanía valoró su “estilo" acorde a los tiempos de un Chile modélico, vinculado al éxito económico, el mérito y el emprendimiento. Queda mucho por investigar al respecto, pero queda en claro que Piñera representará su propio estilo, un estilo cercano al país de la democracia "modélica", contradictoria y paradojal.

$<$ http://www.latercera.com/noticia/politica/2013/09/674-544295-9-pinera-anuncia-cierre-definitivo-del-penal-cordillera-y$\underline{\text { traslado-de-los.shtml> }}$

551 T13. “Axel Kaiser: "El Gobierno de Piñera fue uno más de la Concertación” [En línea] 5 de agosto del 2015 [fecha de consulta 12 de agosto del 2015]. Disponible en internet: < http://www.t13.cl/radio/mesa-central/noticia/axel-kaiser-gobiernopinera-fue-uno-mas-concertacion> 


\section{5.-CONCLUSIONES.}

Las lecturas y relecturas que hace un historiador acerca de su contexto son complejas en varios sentidos. Y no es sólo porque su representación del mundo está mediada por su subjetividad, éste es un hecho reconocido hace ya un tiempo, sino que más bien porque el investigador a la vez que busca dar cuenta de un acontecimiento o proceso determinado debe, desde mi punto de vista, ser capaz de ser crítico de ellos. El investigador es una especie de joven David bíblico, que derriba gigantes como Goliat con el arma más humilde que se puede encontrar: una honda o resortera que para nuestro caso es, sin duda, la palabra reflexionada.

Los mitos en la Historia son muchos y están profundamente arraigados en las sociedades, al punto que en algunos casos se han venido transformando en verdaderos pilares de su identidad. Es cierto que en ocasiones han sido útiles, como por ejemplo para dar solidez a la construcción del Estado Nación, en especial en los países Latinoamericanos donde la Historia y la Educación en conjunto fueron fundamentales para consolidar las bases de la identidad nacional en una población reacia a ser parte de una "idea" impuesta -a la fuerza en ocasiones- por las élites.

En el fondo, utilizando la conceptualización de Anderson, es posible detectar cómo los mitos, reafirmados muchas veces por la historia enseñada, crean verdaderas "comunidades imaginadas" 552 que delinean lo que el ciudadano común "siente" o "percibe" de su propio país, generando una adscripción no siempre racional. Vinculado a esto, Baczko definirá como "imaginarios sociales" 553 a aquella invención permanente de sus propias representaciones globales que irá conformando su propia identidad. Este proceso que bien define al siglo XIX

\footnotetext{
552 ANDERSON, Benedict. Comunidades Imaginadas, Reflexiones sobre el origen y la difusión del nacionalismo. Fondo de Cultura económica, México.1983.

${ }^{553}$ BACZKO, Bronislaw. Los imaginarios sociales. Memorias y esperanzas colectivas. Nueva Visión, Buenos Aires. 1991.
} 
latinoamericano no se cierra con él y en distintos periodos de su Historia surgirán nuevas representaciones, transformaciones y superaciones.

En este sentido, las etapas críticas de la historia de los países resultan un lugar ideal para que surjan o se renueven estos imaginarios de la mano de nuevos discursos que apelan a forjar sociedades nuevas. De esta manera, el Chile del siglo XIX se verá enfrentado en diversas ocasiones a duros traspiés que ponen en entredicho su uniformidad nacional, de la mano de nuevas ideologías, crisis sociales y nuevos movimientos sociales nos encontramos entrando al siglo XX y en pleno centenario de la Independencia con un Chile que se veía a sí mismo como dividido entre una "fronda aristocrática" y los marginados de la sociedad (obreros y campesinos). La década del veinte del nuevo siglo estará indefectiblemente unida al impulso de los grupos medios o "clase media" que verán sus objetivos alcanzados con Arturo Alessandri. Los años 40 para Chile será la consolidación del movimiento obrero cuando el Frente Popular llegue al poder, de manera efímera, pero ahí estarán, tomando decisiones por hacer un política en que el Estado participará más activamente de todas las actividades de la economía y la política.

Los años 50 y 60 verán surgir nuevos imaginarios, que consolidarán un nuevo centro socialcristiano, que irá poco a poco aislándose de los extremos en pos de su propuesta por una tercera vía, no capitalista ni marxista. Así se inicia una movilización masiva del campo y los sectores urbanos marginados que tendrá como efecto que nuevos ideales surjan con mayor potencia. Allende será el reflejo de esta "nueva sociedad" que intentará durante los setenta canalizar este nuevo imaginario de Chile, el de un país socialista, pero a su manera. El objetivo será truncado severamente por los militares, lo que podría llevar a pensar que lo que queda de Chile sólo serán cenizas y olvido y, sin embargo, lo que resurgirá de en medio del terror será otro Chile imaginado, esta vez de manera violenta e incluyendo a muy pocos. 
En la práctica, el camino que se inicia a mediados de los setenta será una nueva "comunidad imaginada", la de una democracia modélica, pero bajo un modelo basado en restricciones y limitaciones que se instalará en los años noventa con escasas cortapisas y que irá ajustando sus fronteras para hacerla más aceptable al contexto internacional. En otras palabras, recibirá un "maquillaje" a la moda para el "desfile internacional", pero que tarde o temprano vuelve a casa a mostrar su peor rostro. Porque en la práctica el modelo chileno no es un mejor modelo de democracia por sus "éxitos" o "logros" sino justamente por sus imperfecciones, como hemos podido corroborar en esta investigación.

En este sentido, lamentablemente lo que se suele investigar son justamente los "éxitos" y se tienden a omitir los fracasos. Así se repite hasta el cansancio que la herencia "positiva" de Pinochet es la economía, que si no fuera por su buen manejo hoy no estaríamos en la vía del progreso; pero se omite que eso no es más que el "cascarón" de una realidad que oculta una desigualdad profunda en la sociedad que ha permeado la educación, la salud, el trabajo, las pensiones y hasta el espacio geográfico, existiendo "lugares para vivir" de primera y segunda categoría, con poblaciones marginales que nunca conocen los barrios de "ricos" y barrios de "ricos" que no necesitan salir de su entorno y conocer a ese otro Chile mayoritario.

Hemos visto cómo se persigue con insistencia encontrar el modelo elaborado por la Ciencia Política más adecuado para entender el Chile de los 90, haciéndolo calzar con el desarrollo de democracias liberales post-autoritarias, que dejan la impresión de que nuestro país es un verdadero ejemplo del triunfo ciudadano o político sobre el Dictador y, sin embargo, cuando escarbamos la superficie de esta realidad a través de la Historia Reciente nos encontramos con que existen más acuerdos entre políticos profesionales y el Dictador que el triunfo de la "gente de la calle.” Qué mientras se violaban los derechos humanos cada día, se realizaban seminarios teóricos acerca de cómo hacer concesiones al modelo para poder regresar al poder y en menor medida se pensaba en cómo llevar a la ciudadanía a la democracia plena. 
En nuestra investigación hemos cumplido con nuestros objetivo general y específico, ya que pudimos reflexionar desde la Historia del Tiempo Presente acerca de la complejidad con que se nos presenta en el largo plazo la Transición chilena, matizando las teorías politológicas, aportando luces sobre el mito de la democracia chilena, dejando en evidencia sus debilidades y fracasos; y hemos procurado analizar uno a uno los pilares de la democracia "modélica" para lo cual hemos recurrido a bibliografía actualizada, fuentes primarias y documentos periodísticos y audiovisuales de nuestra Historia reciente.

Está claro, como propusimos en nuestra hipótesis, que la Transición no se puede estudiar como un proceso divorciado de la dictadura, ya que hasta el día de hoy sigue estando vinculada, tanto de manera práctica (con la Constitución que le da forma, por ejemplo) como teórica, a través de ciertos imaginarios acerca del éxito de la misma, que ponían a los políticos de la Concertación; los mismos que gobernaron desde los 90 como los grandes "héroes" del retorno a la democracia y que habían sido ensalzados por las ciencias sociales en sus análisis acerca de la misma. A su vez, pudimos analizar de manera específica que a falta de una mejor definición que democracia para el Gobierno de los años 90 en Chile, ésta exhibe ciertas características peculiares que la distinguen de una democracia en plenitud. Ya que el mismo hecho de que fuese la dictadura la que impusiera su itinerario, su forma (Constitución y Sistema político electoral) y su "imaginario" ("Revolución silenciosa”, Política laboral y social) hace pensar que en el caso chileno, se ha forjado una versión particular de democracia en el que el ciudadano se ve sometido a los avatares de la política, mediatizada por el dictador mientras permaneció vivo y luego por su normativa y sus herederos políticos en el poder, una vez muerto.

Esta "vía Chilena a la Democracia” que irónicamente instalará Pinochet de la manera más sádica y violenta, se consolidará en los noventa gracias a los más beneficiados por ella. Por una parte, los políticos de oposición que llegaron nuevamente -por fin- al poder y por otra parte, 
los empresarios y políticos -por separados y juntos- que apoyaron y se enriquecieron con favores del dictador y que ahora "sacan brillo" a los éxitos del sistema "neoliberal" que premia al "esforzado" -y sumiso- trabajador que lucha por el progreso del país, aunque su voto valga menos que los acuerdos intra-elitarios previos a las elecciones. Esta es la democracia chilena, una democracia protegida, como le llamará la propia dictadura mientras estaba vivo Pinochet. Pero que poco a poco se convirtió también en una democracia "controlada", como han dejado de manifiesto los últimos escándalos de corrupción política vinculados al financiamiento de la empresa privada de los partidos políticos de manera trasversal (insólitamente o no, el ex yerno de Pinochet se encuentra entre los financistas del Partido Socialista).

Dejamos en evidencia en esta investigación, tal como propusimos en las hipótesis específicas, los diversos mitos de la "vía chilena a la democracia" de Pinochet. El mito "políticosocial", que hace mención al triunfo del pueblo en la conquista de la democracia, relevado tantas veces por los Gobiernos de la Concertación cada vez que quería validar los consensos llevados a efecto con el dictador. Pero aquellos movimientos sociales que lucharon y y se jugaron el tipo en las calles de Chile han sido marginados de la política y, salvo algún dirigente estudiantil o dirigente social que ha llegado al poder de manera independiente en los últimos diez o quince años, quienes han participado directamente de la política son los mismos políticos de los años 70, entre ellos Patricio Aylwin, Ricardo Lagos, los hermanos Zaldívar, etc., sólo por mencionar algunos, escapándose a la regla el Gobierno de Michelle Bachelet. No existen referéndums participativos, ni la Constitución lo permite, ni ha habido intentos genuinos de transformación que hayan emanado de la ciudadanía, que al parecer se ha mantenido al margen de la toma de decisiones de manera voluntaria - por el trauma a la participación dejado por la dictadura- o involuntaria -debido a la marginación del propio sistema-; cuestión que ha repercutido en un fuerte malestar durante este último decenio, tanto de estudiantes, trabajadores, sectores populares en general, como de los pueblos originarios. 
Al final, "el pueblo" o "la ciudadanía" ha obtenido lo que se propuso imponer la dictadura y que consagró como el mito de la "libertad", sustentada más bien en la economía y no en los derechos ciudadanos. El chileno de los noventa será al fin libre, pero para comprar lo que quiera o, más bien, lo que pueda . Un chileno que podrá decidir qué "empresa" prosperará o no en base a su libreelección que, sin embargo, no será extensible o será limitadamente extensible, a su elección política. Los Gobiernos de la emocracia celebrarán que no haya más persecución y muerte por parte del Estado, pero omitirán la persecución que se iniciará con la marginación social impuesta por las empresas y el crédito, por el drama de la desigualdad profunda para millones que no pueden acceder a una educación y salud de calidad.

Desde otro punto de vista, llama la atención que en general hayan desaparecido de la primera línea política muchos miembros civiles de la dictadura, siendo tal vez la Unión Demócrata Independiente (UDI) su gran heredera de la mano de Jaime Guzmán -asesinado en democraciay Jovino Novoa. Entonces ¿Qué pasó con ellos? La realidad nos ha confirmado que siempre han seguido en el poder, pero desde otra vereda, menos expuesta y más lucrativa, como si el aprendizaje fundamental de las élites formadas en dictadura hubiese sido que el lugar más seguro para seguir controlando el poder en un contexto neoliberal fuese la economía.

Y así ha sido, ya que muchos de los líderes con Pinochet son actualmente miembros de los más altos directorios de empresas, como Carlos Délano, Hernán Büchi, José Piñera, Julio Ponce Lerou, José Yurazeck, sólo por nombrar algunos, que canalizaron su poder comprando-favores mediante- empresas estatales, o se aprovecharon de información privilegiada por lo cual, en un contexto donde la economía es la medida de las cosas, son admirados como hombres de éxito y poder. Este "saqueo de Chile"554, como le llamará María Olivia Monckeberg, ha tenido

\footnotetext{
${ }^{554}$ MONCKEBERG, María Olivia. El saqueo de los grupos económicos al Estado chileno. Grupo ZETA. Chile. 2001.
} 
importantes frutos en democracia, ya que evitando el desprestigio que suponía haber sido parte de la dictadura, fueron capaces de asumir un poder casi total, pagando favores a políticos de distinto color y llenándose de elogios por sus "logros" e incluso por su espíritu benefactor (Como Carlos Dénalo, miembro del directorio de Teletón Chile). Así, Chile se ha seguido manejando entre pinochetistas y políticos profesionales, unos financiando, los otros manteniendo las cosas como "siempre". Esto, que hace años podía ser nada más que una teoría "conspiratoria", durante los últimos tiempos se ha ido corroborando con tintes dramáticos con el caso Soquimich y Penta.

El "mito económico" es otro ítem que pudimos corroborar y desmantelar. Chile efectivamente terminó siendo exitoso macroeconómicamente y pudo entrar a las "grandes ligas" del mercado internacional. Sin embargo, lo que poco se señala es que este modelo prontamente instalado en Chile fue asumido con costos dramáticos para la ciudadanía como la muerte y persecución, cesantía y endeudamiento personal para obtener los mínimos derechos sociales. Junto a esto, gran parte de la población tuvo que asumir los costos de su fracaso a comienzos de los 80 y previendo las crisis capitalistas contemporáneas, será el Estado -y la población en general- el que terminará salvando al sector financiero. Los años 90 Chile se encontrará con las “mejores" condiciones económicas posibles, lo que sustentará el éxito de la transición; sin embargo, se oculta la desigualdad y la casi inexistencia de derechos sociales, todos los cuales fueron privatizados en dictadura. Los cambios se han hecho esperar y en "oleadas" consecutivas los ciudadanos se han manifestado contra el Chile dividido que genera la desigualdad de los pocos beneficiados por la economía y los marginados del desarrollo. Pero los resultados siguen tardando y en vez de hacer "golpes de timón” se ha preferido seguir -e incluso profundizar- el modelo económico. En la práctica, los clásicos “monetaristas” hicieron un gran trabajo en los economistas nacionales, quienes siguen pensando que el gran problema no es la ausencia del Estado en áreas claves, sino la insuficiente competencia y participación de privados en el 
mercado, con lo que se ha llegado a situaciones extremas que van desde las concesiones en áreas relevantes para el país como carreteras y salud, la instalación en todos los niveles educativos del "voucher", el involucramiento del sector financiero en la educación superior, un sistema único de pensiones basados en la bolsa y la tercerización generalizada de la economía. Y esto sin mencionar el régimen laboral y su legislación en Chile, que ha evitado durante años la sindicalización.

En nuestra tesis consideramos que queda en claro que Chile no sólo fue precursor de una "vía chilena al socialismo" que hizo que el mundo mirara la única experiencia marxista que llegaba al poder por el camino democrático en los años 70, sino que también es precursor de una "vía a la democracia", con tintes terribles pero que son escondidos por sus logros. Este camino diseñado y recorrido por la dictadura creó tempranamente un gobierno con clientes más que ciudadanos, que creó una "comunidad imaginada" nueva donde la competencia y el emprendimiento serían los verdaderos principios fundantes de la libertad, donde el dinero será la verdadera papeleta de votación y en el que lo colectivo se transformó prontamente en lo individual.

Este proceso de “des-ideologización” que habría llevado a cabo la dictadura terminó por crear un nuevo ciudadano con un nuevo pensamiento, el que se mide por el éxito económico alcanzado, donde es mejor comprar un servicio a que lo asegure el Estado "gratis" pero de peor calidad, un caso insólito se dio en Chile con las protestas de padres de colegios subvencionados -que son principalmente de clase media- que reclamaban porque el Estado quería suspender el co-pago, lo que rechazan por atentar contra la libertad que ellos tenían para elegir el colegio de sus hijos.

Esta tipo de democracia que está instalándose incluso en países de Europa donde hasta ahora el Estado tenía un fuerte y claro rol, ha sido también un experimento temprano chileno. Un 
gobierno de políticos, más preocupados de satisfacer al mercado y sus demandas para evitar las amenazas de crisis y desempleo de manera constante - sea esto ficticio o real- con un sector financiero robusto y "empoderado" donde la banca y sus organismos internacionales dan directrices claras acerca de cómo tomar decisiones de política interna -como sucedió en los 90 en Chile con el Banco Mundial y el FMI-, con un ciudadanía que pese a tomarse las calles es considerada solamente en elecciones, generalmente "cuoteadas" previamente. Esta descripción que parece definir lo que acontece actualmente en varios países del mundo es lo que creó Pinochet en los 80 y consolidó la democracia chilena en los 90, una democracia "semisoberana"555 para algunos o "protegida" para otros, pero que en definitiva es todo lo contrario: es soberana, en tanto existe un poder en las sombras que gobierna junto a la política, y es “desprotegida" en tanto el verdadero control está basado en los vaivenes de la economía que “aceleran" o "frenan" el progreso si éste se ve amenazado por los derechos ciudadanos. ¿Es esto una democracia? Al parecer es un sistema que funciona para algunos, pero no para los ciudadanos. ¿Qué es entonces? y ¿Cómo mejorarla? Es el desafío que tiene los chilenos los próximos años.

\footnotetext{
${ }^{555}$ HUNEEUS, Carlos. La democracia semisoberana: Chile después de Pinochet. Editorial Taurus. Chile. 2014.
} 


\section{BIBLIOGRAFÍA Y FUENTES}

ABDÓN, Mateos. "Historia, Memoria, Tiempo Presente”. Hispania Nova No 1. 1998.

ACEITUNO, David y ESTRADA, Baldomero. (Coord.) Reflexiones y Miradas a nuestro Pasado Reciente. Actas de la I Jornada de Historia de Chile Contemporáneo. [en línea] Edición Digital. Instituto de Historia. PUCV. 2013. disponible en: http://www.ihistoriapucv.cl/?attachment id=1883

ACEITUNO, David, et. al. "La memoria transicional en los profesores de Historia de España y Chile." En: PAGEZ, Joan y SANTISTEBAN, Antoni. Una mirada al pasado y un proyecto de futuro. 25 años de Investigación e Innovación en Didáctica de las Ciencias Sociales. Vol 2. UAB. Barcelona. 2013. pp. 13-20.

ACEITUNO, David. "El cine de ficción como lectura crítica de la historia y su utilización en la enseñanza el caso de la transición a la democracia en Chile”. En: DÍAZ MATARRANZ Juan José. Et. Al. Medios de comunicación y pensamiento crítico: nuevas formas de interacción social. Universidad de Alcalá, Servicio de Publicaciones. España. 2013. pp. $527-553$.

ACEITUNO, David. "Reflexiones en torno al Chile postpinochet: la memoria, el miedo y la didáctica de la historia". Revista Nuevas Dimensiones, No 4, Santiago, Chile, Diciembre del 2013.

ACTAS OFICIALES. Comisión de Estudios de la Nueva Constitución política de la República. Tomo I. Sesión primera. 24 de septiembre de 1973. 
ACUÑA Rodrigo. y IGLESIAS, Augusto. “La Reforma a las Pensiones” En: LARRAÍN Felipe y VERGARA Rodrigo. La transformación económica de Chile. Centro de Estudios Públicos. Santiago. 2001.

ACUÑA, Rodrigo e IGLESIAS, Augusto. “Chile's Pension Reform After 20 Years” Social Protection Discussion Paper Series No 0129. 2001.

ADNRADIO. "Investigan a fiscal por supuestas filtraciones del caso Penta-SQM a Rodrigo Peñailillo" [en línea]. 3 de agosto del 2015. [fecha de consulta 12 de agosto de 2015] Disponible en internet: < por-supuestas-filtraciones-del-caso-pentasqm-a-rodrigopenailillo/20150803/nota/2878877.aspx>

AGÜERO, Felipe. La Reforma en la Universidad de Chile. Ediciones Sur, Chile. 1987.

AGUILAR FERNÁNDEZ, Paloma. Memoria y olvido de la Guerra Civil. Alianza Editorial. Madrid. 1996.

AHUMADA, Eugenio et al., Chile: la memoria prohibida. Tres volúmenes. Pehuén, Santiago. 1989.

ALMOND, Gabriel y COLEMAN James (eds.). The Politics of the Developing Areas. N.J. Princeton University Press. Princeton. 1960.

ÁlVAREZ VALLEJOS, Rolando. "Los "hermanos Rodriguistas". La división del Frente Patriótico Manuel Rodríguez y el nacimiento de una nueva cultura política en la izquierda chilena. 1975-1987” Revista IZQUIERDAS Año 2, No 3, 2009.

ALlAMAND, Andrés. La Travesía Del Desierto. Editorial Aguilar. Chile. 1999. 
AMERICA ECONOMÍA. "La Polar: estafa financiera en Chile" [En línea] 21 de junio de 2011. [fecha de consulta 12 de agosto del 2015]. Disponible en internet: $<$ http://www.americaeconomia.com/analisis-opinion/la-polar-estafa-financiera-en$\underline{\text { chile> }}$

AMOROS, Mario. La Memoria Rebelde, testimonios sobre el exterminio del MIR: de Pisagua a Malloco, 1973-1975. Ediciones Escaparate. Concepción. 2008.

ANDERSON, Benedict. Comunidades Imaginadas, Reflexiones sobre el origen y la difusión del nacionalismo. Fondo de Cultura económica, México.1983.

ANGELL, Alan. Chile de Alessandri a Pinochet. Editorial Andrés Bello. Santiago de Chile. 1993.

ANNICK, Manuel "The Chilean Health System: 20 Years of Reforms". Salud pública de México. Vol. 44, №.1, enero-febrero de 2002.

ARAYA LEÜPIN, Eduardo “Transición y transiciones a la Democracia”. Iber: Didáctica de las Ciencias sociales, Geografia e Historia, № 67, 2011. pp. 10-24.

ARAYA LEÜPIN, Eduardo. "Las transiciones chilenas: Una retrospectiva sobre el estado del arte y construcciones discursivas. Comunicación presentada en el XII Seminario didáctica de la Historia, "La enseñanza de las transiciones de la Dictadura a la Democracia en el mundo escolar " P. Universidad Católica de Valparaíso. 1 y 2 de diciembre del 2010.

ARENAS DE MESA, Alberto. Cobertura previsional en Chile: Lecciones y desafios del sistema de pensiones administrado por el sector privado. CEPAL. Chile. 2000. 
ARÓSTEGUI, Julio. "Historia y Tiempo Presente. Un nuevo horizonte de la historiografía contemporaneísta", Cuadernos de Historia Contemporánea, № 20, 1998, pp. 15-105.

ARÓSTEGUI, Julio. La Historia del presente. ¿Una cuestión de método? Actas del IV Simposio de Historia Actual. 17-19 de octubre de 2002 / coord. por Carlos Navajas Zubeldía, Vol. 1, Logroño. 2004.

ARÓSTEGUI, Julio. La Historia vivida. Sobre la Historia del presente. Alianza Editorial, Madrid. 2004.

ARRIAGADA Genaro y VALDÉS Juan Gabriel. Campaña del NO. Análisis y Perspectivas. CIS -CEDILET-SUR. Santiago, 1988.

ARRIAGADA, Genaro. ¿Hacia un "big bang" del sistema de partidos?. Editorial Los Andes, Santiago de Chile. 1997.

ARRIAGADA, Genaro. "Por la Razón o la Fuerza. Chile Bajo Pinochet". Editorial Sudamericana, Santiago de Chile. 1998.

ARRIAGADA, Genaro. 10 Años: Visión Crítica. Editorial Aconcagua. Chile. 1983.

ASMAL, Kader. "Verdad y Reconciliación en la Transición a la Democracia en Sudáfrica" Revista de Relaciones Internacionales No. 13. UNLP. 1997.

ATRIA, Fernando. La Constitución Tramposa, Editorial LOM, Santiago. 2013.

Ávalos, Beatrice. Profesores para Chile: historia de un proyecto. Ministerio de Educación, Chile. 2002.

AYLWIN, Andrés. Simplemente lo que vi, 1973-1990: y los imperativos que surgen del dolor, Editorial LOM. Santiago de Chile. 2003. 
AYLWIN, Mariana; BASCUÑÁN, Carlos; SERRANO, Sol (et. al). Chile en el siglo XX. Planeta. Santiago de Chile. 1990.

AYLWIN, Patricio. El Reencuentro de los Demócratas: Del Golpe al Triunfo del No. Ediciones Grupo Zeta, Santiago de Chile.1998.

BACZKO, Bronislaw. Los imaginarios sociales. Memorias y esperanzas colectivas. Nueva Visión, Buenos Aires. 1991.

BALOYRA, Enrique (ed.). Comparing new democracies. Transition and consolidation in mediteranean Europea and the southern cone. Boulder. Colorado. 1987.

BARDÓN, Álvaro, CARRASCO Camilo y VIAL, Álvaro. Una década de cambios económicos : la experiencia chilena : 1973-1983. Alfabeta. Santiago de Chile. 1985.

BARRY, Brian. Sociologists, Economists and Democracy. University of Chicago Press. USA. 1978.

BARTOLINI, Stefano. “Collusion, competition, and Democracy. Part I." Journal of theorical politics. Vol. 11. $\mathrm{N}^{\mathrm{o}}$ 4. pp. 435-470.

BAYER, Harald. “¿El fin de la democracia de consenso?” [en línea]. Publicado en El Mercurio, 16 de agosto de 2013 . [fecha de consulta 12 de mayo de 2015] Disponible en internet: $\quad<\underline{\text { http://www.elmercurio.com/blogs/2013/08/16/14402/El-fin-de-la- }}$ democracia-de-consenso.aspx>

BCN. "Nuevo sistema electoral para elecciones parlamentarias (Fin del sistema binominal)" [en línea] 5 de mayo del 2015. [fecha de consulta 12 de mayo de 2015] disponible en

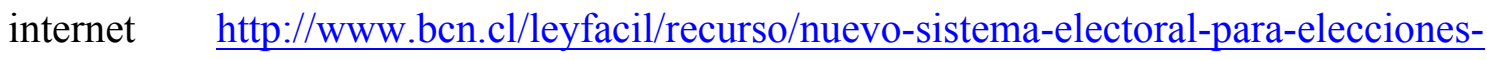
parlamentarias-(fin-del-sistema-binominal) 
BEDÁRIDA, Francois. "Definición, método y practica de la Historia del Tiempo Presente", Cuadernos de Historia Contemporánea, 20. 1998.

BELLEI, Cristián. "El estudio de la segregación socioeconómica y académica de la educación chilena." [en línea]. Estudios pedagógicos. Valdivia, V. 39, № 1. 2013. pp. 325-345. [fecha de consulta 12 de octubre del 2014]. Disponible en internet en $<\underline{\text { http://www.scielo.cl/scielo.php?script }=\text { sci arttext\&pid }=\text { S0718- }}$ $\underline{07052013000100019 \& \operatorname{lng}=\mathrm{es} \& \mathrm{nrm}=\mathrm{iso}}>$

BITAR, Sergio. Chile 1970-1973, Asumir la Historia para construir el futuro: Editorial Pehuen. Chile. 2001.

BITAR, Sergio. Isla 10. Pehuén, Santiago de Chile.1987.

BLOCH, Marc. Apología para la Historia o el oficio de historiador. FCE, México. 2001.

BOENINGER, Edgardo. Democracia en Chile: lecciones para la gobernabilidad. Andrés Bello, Santiago de Chile. 1998.

BORIC, Gabriel. ¿Podemos los estudiantes creer en el Presidente? Discurso realizado en la marcha en Santiago de Chile el 16 de mayo del 2012. En: Diario "The Clinic" [fecha de consulta 3 de mayo del 2011]. Disponible en internet: $<$ http://www.theclinic.cl/2012/05/16/discurso-de-gabriel-boric-podemos-los$\underline{\text { estudiantes-creer-en-el-presidente/> }}$

BRAUDEL, Fernand, La Historia y las Ciencias Sociales, Alianza Editorial, Madrid. 1968.

BRAUDEL, Fernand. El Mediterráneo y el mundo mediterráneo en la época de Felipe II. Fondo de Cultura Económica de España. España. 2001. 
BRAVO LIRA, Bernardino. "La Constitución de 1833” Revista Chilena de Derecho, (2): mayoagosto de 1983. pp. 217-329.

BRESCIANO,Juan Andrés (Comp.). El tiempo presente como campo historiográfico. Ensayos teóricos y estudios de casos. Ediciones Cruz del Sur. Uruguay. 2010.

BRIONES, Álvaro. La pata coja y la Transición infinita. Santiago de Chile: Ediciones B, 1999.

BRITO, Juan Ignacio. “Ideas y Debates: Historia y Verdad Oficial”. Diario La Tercera, Chile, 28 de abril del 2011. [Fecha de consulta: 2 de mayo del 2011] Disponible en internet: $<$ http://www.latercera.com/noticia/opinion/ideas-y-debates/2011/04/895361586-9-historia-y-verdad-oficial.shtml>.

BRUNNER, José J. “Chile: claves de una Transición pactada” Nueva sociedad Nº.106. Marzoabril. 1990. pp. 6-12.

BRUNNER, José Joaquín y ELACQUA, Gregory. Capital Humano en Chile. Editorial Universidad Adolfo Ibáñez y La Araucana, Santiago de Chile, 2003.

BRUNNER, José Joaquín: El Diseño Autoritario de la Educación en Chile. Santiago de Chile. 1980.

BÜCHI, Hernán. La transformación económica de Chile. (Reedición) Aguilar-El Mercurio. Chile. 2008.

CABANILLAS, Natalia. "Incorporando la nación: mujeres africanas ante la comisión de verdad y reconciliación sudafricana." Nómadas № 38, Colombia. Abril de 2013.

CAMBIO 21. “¿Qué fue de los Tantauco? El “Think tank” de Piñera que elaboró los famosos pendrive que se le entregó a cada ministro hoy no se encuentran en ninguna parte. Como que no hubieran existido nunca" [En línea] 5 de agosto del 2011. [fecha de consulta 12 
de

abril

del

2014].

Disponible

en

internet:

$<\underline{\text { http://www.cambio21.cl/cambio21/site/artic/20110805/pags/20110805190340.html }>}$

CANESSA, Julio. BALART, Francisco.Pinochet y la restauración del consenso nacional. Santiago de Chile: Geniart. 1998.

CAÑAS KIRBY, Enrique. Proceso politico en Chile: 1973-1990. Editorial Andrés Bello. Santiago de Chile. 1997.

CAREY, John. "Las virtudes del sistema binominal." Revista de Ciencia política. (Santiago) [en línea]. vol. 26, $\mathrm{N}^{\mathrm{o}}$ 1. 2006. pp. 226-235 . [fecha de consulta 12 de mayo de 2015]

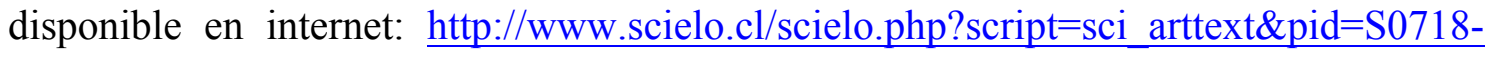
$\underline{090 \times 2006000100016 \& \operatorname{lng}=\mathrm{es} \& \mathrm{nnm}=\mathrm{iso}}$

CARO, Isaac y KAUFMAN, Edy. El régimen militar chileno dentro del análisis de los patrones represivos en el Cono Sur. College Park, Maryland. 1991.

CARRASCO, Camilo, VIAL, Álvaro, BARDÓN, Álvaro. Una década de cambios económicos: la experiencia chilena : 1973-1983. Editorial Andrés Bello. Chile. 1985.

CASANOVA, Julián. "Secretos de Estado" [en línea] Periódico El País, 03 de diciembre del 2010. [fecha de consulta 3 de octubre del 2011] disponible en internet $<$ http://www.elpais.com/articulo/opinion/Secretos/Estado/elpepuopi/20101203elpepiopi $\underline{5 / \text { Tes }}>$

CASANOVA, Julián. "Los límites de la objetividad y el desafío posmodernista" En: "Razones de historiador. Magisterio y presencia de Juan José Carreras”, Institución Fernando el Católico, Zaragoza, 2009. 
CASTILlO VELASCO, Jaime. ¿Hubo en Chile violaciones a los derechos humanos?: comentario a las memorias del general Pinochet. Editora Nacional de Derechos Humanos. Chile. 1995.

CASTILlO, Carmen. Un día de octubre en Santiago. Santiago de Chile: Editorial Sin Fronteras, 1987.

CAVALLO, Ascanio; SALAZAR, Manuel y SEPÚLVEDA, Oscar; La historia oculta del régimen militar. Editorial Grijalbo, Chile, 1997.

CAVAROZZI, Marcelo y GARRETÓN, Manuel A. (Ed.), Muerte y resurrección: Los partidos políticos en el autoritarismo y las transiciones en el Cono Sur. FLACSO, Chile. 1989.

CED. Informe XII. Repasando las críticas al sistema binominal. CED. Chile. 2008

CEP. "Tema especial: Evaluación del Conflicto Estudiantil” . Estudio Nacional de Opinión Pública, $\mathrm{N}^{\circ}$ 52, Chile, junio-julio 2006.

CENTRO DE ESTUDIOS PÚBLICOS. El ladrillo. Bases de la política económica del gobierno militar chileno. CEP. (Reedición). Santiago de Chile. 1992.

CIPER CHILE. "Cómo se ha desmantelado la salud pública.” [En línea] 25 de mayo del 2005. [fecha de consulta 23 de agosto del 2015]. Disponible en internet: $<\underline{\text { http://ciperchile.cl/2013/05/27/como-se-ha-desmantelado-la-salud-publica/> }}$

CIPER CHILE. "Hijos de Piñera y de Pizarro y sur consultores. Los nombres y conexiones políticas detrás de las empresas que facturaron a SQM” [En línea] 2 de abril del 2015. [fecha de consulta 12 de abril del 2014]. Disponible en internet: < http://ciperchile.cl/2015/04/02/los-nombres-y-conexiones-politicas-detras-de-lasempresas-que-facturaron-a-sqm/> 
CIPER. "Trabajar en una economía de la deuda" [en línea]. 20 de julio de 2015 [fecha de consulta 12 de agosto de 2015] Disponible en internet: < http://ciperchile.cl/2015/07/20/trabajar-en-una-economia-de-la-deuda/>

CIPERCHILE. "CAE: Cómo se creó y opera el crédito que le deja a los bancos ganancias por \$150 mil millones” [En línea] 20 de Diciembre del 2011. [fecha de consulta 3 de mayo del 2012]. Disponible en internet:: $<$ http://ciperchile.cl/2011/12/20/cae-como-se-creo-yopera-el-credito-que-le-deja-a-los-bancos-ganancias-por-150-mil-millones/>

CLARIN. "Sebastián Piñera: cuna de clase media y una fortuna de US\$ 1.200 millones" [En línea] 18 de enero del 2010. [fecha de consulta 12 de abril del 2014]. Disponible en internet: $\quad<$ http://www.ieco.clarin.com/economia/Sebastian-millones-fortuna-clase$\underline{\text { media } 0 \quad 191980815 . h t m l}>$

CLARO, Susana. "Chile lidera ranking educacional en América Latina. Avances y desafíos para Chile de acuerdo a TERCE”. Puntos de referencia CEP Chile. 2013.

CLAUDE, Marcel. El retorno de Fausto. Ricardo Lagos y la concentración del poder económico. Ediciones Política y Utopía, Santiago. 2006.

CLAUDE, Marcel. Una vez más la miseria: ¿Es Chile un país sustentable?. Editorial LOM. Chile. 1997.

CNN CHILE. "El drama de las pensiones de jubilación” [En línea] 13 de junio del 2013. [fecha de consulta 23 de agosto del 2015]. Disponible en internet: < http://www.cnnchile.com/noticia/2013/06/13/el-drama-de-las-pensiones-de-jubilacion->

COLLIER, Ruth Berins y COLLIER, David Shaping the Political Arena: Critical Junctures, the Labor Movement, and the Regime Dynamics in Latin America. Princeton University Press. Princeton. 1991. 
COLLIER, Simon y SATER, William. Historia de Chile, 1808-1994. Cambridge University Press, Sucursal España, Madrid. 1998.

COLLINS, Cath. "Exceso de profesionalización, exceso de privatización." Conferencia Experiencias nacionales e internacionales de Museos de la Memoria. Santiago de Chile. 2009.

COLLINS, Cath. "grounding global justice: International networks and domestic human right accountability in Chile and El Salvador. Journal of latinoamerica studies. Vol. 38. № 4. 2006. pp. 711-738.

COLLINS, Cath. "State terror and the law: The (Re) judicialization of human right accountability in Chile and El Salvador. Latinoamerican perspectives. Vol. 35, $\mathrm{N}^{\mathrm{o}} 5$, 2008. pp. 20-37.

COLLINS, Cath. HITE, Katherine y JOIGNANT, Alfredo. Las políticas de la memoria en Chile: desde Pinochet a Bachelet. Ed. UDP. Chile. 2013.

COLLINS, Cath. HITE, Katherine y JOIGNANT, Alfredo. Las politicas de la memoria en Chile: desde Pinochet a Bachelet. Editorial UDP. Chile. 2013.

COMISIÓN NACIONAL DE REPARACIÓN Y RECONCILIACIÓN. Informe sobre calificación de víctimas de violaciones de los derechos humanos y de la violencia política. Santiago: Comisión Nacional de Reparación y Reconciliación, Chile. 1996.

COMISIÓN NACIONAL DE VERDAD Y RECONCILIACIÓN, Informe Rettig. Dos volúmenes. Santiago: La Nación, 1991. 
COMISIÓN NACIONAL SOBRE PRISIÓN POLÍTICA Y TORTURA. Informe de la Comisión Nacional sobre política y tortura. Chile [fecha de consulta 3 de mayo del 2011] disponible en internet: $<$ http://www.comisionvalech.gov.cl/InformeValech.html $>$

CONGRESO NACIONAL. "Reseña Biográfica Parlamentaria: Sebastián Piñera Echenique”. [En línea] [fecha de consulta 12 de marzo del 2015]. Disponible en internet: $<\underline{\text { http://historiapolitica.bcn.cl/resenas parlamentarias/wiki/Sebastián_Piñera_Echenique }>}$

CONNERTON, Paul. How Societes Remember, Cambridge University Press, UK. 1989.

COOPERATIVA. "EL caso Chispas" [En línea] 12 de enero de 2006 [fecha de consulta 12 de abril del 2014]. Disponible en internet: $<$ http://www.cooperativa.cl/noticias/pais/sebastian-pinera/el-caso-chispas/2006-0112/080740.html>

COOPERATIVA. "Presidente Lagos: Reformas constitucionales marcan el fin de la transición" 14 de Julio de 2005 [fecha de consulta: 10 de junio del 2015]. Disponible en internet: $<$ http://www.cooperativa.cl/noticias/pais/politica/reformas-constitucionales/presidentelagos-reformas-constitucionales-marcan-el-fin-de-la-transicion/2005-0714/100948.html >

COOPERATIVA. "Sebastián Piñera: En 20 días hemos avanzado más que otros en 20 años" [En línea] 1 de abril del 2010. [fecha de consulta 12 de abril del 2014]. Disponible en internet: $\quad<$ http://www.cooperativa.cl/noticias/pais/sismos/catastrofe-en-chile/sebastianpinera-en-20-dias-hemos-avanzado-mas-que-otros-en-20-anos/2010-04$\underline{01 / 133613 . h t m l}>$ 
CORPORACIÓN Latinobarómetro. Informe Anual 2010. [fecha de consulta 3 de mayo del 2011] Santiago de Chile. Diciembre 2010. Disponible en internet: $<$ http://www.latinobarometro.org/latino/LATContenidos.jpp $>$

CORREA, Sofía. Con las Riendas del Poder. La Derecha Chilena en el Siglo XX. Editorial Sudamericana. Chile. 2005.

CORVALÁN, Luis. Camino de Victoria. Editorial Horizonte, Chile. 1971.

CORVALÁN, Luis. El Gobierno de Salvador Allende, Editorial LOM, Chile, 2003.

CORVALÁN, Luis. Nacionalismo y Autoritarismo durante el siglo XX en Chile. Los orígenes, 1903-1931, Ediciones UCSH, Santiago. 2009.

COX, Cristián; GYSLING, Jacqueline. La formación del profesorado en Chile, 1842-1987. CIDE, Chile. 1990.

COX, Cristián. (Ed.). Políticas Educacionales en el cambio de siglo. La reforma del sistema escolar en Chile. Editorial Universitaria. Santiago de Chile. 2003.

COZZI, Adolfo. Estadio Nacional. Editorial Sudamericana, Santiago de Chile. 2000.

CRISTI, Renato. El pensamiento político de Jaime Guzmán. Autoridad y libertad. Editorial LOM, Santiago de Chile. 2000.

CRUZ-COKE, Ricardo. Historia electoral de Chile 1925-1973. Editorial Jurídica. Chile. 1984.

CUESTA Josefina. Historia del presente. Madrid: EUDEMA, España. 1993.

CUESTA. Josefina. "Memoria e historia. Un estado de la cuestión". Ayer, No. 32, Memoria e historia. 1998. 
CHILE B "Listas de espera: el túnel sin salida de la salud pública en Chile. [En línea] 25 de julio del 2015. [fecha de consulta 23 de agosto del 2015]. Disponible en internet: $<$ http://www.chileb.cl/reporteros/listas-de-espera-el-tunel-sin-salida-de-la-saludpublica-en-chile/>

CHOMSKY, Noam. La (des) educación. Editorial Crítica. Barcelona. 2001.

DA SILVA CATELA, Ludmila y JELIN, Elizabeth (comps.), Los archivos de la represión: documentos, memoria y verdad. Siglo XXI, Madrid. 2002.

DAHL, Robert. Democracy and its Critics Yale U. Press, New haven. 1989.

DAHL, Robert. La poliarquía. Participación y oposición. Tecnos. Madrid, 1989.

DAZA, Loreto y DE SOLAR, Bernardita. Piñera. Historia de ascenso. Editorial Debate. 2011.

DEL ALCÁZAR, Joan. Chile en la pantalla. Cine para escribir y enseñar la historia (19701998). Publicacions de la Universitat de València - Centro de Investigaciones Diego Barros Arana, Valencia. 2013.

DEL ALCÁZAR, Joan. Et. Al. Historia contemporánea de América. PUV. Valencia. 2002.

DEL ALCÁZAR, Joan. Yo pisaré las calles nuevamente: Chile, revolución, dictadura, democracia (1970-2006). Santiago de Chile: Editorial Universidad Bolivariana, 2009.

DEL VILLAR Rafael, MURILLO José Antonio y BACKAL Daniel. "La crisis financiera en Asia: orígenes y evolución en 1997 y 1998”. Documento de Investigación No 9807 Dirección General de Investigación Económica Banco de México. Diciembre de 1998.

DELANO, Manuel y TRASLAVIÑA, Hugo. La herencia de los Chicago boys. Ediciones del Ornitorrinco. Santiago 1989. 
DIAMOND, Larry. "Reconsideración del nexo entre desarrollo económico y democracia". Estudios Públicos 49. 1993. pp. 37-98.

DIARIO OFICIAL. 2 de octubre de 1973.

DIARÍO PÚBLICO. "La transición de Chile tras Pinochet siguió el modelo español" 10 de abril del 2013. [en línea] Santiago de Chile. 14 de marzo de 1983. [fecha de consulta 12 de diciembre de 2014] disponible en internet $<$ http://www.publico.es/culturas/transicionchile-pinochet-siguio-modelo.html>

DIARIO UDECHILE. "Consumidores por caso Farmacias: "Los delitos de cuello y corbata siempre quedan en la impunidad" [en línea]. 23 de junio 2015. [fecha de consulta 12 de julio de 2015] Disponible en internet: $<\underline{\text { http: } / / \text { radio.uchile.cl/2015/06/23/consumidores- }}$ por-caso-farmacias-los-delitos-de-cuello-y-corbata-siempre-quedan-en-la-impunidad >

DÍAZ BARRADO, Mario P. (coord.) Historia del tiempo presente. Teoría y metodología Universidad de Extremadura, Cáceres. 1998.

DIEZ, Sergio. Reflexiones sobre la Constitución de 1980. 50 años de un actor y testigo de la vida política chilena. E1 Mercurio-Aguilar. Chile. 2013.

DONOSO, Sebastián. "Reforma y política educacional en Chile 1990-2004: El neoliberalismo en crisis." [En línea]. Estudios pedagógicos vol.31, №.1. 2005. p.113-135. [fecha de consulta 3 de mayo del 2011]. Disponible en internet:: $<\underline{\mathrm{http}}$ ://mingaonline.uach.cl/scielo.php?script=sci arttext\&pid=S0718$\underline{07052005000100007 \& \operatorname{lng}=\mathrm{es} \& \mathrm{nrm}=\mathrm{iso}}>$

DORAT, Carlos y WIBEL, Mauricio. Asociación ilícita. Los archivos secretos de la dictadura. CEIBO Ediciones. 2012. 
DRAKE, Paul y JAKSIC, Ivan (comp.) El Modelo Chileno. Democracia y Desarrollo en los Noventa”, Editorial LOM, Santiago de Chile. 1999.

DRAKE, Paul y JAKSIC, Ivan (ed.). El dificil camino hacia la Democracia en Chile 19821990. FLACSO-Chile. Santiago de Chile. 1993.

DURÁN, Gonzalo y KREMERMAN Marco. Salario Mínimo y CASEN 2013 Trabajadores ganando el salario mínimo o menos en Chile. [en línea]. Documento Fundación SOL. Julio 2015. [fecha de consulta 12 de julio de 2015]. Disponible en internet: $<$ http://www.fundacionsol.cl/wp-content/uploads/2015/07/estudiosalariominimo.pdf $>$

DURÁN, Sergio. Ríe cuando todos estén tristes. El entretenimiento televisivo bajo la dictadura de Pinochet, Editorial LOM. Santiago de Chile. 2012.

EASTMAN. Jorge. De Allende y Pinochet al "milagro" chileno. Editorial Ariel, 1997.

EGÍO, José Luis. "Políticas del rompeolas". $\Delta \alpha \mu \omega \omega v$ Revista de Filosofia, № 39, 2006.

EL COMERCIO. “Alan García: El modelo económico chileno-peruano es el más eficaz" [en línea] 20 de enero del 2011. [fecha de consulta 12 de octubre de 2013] disponible en internet $<\underline{\text { http://elcomercio.pe/politica/gobierno/alan-garcia-modelo-economico-chileno- }}$ peruano-mas-eficaz-noticia-701285>

EL MERCURIO, Santiago de Chile, 9 de Julio de 1977.

EL MOSTRADOR “Las cuentas pendientes de la Concertación en DD.HH.” [En línea] 30 de agosto del 2015. [fecha de consulta: 1 de septiembre del 2015]. Disponible en internet: $<$ http://www.elmostrador.cl/noticias/pais/2015/07/30/las-cuentas-pendientes-de-la$\underline{\text { concertacion-en-dd-hh/> }}$ 
EL MOSTRADOR. “"Tusunami": La lista de errores y lapsus de Piñera a un año del terremoto” [En línea] 28 de febrero del 2011. [fecha de consulta 12 de abril del 2014]. Disponible en internet: $\quad<\underline{\text { http://www.elmostrador.cl/noticias/pais/2011/02/28/tusunami-la-lista-de- }}$ errores-y-lapsus-de-pinera-a-un-ano-del-terremoto/>

EL MOSTRADOR. "Columna: De la democracia protegida a la controlada" [en línea]. 1 de abril del 2015. [fecha de consulta 12 de agosto de 2015] Disponible en internet: < http://www.elmostrador.cl/noticias/opinion/2015/04/01/de-la-democracia-protegida-a$\underline{\text { la-controlada/> }}$

EL MOSTRADOR. "Chile, un país-estafa.” [en línea]. 6 de julio de 2014 [fecha de consulta 12 de mayo de 2015] Disponible en internet: $<\underline{\text { http://www.elmostrador.cl/noticias/opinion/2014/07/06/chile-un-pais- }}$

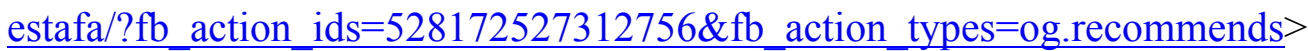

EL MOSTRADOR. "Exclusivo: todas las verdades del expediente de la quiebra del Banco de Talca" [En línea] 19 de julio de 2009 [fecha de consulta 12 de abril del 2014]. Disponible en internet: < http://www.elmostrador.cl/noticias/pais/2009/07/29/exclusivo-todas-lasverdades-del-expediente-de-la-quiebra-del-banco-de-talca/>

EL MOSTRADOR. "Héctor Salazar sobre supuesta cita de Carmen Gloria Quintana con Enrique Correa: "No me acuerdo" [En línea] 23 de julio del 2015. [fecha de consulta: 25 de julio del 2015]. Disponible en internet: < http://www.elmostrador.cl/noticias/pais/2015/07/23/hector-salazar-sobre-supuesta-cita$\underline{\text { de-carmen-gloria-quintana-con-enrique-correa-no-me-acuerdo/ }>}$

EL MOSTRADOR. "La “tercera vía” de Piñera”. [En línea] 16 de octubre del 2013 [fecha de consulta 12 de agosto del 2015]. Disponible en internet: $<\underline{\text { http://www.elmostrador.cl/noticias/pais/2013/10/16/la-tercera-via-de-pinera/ }>}$ 
EL MOSTRADOR. "Rafael Caviedes: "Hay espacio para llegar a un acuerdo histórico que cambie radicalmente el modelo de salud" [En línea] 19 agosto 2015. [fecha de consulta 23 de agosto del 2015]. Disponible en internet: < http://www.elmostrador.cl/mercados/2015/08/19/rafael-caviedes-hay-espacio-para$\underline{\text { llegar-a-un-acuerdo-historico-que-cambie-radicalmente-el-modelo-de-salud/> }}$

EL MOSTRADOR. "Ranking Forbes: Familia Luksic nuevamente lidera chilenos entre las mayores fortunas del mundo" [en línea]. 2 de marzo 2015. [fecha de consulta 12 de mayo de 2015] Disponible en internet: $<$ http://www.elmostrador.cl/mercados/2015/03/02/ranking-forbes-familia-luksicnuevamente-lidera-chilenos-entre-las-mayores-fortunas-del-mundo/>

EL MOSTRADOR. "SQM: Conflicto de interés llega al Congreso y piden inhabilitarse a parlamentarios en votación del caso Cascadas" [en línea]. 7 abril 2015. [fecha de consulta 12 de julio de 2015] Disponible en internet: $<$ http://www.elmostrador.cl/noticias/pais/2015/04/07/sqm-conflicto-de-interes-llega-alcongreso-y-piden-inhabilitarse-a-parlamentarios-en-comision-del-caso-cascadas/>

EL MUNDO. “Piñera un hombre forjado a si mismo.” [En línea] 11 de marzo del 2010. [fecha de consulta 12 de abril del 2014]. Disponible en internet: < http://archivo.eluniversal.com.mx/notas/665339.html>

EL PAÍS. “Aylwin reitera que investigará a fondo la violación de los derechos humanos en Chile" [En línea] 2 de Enero de 1991. [fecha de consulta: 5 de mayo del 2015]. Disponible

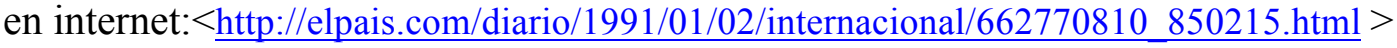

EL PAÍS. “Chile conmueve al mundo con el rescate de los 33 mineros” [En línea] 14 de octubre del 2010. [fecha de consulta 12 de agosto del 2015]. Disponible en 
internet: $<$ http://internacional.elpais.com/internacional/2010/10/12/actualidad/12868344 $\underline{09}$ 850215.html>

EL PAÍS. "Pinochet rechaza el acuerdo nacional propuesto por la oposición" [En línea] 22 de Diciembre de1985. [fecha de consulta: 3 de mayo del 2012]. Disponible en internet: http://elpais.com/diario/1985/12/22/internacional/504054014 850215.html

EL PAÍS. "Los chilenos, por primera vez desde el golpe de Pinochet, pueden inscribirse para votar". 2 de febrero de 1987. [fecha de consulta: 3 de diciembre del 2015]. Disponible en internet:

$<\underline{\text { http://elpais.com/diario/1987/02/26/internacional/541292415 850215.html }>}$

EL QUINTO PODER. “Los “cómplices pasivos” [En línea] 11 de septiembre del 2013 [fecha de consulta 12 de agosto del 2015]. Disponible en internet: < http://www.elquintopoder.cl/politica/los-complices-pasivos/>

EL QUINTO PODER. "Los secretos del árbol genealógico de Piñera” [En línea] 16 de junio del 2011. [fecha de consulta 12 de marzo del 2015]. Disponible en internet: $<\underline{\text { http://www.elquintopoder.cl/politica/los-secretos-del-arbol-genealogico-de-pinera/ }>}$

ELQUINTOPODER. "Clínicas Privadas e Isapres: El Negocio de la Salud”. [En línea] 11 de febrero del 2011. [fecha de consulta 23 de agosto del 2015]. Disponible en internet: $<\underline{\text { http://www.elquintopoder.cl/salud/clinicas-privadas-e-isapres-el-negocio-de-la-salud/> }}$

ELTER, Doris. Sistema de A.F.P. chileno: injusticia de un modelo. Editorial LOM. Chile.1999.

EMOL "Caso Quemados: PS valora fin de pacto de silencio e insta a uniformados a seguir actuar de ex conscripto". 22 de julio del 2015. [fecha de consulta: 23 de junio del 2015]. Disponible

en internet:

$<$ http://www.emol.com/noticias/Nacional/2015/07/22/735344/Caso-Quemados-PS- 
valora-fin-de-pacto-de-silencio-e-insta-a-uniformados-a-seguir-actuar-de-exconscripto.html>

EMOL. "Encuesta CERC refleja nueva caída en popularidad de Presidente Piñera". [En línea] 27 de septiembre de 2011 [fecha de consulta 12 de marzo del 2015]. Disponible en internet: $\quad<$ http://www.emol.com/noticias/nacional/2011/09/27/505240/encuesta-cercrefleja-nueva-caida-de-popularidad-del-presidente.html >

EMOL. "La historia de Pinochet en algunas de sus más célebres frases." 10 de diciembre de 2006 [fecha de consulta: 10 de diciembre del 2013]. Disponible en internet: $<$ http://www.emol.com/noticias/nacional/2006/12/10/238587/la-historia-de-pinocheten-algunas-de-sus-mas-celebres-frases.html>

EMOL. "Piñera y sus acciones en FASA: "No sabía que las tenía" [En línea] 27 de marzo del 2009 [fecha de consulta 12 de abril del 2014]. Disponible en internet: $<\underline{\text { http://www.emol.com/noticias/nacional/detalle/detallenoticias.asp?idnoticia }=350965>}$

ESCALONA, Camilo. Chile, 20 años después 1988-2008. Editorial Diagrama. Santiago de Chile. 2008.

ESCALONA, Camilo. Una Transición de dos caras. Crónica crítica y autocrítica, Editorial LOM, Santiago de Chile. 1999

ESTEVEZ, Francisco Javier. “Columna: De la Constitución de 1980 y la Crisis de la República Elitista " 28 de abril del 2015 [fecha de consulta: 1 de julio del 2015]. Disponible en internet: < http://radio.uchile.cl/2015/04/28/de-la-constitucion-de-1980-y-la-crisis-de-la$\underline{\text { republica-elitista> }}$

ESTÉVEZ, Jorge. "La "democracia protegida" en Chile" . Revista de Sociología. FACSO. № 21. 2007. 
FARÍAS, Víctor. La izquierda chilena (1969-1973): documentos para el estudio de su línea estratégica. Berlín, Wissenschaftlicher Verlag. Berlin. 2000.

FARIÑA, Carmen. “Génesis y Significación de las Ley de Partidos Políticos”. Estudios Públicos. No 271987.

FERMANDOIS, Joaquín. La Revolución inconclusa. La izquierda chilena y el gobierno de la unidad Popular. Estudios Públicos. 2013.

FERNÁNDEZ, David. La "Iglesia" que resistió a Pinochet: historia, desde la fuente oral, del Chile que no puede olvidarse. IEPALA. Madrid.1996.

FERNÁNDEZ, Mario. 1988. "El proyecto de ley electoral chilena de agosto de 1988. Análisis de algunos de sus fundamentos y alcances". Estudios Sociales. 59. 1988. pp.45-61.

FERNÁNDEZ, Miguel Ángel. “Origen, legitimidad y consolidación de la Constitución.” Revista de Derecho de la Universidad Católica de Valparaíso XXII , 2001.

FERNÁNDEZ, Sergio. Mi lucha por la Democracia. $2^{\mathrm{a}}$ ed., Santiago de Chile: Los Andes, 1997.

FONTAINE, Arturo. La historia no contada de los economistas y el presidente Pinochet. Editorial Zig-Zag. Santiago de Chile. 1988.

FONTAINE, Arturo. La historia no contada de los Economistas y el Presidente Pinochet. Editorial Zig-Zag. Chile.1988.

FONTAINE, Juan Andrés. “Transición económica y política en Chile: 1970-1990” Estudios Públicos, N50. 1993.

FOXLEY, Alejandro. "Experimentos neoliberales en América Latina.” Estudios CIEPLAN. 7. 1982. 
FOXLEY, Alejandro. La economía política de la Transición. Dolmen, Santiago de Chile. 1993.

FRIEDMAN, Milton. "Bases para un el desarrollo económico. Versión de la conferencia publica ofrecida por el Dr. Milton Friedman en el Edificio Diego Portales de Santiago, el 26 de marzo de 1975." En: VVAA. Un legado de libertad. Milton Friedman en Chile. Instituto Democracia y Mercado /Atlas Economic Research Foundation / Fundación para el Progreso, 2012. pp. 17-62.

FRIEDMANN, Reinhard. La Política Chilena de la A a la Z. Melquíades. Servicio Editorial. Santiago de Chile. 1988.

FUENTES, Claudio y RÍOS, Marcela. (Ed.). Una Reforma Necesaria. Efectos del Sistema Binominal. FLACSO. Chile. 2006.

FUENTES, Claudio. El Fraude. Crónica sobre el plebiscito de la constitución 1980. Editorial Hueders. Chile. 2013.

FUENTES, Claudio. La transición de los militares. Editorial LOM. Chile. 2006

FUKUYAMA, Francis. The end of History and the last Man. Free press. 1992.

FUNDACION SOL. Presentación Fundación SOL para Comisión Asesora Presidencial sobre el Sistema de Pensiones. Cuaderno de Trabajo. Chile. 2014.

GAETE, María Elena. “La Transición del Régimen de Reparto al de Ahorro Individual.” En: ARIZTÍA. Juan. AFP: Las tres letras que revolucionan América. CIEDESS. Chile. 1997.

GARCÉS, Joan. Allende y la experiencia chilena. BAT Ediciones. Santiago de Chile. 1990.

GARCÉS, Joan. El estado y los problemas tácticos en el gobierno de Allende. Editorial Siglo XXI S.A. Madrid.1974. 
GARCÉS, Mario. (comp.), Memoria para un nuevo siglo: Chile, miradas a la segunda mitad del siglo XX. LOM/ECO, Chile. 2000.

GARCÍA-HUIDOBRO Juan E. (Ed.). La Reforma Educacional Chilena. Editorial Popular. Madrid. 1999.

GARCIA-HUIDOBRO, Juan E. y BELLEI, Cristián. Desigualdad educativa en Chile. Santiago: Universidad Alberto Hurtado. Chile. 2003.

GARCIA, René. Soy testigo. Dictadura, tortura e injusticia. Editorial Amerinda. Santiago de Chile. 1990.

GARRETÓN, Manuel A. "La transición chilena. Una evaluación provisoria”. Documento de Trabajo FLACSO. Serie Estudios Políticos, 8. Enero de 1991.

GARRETÓN, Manuel A. “Las revanchas de la democratización incompleta”. Mensaje. 1999.

GARRETÓN, Manuel A. y GARRETÓN, Roberto. "La Democracia incompleta en Chile: la realidad tras los rankings internacionales". Revista de Ciencia Política. Vol. 30, No. 1, 2010.

GARRETÓN, Manuel A. y RAMMSY, Claudio. Iglesia y Transición en Chile. Ediciones Rehue. Santiago de Chile. 1990.

GARRETÓN, Manuel Antonio. "Revisando las transiciones democráticas en América Latina”. Revista Nueva sociedad. Chile, 1997.

GARRETÓN, Manuel Antonio. Del Pinochetismo a la sociedad democrática. Globalización y politica en el Bicentenario. Debate, Santiago de Chile. 2007.

GARRETON, Manuel Antonio. El plebiscito de 1988 y la transición a la democracia. FLACSO. Chile.1988. 
GARRETÓN, Manuel y MOULIAN, Tomás. La Unidad Popular y el conflicto político en Chile, Ediciones Chile América CESOC y LOM Ediciones, Santiago de Chile 1993.

GARRETÓN, Manuel. El plebiscito de 1988 y la Transición a la Democracia. Editorial FLACSO. Santiago de Chile. 1988.

GAZMURI Cristián, ARANCIBIA Patricia, GÓNGORA, Álvaro. Eduardo Frei Montalva : 1911-1982. Fondo de Cultura Económica : Fundación Eduardo Frei Montalva, México. 1996.

GAZMURI, Cristian. ¿Quién era Jaime Guzmán?. Editorial RIL. Chile. 2013.

GAZMURI, Cristian. "El Lugar de Pinochet en la Historia: Una Interpretación Política de la Experiencia Autoritaria 1973-1990” [en línea]. Diario La Tercera, 1999 [fecha de consulta 12 de octubre del 2011] disponible en internet en $<\underline{\text { http://www.uc.cl/historia/cinfo/Articulos/gazmuri7.htm }>}$

GAZMURI, Cristián. "Nueva Historia de Chile: Desde los Orígenes Hasta Nuestros Días”, Editorial Zig-Zag, Santiago de Chile. 1996.

GAZMURI, Cristián. La Historiografia Chilena 1842.-1970. Tomo 2. Editorial Aguilar. Santiago de Chile. 2009.

GAZMURI, Cristián. La Persistencia de la Memoria. Reflexiones de un civil sobre la Dictadura. Ril Editores, Santiago de Chile. 2000.

GESTION. "Las AFP en el Perú y el nuevo enfoque de las pensiones” [En línea] 28 de mayo del 2015 [fecha de consulta 13 de junio del 2015]. Disponible en internet: $<\underline{\text { http://gestion.pe/economia/afp-peru-y-nuevo-enfoque-pensiones-2132834> }}$ 
GOBIERNO DE CHILE. "Fin al binominal: Conoce el nuevo sistema electoral” [En línea] 27 de abril del 2015. [fecha de consulta 13 de junio del 2015]. Disponible en internet: $<$ http://www.gob.cl/2015/04/27/fin-al-binominal-conoce-el-nuevo-sistema-electoral/>

GODOY, Oscar. "Algunas Claves de la Transición Política en Chile”. Estudios Públicos. N $38,1990$.

GODOY, Oscar. "La transición chilena a la democracia: pactada. Estudios Públicos. № 74. 1999

GOICOVIC, Igor. “La refundación del capitalismo y la transición democrática en chile (19732004)." HAOL, Nº 10 Primavera, 2006.

GREZ, Sergio. La cuestión social en Chile: ideas y debates precursores (1804-1902). DIBAM, Chile. 1997.

GROPPO, Bruno y FLIER, Patricia (comps.), La imposibilidad del olvido: recorridos de la memoria en Argentina, Chile y Uruguay. Ediciones Al Margen, La Plata. 2001.

GRUPO DE LOS 24. "Bases Fundamentales de la Reforma Constitucional.” Octubre de 1979 [fecha de consulta: 1 de julio del 2015]. Disponible en internet: $<\underline{\text { http://www.blest.eu/lex/grupo24.html }>}$

GÜELL, Pedro. “Desarrollo Humano y ciudadanía en Chile: los nuevos desafíos” [en línea]. Revista Polis $\mathrm{N}^{\mathrm{o}}$ 12, 2005. [fecha de consulta: 3 de mayo del 2011]. Disponible en internet: $<$ http://www.revistapolis.cl/12/guell.htm $>$

GUTIÉRREZ, Tamara y CAVIEDES, Cristina. Revolución Pingüina: la primera gran movilización del siglo XXI en Chile. Editorial Ayun, Chile:. 2006. 
GUTTMAN, Cynthia. Todos los niños pueden aprender. El programa de las escuelas para lo sectores pobres de Chile. UNESCO. 1994.

GUZMÁN, Jaime. “El sentido de la Transición”. Revista Realidad, Nº 38, julio de 1982.

GUZMÁN, Jaime. Escritos Personales. Editorial Zig-Zag. Santiago de Chile. 1993.

HALBWACHS, Maurice. On Collective Memory. University Press, Chicago. 1992.

HARDY. Clarisa. La reforma social pendiente. Ediciones de Chile 21. Chile. 1997.

HEISSE GONZÁLEZ, Julio.. "Del autoritarismo al régimen parlamentario" Revista Chilena de Historia y Geografía, (138). 1970. pp. 140-174.

HERRERA, Hugo. La derecha en la crisis del bicentenario. Ediciones UDP. Chile. 2015.

HIGLEY, John y BURTON, Michael. "Elite Settlements”.American Sociological Review, Vol. 52, No 3. Jun 1987. pp. 295-307.

HIGLEY, John. "Elite Theory in Political Sociology”. Paper IPSA. 2008.

HINER, Hillary. "Voces soterradas, violencias ignoradas: Discurso, violencia política y género en los Informes Rettig y Valech.” Latin American Research Review. Vol. 44, Nª 3. 2009. pp. 50-74.

HITE, Katherine. "Breaking the Pacto de Silencio: Memories of defeat, contemporary politics, and the Chilean political class in the 1990s". Latin American Research Review. October 16-17. 2003.

HONORABLE JUNTA DE GOBIERNO. Constitución Politica de la República de Chile, Art. $8^{\mathrm{a}}$, S. 1980. 
HUNEEUS Carlos, MARTÍN Jorgelina. El Régimen de Pinochet. Editorial Sudamericana. Chile. 2000.

HUNEEUS, Carlos (ed.) Para vivir en Democracia, dilemas para su consolidación. CERC. Santiago. 1984.

HUNEEUS, Carlos Los chilenos y la política. Cambio y continuidad en el Autoritarismo, Santiago de Chile: Editorial Fundación Konrad, Adenauer RFA, 1987.

HUNEEUS, Carlos; GODOY, Oscar; GARRETÓN, Manuel A. “¿Terminó ya el proceso de Transición?” Revista de Ciencia Política. No. 1-2, 1994. pp. 9-40.

HUNEEUS, Carlos. La democracia semisoberana: Chile después de Pinochet. Editorial Taurus. Chile. 2014.

HUNEEUS, Carlos. “Tecnócratas y políticos en un régimen autoritario. Los Odeplan boys y los Gremialistas en el Chile de Pinochet.” Revista Ciencia Política. V. XIX. 1998.

HUNEEUS, Carlos. El Régimen de Pinochet . Editorial Sudamericana, Chile. 2000.

HUNEEUS, Carlos. La Reforma universitaria. Veinte años después. CPU, Chile 1988.

HUNTINGTON, Samuel P. La Tercera Ola. La democratización a finales del siglo XX, Buenos Aires: Paidós, 1994.

HUTCHISON, Elizabeth y ORELLANA, Patricio. El movimiento de derechos humanos en Chile, 1973-1990. Centro de Estudios Políticos Latinoamericanos Simón Bolívar, Chile. 1991.

ILLANES, María Angélica. La batalla de la memoria, Santiago de Chile: Ed. Planeta. 2002. 
INSTITUTO NACIONAL DE DERECHOS HUMANOS. Informe anual. Situación de los derechos humanos en Chile. [En línea] Gobierno de Chile. 2010. [fecha de consulta 2 de marzo de 2014] disponible en internet < http://www.indh.cl/primer-informe-anual-2010de-derechos humanos-en- chile $>$

INSUNZA, Andrea y ORTEGA, Javier (Eds.). Los archivos del cardenal. Casos reales. Editorial Catalonia-UDP. Chile. 2011.

INSUNZA, Andrea y ORTEGA, Javier (Eds.). Los archivos del cardenal 2. Casos reales. Editorial Catalonia. Chile. 2014.

JADRESIC, Alfredo. La reforma de 1968 en la Universidad de Chile. Editorial Universitaria. Chile. 2002.

JAKSON, Giorgio. "La Mala Educación: ideas que inspiran al movimiento estudiantil en Chile. [en línea]. Revista on line Paradigmas del siglo XXI. 12 de junio 2012. [fecha de consulta 12 de mayo de 2015] Disponible en internet: $<$ http://paradigmasenelsigloxxi.wordpress.com/2012/06/12/la-mala-educacion-ideasque-inspiran-al-movimiento-estudiantil-en-chile-giorgio-jackson/>

JDC. La democracia cristiana y la revolución en libertad. La Nación. Chile. 1965.

JELIN, Elizabeth (comp.), Las conmemoraciones: las disputas en las fechas "in-felices". Siglo XXI, Madrid. 2002.

JELIN, Elizabeth y LANGLAND, Victoria (comps.), Monumentos, memoriales y marcas territoriales. Siglo XXI, Madrid. 2003.

JOCELYN -HOLT LETELIER, Alfredo. El Chile Perplejo. Del Avanzar Sin Transar al Transar Sin Parar. Santiago de Chile: Editorial Planeta / Ariel, 1998. 
JOIGNANT, Alfredo y GÜELL, Pedro (ed.). Notables, tecnócratas y mandarines. Elementos de sociología de las elites en Chile (1990- 2010). Ediciones Universidad Diego Portales Santiago de Chile. 2011.

JUAN PABLO II. Mensajes de Juan Pablo II al pueblo de Chile. Editorial Salesiana. Santiago de Chile. 1987.

JULIÁ DÍAZ, Santos. "Raíces y legado de la transición.” En: SANTOS JULIÁ; PRADERA, J.; PRIETO, J. (coord.) Memoria de la transición. El País. España. 1996.

JUNTA MILITAR. Declaración de principios. 11 de Marzo de 1974.

JUNTA MILITAR. Objetivo nacional del Gobierno de Chile. Resolución 3102. 23 de diciembre de 1975.

KARL, Terry Lynn. "Dilemas de la democratización en América Latina”, Foro Internacional 31. 1991.

KLEIN, Naomi. La doctrina del shock: El auge del capitalismo del desastre. Planeta, España. 2012.

KNIGHT, Alan. Revolución Democracia y populismo en América Latina. Centro de estudios bicentenario. Chile. 2005.

KORNBLUH, Peter. Pinochet: Los Archivos Secretos. Barcelona: Critica. 2004.

KOSELLECK, Reinhart. Futuro pasado. Para una semántica de los tiempos histórico, Barcelona: Paidos, 1993.

KREBS, RICARDO. (et. al.) Nueva Historia de Chile: Desde los Orígenes Hasta Nuestros Días, Santiago de Chile: Editorial Zig-Zag, Instituto de Historia de la Pontificia Universidad Católica de Chile, Chile. 1996. 
LA NACIÓN “Revelan fraude en plebiscito que aprobó constitución de 1980.” 11 de Junio del 2012 [fecha de consulta: 1 de julio del 2015]. Disponible en internet: $<$ http://www.lanacion.cl/noticias/pais/politica/revelan-fraude-en-plebiscito-que-aproboconstitucion-de-1980/2012-06-11/115506.html>

LA NACION. "Inversionista en fuga: cuando Piñera arrancó de la justicia” [En línea] 19 de abril de 2009 [fecha de consulta 12 de marzo del 2015]. Disponible en internet: < http://www.lanacion.cl/noticias/site/artic/20090418/pags/20090418205903.html >

LA NACION. “Jaime Bellolio, el UDI que se desmarcó del minuto de silencio a Pinochet.” [En línea] 10 de diciembre del 2014. [fecha de consulta 12 de marzo del 2015]. Disponible en internet: $\quad<$ http://www.lanacion.cl/noticias/pais/politica/jaime-bellolio-el-udi-que-se$\underline{\text { desmarco-del-minuto-de-silencio-a-pinochet/2014-12-10/130326.html }>}$

LA TERCERA. “AFP Estatal: mala idea.” [En línea] 2 de septiembre del 2014 [fecha de consulta 13 de junio del 2015]. Disponible en internet: $<$ http://www.latercera.com/noticia/opinion/ideas-y-debates/2014/09/895-593986-9-afp$\underline{\text { estatal-mala-idea.shtml> }}$

LA TERCERA. “Autoridades e historiadores polemizan sobre el rol del Museo de la Memoria” 26 de junio del 2012. [fecha de consulta: 1 de junio del 2015]. Disponible en internet: $<$ http://www.emol.com/noticias/Nacional/2015/07/22/735344/Caso-Quemados-PS$\underline{\text { valora-fin-de-pacto-de-silencio-e-insta-a-uniformados-a-seguir-actuar-de-ex- }}$ conscripto.html>

LA TERCERA. “Caso Caval: Ejecutivo del Banco de Chile testifica que "en mis 16 años de experiencia primera vez que veo la concesión de un crédito de éstas características” [en línea]. 4 de agosto del 2015. [fecha de consulta 12 de agosto de 2015] Disponible en internet: < http://www.elmostrador.cl/noticias/pais/2015/08/04/caso-caval-ejecutivo-del- 
banco-de-chile-testifica-que-en-mis-16-anos-de-experiencia-primera-vez-que-veo-la$\underline{\text { concesion-de-un-credito-de-estas-caracteristicas/> }}$

LA TERCERA. "El largo camino que recorren los casos de DD.HH. en tribunales". [En línea] 14 de agosto del 2015. [fecha de consulta: 16 de agosto del 2015]. Disponible en internet: $<\underline{\text { http://www.latercera.com/noticia/nacional/2015/08/680-642882-9-el-largo-camino- }}$ que-recorren-los-casos-de-ddhh-en-tribunales.shtml>

LA TERCERA. "Las cinco claves de la Ley de Pesca que genera protestas en las ciudades portuarias de Chile" [en línea]. 11 de julio del 2012. [fecha de consulta 12 de julio de 2015] Disponible en internet: <http://www.latercera.com/noticia/nacional/2012/07/680471587-9-las-cinco-claves-de-la-ley-de-pesca-que-genera-protestas-en-lasciudades.shtml $>$

LA TERCERA. "Las isapres "generan situaciones de segregación y discriminación que no parecen aceptables" [En línea] 15 de marzo del 2015. [fecha de consulta 23 de agosto del 2015]. Disponible en internet: $<\underline{\text { http://diario.latercera.com/2014/03/15/01/contenido/pais/31-159911-9-las-isapres- }}$ generan-situaciones-de-segregacion-y-discriminacion-que-no-parecen.shtml>

LA TERCERA. "Lo que aprendió Piñera en Boston” [En línea] 9 de junio de febrero del 2015. [fecha de consulta 12 de agosto del 2015]. Disponible en internet: $<$ http://diario.latercera.com/2011/09/24/01/contenido/reportajes/25-84592-9-loque-aprendio-pinera-en-boston.shtml>

LA TERCERA. "Piñera anuncia cierre definitivo del penal Cordillera y traslado de los condenados a Punta Peuco" [En línea] 26 de septiembre del 2013 [fecha de consulta 12 de agosto del 2015]. Disponible en internet: 
$<\underline{\text { http://www.latercera.com/noticia/politica/2013/09/674-544295-9-pinera-anuncia- }}$ $\underline{\text { cierre-definitivo-del-penal-cordillera-y-traslado-de-los.shtml> }}$

LA TERCERA. "Piñera culmina gobierno con un 50\% de aprobación y 36\% de rechazo según la encuesta Adimark de febrero”. [En línea] 3 de marzo del 2014. [fecha de consulta 12 de agosto del 2015]. Disponible en internet: $<\underline{\text { http://www.latercera.com/noticia/politica/2014/03/674-567703-9-pinera-culmina- }}$ gobierno-con-un-50-de-aprobacion-y-36-de-rechazo-segun-la.shtml>

LA TERCERA. "Presidente Sebastián Piñera y su juicio a 40 años del Golpe: Hubo muchos que fueron cómplices pasivos: que sabían y no hicieron nada o no quisieron saber" [En línea] 31 de agosto del 2013. [fecha de consulta: 1 de junio del 2015]. Disponible en internet: $\quad<$ http://www.latercera.com/noticia/politica/2013/08/674-540379-9-pinera-y-

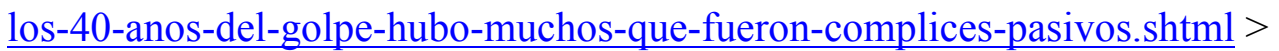

LA TERCERA. "Utilidades del sistema isapres suben 56\% y bordean los $\$ 60$ mil millones en 2014”. [En línea] 13 de marzo del 2005. [fecha de consulta 23 de agosto del 2015]. Disponible en internet: <http://www.latercera.com/noticia/nacional/2015/03/680620609-9-utilidades-del-sistema-isapres-suben-56-y-bordean-los--60-mil-millones-en2014.shtml>

LABRA, María E. "La reinvención neoliberal de la inequidad en Chile. El caso de la salud" Cadernos Saúde Pública, Ri 18 (4), jul-ago, 2002. pp. 1041-1052

LAGOS, Ricardo. Así lo vivimos. Taurus. Chile. 2013; DIEZ, Sergio. Reflexiones sobre la constitución de 1980. Aguilar. Chile. 2013.

LANDMAN, Todd. "Economic Development and Democracy: The View from Latin America”, Political Studies 47 (1). 1999. pp.607-626 
LARRAGAÑA, Osvaldo. El Estado Bienestar en Chile: 1910-2010. Programa de las Naciones Unidas para el Desarrollo, Chile. 2010.

LARRAÍN Carlos. "Carlos Larraín: "No nos va a doblar la mano una manga de inútiles subversivos" [en línea]. Publicado en La Tercera 6 de agosto 2011. [fecha de consulta 12 de mayo de 2015] Disponible en internet: < http://www.latercera.com/noticia/politica/2011/08/674-384606-9-carlos-larrain-no-nosva-a-doblar-la-mano-una-manga-de-inutiles-subversivos.shtml >;

LARRAÍN, Felipe y VERGARA Rodrigo (ed.). La transformación económica de Chile. Centro de Estudios Públicos, Chile. 2001.

LARRAIÍN, Felipe. "Nada es suficiente para los estudiantes" [en línea]. 22 de octubre 2011. Publicado en Soychile. . [fecha de consulta 12 de mayo de 2015] Disponible en internet: $<$ http://www.soychile.cl/Santiago/Sociedad/2011/08/22/33635/Larrain-Nada-es$\underline{\text { suficiente-para-los-estudiantes.aspx }>}$

LAVIN, Joaquín. Chile: Una revolución silenciosa. Editorial Zig-Zag, Chile. 1987.

LEE, Donald. Poliarchy. The Political Theory of Robert Dahl Gatland: N. York, 1991.

LINZ, Juan J. y STEPAN, Alfred (eds.), The Breakdown of Democratic Regimes, vols. 1, 2 y 3. Baltimore: John Hopkins, 1978.

LINZ, Juan J. "Totalitarianism and Authoritarian Regimes", En: GREENSTEIN, Fred y POLSBY, Nelson (eds.), Handbook of Political Science 3, Macropolitical Theory Reading, Mass.: Addison-Wesley Press. USA. 1975. pp. 175-411. 
LINZ, Juan J. y STEPAN, Alfred. Problems of Democratic Transition and Consolidation: Southern Europe, South America and Post-Communist Europe. The Johns Hopkins University Press. Baltimore. 1996.

LINZ, Juan J., "La transición española en perspectiva comparada". En TUSELL, Javier y SOTO, Álvaro (eds.), Historia de la transición 1975-1986, Alianza Universidad, Madrid. 1996.

LINZ, Juan y STEPAN, Alfred. (Ed). The breackdown of democratic regimens. John Hopkins University Press. Baltimore. 1978.

LINZ, Juan. J. "Del autoritarismo a la democracia”. Estudios públicos. 1986. pp. 5-58.

LINZ, Juan. Transiciones a la Democracia. REIS. N 51. 1990.

LIPSET, Seymour Martin. "Some Social Requisites of Democracy: Economic Development and Political Legitimacy”. American Political Science Review 53.. 1959. pp. 69-105.

LIPSET, Seymour Martin. "Democracy and Working-Class Authoritarianism", American Sociological Review 24 -4.. 1959. pp. 482-501

LIRA, Elizabeth; WEINSTEIN, Eugenia; ROJAS, María Eugenia. Trauma, Duelo y Reparación. Santiago de Chile: FASIC/Ed. Inter-Americana. 1987.

LOVEMAN Brian y LIRA Elizabeth. Arquitectura politica y seguridad interior del estado. Chile, 1811-1990. Dirección de Bibliotecas, Archivos y Museos - Universidad Jesuita Alberto Hurtado, Centro de Investigaciones Diego Barros Arana, Chile. 2002. pp. 345444. 
LOVEMAN, Brian y LIRA, Elizabeth. et al., Historia, política y ética de la verdad en Chile, 1891-2001: reflexiones sobre la paz social y la impunidad. Ediciones LOM, Chile. 2001.

LOVEMAN, Brian y LIRA, Elizabeth. Las ardientes cenizas del olvido: vía chilena de reconciliación política, 1932-1994. LOM/DIBAM, Chile. 2000.

LOVEMAN, Brian; LIRA, Elizabeth. Arquitectura politica y seguridad interior del estado: Chile 1811-1990, Dibam, Santiago, 2002.

LLANOS, Claudio. Cuando el pueblo unido fue vencido. Estudios sobre la vía chilena al socialismo. Editorial Univeristaria de Valparaíso. Chile. 2014.

MAGENDZO, Abraham, VENEROS, Diana, TOLEDO, María Isabel. Visita a un lugar de memoria. Guía para el trabajo en derechos humanos. Editorial LOM. Chile. 2010.

MAGENDZO, Abraham. Educación en derechos humanos. Editorial LOM. Chile. 2006.

MAGENDZO. Abraham. De miradas y mensajes en la educación de derechos humanos. Editorial LOM. Chile. 2004.

MAINWARING, Scott; O’DONNEL, Guillermo; VALENZUELA, J. Samuel. (Eds). Issues in democratic consolidation: The new south american democracies in comparative perspective. University of notredame press. Notre Dame. 1992.

MAIRA, Luis. “Chile, la Transición Interminable”. Editorial Grijalbo, Ciudad de México. 1999.

MAIRA, Luis. Los tres Chile de la segunda mitad del siglo XX. Editorial LOM. Chile. 1998.

MARCEL, Mario y ARENAS, Alberto. "Social security reform in Chile", Inter-American Development Bank, Occasional Papers, № 5, 1992. 
MARITAIN, Jacques. El hombre y el estado. Ediciones Encuentro. España. 1983.

MARTÍNEZ, Gerardo. "Causas de la gran depresión de los años treinta: Aportes recientes.” Revista Universitaria. PUC. Abril Nº 9. 1983.

MARTNER, Gonzalo y RIVERA, Eugenio (Editores). Radiografía crítica al modelo chileno. Balances y propuestas. LOM ediciones-USACH. 2013.

MARTNER, Gonzalo. Remodelar el modelo. Editorial LOM. 2007

MATEOS LÓPEZ, Abdón. Historia y memoria democrática. Eneida. Madrid. 2007.

MATEOS, Abdón. "Historia, Memoria, Tiempo Presente”. Hispania Nova, No 1. 1998.

MAYOL Alberto. El derrumbe del modelo. La crisis de la economía de mercado en el Chile contemporáneo. Editorial LOM. Chile. 2013.

MAYOL, Alberto y AHUMADA, José M. Economía politica del fracaso: la falsa modernización del modelo neoliberal. Editorial el Desconcierto. 2015.

MELLER, Patricio. Un siglo de economía política chilena (1890-1990). Editorial Andrés Bello. Chile 1996.

MENANTEAU-HORTA, Darío. "El rol del Estado en el desarrollo social y la Reforma de la previsión en Chile y EE.UU.” Revista Austral de Ciencias Sociales. No 10. 2006. pp. 522.

MÉNDEZ GODOY, Roberto, Oscar BARROS , Enrique FONTAINE TALAVERA, Arturo. “¿POR QUE GANO EL NO?. Análisis y exposición de la encuesta CEP-Adimark de septiembre de 1988” [En línea]. Centro de Estudios Públicos. Chile. 10 de octubre de 1988. [fecha de consulta: 3 de diciembre del 2015]. Disponible en internet: < http://www.cepchile.cl/dms/archivo 1190 1158/rev33 mendez.pdf $>$ 
MENÉNDEZ-CARRIÓN, Amparo; JOIGNANT, Alfredo. (ed.) La caja de Pandora: el retorno de la Transición chilena, Santiago de Chile. Editorial Planeta. 1999.

MIDEPLAN. Integración al desarrollo, balance de la política social 1990-1993. Mideplan, Santiago. 1994.

MILOS, Pedro. Frente Popular en Chile. Su configuración: 1935-1938. LOM Ediciones, Chile, 2008.

MINEDUC. "Equidad en los aprendizajes escolares en Chile en la ultima década." Serie Evidencias. Ministerio de Educación. Año 2, N 17. CHILE. Mayo de 2013

MINISTERIO DE EDUCACIÓN. Antecedentes para la fundamentación de la ENU. Santiago. 1973.

MINISTERIO DEL INTERIOR. Ley 18.799: “Modifica leyes orgánicas constitucionales $\mathrm{N}^{\circ} \mathrm{s}$. 18.603 y $18.700 ” .26$ de mayo de 1989.

MINSAL. Sistema Nacional de Servicios de Salud. MINSAL. Chile. 1975.

MIRA DELLI-ZOTTI, Guillermo. "Transiciones a la Democracia y democratización en América Latina: un análisis desde la Historia del presente". Actas del Congreso Internacional XIV Encuentro de Latinoamericanistas Españoles: 1810-2010: 200 años de Iberoamérica. Santiago de Compostela 15-18 de septiembre de 2010.

MONCADA, Belén. Jaime Guzmán El Politico. Una Democracia contrarrevolucionaria 1964-1980, Editorial Ril Editores. Santiago de Chile. 2006.

MONCKEBERG, María Olivia. Con fines de lucro, Random House Mondadori. Chile. 2013.

MONCKEBERG, María Olivia. El negocio de las universidades en Chile, Random House Mondadori. Chile. 2007. 
MONCKEBERG, María Olivia. El saqueo de los grupos económicos al Estado chileno. Grupo ZETA. Chile. 2001.

MONTEALEGRE. Jorge. Frazadas del Estadio Nacional. Santiago: LOM, 2003

MORENO, Felipe. "Silent Revolution: An Early Export from Pinochet's Chile." $G C G$ Georgetown University - Universia. Vol. 2 N² 2. 2008. pp. 90-98.

MORRIS, James. Las elites, los intelectuales y el consenso : estudio de la cuestión social y del sistema de relaciones industriales de Chile. Ediciones del Pacífico, Chile. 1967.

MOULIAN, Tomás. Contradicciones del desarrollo político chileno. 1920-1990. LOM-Arcis. Santiago. 2009

MOULIÁN, Tomás. Conversación Interrumpida con Allende. Editorial LOM, Santiago de Chile. 1998

MOULIAN, Tomás. Chile actual anatomía de un mito. Editorial LOM. Santiago de Chile. 2002.

MOULIÁN, Tomás. El consumo me consume. Editorial LOM. Santiago de Chile. 1998.

MOULIAN, Tomás. Fracturas: De Pedro Aguirre Cerda a Salvador Allende. Editorial LOM. Santiago de Chile. 2006.

MULLER, Edward y SELIGSON, Mitchell. "Civic Culture and Democracy: The Question of the Causal Relationships", American Political Science Review 88 3. 1994. pp. 635-652.

MUNCK, Gerardo (ed.), Regimes and Democracy in Latin America. Theories and Methods Oxford University Press. Oxford. 2007. 
MUNIESA BRITO, Bernat. Dictadura y Transición. La España lampedusiana. II: La monarquía parlamentaria. Universitat de Barcelona. Barcelona. 2005.

NAISBITT, John. Megatrends: Ten New Directions Transforming Our Lives. Warner Books / Warner Communications Company. USA. 1982.

NAVAJAS, Carlos. “QQué es la historia actual?”. En: DELGADO IDARRETA, José Miguel (coord.), Franquismo y Democracia. introducción a la historia actual de La Rioja, Logroño. Gobierno de La Rioja/LER, La Rioja. 2000. pp. 13-41

NAZER, Ricardo. "El surgimiento de una nueva élite empresarial en Chile: 1830-80” En: BONELLI, Franco y STABILI María Rosaria. Minoranze e culture imprenditoriali. Cile e Italia (secoli XIX-XX). Editorial Carocci. Italia. 2000.

NOHLEN, Dieter. Chile: Das sozialistische Experiment. Hoffmann und Campe, Hamburg. 1973.

NOHLEN, Dieter. Elecciones y sistemas electorales. Nueva Sociedad, Caracas. 1995.

NORA, Pierre. Les Lieux de Memoire. 7 vols., Paris,1983-1994; CUESTA. Josefina. "De la memora a la historia”. En ALTED, A. Entre el pasado y el presente. Historia y memoria. Madrid. UNED,1996, pp. 55-89

NÚÑEZ, Javier y PÉREZ, Graciela. "Classism, meritocracy and discrimination in the labor market: The case of Chile". Serie Documentos de Trabajo $N^{\circ} 208$. Departamento de Economía, Universidad de Chile. 2004.

NÚÑEZ, Javier y PÉREZ, Graciela. "Dime cómo te llamas y te diré quién eres: la Ascendencia como mecanismo de diferenciación social en Chile". Serie Documentos de Trabajo $N^{o}$ 269. Departamento de Economía, Universidad de Chile. 2007. 
NUÑEZ, Ramón. Et. Al. Las transformaciones educacionales bajo el régimen militar. Vol. 1. (reimpresión) PIIE. Chile. 1991.

O’DONNELL, Guillermo y SCHMITTER, Philippe Transiciones desde un gobierno autoritario 4. Conclusiones tentativas sobre las democracias inciertas. Paidós, Buenos Aires. 1994.

O’DONNELL, Guillermo; SCHMITTER, Philippe y WHITEHEAD, Laurence, Transiciones desde un gobierno autoritario. 2 América Latina. Paidós, Barcelona. 1986

O’DONNELL, Guillermo. 1992. “Transitions, Continuities, and Paradoxes.” en: Mainwaring, Scott, Guillermo O'Donnell, and J. Samuel Valenzuela., Issues in Democratic Consolidation, University of Notre Dame Press. 1992. Indiana. pp. 17-56.

O’DONNELL, Guillermo. Contrapuntos, Ensayos escogidos sobre Autoritarismo y Democratización, Editorial Paidós, Buenos Aires, 1997.

O’DONNELL, Guillermo. Modernization and Bureaucratic-Authoritarianism: Studies in South American Politics (Berkeley, Cal.: Institute of International Studies/University of California). 1973.

OECD. "Todos Juntos ¿Por qué reducir la desigualdad nos beneficia?...en Chile” . [en línea] Mayo del 2015. [fecha de consulta 12 de junio de 2015] Disponible en internet: $<$ http://www.oecd.org/chile/OECD2015-In-It-Together-Highlights-Chile.pdf $>$

OLEA, Raquel y GRAU, Olga (comps.), Volver a la memoria. LOM, Chile. 2001.

OLIVA, María A. "Política educativa chilena 1965 - 2009 ¿Qué oculta esa trama?.” Revista Brasileira de Educaçao, 15(44), 2010. pp. 311-410. 
OLIVA, María. A. "Política educativa y profundización de la desigualdad en Chile." Revista Estudios Pedagógico, XXXIV(2), 2008. pp. 207-226.

OMINAMI, Carlos. Secretos de la Concertación. Recuerdos para el futuro. La Tercera Ediciones. Santiago. 2011.

OMINAMI, Carlos. "Chile: una transición paradojal. Notas para un examen crítico." En: QUIROGA, Yesko y ENSIGNIA, Jaime. (Ed). Chile en la Concertación (1990 - 2010). Una mirada crítica, balance y perspectivas. Tomo II. Friedrich Ebert Stiftung, Santiago. 2010. pp. 21-62.

ORTEGA FREI, Eugenio. de una alianza politica: el partido Socialista de Chile y el partido Demócrata Cristiano: 1973-1988. CED-CESOC. Santiago de Chile. 1992.

ORTIZ LETELIER, Fernando. El movimiento obrero en Chile (1891-1919), Ediciones Michay S.A , España. 1985

OTANO, Rafael. Nueva crónica de la Transición. Editorial LOM. Santiago de Chile. 2006.

OVIEDO CAVADA, Carlos (ed), Documentos del Episcopado. Chile, 1974-1980. Ediciones Mundo, Santiago, 1982.

PACHECO, Teresa. "La historia del presente inmediato en el contexto del debate epistemológico de las ciencias sociales". LUDUS VITALIS. vol. XX. № . 3. 2012,

PDC. Cómo avanza la revolución en libertad : un programa que se cumple y no se transa. Editorial del Pacífico. Chile. 1967.

PEDROSA, Fernando. "La influencia externa en las transiciones de la "tercera ola" en América Latina. Debates, definiciones y propuestas teóricas”. Polis. Año $6 \mathrm{~N}^{\mathrm{a}}$ 12. 2013. 
PEÑA, Cristóbal. Los fusileros: Crónica secreta de una guerrilla en Chile. Editorial Debate. Chile. 2006

PEREZ SANCHEZ Guillermo. “Crisis, Revolución y Transición en la Europa del Este.” Editorial ARIEL. Madrid., 1999.

PICAZO, María Inés. Las políticas escolares de la concertación durante la transición democrática. Ediciones UDP. Chile. 2013.

PIKETTY, Thomas. El capital en el siglo XXI. Fondo de Cultura Económica de España. España. 2014.

PINOCHET, Augusto Visión Futura de Chile. Dirección Nacional de Comunicaciones (DINACOS), Santiago, 1979.

PINOCHET, Augusto. Declaración de Principios del Gobierno de Chile. Edición Oficial. 11 de marzo de 1974.

PINOCHET, Augusto. El Dia Decisivo: 11 de septiembre de 1973. Editorial Andrés Bello Chile. 1979.

PINOCHET, Augusto. Mensaje Presidencial: 11 septiembre 1975-11 septiembre 1976: S.E. el Presidente de la República General de Ejército Augusto Pinochet Ugarte informa al país. BCN. Chile. 2006.

PINOCHET, Augusto. Pinochet: Patria y Democracia, Chile: Editorial Andrés Bello, Chile, 1983.

PINOCHET, Augusto. Política, Politiquería, Demagogia. La Nación. Chile. 1983. 
PINOCHET, Augusto. Un año de reconstrucción. 11 de septiembre 1973 - 11 de septiembre 1974: el Jefe Supremo de la nación General de Ejército Augusto Pinochet Ugarte informa al país. Santiago. Chile. 1974.

PINOCHET, Augusto. Directiva Presidencial sobre Educación. (Carta al Ministro de Educación, Gonzalo Vial). 5 de Marzo de 1979.

PIÑERA, José. El Cascabel al Gato. La Batalla por la Reforma Previsional. Editora Zig-Zag. Chile. 1991.

PIÑERA, Sebastián. "En menos de 24 horas Chile rescató a sus 33 mineros. Especial de prensa. BBC Londres.” 14 de Octubre del 2010. Fecha de consulta: [2 de mayo del 2014] Disponible en internet: http://www.bbc.co.uk/mundo/noticias/2010/10/101014 chile mineros ultimo final_az. $\underline{\text { shtml }}$

PIÑERA, Sebastián. Programa de Gobierno para el cambio, el futuro y la esperanza. 20102014. Alianza por Chile. Chile. 2009.

PIÑERA, Sebastián. Rindiendo cuenta: Balance de cuatro años de Gobierno del Presidente Sebastián Piñera. Informe de avance de los siete ejes prioritarios del gobierno y de la reconstrucción” Secretaría de Gobierno. Chile. 2014.

PNUD. Informe de desarrollo humano: Los tiempos de la politización en Chile. Programa de desarrollo humano en Chile. 2015.

PORTALES, Felipe. Chile: Una Democracia tutelada. Editorial Sudamericana. Santiago de Chile. Chilena. 1999. 
PORTALES, Felipe. Los mitos de la Democracia chilena. Volumen I. Desde la Conquista a 1925. Editorial Catalonia. Santiago de Chile. 2004.

PORTALES, Felipe. Los mitos de la Democracia chilena. Volumen II. Desde 1925 a 1938. Editorial Catalonia. Santiago de Chile. 2010.

PRIDHAM G. Y VANHANEN T. (eds.). Democratization in Eastern Europe: domestic and international perspectives. Routledge. USA. 1994.

PROGRAMA DE DDHH-CHILE. Balance año 2014 Programa de DDHH . [En línea] [fecha de consulta 2 de marzo de 2015] disponible en internet < $\underline{\text { http://www.ddhh.gov.cl/filesapp/balanceprensa.pdf }>}$

PRZEWORSKI, Adam. 2009. "The Mechanics of Regime instability in Latin America”, Journal of Politics in Latin America, 2009. pp. 5-36.

PRZEWORSKI, Adam. Democracy and the Market. Political and Economic Reforms in Eastern Europe and Latin America. Cambridge University Press. Nueva York. 1991.

PULSO. "Los 5 mitos sobre la AFP estatal. ¿Es posible hoy en Chile?. [En línea] 2 de mayo del 2015 [fecha de consulta 13 de junio del 2015]. Disponible en internet: $<\underline{\text { http://www.pulso.cl/noticia/economia/economia/2013/04/7-21191-9-los-5-mitos- }}$ $\underline{\text { sobre-la-afp-estatal-es-posible-hoy-en-chile.shtml> }}$

QUINZIO, Jorge. “El Grupo de los 24 y su Critica a la Constitución Política de 1980”. Revista de Derecho de la Universidad Católica de Valparaíso XXIII, Chile. 2002.

QUIROGA, Yesko y ENSIGNI,Jaime (ed.) Chile en la Concertación (1990 - 2010): Una mirada crítica, balance y perspectiva. Friedrich Ebert Stiftung, Santiago de Chile. 2010. 
RADIO UCHILE. “Debate por AFP Estatal: “Nos dan una aspirina para el cáncer en el modelo previsional" [En línea] 2 de mayo del 2014 [fecha de consulta 13 de junio del 2015]. Disponible en internet: <http://radio.uchile.cl/2014/05/04/debate-por-afp-estatal-es-laaspirina-para-un-cancer-en-el-modelo-previsional>

RADIO UCHILE. “Los desafíos e interrogantes que plantea el fin del binominal”. En línea] 27 de abril del 2015. [fecha de consulta 13 de junio del 2015]. Disponible en internet: < http://radio.uchile.cl/2015/04/27/los-desafios-e-interrogantes-que-plantea-el-fin-del$\underline{\text { binominal }>}$

RADIO UCHILE. "Pensiones de uniformados muestran amplia diferencia con jubilación por AFP” [En línea] 3 de agosto del 2013. [fecha de consulta 23 de agosto del 2015]. Disponible en internet: < http://radio.uchile.cl/2013/08/03/pensiones-de-uniformados$\underline{\text { muestran-amplia-diferencia-con-jubilacion-por-afp }>}$

RADIO UDECHILE. "Presidenta anuncia nueva Constitución pero sin asamblea constituyente" 28 de abril de 2015 [fecha de consulta: 10 de junio del 2015]. Disponible en internet: $<\underline{\mathrm{http}}: / /$ radio.uchile.cl/2015/04/28/presidenta-anuncia-nueva-constitucionpero-sin-asamblea-constituyente $>$

RAJEVIC, Enrique. "La precarización del empleo público en Chile y el mito de la carrera funcionaria" V Encuentro Anual de la Sociedad Chilena de Políticas Públicas, 16 de enero de 2014 o los estudios que respecto al tema tiene la Fundación SOL en: http://www.fundacionsol.cl/estudios/

RAMÍREZ, Álvaro. "Las grietas del modelo chileno frente a los desafíos del siglo XXI". Revista Más poder local, , №. 8, 2011. 
RELLANO, José Pablo. Politicas sociales y desarrollo. Chile 1924-1980. Cieplan, Santiago. 1985.

RÉMOND, René, "Le retour du politique" en: CHAUVEAU A. y TÉTART, Ph. Questionsá l'histoire des temps présents, Bruselas, Éditions Complexe, 1992.

RICHARD, Nelly. "Recordar el olvido". En OLEA, R. \& GRAU, O. (Edits.), Volver a la memoria. Editorial LOM. Chile. 2001. pp. 15-21.

RICHARD, Nelly. Ensayos de crítica cultural sobre el Chile de la Transición. Editorial Cuarto propio. Chile. 2001.

RÍOS, Lautaro, "Razón y fuerza de la Constitución de 1980.” Revista Chilena de Derecho,16, 1989.

ROJAS, Luis. De la rebelión popular a la sublevación imaginada (FPMR). Editorial LOM. Chile. 2011.

ROJAS, María Eugenia. Represión política en Chile. [En línea] [fecha de consulta 12 de octubre de 2013] disponible en internet $<\underline{\text { http://www.derechos.org/nizkor/chile/libros/represion/cifras.html }>}$

RUBILAR, Luis. "La Escuela Nacional Unificada (ENU, febrero de 1973)". Revista Extramuros. UMCE. Año 3 Número 3. 2004.

RUBIO, Pablo. Los civiles de Pinochet. La derecha en el régimen militar chileno, 1983-1990. Dirección de Bibliotecas, Archivos y Museos - Centro de Investigaciones Diego Barros Arana, Santiago, 2013.

SALAZAR, Gabriel. Movimientos sociales en Chile: Trayectoria histórica y proyección política. Editorial Uqbar. Chile. 2012. 
SALAZAR, Gabriel y PINTO, Julio. Historia Contemporánea de Chile, Volúmenes I al V. Editorial LOM. Santiago de Chile. 1999-2002.

SALINAS, Sergio. El tres letras. Historia y contexto del Movimiento de Izquierda Revolucionaria (MIR). RIL Editores, Santiago de Chile. 2013.

SÁNCHEZ GONZÁLEZ; Sebastián. "El concepto de presente extendido: un aporte de la Historia del Tiempo Presente a las Ciencias Sociales" Coetánea: III Congreso Internacional de Historia de Nuestro Tiempo / coord. por Carlos Navajas Zubeldía, Diego Iturriaga Barco, 2012.

SCULLY, Timothy y VALENZUELA, Samuel, "De la democracia a la democracia: Continuidad y variaciones en las preferencias del electorado y en el sistema de partidos en Chile”, Estudios Públicos, 51. 1993.

SCHMITTER, Philippe 2009. “Twenty-five Years, Fifteen Findings”, Journal of Democracy 21 (1). 2009. pp. 17-28.

SCHNEIDER, Carsten. The Consolidation of Democracy: Comparing Europe and Latin Americ. Routledge. Londres. 2009.

SEHNBRUCH, Kirsten y SIAVELIS, Peter. El balance: política y políticas de la concertación 1990-2010. Editorial Catalonia. Chile. 2014.

SELZER, Gregorio. Los días del Presidente Allende, Archivo Salvador Allende. México, Universidad Autónoma de México, Centro de Estudios Latinoamericanos, Tomo XIII. México. 1991.

SEPULVEDA, Luis. La sombra de lo que fuimos. ESPASA-CALPE, España. 2009. 
SHOEMAKER, Luke, "La Crisis Financiera de 1982-1983 en Chile: Orígenes, Intervención, Efectos e Implicancias para el Modelo Neoliberal" ISP Collection. Paper 711. 2009.

SIAVELIS, Peter. "Enclaves de la transición y democracia chilena.” [en línea] Revista Ciencia Política. Vol. 29, No 1 , 2009. pp. 3-21. [fecha de consulta 12 de mayo de 2015]

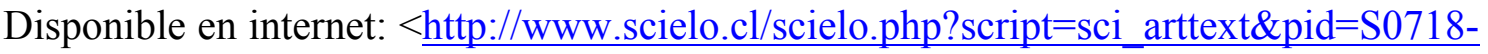
$\underline{090 X 2009000100001 \& \operatorname{lng}=\text { es\&nrm }=\text { iso }>}$

SIAVELIS, Peter. The presidente and congress in postauthoritain Chile: Institutional contraints to democratic consolidation. Penn State University Press. USA. 2000.

SILVA, Adolfo. Testimonio de Adolfo Silva González. Jefe del Depto. De Cine y T.V. de la Oficina de Informaciones y Radiodifusión de la Presidencia de la República-Chile. [En línea] [fecha de consulta 12 de diciembre de 2014] disponible en $<\underline{\text { http://www.memoriaviva.com/testimonios/testimonio_de_adolfo_silva_gonzalez.htm }}>$

SILVA, Eduardo. "The import substitution model. Chile in comparative perspective", Latin American Perspectives, Issue 154, Vol. 34, No 3, 2007. pp. 67-90.

SKÁRMETA, Antonio. Los días del arcoiris. Planeta-Casaamerica. Chile. 2011.

SMITH, Peter. Democracy in Latin America: Political Change in Comparative Perspective. Oxford University Press. USA. 2005.

SOLIMANO, Andrés. Capitalismo a la chilena y la prosperidad de la élites. Editorial Catalonia.2a edición. Chile. 2013.

SOTO, Ángel, "Historia del presente: estado de la cuestión y conceptualización”, Historia Actual Online, HAOL 3. 2004. pp. 101-116. 
SOTO, Ángel. El presente es historia. Reflexiones sobre teoría y método. Centro de estudios bicentenario. Chile. 2006.

SOTO, Eric. “Columna: La alegría que nunca llegó”. El quinto poder. [En línea 29 de junio del 2011. [fecha de consulta: 3 de diciembre del 2015]. Disponible en internet: < $\underline{\text { http://www.elquintopoder.cl/politica/la-alegria-que-nunca-llego/ }>~}$

SOTO, Francisco. “Asamblea constituyente: la experiencia latinoamericana y el actual debate en Chile. Estudios constitucionales, 2014. V. 12, No 1, pp. 397-428,. [fecha de consulta: 10 de junio del 2015]. Disponible en internet:

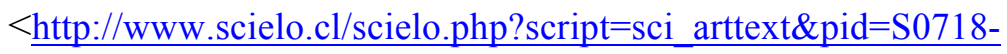
$52002014000100010 \& \operatorname{lng}=\mathrm{es} \& \mathrm{nrm}=\mathrm{iso}>$

SOYCHILE. "El Jumbo del Costanera Center paga menos que un kiosko por patente comercial" [en línea]. 30 de junio del 2012. [fecha de consulta 12 de MAYO de 2015] Disponible en internet: $\quad<\quad$ http://www.soychile.cl/Santiago/Economia-yNegocios/2012/06/30/102085/El-Jumbo-del-Costanera-Center-paga-menos-impuestosque-un-kiosko.aspx $>$

SQUELLA, Agustín y SUNKEL, Osvaldo (comp.) Democratizar la Democracia: reformas pendientes. Santiago de Chile: Editorial LOM, 2000.

SQUELLA, Agustín y SUNKEL, Osvaldo. Democratizar la democracia. Reformas pendientes. LOM. Chile. 2000.

STERN, Steve. Luchando por mentes y corazones, las batallas de la memoria en el Chile de Pinochet. libro dos de la trilogía la caja de la memoria del Chile de Pinochet. UDP. Chile. 2013. 
STERN, Steve. Recordando el Chile de Pinochet: en vísperas de Londres 1998. Libro uno de la trilogía la caja de la Memoria del Chile de Pinochet. Ediciones UDP. Santiago de Chile. 2009.

STERN, Steve. The Memory Box of Pinochet's Chile (3 vols.). Vol. 1: Remembering Pinochets's Chile. On the eve of London 1998. Vol. 2: Battling for Hearts and Minds. Memory Struggles in Pinochet's Chile, 1973-1988. Vol. 3: Reckoning with Pinochet: The Memory Question in Democratic Chile, 1989-2006. Durham-London. Duke University Press. 2001-2006.

STONE, Lawrence. "History and post-modernism". Past and Present: A journal of Historical Studies 131. 1991. pp. 217-218.

SUAREZ, Christian. “ La constitución celda o la dogmática constitucional”. Universum” $N^{o}$ 24. UTAL. 2009. pp. 248-271.

SURA. Contribución del sistema privado de pensiones al desarrollo económico de Latinoamérica. Experiencias de Colombia, México, Chile y Perú. Asset Management Impreso en Chile. Chile. 2013

T13. “Axel Kaiser: "El Gobierno de Piñera fue uno más de la Concertación” [En línea] 5 de agosto del 2015 [fecha de consulta 12 de agosto del 2015]. Disponible en internet: < http://www.t13.cl/radio/mesa-central/noticia/axel-kaiser-gobierno-pinera-fue-uno-mas$\underline{\text { concertacion }>}$

TAIBO, Carlos. Las transiciones en la Europa central y oriental: ¿copias de papel carbón? Los libros de Cataratas. Madrid.1998.

TANAKA, Martin (ed.). La nueva coyuntura crítica en los países andinos. IEP e IDEA. Lima. 2009. 
TEITELBOIN, Carolina. La Transformación Neoliberal Del Sistema de Salud, Chile: 19731990: Reformas de Primera Generación. Universidad Autónoma Metropolitana, México. 2003.

THE CLINIC. "El vengativo señor Claro" [En línea] 28 de octubre de 2008 [fecha de consulta 12 de marzo del 2015]. Disponible en internet: < http://www.theclinic.cl/2008/10/28/el$\underline{\text { vengativo-senor-claro/> }}$

THE CLINIC. "La Maldición de Pinochet: empresarios que se enriquecieron en dictadura y que cayeron en desgracia" [en línea]. 14 de octubre del 2014. [fecha de consulta 12 de julio de 2015] Disponible en internet: < $\underline{\text { http://www.theclinic.cl/2014/10/14/la-maldicion-de- }}$ pinochet-empresarios-que-se-enriquecieron-en-dictadura-y-que-cayeron-en-desgracia/>

TILLY, Charles. Violencia Colectiva. Editorial Hacer, Barcelona. 2007.

TIRONI, Eugenio y AGÜERO, Felipe. “¿Sobrevivirá el nuevo paisaje político chileno?” Estudios Públicos (74). 1999.

TIRONI, Eugenio. “¿Vivimos una revolución cultural?” [en línea]. Columna Diario. EL MERCURIO. Noviembre del 2011. [fecha de consulta 12 de MAYO de 2015] Disponible en internet: $<$ http://www.cieplan.org/opinion/detalle.tpl?id=220 $>$

TIRONI, Eugenio. El Régimen Autoritario. Para una Sociología de Pinochet. Santiago de Chile: Ediciones Dolmen, 1997.

TIRONI, Eugenio. Sin miedo, sin odio, sin violencia. Una historia personal del No. Ariel. Chile. 2013.

TOEWS, John E. "Intellectual History after the Linguistic Turn: The Autonomy of Meaning and the Irreducibility of Experience". American Historical Review 92.1987. pp. 879-907 
TOLOZA, Cristián y LAHERA, Eugenio (comp.) Chile en los noventa. Santiago de Chile: Dolmen, 1998.

TORRES, Isabel. La crisis del sistema democrático. Ediciones Universitarias. Chile. 2014

TOURAINE, Alain. América Latina: Política y sociedad. Espasa-Calpe. Madrid.1989.

TRIBUNAL CONSTITUCIONAL. Sentencia Rol $N^{o}$ 33. 1988 . en: < http://www.tribunalconstitucional.cl/wp/desent.php?id=33>

UNIDAD POPULAR. Programa de la Unidad Popular. Las primeras 40 medidas del gobierno popular [En línea] 1970. [fecha de consulta 23 de agosto del 2015]. Disponible en internet: $<$ http://www.abacq.net/imagineria/medidas.htm $>$

URBINA, José Leandro. Cobro revertido. Santiago de Chile: Planeta, 1992. DONOSO, José. La desesperanza. Seix Barral, Barcelona. 1986.

VALDÉS, Hernán Tejas Verdes: diario de un campo de concentración. LOM/CESOC, Santiago de Chile. 1996.

VALDÉS, Juan Gabriel. La escuela de Chicago: Operación Chile. Ediciones Grupo Zeta. Buenos Aires. 1989.

VALDES, Juan Gabriel. La escuela de Chicago: Operación Chile. Grupo Editorial Zeta, Argentina. 1989.

VALDIVIA, Verónica (et. al). Su revolución contra nuestra revolución: La pugna marxistagremialista en los ochenta. Vol II. Editorial LOM. Santiago de Chile. 2008

VALDIVIA, Verónica. "¡Estamos en guerra, señores!". el Régimen militar de Pinochet y el "pueblo", 1973-1980" Revista Historia. I. 43. 2010. 
VALDIVIA, Verónica. Nacionales y gremialistas: el "parto" de la nueva derecha política chilena 1964-1973. Editorial LOM. Santiago de Chile. 2008.

VALENZUELA, Arturo y VALENZUELA, Samuel. "Los orígenes de la democracia: Reflexiones teóricas sobre el caso de Chile", Estudios Públicos 12. 1983

VALENZUELA, Arturo. El quiebre de la Democracia en Chile. Chile: FLACSO, 1989.

VALENZUELA, Samuel. "Orígenes y transformaciones del sistema de partidos en Chile". Estudios Públicos. 58. 1995.

VASQUEZ Nelson y IGLESIAS, Ricardo. "La construcción de la memoria colectiva en la historia reciente de Chile. Una tarea pendiente en el mundo escolar”, en: PAGÉS y GONZÁLEZ. Historia, memoria i ensenyament de la història, Universidad Autónoma de Barcelona. 2009. pp. 114-117

VELÁSQUEZ, Edgar de Jesús. "La Transición a la Democracia en Chile según la derecha" Estudios Politicos No. 29, julio-diciembre 2006. pp.189-215.

VERA LAMPEREIN, Hernán y VERA LAMPEREIN, José. La municipalización de la enseñanza. Editorial Andrés Bello. Chile. 1982.

VERDUGO, Patricia y HERTZ, Carmen. Operación Siglo XX. Ediciones del ornitorrinco. Chile. 1990 VERDUGO, Patricia: Tiempo de días claros. Los desaparecidos; Santiago de Chile: Ediciones Chileamérica-Cesoc. 1990.

VERGARA, Jorge. "La democracia protegida en Chile". Revista de sociología. U. de Chile. $\mathrm{N}^{\mathrm{o}} 27.2007$.

VIAL CORREA, Gonzalo. "Historia de Chile en el Siglo XX”, Santiago de Chile: Editorial Santiago, 2003. 
VIAL, Gonzalo. Análisis crítico del régimen militar. Santiago, Universidad. Finis Terrae, 1998.

VICARÍA. Vicaría de la Solidaridad : historia de su trabajo social. Eds. Paulinas, Chile. 1991.

VILLALOBOS, Sergio. Chile y Su Historia. Santiago de Chile: Editorial Universitaria, 1992.

VILLALOBOS, Sergio. Origen y ascenso de la burguesía chilena, Editorial Universitaria, Santiago, 1987.

VITALE, Luis. Interpretación marxista de la Historia de Chile, Tomo I, $7^{\mathrm{a}}$ Edición. CELALOM, Santiago de Chile. 1991.

VON BAER, Ena. "Sistema Binominal. consensos y disensos”. En FONTAINE, Arturo (et al.). Reforma al Sistema Electoral Chileno. Satiago de Chile: Cep-Cieplan-Pnud-LydProyectamérica, 2009. pp. 177-206.

VV.AA. "Bases para un acuerdo Nacional”. Panfleto. Santiago. 1983

VV.AA. “Acuerdo Nacional para la Transición a la Plena Democracia”, El Mercurio, 27 de agosto de 1985.

VV.AA. "Informe del Grupo de los 24" [en línea]. Revista HOY. octubre de 1979. [fecha de consulta 12 de septiembre del 2011] disponible en Internet en: $<\underline{\text { http://www.archivochile.com/Partidos burguesia/doc gen/PBdocgen0013.pdf }>}$

VVAA. Antecedentes Histórico jurídicos años 1972-1973. Editorial jurídica de Chile. Chile. 1980.

VVAA. Manifiesto Democrático. [en línea] Santiago de Chile. 14 de marzo de 1983. [fecha de consulta 12 de octubre de 2011] disponible en internet $<$ http://es.wikisource.org/wiki/Manifiesto democr\%C3\%Altico (14 de marzo de 19 $\underline{83)}>$ 
WAISMAN, Carlos. et. al. Transiciones de la dictadura a la democracia: los casos de España y América Latina. UPV.EHU. Bilbao. 2005.

WAISSBLUTH, Mario. "Manifestaciones estudiantiles en Chile", Foreign Affairs Latinoamérica, Vol. 11: No. 4. 2011.

WAISSBLUTH, Mario. La educasión esta vien: Un ensayo preocupado y posiblemente propositivo. Educación 20/20 libre de derechos. Chile. 2014.

WAISSBLUTH, Mario. Se acabó el recreo. Editorial Debate. Chile. 2011.

WALDMAN, Gilda “Chile: la persistencia de las Memorias antagónicas”. Política y cultura No31 México, 2009. pp. 211-234.

WALKER, Horacio. (Senador Oficialista) "Educación superior: el debate que viene” [En línea] Columna El Mercurio. Martes 18 de agosto de 2015. [fecha de consulta 23 de agosto del 2015].

Disponible

en

internet:: $<$ http://www.elmercurio.com/blogs/2015/08/18/34449/Educacion-superior-eldebate-que-viene.aspx $>$

WHITEHEAD, Laurence. "El lugar de chile en los estudios comparados". En: MENÉNDEZ, Amparo y JOIGNANT, Alfredo (edit). La caja de Pandora. El retorno de la Transición chilena. Editorial Planeta-Ariel. Chile. 1999.

WIARDA, Howard J. 2001. The Soul of Latin America: The Cultural and Political Tradition. Yale University Press. USA. 2001.

WILDE Y A.. "Irruptions of memory: Expressive politics in Chile's transition to democracy". Journal of Latin American Studies. 31(2), mayo de 1999. 
WINN, Peter. "El pasado está presente. Historia y memoria en el Chile contemporáneo", en PÉROTIN-DUMON, Anne (dir.). Historizar el pasado vivo en América Latina. Chile, 2007. http://etica.uahurtado.cl/historizarelpasadovivo/es_contenido.php

YTURBE, Corina. Pensar la democracia: Norberto Bobbio. UNAM. México. 2002. 